

\section{Propositions}

1. A single Verticillium dahliae effector of defoliating pathotype strains is responsible for pathogenicity on various host plants and for defoliation on cotton and olive. (this thesis)

2. LysM effectors can be used to engineer chimeric immune receptors with improved pathogen recognition capacities in plants.

(this thesis)

3. Artificial intelligence will revolutionize all aspects of biology.

4. Looking at our body as a holobiome that comprises an entire microbial ecosystem will change medicinal practices.

5. Leadership training should be an integral part of any PhD program.

6. A good team player is someone who can always find a "niche" in a team.

Propositions belonging to the thesis, entitled

"Identification of host-specific effectors mediating pathogenicity of the vascular wilt pathogen Verticillium dahliae"

Jinling Li

Wageningen, 13 February 2019 


\section{Identification of host-specific effectors mediating pathogenicity of the vascular wilt pathogen Verticillium dahliae}




\section{Thesis Committee}

\section{Promotor}

Prof. Dr B.P.H.J. Thomma

Professor of Phytopathology

Wageningen University \& Research

\section{Co-promotor}

Dr L. Faino

Researcher in Plant Pathology

Dept. Environmental Biology

Università Sapienza, Italy

\section{Other members}

Prof. Dr Y. Bai, Wageningen University \& Research

Prof. Dr G. Doehlemann, University of Cologne, Germany

Prof. Dr M. Rep, University of Amsterdam

Dr R. Geurts, Wageningen University \& Research

This research was conducted under the auspices of the Graduate School Experimental Plant Sciences (EPS). 


\title{
Identification of host-specific effectors mediating pathogenicity of the vascular wilt pathogen Verticillium dahliae
}

\author{
Jinling Li
}

Thesis

submitted in fulfilment of the requirements for the degree of doctor at Wageningen University by the authority of the Rector Magnificus, Prof. Dr A. P. J. Mol, in the presence of the

Thesis Committee appointed by the Academic Board to be defended in public

on Wednesday 13 February 2019 at 1:30 p.m. in the Aula. 
Jinling Li

Identification of host-specific effectors mediating pathogenicity of the vascular wilt pathogen Verticillium dahliae,

180 pages.

PhD thesis, Wageningen University, Wageningen, the Netherlands (2019)

With references, with summary in English

ISBN: 978-94-6343-551-2

DOI: $10.18174 / 464935$ 


\section{Table of contents}

$\begin{array}{lll}\text { Chapter } 1 & \text { General introduction } & 7\end{array}$

Chapter 2 A single Verticillium dahliae effector is responsible for the 25

highly aggressive defoliating pathotype on cotton and olive

Chapter 3 A single effector mediates pathogenicity of Verticillium dahliae on tomato

Chapter 4 The Verticillium dahliae effector Sunı quantitatively contributes to virulence on sunflower

Chapter 5 Verticillium dahliae strains that infect the same host plant display highly divergent effector catalogs

Chapter 6 Engineering of a chimeric receptor to mediate improved chitin-triggered immunity in Arabidopsis

Chapter 7 General discussion

Summary

Acknowledgements

About the author 



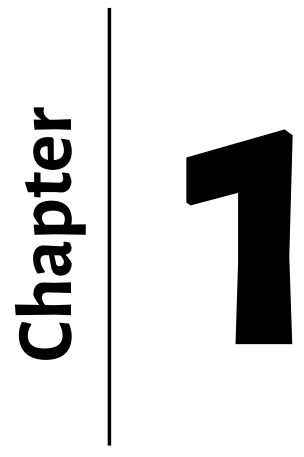

General introduction 


\section{Introduction}

Plant diseases that are caused by pathogenic microorganisms have long been known as major biotic constraints to crop production worldwide (Strange and Scott, 2005; Fisher et al., 2012). For example, persistent and epidemic outbreaks of fungal and oomycete infections on important staple crops such as rice (blast caused by Magnaporthe oryzae), wheat (rust caused by Puccinia graminis), potato (late blight caused by Phytophthora infestans) and soybean (rust caused by Phakospora pachyrizi) result in enormous yield losses and pose a threat to global food security (Fisher et al., 2012). Current efforts to control plant diseases include the deployment of resistant varieties and the application of agrochemicals (Zhan et al., 2015). However, excessive agrochemical applications do not only cause environmental problems but also lead to the selection for resistance to the chemical agents in pathogen populations. Resistant plant varieties can lose their disease control efficacy due to rapid evolutionary changes in pathogen populations that give rise to novel genotypes that defeat host resistance (Zhan et al., 2015). A striking example is the outbreak of wheat stem rust in Africa caused by the highly aggressive P. graminis f. sp. tritici race Ug99 that has broken widely deployed resistance genes and is virulent on most of the wheat varieties grown worldwide (Pretorius et al., 2000). Due to its resistance-breaking capacities, this novel, virulent race of the pathogen represents a major threat to global wheat production (Singh et al., 2011) and emphasizes the importance of developing effective strategies to protect agricultural production systems from disease threats (Dodds, 2010). To develop innovative, effective disease management strategies, a thorough understanding of the mechanisms by which plant pathogens cause disease in their host plants is of vital importance (Gibriel et al., 2016; Gawehns et al., 2013).

\section{Effectors: versatile molecules employed by microbial symbionts with diverse lifestyles}

In nature, plants and microbes engage in an array of symbiotic relationships, ranging from pathogenic to mutualistic. Pathogenic interactions between plants and microbial pathogens are frequently described as ongoing arms races in which plants try to halt microbial ingress while pathogens attempt to continue the symbiosis (Jones and Dangl, 2006; Thomma et al., 2011; Cook et al., 2015). In such arms races, plants develop immune receptors of various types to detect pathogen invasion through sensing pathogen-derived or pathogen-induced molecular patterns of various nature that betray microbial invasion, also called invasion patterns, to activate appropriate immune responses (Cook et al., 2015; Rodriguez-Moreno et al., 2017). In turn, successful pathogens secrete so-called effector molecules to deregulate host immune responses, and thus support host colonization (Jones and Dangl, 2006; Rovenich et al., 2014; Cook et al., 2015). These effector molecules act either in the apoplastic space of the plant or inside plant cells to facilitate the infection process (De Wit, 2016; Büttner, 2016; Giraldo and Valent, 2013). Whereas most extensively studied effectors are proteinaceous molecules, typically small cysteine-rich proteins, other types of microbially-secreted molecules, such as secondary metabolites and small RNAs, have been assigned typical effector activities as well (Rodriguez-Moreno et al., 2018). 
Many pathogens establish their initial phase of infection in the apoplast, which represents a hostile environment that contains various plant-secreted hydrolytic enzymes, including chitinases and glucanases, (Sánchez-Vallet et al., 2015; Rovenich et al., 2016). Host-secreted chitinases target fungal cell walls to release chitin fragments that activate host immune receptors on the one hand, and degrade fungal cell walls to induce cellular collapse, and thus inhibition of fungal proliferation, on the other hand (Sánchez-Vallet et al., 2015). To prevent this, the tomato leaf mould fungus Cladosporium fulvum secretes the apoplastic effector Avr4 that binds fungal cell walls through an invertebrate chitin-binding domain such that the cell wall chitin is inaccessible to chitinases and consequently protects it against hydrolysis (van den Burg et al., 2006; van Esse et al., 2007). Besides Avr4, C. fulvum also secretes the LysM domain-containing effector protein Ecp6 (extracellular protein 6) to interfere with chitin recognition and prevent the activation of chitin-induced plant immunity during host colonization (de Jonge et al., 2010). Structural analysis of Ecp6 revealed that the concerted action of two LysM domains (LysM1 and LysM3) results in the formation of a groove with ultra-high chitin-binding affinity that permits it outcompeting host immune receptors for chitin binding (Sánchez-Vallet et al., 2013). Additionally, the remaining singular LysM domain (LysM2) of Ecp6 binds chitin with lower affinity but can still perturb chitin-triggered immunity (Sánchez-Vallet et al., 2013). Because of its lower affinity, it has been hypothesized that, instead of scavenging of chitin fragments, LysM2 may suppress chitin-triggered immunity by interfering with the host chitin receptor complex formation that is needed to activate immune signalling (Sánchez-Vallet et al., 2013, 2015). Interestingly, in contrast to most fungal effectors that are lineage-specific or only occur in a limited set of related fungal species (Stergiopoulos and de Wit, 2009; de Jonge et al., 2011), conserved Ecp6 orthologs, termed LysM effectors, widely occur in the fungal kingdom (de Jonge and Thomma, 2009). Various fungal plant pathogens, such as the Septoria tritici blotch fungus Zymoseptoria tritici, the Brassicaceae anthracnose fungus Colletotrichum higginsianum, the rice blast fungus M. oryzae and the vascular wilt fungus Verticillium dahliae have also been shown to secrete LysM effectors to perturb chitintriggered immunity and promote fungal host colonization (Marshall et al., 2011; Mentlak et al., 2012; Takahara et al., 2016; Kombrink et al., 2017). Particular LysM effectors, such as Mg1LysM and Mg3LysM from $Z$. tritici and Vd2LysM from V. dahliae, were found to additionally protect fungal hyphae against plant hydrolytic enzymes (Marshall et al., 2011; Kombrink et al., 2017).

Besides various hydrolytic enzymes, the host apoplast also contains a diverse group of proteases that contribute to basal defence (van Esse et al., 2008). Hence, some microbial effectors target and inhibit such proteases in order to promote host colonization (van Esse et al., 2008; Jashni et al., 2015). For example, C. fulvum secretes the cysteine protease inhibitor Avr2 that inhibits a set of tomato proteases in order to promote virulence (van Esse et al., 2008). The smut fungus Ustilago maydis inhibits apoplastic proteases of its maize host via the secreted effector Pit2 (Mueller et al., 2013). In addition, the oomycete pathogen P. infestans effector AVRblb2 targets the host papain-like cysteine protease $\mathrm{C} 14$ and specifically prevents its secretion (Bozkurt et al., 2011). Therefore, the apoplast is a dynamic battlefield for various microbial effectors to modulate apoplastic immunity and thus support successful infection (Du et al., 2016). 
In addition to apoplastic effectors, various plant pathogens are able to translocate their effectors into the host cytoplasm where they modulate diverse cellular processes to favour pathogen infection (Giraldo and Valent, 2013; Grant et al., 2006). The mechanism of effector delivery to host cells has been well characterized in plant pathogenic bacteria (Galán et al., 2014). It has been shown that many bacterial plant pathogens (e.g. Pseudomonas syringae, Ralstonia solanacearum, Xanthomonas spp. and Erwinia spp.) have evolved a "syringe-like" type III secretion system (T3SS) to directly deliver effectors into the host cytosol (Grant et al., 2006; Büttner and He, 2009). Although various fungal and oomycete plant pathogens also secrete effectors that operate inside host cells (Djamei et al., 2011; Yaeno et al., 2011), the mechanisms by which effectors are delivered into host cells remain poorly understood (Petre and Kamoun, 2014). Many highly divergent oomycete effectors contain an N-terminal RxLR motif (Tyler et al., 2006; Jiang et al., 2008), which has been implicated in effector uptake (Whisson et al., 2007; Dou et al., 2008). Kale and colleagues (2010) proposed that the RxLR motif mediates effector uptake by binding to host cell surface phosphatidylinositol-3-phosphate (PI3P). Upon binding to PI3P, oomycete RxLR effectors are presumed to enter host cells via vesicle-mediated endocytosis (Kale et al., 2010; Kale and Tyler, 2011). However, this model remains controversial as several studies challenge reproducibility of the assays (Wawra et al., 2013; Petre and Kamoun, 2014). A recent study showed that the RxLR motif of the oomycete effector AVR3a is cleaved off prior to secretion, which suggests a role for the RxLR motif in the effector secretion from the pathogen, rather than a direct role in mediating host cell entry (Wawra et al., 2017). So far, no conserved motifs involved in effector uptake have been identified in fungal effectors (Rafiqi et al., 2012). Direct evidence for fungal effector translocation into plant cells comes from live fluorescence microscopy studies in the rice blast pathogen $M$. oryzae (Giraldo and Valent, 2013). Live-cell imaging of transgenic $M$. oryzae strains expressing fluorescently-tagged effector proteins has allowed tracking of secreted effectors during pathogen invasion (Yi and Valent, 2013). Several fluorescently-labelled effectors have been shown to preferentially accumulate in a unique host-pathogen interfacial structure, called the biotrophic interfacial complex (BIC), before being translocated into the rice cytoplasm (Khang et al., 2010; Giraldo et al., 2013). Interestingly, M. oryzae has evolved a distinct, Golgiindependent secretion system to deliver effectors to BICs (Giraldo et al., 2013). Unravelling the mechanisms how filamentous pathogens deliver their effectors into plant cells remains an important challenge in the field of molecular plant pathology.

Plant cell surface-localized immune receptors that comprise receptor-like proteins (RLPs) and receptor kinases (RKs) monitor the apoplastic space and sense various pathogen-derived ligands, such as fungal chitin, bacterial flagellin, elongation factor $\mathrm{Tu}$, to activate immune responses and prevent microbial ingress (Jones and Dangl, 2006; Thomma et al., 2011). In order to establish themselves, adapted pathogens deliver cytoplasmic effectors to not only target cell surfacelocalized immune receptors but also interfere with important downstream immune signalling activated by immune receptors (de Jonge et al., 2011; Rovenich et al., 2014; Macho and Zipfel, 2015; Toruño et al., 2016). Some bacterial effectors have been shown to directly target immune receptors for degradation (Macho and Zipfel, 2015). For example, the bacterial effector protein AvrPtoB functions as an $\mathrm{E}_{3}$ ubiquitin ligase that promotes proteasome-mediated degradation of the Arabidopsis RK-type immune receptors FLS2 (flagellin-sensing 2) and CERK1 (chitin elicitor 
receptor kinase 1) (Gohre et al., 2008; Gimenez-Ibanez et al., 2009). Upon ligand perception, RKtype immune receptors directly associate with members of the receptor-like cytoplasmic kinases (RLCKs), which are thought to be responsible for transducing signals from extracellular ligand perception into intracellular downstream signalling via phosphorylation events (Couto and Zipfel, 2016; Tang et al., 2017). Several studies have shown that multiple bacterial cytoplasmic effectors specifically target RLCKs to interfere with immune signalling (Lee et al., 2013). For instance, the $P$. syringae cysteine protease effector AvrPphB proteolytically cleaves RLCK VII subfamily proteins BIK1, PBL1, and other RLCKs (Zhang et al., 2010). Additionally, the cytoplasmic effector AvrAC from X. campestris pv. campestris is an uridylyl transferase that uridylylates and inhibits kinase activity of two closely related RLCKs, BIKI and RIPK, thereby blocking downstream immune signalling (Feng et al., 2012). In addition to interacting with RLCK members, a number of microbial effectors target and inactivate the mitogen-activated protein kinases (MAPKs) cascades that transduce and amplify the pathogen-derived signals from upstream immune receptors (Bi and Zhou, 2017; Meng and Zhang, 2013). For instance, the P. syringae cytoplasmic effector HopAI1 directly dephosphorylates MAPKs, MPK3 and MPK6 to inhibit MPK activation (Zhang et al., 2007). Another P. syringae effector, HopF2, can target Arabidopsis MAPK kinase 5 (MKK5) and suppresses MKK5 phosphorylation through its ADP-ribosyltransferase enzymatic activity (Wang et al., 2010). Perturbation of plant MAPK cascades is not limited to bacterial pathogens (Bi and Zhou, 2017), as the P. infestans cytoplasmic RxLR effector PexRD2 was found to interact with host MAPKKKe to perturb immune signalling (King et al., 2014).

Plant hormones such as salicylic acid (SA), jasmonic acid (JA), and ethylene (ET) have been shown to play important roles in plant defence, and several cytoplasmic effectors were shown to target and modify the biosynthesis of, and signalling pathways activated by, these defence hormones (Kazan and Lyons, 2014). For example, $U$. maydis secretes the chorismate mutase Cmur into the cytosol of maize plants to interfere with SA biosynthesis (Djamei et al., 2011). Cmu1 presumably acts together with the maize cytosolic chorismate mutase $\mathrm{ZmCm} 2$ to alter the flow of chorismate from the plastid to the cytosol, consequently diminishing the available chorismate for SA biosynthesis in plastids (Djamei et al., 2011). Interestingly, secreted chorismate mutases have been found in many plant-associated microbes, pointing towards a common strategy for host manipulation (Djamei et al., 2011). In addition, the effectors Pslsc1 and Vdlscl that are secreted by the two taxonomically distinct filamentous pathogens $P$. sojae and V. dahliae, respectively, are isochorismatases that can hydrolyze the SA precursor isochorismate to actively suppress SA accumulation (Liu et al., 2014). Besides targeting SA signalling, cytoplasmic effectors that target JA or ET signalling have been described as well (Patkar et al., 2015; Kim et al., 2013; Ma and Ma, 2016). For instance, $M$. oryzae secretes a JA monooxygenase effector to convert host-derived JA to 12-hydroxyjasmonic acid to perturb JA signalling and attenuate host innate immunity (Patkar et al., 2015). XopD, a cytoplasmic effector from the bacterial tomato pathogen X. euvesicatoria, directly targets and desumoylates the tomato ethylene responsive transcription factor SlERF4 to suppress ethylene-induced immunity and promote pathogen infection (Kim et al., 2013). These examples demonstrate that the manipulation of plant hormone signalling by effectors is an important strategy for plant pathogens to establish infection. 
Effectors are not uniquely employed by plant pathogens, as endophytes and mutualistic microbes similarly employ effectors to establish their association with plants (Rovenich et al., 2014; Cook et al., 2015). For instance, the symbiotic arbuscular mycorrhizal fungus Glomus intraradices secretes effector protein SP7 to interact with pathogenesis-related transcription factor ERF19 and attenuates ethylene-mediated plant defence, thereby promoting fungal colonization in host roots (Kloppholz et al., 2011). The mutualistic fungus Laccaria bicolor genome was found to contain hundreds of secreted proteins (Martin et al., 2008). Of these, the effector MiSSP7 has been shown to perturb JA-mediated host immune responses and facilitate symbiosis through its interaction with the host plant JA signalling repressor PtJAZ6 (Plett et al., 2014). These findings show that, like their pathogenic counterparts, mutualistic fungi similarly secrete effectors to subvert host immunity for establishing successful symbioses.

All microbial symbionts establish themselves in environments that also comprise other microbes, including antagonists (Rovenich et al., 2014). Likely, microbes may secrete effector molecules that act in self-defense and competition with other microbiome co-inhabitants (Rovenich et al., 2014; Snelders et al., 2018). For instance, the effector Zt6, secreted by the wheat pathogen $Z$. tritici, was found to possess highly potent cytotoxic activity against various prokaryotic and eukaryotic microbes but not against $Z$. tritici itself (Kettles et al., 2017). Therefore, Zt6 may act in microbial competition and niche protection (Kettles et al., 2017; Snelders et al., 2018).

In conclusion, effectors are highly versatile molecules that play essential roles in niche establishment of symbionts with diverse lifestyles. Clearly, functional characterization of effector molecules and deciphering their role could provide novel insight into how microbes establish their associations with host plants (Rovenich et al., 2014).

\section{Plant pathogen effector identification}

As effector molecules are pivotal for the infection process of plant pathogens, research on deciphering microbial pathogenesis has focused on the identification and characterization of effectors from various plant pathogens (de Jonge et al., 2011; Gibriel et al., 2016). Prior to the advent of genomic sequencing, map-based cloning approaches and biochemical analyses of pathogen secretomes during infection have been pursued to identify novel effectors (Stergiopoulos and de Wit, 2009). For example, proteins AvrPi-ta and ACE1 from the rice blast fungus M. oryzae, as well as effector proteins AvrLm1 and AvrLm6 from the oilseed rape pathogen Leptosphaeria maculans, were identified by map-based cloning (Orbach et al., 2000; Böhnert et al., 2004; Gout et al., 2006; Fudal et al., 2007). Proteomic analysis of apoplastic fluids that were isolated from C. fulvuminfected tomato leaves by using polyacrylamide gel electrophoresis and mass spectrometry led to identification of several effector proteins of C. fulvum (Joosten and de Wit, 1988; Wubben et al., 1994; Laugé et al., 1998, 2000; Bolton et al., 2008). Using a similar approach, a number of SIX (secreted in xylem) effector proteins from the tomato wilt fungus Fusarium oxysporum f.sp. lycopersici were identified in the xylem sap of infected tomato plants (Rep et al., 2004; Houterman et al., 2007, 2008). 
Recentadvances in genome sequencing technologies and rapid development of new bioinformatics algorithms enable genomics-based discovery of effector candidates (Gibriel et al., 2016). The majority of microbial effector proteins are secreted via the classical endoplasmic reticulum/ Golgi-dependent secretion route, which requires the $\mathrm{N}$-terminal signal peptide for extracellular secretion (Von Heijne, 1990). Therefore, effector candidates can be identified by computational prediction from pathogen genomes through querying for the presence of $\mathrm{N}$-terminal signal peptides (de Jonge et al., 2011; Gibriel et al., 2016). In addition, conserved amino acid motifs that are specific to particular groups of effectors have been used for effector identification as well (Gibriel et al., 2016). For instance, in several oomycete pathogens, consensus N-terminal RxLR and LxLFLAK motifs that have been implicated in effector uptake can be queried to identify RxLR and Crinker (CRN) effector genes (Tyler et al., 2006; Schornack et al., 2010; Haas et al., 2009). In contrast, prediction of effector genes from fungal genomes is less straightforward due to the lack of conserved motifs (Sperschneider et al., 2015). Recently, the machine learning program 'EffectorP' was developed by using sequences of experimentally validated fungal effectors to improve effector prediction from secretomes (Sperschneider et al., 2016). Sperschneider et al. (2016) showed that in addition to presence of $\mathrm{N}$-terminal secretion signal peptide, low molecular weight, overall protein charge, as well as serine and tryptophan content were important features that can be used for more precise fungal effector prediction.

The relatively low cost of present-day genome sequencing (Faino and Thomma 2014) has made it possible to sequence (populations of) plant pathogen species that can be leveraged for effector discovery through comparative genomics (Thomma et al., 2015; Jones et al., 2018). In comparative genomics, genome sequences are compared in order to reveal the similarities and differences between selected genomes and subsequently link these to phenotypic differences (Jones et al., 2018). For example, genome comparisons of $U$. maydis and Sporisorium reilianum, two smut fungi that infect maize but cause different symptoms, revealed 43 distinct genomic regions that primarily contain species-specific genes encoding putative effectors (Schirawski et al., 2010). Functional analyses confirmed that some of these effectors in $U$. maydis contribute to virulence on maize (Schirawski et al., 2010). In another study, comparative analysis of the genome sequences of three Fusarium species with different host ranges, namely F. oxysporum f.sp. lycopersici (a tomato pathogen), F. graminearum (a cereal pathogen) and F. verticillioides (another cereal pathogen), revealed that four dispensable chromosomes are specific to the tomato-infecting F. oxysporum $\mathrm{f}$. sp. lycopersici (Ma et al., 2010). Interestingly, pathogenicity of F. oxysporum f. sp. lycopersici towards tomato can be specifically attributed to one dispensable chromosome, which contains a number of effector genes (Ma et al., 2010). These studies highlight the power of comparative genomics for the identification of virulence effectors from various plant pathogens.

Comparative genomics can also be used to identify effectors that are recognized by host immune receptors and thus act as avirulence factors (Gibriel et al., 2016). The tomato immune receptor Ve1 mediates resistance to race 1 strains of $V$. dahliae, while strains that are not contained by Ve1 are assigned to race 2 (Schaible et al., 1951; Kawchuk et al., 2001; Fradin et al., 2009). Comparative analyses of race 1 and race 2 strains revealed $50 \mathrm{~kb}$ of sequence that is specifically present in race 1 strains, containing only a single effector gene that is highly expressed in planta, named 
Ave1 (for Avirulence on Ve1 tomato). Functional analyses confirmed that recognition of effector Ave1 by the immune receptor Ve1 mediates resistance to race 1 strains of $V$. dahliae (de Jonge et al., 2012). Using a similar approach, the effector protein AVRFOM2 that is recognized by melon immune receptor Fom-2 was identified by comparative genome analysis of strains of the melon wilt fungus F. oxysporum f. sp. melonis (Schmidt et al., 2016). More recently, Salcedo et al. (2017) used comparative whole-genome analysis of chemically mutagenized and natural P. graminis $f$. sp. tritici isolates to identify the effector protein AvrSr35 that is recognized by the corresponding wheat resistance protein $\mathrm{Sr} 35$.

\section{The vascular wilt pathogen V. dahliae}

The Verticillium genus comprises ten soil-borne asexual species of Ascomycete fungi that differ significantly in their lifestyles, ranging from saprophytic to pathogenic (Fradin and Thomma, 2006; Klosterman et al., 2009; Inderbitzin et al., 2011; Inderbitzin and Subbarao, 2014; Klimes et al., 2015). Among these, V. isaacii, V. klebahnii, V. zaregamsianum, V. tricorpus, and V. nubilum are mostly considered saprophytes that occasionally cause opportunistic infections of plants (Inderbitzin et al., 2011; Gurung et al., 2015; Fradin and Thomma, 2006; Seidl et al., 2015). The remaining species $V$. dahliae, $V$. albo-atrum, V. alfalfae, $V$. nonalfalfae, and $V$. longisporum are plant pathogens that mostly cause vascular wilt diseases on crops and lead to significant crop losses (Pegg and Brady, 2002; Fradin and Thomma, 2006; Inderbitzin et al., 2011; Depotter et al., 2016). However, despite the fact that the latter five species are all pathogenic, they differ significantly in host range. $V$. dahliae is the most notorious plant pathogen with an extremely wide host range that comprises hundreds of plant species, including economically important crops like tomato (Solanum lycopersicum), cotton (Gossypium hirsutum), olive (Olea europaea), sunflower (Helianthus annuus) and tobacco (Nicotiana tabacum) (Figure 1) (Pegg and Brady, 2002; Fradin and Thomma, 2006). In contrast, other pathogenic Verticillium species have more restricted host ranges as, for instance, V. albo-atrum mainly infects hop, soybean, tomato and potato (Fradin and Thomma, 2006), while V. longisporum generally causes disease on brassicaceous plant hosts such as oilseed rape and cauliflower (Depotter et al., 2016), and V. alfalfae only infects lucerne (Inderbitzin et al., 2011). The economic losses caused by Verticillium wilts on the 20 most affected hosts collectively amount up to $€ 3$ billion worldwide (Depotter et al., 2016).

V. dahliae typically colonizes plant water-conducting xylem vessels, thus disrupting transportation of water and minerals to the foliage which may cause typical Verticillium wilt symptoms in infected plants (Fradin and Thomma, 2006; Yadeta and Thomma, 2013). Verticillium wilt disease control is particularly challenging since traditional fungicides cannot reach the pathogens once they have entered xylem vessels (Fradin and Thomma, 2006; Klosterman et al., 2011). Moreover, $V$. dahliae can survive in the soil for long periods of time due to the formation of resilient resting structures, called microsclerotia, and therefore agricultural practices such as crop-rotation do not result in effective crop protection. Although genetic resistance is the preferred strategy for disease management, only a few Verticillium wilt resistance genes have been identified (Schaible et al., 1951; Simko et al., 2004; Hayes et al., 2011; Song et al., 2017). The substantial economic impact of Verticillium wilt disease combined with the lack of effective disease control treatments substantiates the need for developing novel disease control strategies (Fradin and Thomma, 2006). 


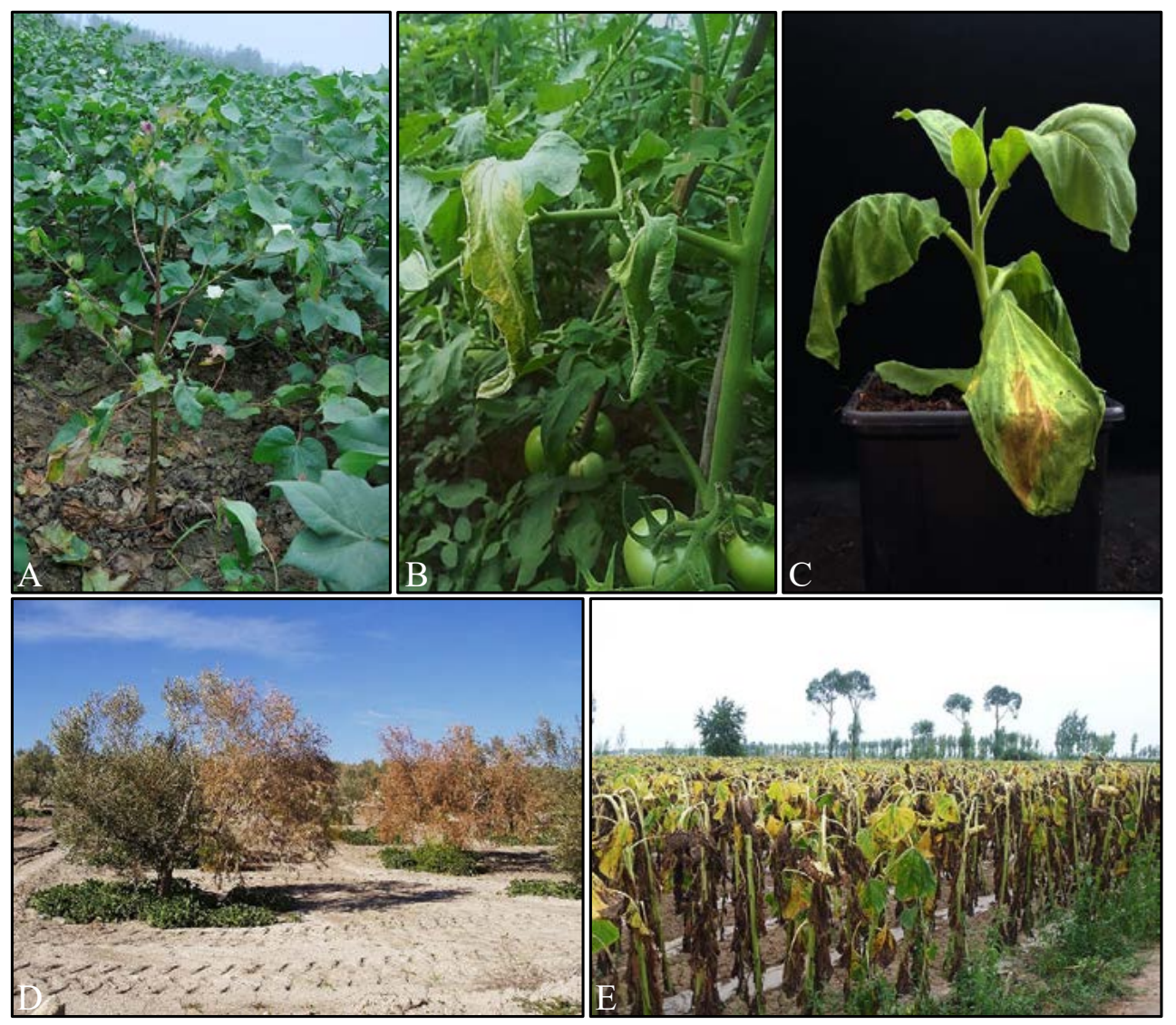

Figure 1. Disease symptoms caused by V. dahliae on various host plants. Verticillium wilt symptoms caused by $V$. dahliae on cotton (A), tomato (B), tobacco (C), olive (D) and sunflower (E). Photos are courtesy of Longfu Zhu (panel A), Yin Song (panel B-C), Jesús Mercado-Blanco (panel D), Shuqing Yang (panel E).

To design novel control strategies to combat Verticillium wilt disease, a thorough understanding of the molecular mechanisms underlying $V$. dahliae pathogenesis is of fundamental importance. A number of pathogenicity and virulence factors of $V$. dahliae have been identified (Zhou et al., 2012; de Jonge et al., 2012; Santhanam and Thomma, 2013; Santhanam et al., 2017; Kombrink et al., 2017; Liu et al., 2014; Klimes et al., 2015). For instance, the transcriptional regulator Sger has been shown to differentially regulate expression of a number of putative effector genes in planta and is required for radial growth, conidiospore production, and pathogenicity (Santhanam and Thomma, 2013). Also the transcriptional regulator Vta2 was found to be required for pathogenicity (Tran et al., 2014). Vta2 suppresses the formation of microsclerotia and controls the expression of effector genes that may be involved in $V$. dahliae pathogenicity (Tran et al., 2014). In addition, a rhamnose synthase of $V$. dahliae, which functions in the formation rhamnose-containing glycans in the fungal cell wall, was found to be essential for pathogenicity on tomato and Nicotiana benthamiana (Santhanam et al., 2017). Necrosis and ethylene-inducing-like proteins (NLPs) are a group of conserved effectors that are widely spread in bacteria, fungi, as well as oomycetes (Gijzen 
and Nürnberger, 2006; Oome and Van den Ackerveken, 2014). Interestingly, most ascomycete plant pathogens contain up to three NLP genes, while the $V$. dahliae genome was predicted to have eight NLP genes (Klosterman et al., 2011).Members of the expanded NLP family have been shown to be associated with functional diversification, as they display differential cytotoxicity (Zhou et al., 2012; Santhanam et al., 2013). Surprisingly, only NLP1 and NLP2 show cytotoxic activity, while the remaining NLP family members are non-cytotoxic (Zhou et al., 2012; Santhanam et al., 2013). Further evidence for functional diversification within the V. dahliae NLP family comes from the differential contributions of NLP1 and NLP2 to fungal virulence on distinct host plants. Although both NLP1 and NLP2 contribute to virulence of V. dahliae strain JR2 on tomato and Arabidopsis (Santhanam et al., 2013), neither is required for virulence of strain V592 on cotton (Zhou et al., 2012). Moreover NLP1, but not NLP2, is required for virulence of $V$. dahliae strain JR2 on $N$. benthamiana, owing to the fact that $N L P 1$, but not NLP2, is expressed on this plant species (Santhanam et al., 2013). Thus, it has been proposed that the functional diversification of $V$. dahliae NLP effectors may contribute to the broad host range of the pathogen (Zhou et al., 2012; Santhanam et al., 2013; Klimes et al., 2015).

Through comparative genomics, highly variable lineage-specific (LS) genomic regions that are only found in subsets of the $V$. dahliae population were identified (de Jonge et al., 2013; Faino et al., 2016). Interestingly, these LS genomic regions are greatly enriched in in planta-induced effector genes, targeted deletion of which typically results in significantly compromised fungal aggressiveness, suggesting that these effectors contribute to host colonization (de Jonge et al., 2012, 2013; Kombrink et al., 2017). Remarkably, V. dahliae LS regions are also enriched in transposable elements (TEs) (Faino et al., 2016). TEs can change their genomic position, which may induce gene disruption, or cause double-strand DNA breaks by TE excision (Seidl and Thomma, 2014). Therefore, TEs may actively contribute to the genetic plasticity of LS regions (Faino et al., 2016; Seidl and Thomma, 2017). In addition to active role in promoting genomic plasticity, TEs can contribute to genome evolution of $V$. dahliae in a passive manner as well (Faino et al., 2016). It has been shown that highly variable LS regions evolved by genomic rearrangements that are mediated by erroneous double-strand repair, frequently utilizing TEs as substrate due to their abundance and high degree of sequence similarity (Faino et al., 2016). Thus, it has been proposed that TEs are important drivers for adaptive genome evolution in V. dahliae (Faino et al., 2016; Seidl and Thomma, 2014; Seidl and Thomma, 2017).

\section{Thesis outline}

Upon infection of its hosts, $V$. dahliae secretes effectors to enable host colonization. The aim of the research described in this thesis is to gain more insight into molecular mechanisms of $V$. dahliae pathogenesis, with a specific focus on the discovery of novel effectors that contribute to the establishment of $V$. dahliae infections on diverse host plants.

On particular host plants, V. dahliae strains are assigned to so-called "pathotypes". For example, $V$. dahliae strains that are highly virulent and cause rapid and severe defoliation on cotton, olive, okra (Hibiscus esculentus) and pistachio (Pistacia vera) are referred to as strains of the defoliating (D) pathotype, whereas strains that are moderately virulent and induce wilting symptoms 
without defoliation on these hosts are assigned to the non-defoliating (ND) pathotype. However, the molecular basis that underlies differential virulence between $\mathrm{D}$ and ND pathotype strains remained elusive. In Chapter 2, we employed comparative genomics and transcriptomics to identify $V$. dahliae genes that are responsible for defoliation symptoms. To this end, genome sequences of multiple D pathotype and ND pathotype strains were determined. Subsequently, candidate genes were subjected to functional analyses to assess their role in defoliation of cotton and olive.

Chapter 3 focussed on elucidating the molecular basis of $V$. dahliae pathogenicity on tomato. For this purpose, comparative genomics of pathogenic and non-pathogenic $V$. dahliae strains was performed. Targeted deletion of candidate genes was pursued to identify pathogenicity factors. Moreover, candidate genes were introduced into a non-pathogenic $V$. dahliae strain and in the saprophytes $V$. tricorpus and V. nubilum to test whether these recipient strains gain pathogenicity on tomato.

In Chapter 4, genome comparisons of a sunflower pathogenic strain with several non-pathogenic strains were carried out to identify $V$. dahliae genes that contribute to virulence on sunflower. Subsequently, we examined the role of candidate genes in virulence through gene deletion analysis.

Despite the notion that most $V$. dahliae strains have a broad host range, the pathogenic potential and the severity of symptoms that are induced on a particular host plant may vary considerably between $V$. dahliae strains. In Chapter 5, we set out to determine whether V. dahliae strains that infect the same host plant also have similar effector profiles. To this end, we identified the core and lineage-specific (LS) effector repertoires in a collection of $V$. dahliae strains for which we also test the ability to cause disease on tomato, cotton, sunflower, Arabidopsis, and N. benthamiana.

Previous studies have shown that the C. fulvum effector Ecp6 outcompetes host immune receptors for chitin binding (de Jonge et al., 2010; Sánchez-Vallet et al., 2013). In Chapter 6, I generated chimeric chitin receptors by replacing the LysM domain-containing ectodomain of the Arabidopsis chitin receptors with the LysM domains of Ecp6. I further investigated whether expression of the chimeric chitin receptors in Arabidopsis results in enhanced chitin-induced immunity to fungal infection.

Finally, in Chapter 7, the results described in this thesis are summarized and discussed in a broader perspective to illustrate the role of $V$. dahliae effectors in fungal pathogenicity. 


\section{References}

Bi G, Zhou JM (2017) MAP kinase signaling pathways: a hub of plant-microbe interactions. Cell Host Microbe 21: 270-273.

Böhnert HU, Fudal I, Dioh W, Tharreau D, Notteghem JL, Lebrun MH (2004) A putative polyketide synthase/ peptide synthetase from Magnaporthe grisea signals pathogen attack to resistant rice. Plant Cell 16: 2499-2513.

Bolton MD, van Esse HP, Vossen JH, de Jonge R, Stergiopoulos I, Stulemeijer IJ, van den Berg GC, Borrás-Hidalgo O, Dekker HL, de Koster CG, et al. (2008) The novel Cladosporium fulvum lysin motif effector Ecp6 is a virulence factor with orthologues in other fungal species. Mol Microbiol 69: 119-136.

Bozkurt TO, Schornack S, Win J, Shindo T, Ilyas M, Oliva R, Cano LM, Jones AM, Huitema E, van der Hoorn RA, Kamoun S (2011) Phytophthora infestans effector AVRblb2 prevents secretion of a plant immune protease at the haustorial interface. Proc Natl Acad Sci USA 108: 20832-20837.

Büttner D (2016) Behind the lines-actions of bacterial type III effector proteins in plant cells. FEMS Microbiol Rev 40: 894-937.

Büttner D, He SY (2009) Type III protein secretion in plant pathogenic bacteria. Plant Physiol 150: 1656-1664.

Cook DE, Mesarich CH, Thomma BPHJ (2015) Understanding plant immunity as a surveillance system to detect invasion. Annu Rev Phytopathol 53: 541-563.

Couto D, Zipfel C (2016) Regulation of pattern recognition receptor signalling in plants. Nat Rev Immunol 16: 537552.

de Jonge R, Bolton MD, Kombrink A, van den Berg GC, Yadeta KA, Thomma BPHJ (2013) Extensivechromosomal reshuffling drives evolution of virulence in an asexual pathogen. Genome Res 23: 1271-1282.

de Jonge R, Bolton MD, Thomma BPHJ (2011) How filamentous pathogens co-opt plants: the ins and outs of fungal effectors. Curr Opin Plant Biol 14: 400-406.

de Jonge R, Thomma BPHJ (2009) Fungal LysM effectors: extinguishers of host immunity? Trends Microbiol 17: 151-157.

de Jonge R, van Esse HP, Kombrink A, Shinya T, Desaki Y, Bours R, van der Krol S, Shibuya N, Joosten MH, Thomma BPHJ (2010) Conserved fungal LysM effector Ecp6 prevents chitin-triggered immunity in plants. Science 329: 953-955.

de Jonge R, van Esse HP, Maruthachalam K, Bolton MD, Santhanam P, Saber MK, Zhang Z, Usami T, Lievens B, Subbarao KV, et al. (2012) Tomato immune receptor Ve1 recognizes effector of multiple fungal pathogens uncovered by genome and RNA sequencing. Proc Natl Acad Sci USA 109: 5110-5115.

Depotter JR, Deketelaere S, Inderbitzin P, Tiedemann AV, Höfte M, Subbarao KV, Wood TA, Thomma BPHJ (2016) Verticillium longisporum, the invisible threat to oilseed rape and other brassicaceous plant hosts. Mol Plant Patho 17: 1004-1016.

De Wit PJ (2016) Apoplastic fungal effectors in historic perspective; a personal view. New Phytol 212: 805-813.

Djamei A, Schipper K, Rabe F, Ghosh A, Vincon V, Kahnt J, Osorio S, Tohge T, Fernie AR, Feussner I, et al. (2011) Metabolic priming by a secreted fungal effector. Nature 478: 395-398.

Dodds PN (2010) Genome evolution in plant pathogens. Science 330: 1486-1487.

Dou D, Kale SD, Wang X, Jiang RH, Bruce NA, Arredondo FD, Zhang X, Tyler BM (2008) RxLR-mediated entry of Phytophthora sojae effector Avrrb into soybean cells does not require pathogen-encoded machinery. Plant Cell 20: 1930-1947.

Du Y, Stegmann M, Misas Villamil JC (2016) The apoplast as battleground for plant-microbe interactions. New Phytol 209: 34-38.

Faino L, Seidl MF, Shi-Kunne X, Pauper M, van den Berg GC, Wittenberg AH, Thomma BPHJ (2016) Transposons passively and actively contribute to evolution of the two-speed genome of a fungal pathogen. Genome Res 26: $1091-1100$.

Faino L, Thomma BPHJ (2014) Get your high-quality low-cost genome sequence.Trends Plant Sci 19: 288-291.

Feng F, Yang F, Rong W, Wu X, Zhang J, Chen S, He C, Zhou JM (2012) A Xanthomonas uridine 5'-monophosphate transferase inhibits plant immune kinases. Nature 485: 114-118. 
Fisher MC, Henk DA, Briggs CJ, Brownstein JS, Madoff LC, McCraw SL and Gurr SJ (2012) Emerging fungal threats to animal, plant and ecosystem health. Nature 484: 186-194.

Fradin EF, Thomma BPHJ (2006) Physiology and molecular aspects of Verticillium wilt diseases caused by V. dahliae and V. albo-atrum. Mol Plant Pathol 7: 71-86.

Fradin EF, Zhang Z, Ayala JCJ, Castroverde CD, Nazar RN, Robb J, Liu C-M, Thomma BPHJ (2009) Genetic dissection of Verticillium wilt resistance mediated by tomato Ve1. Plant Physiol 150: 320-332.

Fudal I, Ross S, Gout L, Blaise F, Kuhn M, Eckert M, Cattolico L, Bernard-Samain S, Balesdent M, Rouxel T (2007) Heterochromatin-like regions as ecological niches for avirulence genes in the Leptosphaeria maculans genome: map-based cloning of AvrLm6. Mol Plant Microbe Interact 20: 459-470.

Galán JE, Lara-Tejero M, Marlovits TC, Wagner S (2014) Bacterial type III secretion systems: specialized nanomachines for protein delivery into target cells. Annu Rev Microbiol 68: 415-438.

Gawehns F, Cornelissen BJ, Takken FL (2013) The potential of effector-target genes in breeding for plant innate immunity. Microb Biotechnol 6:223-229.

Gibriel HA, Thomma BPHJ, Seidl MF (2016) The age of effectors: Genome-based discovery and applications. Phytopathology 106: 1206-1212.

Gijzen M, Nürnberger T (2006) Nepi-like proteins from plant pathogens: recruitment and diversification of the NPP1 domain across taxa. Phytochemistry 67: 1800-1807.

Gimenez-Ibanez S, Hann DR, Ntoukakis V, Petutschnig E, Lipka V, Rathjen JP (2009) AvrPtoB targets the LysM receptor kinase CERK1 to promote bacterial virulence on plants. Curr Biol 19: 423-429.

Giraldo MC, Valent B (2013) Filamentous plant pathogen effectors in action. Nat Rev Microbiol 11: 800-814.

Gohre V, Spallek T, Häweker H, Mersmann S, Mentzel T, Boller T, de Torres M, Mansfield JW, Robatzek S (2008) Plant pattern-recognition receptor FLS2 is directed for degradation by the bacterial ubiquitin ligase AvrPtoB. Curr Biol 18: 1824-1832.

Gout L, Fudal I, Kuhn ML, Blaise F, Eckert M, Cattolico L, Balesdent MH, Rouxel T (2006) Lost in the middle of nowhere: the AvrLmi avirulence gene of the Dothideomycete Leptosphaeria maculans. Mol Microbiol 60: 67-80.

Grant SR, Fisher EJ, Chang JH, Mole BM, Dangl JL (2006) Subterfuge and manipulation: type III effector proteins of phytopathogenic bacteria. Annu Rev Microbiol 60: 425-449.

Gurung S, Short DPG, Hu X, Sandoya GV, Hayes RJ, Koike ST, Subbarao KV (2015) Host range of Verticillium isaacii and Verticillium klebahnii from artichoke, spinach and lettuce. Plant Dis 99: 933-938.

Haas BJ, Kamoun S, Zody MC, Jiang RH, Handsaker RE, Cano LM, Grabherr M, Kodira CD, Raffaele S, TortoAlalibo T, et al.(2009) Genome sequence and analysis of the Irish potato famine pathogen Phytophthora infestans. Nature 461: 393-398.

Hayes RJ, McHale LK, Vallad GE, Truco MJ, Michelmore RW, Klosterman SJ, Maruthachalam K, Subbarao KV (2011) The inheritance of resistance to Verticillium wilt caused by race 1 isolates of Verticillium dahliae in the lettuce cultivar La Brillante. Theor Appl Genet 123: 509-517.

Houterman PM, Cornelissen BJ, Rep M (2008) Suppression of plant resistance gene-based immunity by a fungal effector. PLoS Pathog 4: e1000061.

Houterman PM, Speijer D, Dekker HL, DE Koster CG, Cornelissen BJ, Rep M (2007) The mixed xylem sap proteome of Fusarium oxysporum-infected tomato plants. Mol Plant Pathol 8: 215-221.

Inderbitzin P, Bostock RM, Davis RM, Usami T, Platt HW, Subbarao KV (2011) Phylogenetics and taxonomy of the fungal vascular wilt pathogen Verticillium, with the descriptions of five new species. PLOS ONE 6: e28341.

Inderbitzin P, Subbarao KV (2014) Verticillium systematics and evolution: how confusion impedes Verticillium wilt management and how to resolve it. Phytopathology 104: 564-574.

Jashni MK, Mehrabi R, Collemare J, Mesarich CH, de Wit PJM (2015) The battle in the apoplast: further insights into the roles of proteases and their inhibitors in plant-pathogen interactions. Front Plant Sci 6: 584.

Jiang RH, Tripathy S, Govers F, Tyler BM (2008) RxLR effector reservoir in two Phytophthora species is dominated by a single rapidly evolving superfamily with more than 700 members. Proc Natl Acad Sci USA 105: 4874-4879.

Jones DA, Bertazzoni S, Turo CJ, Syme RA, Hane JK (2018) Bioinformatic prediction of plant-pathogenicity effector proteins of fungi. Curr Opin Microbiol 46: 43-49.

Jones JD, Dangl JL (2006) The plant immune system. Nature 444: 323-329. 
Joosten MHAJ, De Wit PJGM (1988) Isolation, purification and preliminary characterization of a protein specific for compatible Cladosporium fulvum (syn. Fulvia fulva)-tomato interactions. Physiol Mol Plant Pathol 33: 241-253.

Kale SD, Gu B, Capelluto DG, Dou D, Feldman E, Rumore A, Arredondo FD, Hanlon R, Fudal I, Rouxel T, et al. (2010) External lipid PI3P mediates entry of eukaryotic pathogen effectors into plant and animal host cells. Cell 142: 284-295.

Kale SD, Tyler BM (2011) Entry of oomycete and fungal effectors into plant and animal host cells. Cell Microbiol 13: 1839-1848.

Kawchuk LM, Hachey J, Lynch DR, Kulcsar F, van Rooijen G, Waterer DR, Robertson A, Kokko E, Byers R, Howard RJ (2001) Tomato Ve disease resistance genes encode cell surface-like receptors. Proc Natl Acad Sci USA 98: 6511-6515.

Kazan K, Lyons R (2014) Intervention of phytohormone pathways by pathogen effectors. Plant Cell 26: 2285-2309.

Kettles GJ, Bayon C, Sparks CA, Canning G, Kanyuka K, Rudd JJ (2017) Characterization of an antimicrobial and phytotoxic ribonuclease secreted by the fungal wheat pathogen Zymoseptoria tritici. New Phytol 217: 320-331.

Khang CH, Berruyer R, Giraldo MC, Kankanala P, Park SY, Czymmek K, Kang S, Valent B (2010) Translocation of Magnaporthe oryzae effectors into rice cells and their subsequent cell-to-cell movement. Plant Cell 22: 13881403.

Kim JG, Stork W, Mudgett MB (2013) Xanthomonas type III effector XopD desumoylates tomato transcription factor SlERF4 to suppress ethylene responses and promote pathogen growth. Cell Host Microbe 13: 143-154.

King SR, McLellan H, Boevink PC, Armstrong MR, Bukharova T, Sukarta O, Win J, Kamoun S, Birch PR, Banfield MJ (2014) Phytophthora infestans RxLR effector PexRD2 interacts with host MAPKKK $\varepsilon$ to suppress plant immune signaling. Plant Cell 26: 1345-1359.

Klimes A, Dobinson KF, Klosterman SJ, Thomma BPHJ (2015) Genomics spurs rapid advances in ourunderstanding of the basic biology of vascular wilt pathogens in the genus Verticillium. Annu Rev Phytopathol 53: 181-198.

Kloppholz S, Kuhn H, Requena N (2011) A secreted fungal effector of Glomus intraradices promotes symbiotic biotrophy. Curr Biol 21: 1204-1209.

Klosterman SJ, Atallah ZK, Vallad GE, Subbarao KV (2009) Diversity, pathogenicity, and management of Verticillium species. Annu Rev Phytopathol 47: 39-62.

Klosterman SJ, Subbarao KV, Kang S, Veronese P, Gold SE, Thomma BPHJ, Chen Z, Henrissat B, Lee YH, Park J (2011) Comparative genomics yields insights into niche adaptation of plant vascular wilt pathogens. PLOS Pathog 7: e1002137.

Kombrink A, Rovenich H, Shi-Kunne X, Rojas-Padilla E, van den Berg G, Domazakis E, De Jonge R, Valkenburg DJ, Sánchez-Vallet A, Seidl MF, et al. (2017) Verticillium dahliae LysM effectors differentially contribute to virulence on plant hosts. Mol Plant Pathol 18: 596-608.

Laugé R, Goodwin PH, De Wit PJGM, Joosten MHAJ (2000) Specific HR-associated recognition of secreted proteins from Cladosporium fulvum occurs in both host and non-host plants. Plant J 23: 735-745.

Laugé R, Joosten MHAJ, Haanstra JPW, Goodwin PH, Lindhout P, De Wit PJGM (1998) Successful search for a resistance gene in tomato targeted against a virulence factor of a fungal pathogen. Proc Natl Acad Sci USA 95: 9014-9018.

Lee AH, Middleton MA, Guttman DS, Desveaux D (2013) Phytopathogen type III effectors as probes of biological systems. Microb Biotechnol 6: 230-240.

Liu T, Song T, Zhang X, Yuan H, Su L, Li W, Xu J, Liu S, Chen L, Chen T, Gu L, Zhang B, Dou D (2014) Unconventionally secreted effectors of two filamentous pathogens target plant salicylate biosynthesis. Nat Commun 5: 4686.

Macho AP, Zipfel C (2015) Targeting of plant pattern recognition receptor-triggered immunity by bacterial type-III secretion system effectors. Curr Opin Microbiol 23: 14-22.

Ma LJ, van der Does HC, Borkovich KA, Coleman JJ, Daboussi MJ, Di Pietro A, Dufresne M, Freitag M, Grabherr M, Henrissat B, et al. (2010) Comparative genomics reveals mobile pathogenicity chromosomes in Fusarium. Nature 464: 367-373.

Ma KW, Ma W (2016) Phytohormone pathways as targets of pathogens to facilitate infection. Plant Mol Biol 91: 713-725. 
Martin F, Aerts A, Ahrén D, Brun A, Danchin EG, Duchaussoy F, Gibon J, Kohler A, Lindquist E, Pereda V, et al. (2008) The genome of Laccaria bicolor provides insights into mycorrhizal symbiosis. Nature 452: 88-92.

Marshall R, Kombrink A, Motteram J, Loza-Reyes E, Lucas J, Hammond-Kosack KE, Thomma BPHJ, Rudd JJ (2011) Analysis of two in planta expressed LysM effector homologues from the fungus Mycosphaerella graminicola reveals novel functional properties and varying contributions to virulence on wheat. Plant Physiol 156: 756769.

Meng X, Zhang S (2013) MAPK cascades in plant disease resistance signaling. Annu Rev Phytopathol 51: 245-266.

Mentlak TA, Kombrink A, Shinya T, Ryder LS, Otomo I, Saitoh H, Terauchi R, Nishizawa Y, Shibuya N, Thomma BPHJ, Talbot NJ (2012) Effector-mediated suppression of chitin-riggered immunity by Magnaporthe oryzae is necessary for rice blast disease. Plant Cell 24: 322-335.

Mueller AN, Ziemann S, Treitschke S, Assmann D, Doehlemann G (2013) Compatibility in the Ustilago maydismaize interaction requires inhibition of host cysteine proteases by the fungal effector Pit2. PLOS Pathog 9: e1003177.

Oome S, Raaymakers TM, Cabral A, Samwel S, Böhm H, Albert I, Nürnberger T, Van den Ackerveken G (2014) Nepi-like proteins from three kingdoms of life act as a microbe-associated molecular pattern in Arabidopsis. Proc Natl Acad Sci USA 111: 16955-16960.

Orbach MJ, Farrall L, Sweigard JA, Chumley FG, Valent B (2000) A telomeric avirulence gene determines efficacy for the rice blast resistance gene Pi-ta. Plant Cell 12: 2019-2032.

Patkar RN, Benke PI, Qu Z, Chen YY, Yang F, Swarup S, Naqvi NI (2015) A fungal monooxygenase-derived jasmonate attenuates host innate immunity. Nat Chem Biol 11: 733-740.

Pegg GF, Brady BL (2002) Verticillium wilts. Wallingord, Oxfordhire: CABI Publishing.

Petre B, Kamoun S (2014) How do filamentous pathogens deliver effector proteins into plant cells? PLoS Biol 12: e1001801.

Plett JM, Daguerre Y, Wittulsky S, Vayssières A, Deveau A, Melton SJ, Kohler A, Morrell-FalveyJL, Brun A, VeneaultFourrey C, et al. (2014) Effector MiSSP7 of the mutualistic fungus Laccaria bicolor stabilizes the Populus JAZ6 protein and represses jasmonic acid (JA) responsive genes. Proc Natl Acad Sci USA 111: 8299-8304.

Pretorius ZA, Singh RP, Wagoire WW, Payne TS (2000) Detection of virulence to wheat stem rust resistance gene Sr31 in Puccinia graminis f. sp. tritici in Uganda. Plant Dis 84: 203.

Rafiqi M, Ellis JG, Ludowici VA, Hardham AR, Dodds PN (2012) Challenges and progress towards understanding the role of effectors in plant-fungal interactions. Curr Opin Plant Biol 15: 477-482.

Rep M, van der Does HC, Meijer M, van Wijk R, Houterman PM, Dekker HL, de Koster CG, Cornelissen BJ (2004) A small, cysteine-rich protein secreted by Fusarium oxysporum during colonization of xylem vessels is required for I-3-mediated resistance in tomato. Mol Microbiol 53:1373-1383.

Rodriguez-Moreno L, Ebert MK, Bolton MD, Thomma BPHJ (2018) Tools of the crook-infection strategies of fungal plant pathogens. Plant J 93: 664-674.

Rodriguez-Moreno L, Song Y, Thomma BPHJ (2017) Transfer and engineering of immune receptors to improve recognition capacities in crops. Curr Opin Plant Biol 38: 42-49.

Rovenich H, Boshoven JC, Thomma BPHJ (2014) Filamentous pathogen effector functions: of pathogens, hosts and microbiomes. Curr Opin Plant Biol 20: 96-103.

Rovenich H, Zuccaro A, Thomma BPHJ (2016) Convergent evolution of filamentous microbes towards evasion of glycan-triggered immunity. New Phytol 212: 896-901.

Salcedo A, Rutter W, Wang S, Akhunova A, Bolus S, Chao S, Anderson N, De Soto MF, Rouse M, Szabo L, et al. (2017) Variation in the AvrSr35 gene determines Sr35 resistance against wheat stem rust race Ug99. Science 358: 1604-1606.

Sánchez-Vallet A, Mesters JR, Thomma BPHJ (2015) The battle for chitin recognition in plant-microbe interactions. FEMS Microbiol Rev 39: 171-183.

Sánchez-Vallet A, Saleem-Batcha R, Kombrink A, Hansen G, Valkenburg DJ, Thomma BPHJ, Mesters JR (2013) Fungal effector Ecp6 outcompetes host immune receptor for chitin binding through intrachain LysM dimerization. elife 2: e00790. 
Santhanam P, Boshoven JC, Salas O, Bowler K, Islam MT, Saber MK, van den Berg GC, Bar-Peled M, Thomma BPHJ (2017) Rhamnose synthase activity is required for pathogenicity of the vascular wilt fungus Verticillium dahliae. Mol Plant Pathol 18: 347-362.

Santhanam P, Thomma BPHJ (2013) Verticillium dahliae Sge1 differentially regulates expression of candidate effector genes. Mol Plant-Microbe Interact 26: 249-256.

Santhanam P, van Esse HP, Albert I, Faino L, Nürnberger T, Thomma BPHJ (2013) Evidence forfunctional diversification within a fungal NEP1-like protein family. Mol Plant-Microbe Interact 26: 278-286.

Schaible L, Cannon OS, Waddoups V (1951) Inheritance of resistance to Verticillium wilt in a tomato cross. Phytopathology 41: 986-990.

Schirawski J, Mannhaupt G, Münch K, Brefort T, Schipper K, Doehlemann G, Di Stasio M, Rössel N, MendozaMendoza A, Pester D, et al. (2010) Pathogenicity determinants in smut fungi revealed by genome comparison. Science 330: 1546-1548.

Schmidt SM, Lukasiewicz J, Farrer R, van Dam P, Bertoldo C, Rep M (2016) Comparative genomics of Fusarium oxysporum f. sp. melonis reveals the secreted protein recognized by the Fom-2 resistance gene in melon. New Phytol 209: 307-318.

Schornack S, van Damme M, Bozkurt TO, Cano LM, Smoker M, Thines M, Gaulin E, Kamoun S, Huitema E (2010) Ancient class of translocated oomycete effectors targets the host nucleus. Proc Natl Acad Sci USA 107: 1742117426.

Seidl, MF, Faino L, Shi-Kunn X, van den Berg, GCM, Bolton MD, and Thomma, BPJH (2015) The genome of the saprophytic fungus Verticillium tricorpus reveals a complex effector repertoire resembling that of its pathogenic relatives. Mol Plant-Microbe Interact 28: 362-373.

Seidl MF, Thomma BPHJ (2014) Sex or no sex: evolutionary adaptation occurs regardless. BioEssays 36: 335-345.

Seidl MF, Thomma BPHJ (2017) Transposable elements direct the coevolution between plants and microbes. Trends Genet 33: 842-851.

Simko I, Costanzo S, Haynes K, Christ B, Jones R (2004) Linkage disequilibrium mapping of a Verticillium dahliae resistance quantitative trait locus in tetraploid potato (Solanum tuberosum) through a candidate gene approach. Theor Appl Genet 108: 217-224.

Singh RP, Hodson DP, Huerta-Espino J, Jin Y, Bhavani S, Njau P, Herrera-Foessel S, Singh PK, Singh S, Govindan V (2011) The emergence of Ug99 races of the stem rust fungus is a threat to world wheat production. Annu Rev Phytopathol 49: 465-481.

Snelders NC, Kettles GJ, Rudd JJ. and Thomma BPHJ (2018) Plant pathogen effector proteins as manipulators of host microbiomes? Mol Plant Pathol 19: 257-259.

Sperschneider J, Dodds PN, Gardiner DM, Manners JM, Singh KB, Taylor JM (2015) Advances and challenges in computational prediction of effectors from plant pathogenic fungi. PLOS Pathog 11: e1004806.

Sperschneider J, Gardiner DM, Dodds PN, Tini F, Covarelli L, Singh KB, Manners JM, Taylor JM (2016) EffectorP: predicting fungal effector proteins from secretomes using machine learning. New Phytol 210: 743-761.

Song Y, Zhang Z, Seidl MF, Majer A, Jakse J, Javornik B, Thomma BPHJ (2017) Broad taxonomic characterization of Verticillium wilt resistance genes reveals an ancient origin of the tomato Ver immune receptor. Mol Plant Pathol 18: 195-209.

Stergiopoulos I, de Wit PJ (2009) Fungal effector proteins. Annu Rev Phytopathol 47: 233-263.

Strange RN and Scott PR (2005) Plant disease: A threat to global food security. Annu Rev Phytopathol 43: 83-116.

Takahara H, Hacquard S, KombrinkA, Hughes HB, HalderV, Robin GP, Hiruma K, Neumann U, Shinya T, Kombrink A, ea al. (2016) Colletotrichum higginsianum extracellular LysM proteins play dual roles in appressorial function and suppression of chitin-triggered plant immunity. New Phytol 211: 1323-1337.

Tang D, Wang G, Zhou JM (2017) Receptorkinases in plant-pathogen interactions: more than pattern recognition. Plant Cell 29: 618-637.

Thomma BPHJ, Nurnberger T, Joosten MHAJ (2011) Of PAMPs and effectors: The blurred PTI-ETI dichotomy. Plant Cell 23: 4-15.

Thomma BPHJ, Seidl MF, Shi-Kunne X, Cook DE, Bolton MD, van Kan JAL, Faino L (2015) Mind the gap; seven reasons to close fragmented genome assemblies. Fungal Genet Biol 90: 24-30. 
Toruño TY, Stergiopoulos I, Coaker G (2016) plant-pathogen effectors: cellular probes interfering with plant defenses in spatial and temporal manners. Annu Rev Phytopathol 54: 419-441.

Tran VT, Braus-Stromeyer SA, Kusch H, Reusche M, Kaever A, Kühn A, Valerius O, Landesfeind M, Aßhauer K, Tech M, et al. (2014) Verticillium transcription activator of adhesion Vta2 suppresses microsclerotia formation and is required for systemic infection of plant roots. New Phytol 202: 565-581.

Tyler BM, Tripathy S, Zhang X, Dehal P, Jiang RH, Aerts A, Arredondo FD, Baxter L, Bensasson D, Beynon JL (2006) Phytophthora genome sequences uncover evolutionary origins and mechanisms of pathogenesis. Science 313: 1261-1266.

van den Burg HA, Harrison SJ, Joosten MH, Vervoort J, de Wit PJ (2006) Cladosporium fulvum Avr4 protects fungal cell walls against hydrolysis by plant chitinases accumulating during infection. Mol Plant Microbe Interact 19: $1420-1430$.

van Esse HP, Bolton MD, Stergiopoulos I, de Wit PJ, Thomma BPHJ (2007) The chitin-binding Cladosporium fulvum effector protein Avr4 is a virulence factor. Mol Plant Microbe Interact 20: 1092-1101.

van Esse HP, Van't Klooster JW, Bolton MD, Yadeta KA, van Baarlen P, Boeren S, Vervoort J, de Wit PJ, Thomma BPHJ (2008) The Cladosporium fulvum virulence protein Avr2 inhibits host proteases required for basal defense. Plant Cell 20: 1948-1963.

von Heijne G (1990)The signal peptide. J Membr Biol 115: 195-201.

Wang Y, Li J, Hou S, Wang X, Li Y, Ren D, Chen S, Tang X, Zhou JM (2010) A Pseudomonas syringae ADPribosyltransferase inhibits Arabidopsis mitogen-activated protein kinase kinases. Plant Cell 22: 2033-204d4.

Wawra S, Djamei A, Albert I, Nürnberger T, Kahmann R, van West P (2013) In vitro translocation experiments with RxLR-reporter fusion proteins of Avrib from Phytophthora sojae and AVRza from Phytophthora infestans fail to demonstrate specific autonomous uptake in plant and animal cells. Mol Plant-Microbe Interact 26: 528-536.

Wawra S, Trusch F, Matena A, Apostolakis K, Linne U, Zhukov I, Stanek J, Koźmiński W, Davidson I, Secombes CJ, et al. (2017) The RxLR Motif of the host targeting effector AVR3a of Phytophthora infestans is cleaved before secretion. Plant Cell 29: 1184-1195.

Whisson SC, Boevink PC, Moleleki L, Avrova AO, Morales JG, Gilroy EM, Armstrong MR, Grouffaud S, van West P, Chapman S, et al. (2007) A translocation signal for delivery of oomycete effector proteins into host plant cells. Nature 450: 115-118.

Wubben JP, Joosten MHAJ, De Wit PJGM (1994) Expression and localization of two in planta induced extracellular proteins of the fungal tomato pathogen Cladosporium fulvum. Mol Plant-Microbe Interact 7: 516-524.

Yadeta KA, Thomma BPHJ (2013) The xylem as battleground for plant hosts and vascular wilt pathogens. Front Plant Sci 4: 97.

Yaeno T, Li H, Chaparro-Garcia A, Schornack S, Koshiba S, Watanabe S, Kigawa T, Kamoun S, Shirasu K (2011) Phosphatidylinositol monophosphate-binding interface in the oomycete RxLR effector AVR3a is required for its stability in host cells to modulate plant immunity. Proc Natl Acad Sci USA 108: 14682-14687.

Yi M, Valent B (2013) Communication between filamentous pathogens and plants at the biotrophic interface. Annu Rev Phytopathol 51: 587-611.

Zhan J, Thrall PH, Papaix J, Xie L, Burdon JJ (2015) Playing on a pathogen's weakness: using evolution to guide sustainable plant disease control strategies Annu Rev Phytopathol 53: 19-43.

Zhang J, Li W, Xiang T, Liu Z, Laluk K, Ding X, Zou Y, Gao M, Zhang X, Chen S, et al. (2010) Receptor-like cytoplasmic kinases integrate signaling from multiple plant immune receptors and are targeted by a Pseudomonas syringae effector. Cell Host Microbe 7: 290-301.

Zhang J, Shao F, Li Y, Cui H, Chen L, Li H, Zou Y, Long C, Lan L, Chai J, et al. (2007) A Pseudomonas syringae effector inactivates MAPKs to suppress PAMP-induced immunity in plants. Cell Host Microbe 1: 175-185.

Zhou BJ, Jia PS, Gao F, Guo HS (2012) Molecular characterization and functional analysis of a necrosis-and ethyleneinducing, protein-encoding gene family from Verticillium dahliae. Mol Plant-Microbe Interact 25: 964-975. 



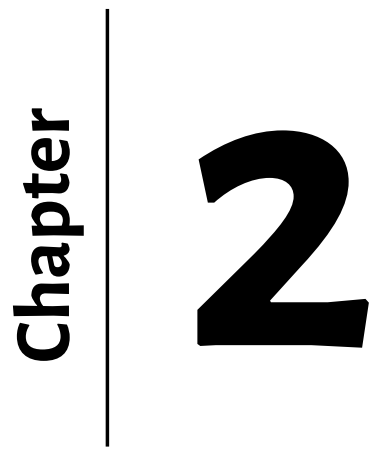

\section{A single Verticillium dahliae effector is responsible for the highly aggressive defoliating pathotype on cotton and olive}

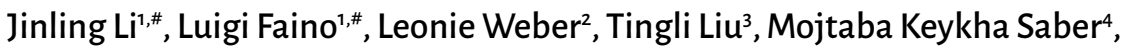
Carmen Cómez-Lama Cabanás ${ }^{5}$, Antonio Valverde-Corredor ${ }^{5}$, Grardy C.M. van den Berg', Hui Tian', Jelle Hiemstra ${ }^{4}$, Jesús Mercado-Blanco5, Volker Lipka ${ }^{2}$, Baolong Zhang ${ }^{3, \$}$, Longfu Zhu ${ }^{6, \$}$, and Bart P.H.J. Thomma ${ }^{1, \$, *}$ 


\section{Abstract}

Plant pathogens from diverse taxonomic origins have been shown to secrete effector molecules to manipulate host physiology and support successful infection. Verticillium dahliae is a soil-borne fungal pathogen that causes Verticillium wilt disease in a wide variety of economically important plant species. On particular host plants, V. dahliae strains are assigned to so-called pathotypes. For example, $V$. dahliae strains that are highly virulent and cause rapid, severe defoliation on cotton (Gossypium hirsutum), olive (Olea europaea), okra (Hibiscus esculentus) and pistachio (Pistacia vera) are referred to as strains of the defoliating (D) pathotype, whereas strains that are moderately virulent and only induce wilting symptoms without defoliation on these hosts are assigned to the nondefoliating (ND) pathotype. In this study, we used comparative genomics and transcriptomics to elucidate the molecular basis that are responsible for the ability of $\mathrm{D}$ pathotype strains to cause defoliation symptoms. Comparative genomics revealed two D pathotype-specific candidate effector genes that are highly expressed during host colonization. Intriguingly, these two genes appeared to be identical copies that arose by a segmental duplication. We demonstrate that this duplicated effector gene is a pathogenicity factor on cotton and olive. Furthermore, application of heterologously produced effector protein to cotton seedling induces defoliation, showing that the effector protein is directly responsible for these symptoms. 


\section{Introduction}

Verticillium dahliae is a soil-borne fungal pathogen that colonizes the xylem vessels of a wide range of dicotyledonous host plants, including economically important crops such as tomato (Solanum lycopersicum), cotton (Gossypium hirsutum) and olive (Olea europaea), resulting in Verticillium wilt disease (Fradin and Thomma, 2006). Infection typically starts by penetration of the root, after which the fungus enters and colonizes xylem vessels, affecting water transport, and causing characteristic symptoms that include wilting, stunting, chlorosis and early senescence (Fradin and Thomma, 2006; Klosterman et al., 2009). Due to the broad host range of the pathogen, the scarcity of disease resistance in crop germplasm and the long-term prevalence of its resilient survival structures in the soil, agricultural practices such as crop rotation do not result in efficient disease management (Fradin and Thomma, 2006). Disease control is particularly difficult as fungicides are generally ineffective to eliminate the fungus from infected plants once it has entered xylem vessels (Fradin and Thomma, 2006; Inderbitzin and Subbarao, 2014).

Although $V$. dahliae causes wilt disease in a broad range of host plants, virulence capacities and the severity of symptoms that are induced on host plants can vary considerably between individual strains. For instance, particular strains of $V$. dahliae can cause severe symptoms that include defoliation on cotton, olive, okra (Hibiscus esculentus) and pistachio (Pistacia vera), while other strains cause milder wilting symptoms and do not cause defoliation (Schnathorst and Mathre, 1966; Schnathorst and Sibbett, 1971a; Jiménez-Díaz et al., 2011; Korolev et al., 2008; Hadizadeh and Banihashemi, 2007). Consequently, on particular host plants, V. dahliae strains are assigned to "pathotypes"; groups of $V$. dahliae strains that show differential virulence capacities and disease symptoms (Schnathorst and Mathre, 1966; Schnathorst and Sibbett, 1971b). As such, V. dahliae strains that are highly virulent and cause rapid and severe defoliation on cotton, olive, okra and pistachio are referred to as strains of the defoliating (D) pathotype, whereas strains that are moderately virulent and only induce mild wilting symptoms without defoliation are assigned to the non-defoliating (ND) pathotype (Schnathorst and Mathre, 1966). The currently increasing prevalence of the highly virulent $\mathrm{D}$ pathotype strains poses a significant threat to cotton and olive plantations worldwide (Dervis et al., 2010; López-Escudero et al., 2004; Milgroom et al., 2016; Leyva-Pérez et al., 2017). Recent studies suggest that D pathotype strains originated once in North America and subsequently spread to other continents by dispersal of contaminated plant commodities (Milgroom et al., 2016; Jiménez-Díaz et al., 2017). Despite many efforts to develop molecular markers to robustly and accurately differentiate D and ND pathotype strains (PérezArtés et al., 2000; Mercado-Blanco et al., 2002, 2003; Collins et al., 2005), the molecular basis for the difference in aggressiveness between $\mathrm{D}$ and ND pathotype strains remains unknown so far.

In order to establish disease on their host plants, adapted pathogens secrete so-called effector molecules to modulate plant immunity and promote successful infection (Jones and Dangl, 2006; de Jonge et al., 2011; Rovenich et al., 2014; Cook et al., 2015). It is becoming increasingly apparent that secreted effector molecules play crucial roles in the virulence of diverse plant pathogens, including bacteria, fungi, oomycetes and nematodes (de Jonge et al., 2011; Rovenich et al., 2014; Rodriguez-Moreno et al., 2018; Mitchum et al., 2013). For example, chitin-binding lysin 
motif (LysM) effectors occur in a wide variety of fungal plant pathogens (de Jonge and Thomma, 2009), and have been demonstrated to contribute to virulence of various fungal pathogens by suppressing chitin-induced plant immunity during host colonization (de Jonge et al., 2010; Marshall et al., 2011; Mentlak et al., 2012; Takahara et al., 2016; Kombrink et al., 2017). Thus, it is well established that comprehensive identification of effector repertoires and determination of their modes of action is key to decipher virulence mechanisms of plant pathogens, and ultimately to design effective disease management strategies (Gibriel et al., 2016).

In the past, various methods, including proteomic and genetic approaches, have been used to identify effectors from plant pathogens (Laugé et al., 1998, 2000; Bolton et al., 2008; Böhnert et al., 2004; Fudal et al., 2007). Recently, genomics strategies have facilitated large-scale and comprehensive effector discovery in various plant pathogens (Hu et al., 2011; Thomma et al., 2016). Moreover, comparative genomics of closely related pathogens or different strains of the same pathogenic species have led to the identification of core and lineage-specific effector repertoires (Gibriel et al., 2016). For example, genome comparisons of Ustilago maydis and Sporisorium reilianum, two smut fungi that infect maize but cause different symptoms, revealed 43 distinct genomic regions that primarily contain species-specific genes encoding putative effectors. Functional analyses confirmed that some of these effectors in $U$. maydis contribute to virulence on maize (Schirawski et al., 2010). Similarly, comparative genomics studies on $V$. dahliae have facilitated the identification of key virulence factors that mediate successful host infection (Klosterman et al., 2011; de Jonge et al., 2012, 2013; Kombrink et al., 2017). We previously identified extensive, large scale chromosomal rearrangements, likely mediated by erroneous double-stranded break repair mechanisms, that gave rise to highly variable lineage-specific (LS) genomic regions that are only present in a part of the V. dahliae population (de Jonge et al. 2013; Faino et al., 2016). Interestingly, these LS genomic regions are greatly enriched for in plantainduced effector genes that contribute to host colonization (de Jonge et al., 2013). One of best characterized LS effector is the V. dahliae effector Ave1 that is important for fungal aggressiveness on tomato plants that lack the race-specific resistance gene Ve1, as well as on Arabidopsis (de Jonge et al., 2012), tobacco and cotton (Song et al., 2018). Another LS effector, Vd2LysM, was found to contribute to virulence of strain VdLs17 on tomato (Kombrink et al., 2017).

The aim of this study was to elucidate the molecular basis for the difference in aggressiveness between $V$. dahliae strains that belong to the D and ND pathotype, respectively. To this end, comparative genomics was performed to identify genomic features in strains of the $\mathrm{D}$ pathotype that confer the ability to cause defoliation. 


\section{Materials and methods}

\section{Disease assays}

Cotton (Gossypium hirsutum cv. Xinluzao63), Nicotiana benthamiana, and Arabidopsis thaliana (Col-o) plants were grown under controlled greenhouse conditions (Unifarm, Wageningen, the Netherlands). Olive (Olea europaea cv. Picual) plants were grown in a greenhouse under natural lighting and day/night temperature of $27 / 21^{\circ} \mathrm{C}$ (Córdoba, Spain). Two-week-old cotton and A. thaliana seedlings, three-week-old $N$. benthamiana seedlings and eight-month-old olive plants were used for inoculation assays.

Verticillium dahliae strains (Table $\mathrm{S} 1$ ) were grown on potato dextrose agar (PDA) at $22^{\circ} \mathrm{C}$ for 7-10 days. Conidiospores were collected from PDA plates and washed with tap water for inoculation assays. V. dahliae disease assays on cotton, $N$. benthamiana and $A$. thaliana plants were performed using the root-dip inoculation method as previously described (Fradin et al., 2009; Song et al., 2018). Disease assays on olive plants were performed as previously described (Leyva-Pérez et al., 2017; Gómez-Lama Cabanás et al., 2018).

Disease symptoms were scored up to 21 (A. thaliana and N. benthamiana), 28 (cotton), or 132 (olive) days post inoculation (dpi). To this end, A. thaliana and N. benthamiana plants were photographed, and Image J was used to determine the canopy area of $N$. benthamiana, and the total rosette area of A. thaliana. A rectilinear scale was used to measure the height of cotton plant. The cotton defoliation symptoms classified as o ( $0 \%$ leaf drop off), 1 ( $<25 \%$ leaf drop off), 2 ( $<50 \%$ leaf drop off), 3 (<75\% leaf drop off) and 4 (<100\% leaf drop off) (Liu et al., 2014; Zhang et al., 2017). Fungal biomass in N. benthamiana, A. thaliana and cotton were determined with real-time PCR as previously described (Fradin et al., 2009; Song et al., 2018). Disease severity in inoculated olive plants were monitored by assessing disease symptoms twice a week based on the percentage of leaves affected by chlorosis, or defoliation: 0 (plant without Verticillium wilt symptoms), 1 (overall 1-33\% leaves affected), 2 (overall 34-66\% leaves affected), 3 (overall 67-100\% leaves affected), 4 (the plant was dead) (González et al., 2015; Gómez-Lama et al., 2018). Disease parameters such as disease incidence (DI), mortality (M), and disease intensity index (DII) were also calculated for each treatment. Specifically, the disease intensity index (DII) was defined as DII $=(\Sigma \mathrm{Si} \times \mathrm{Ni}) /(4$ $\times \mathrm{Nt})(\mathrm{Si}=$ severity of symptoms; $\mathrm{Ni}=$ the number of plants with $\mathrm{Si}$ symptoms severity; $\mathrm{Nt}=$ the total number of plants). A final DI was also established as the percentage of affected plants at the end of the bioassay. Finally, the area under the disease progress curve (AUDPC) of DII plotted over time (days; Campbell and Madden, 1990) and the final severity were calculated. Analysis of variance (ANOVA) analyses were performed, and mean values were compared by the Fisher's protected LSD at $\mathrm{P}=0.05$ using the Statistix program (Version 10.0 for Windows. Analytical software 1985-2013).

\section{Genome sequencing and deep transcriptome sequencing}

The genome of $V$. dahliae strain CQ2 (Table S1) was sequenced using long-read PacBio SingleMolecule Real-Time (SMRT) sequencing technology. The PacBio library for sequencing was constructed as described previously (Faino et al., 2015). V. dahliae strains Vd39, V4, BP2, V574, 
V700, V117, V76, ST.100, T9 and V991 (Table S1) were sequenced using the Illumina HiSeq 2000. Library preparation (500-bp insert size) and Illumina sequencing (100-bp paired-end reads) were performed at the Beijing Genome Institute (BGI, China).

For deep transcriptome sequencing, 12-day-old cotton seedlings were root-inoculated with conidiospores of $V$. dahliae strain V991 that belongs to D pathotype as described previously (Gao et al., 2013). Stems of inoculated cotton plants were harvested at $6,9,12,15$ days post inoculation (dpi) for total RNA extraction. RNA extraction was performed following the procedure of the Spectrum Plant Total RNA Kit of Sigma-Aldrich (USA). cDNA synthesis, library preparation (200 bp insert size), and Illumina sequencing ( $90 \mathrm{bp}$ paired-end reads) were performed at the Beijing Genome Institute (BGI, China).

\section{Phylogenetic analysis of sequenced $V$. dahliae strains}

A phylogenetic tree of the $V$. dahliae strains was generated by REALPHY (version 1.12) (Bertels et al., 2014) using Bowtiez (Langmead and Salzberg, 2012) to map genomic reads against the reference $V$. dahliae strain JR2, for which a gapless genome assembly is available (Faino et al., 2015). A maximum likelihood phylogenetic tree was inferred using RAxML (version 8.2.8) with the GTRGAMMA model and 500 bootstrap replicates (Stamatakis, 2014). V. alfalfae MS 102 was used to root the tree.

\section{V. dahliae comparative genomics}

The V. dahliae strain CQ2 genome was assembled using HGAP (v3.0) with default parameters (Chin et al., 2013). The genome ofCQ2 was annotated using MAKER2 (v2) software (Holt and Yandell, 2011) followed by manual curation of gene models present at the regions of interest. The manual curation included the identification of gene models which were predicted by the MAKER2 annotation and the adjustment of exon/intron boundaries using transcriptome sequencing evidence. In order to identify $V$. dahliae gene(s) that are responsible for cotton defoliation, short DNA sequences (reads) from Illumina sequencing of D and ND pathotype strains (Table S1) were mapped onto the genome of CQ2 using BWA software (Li and Durbin, 2010) with default options. Additionally, we used sequence information from $72 \mathrm{~V}$. dahliae strains which were deposited at the NCBI database under project number PRJNA171348. The presence/absence analysis was performed using BEDtool bedtools software (Quinlan and Hall, 2010) and R software as follows: the CQ2 genome was sliced in bins of $100 \mathrm{bp}$ and a sliding window of $50 \mathrm{bp}$ was checked for presence of reads derived from other $\mathrm{D}$ pathotype strains and for the absence of coverage of ND pathotype strains. The coverage was normalized using \# reads in a bin x 10,000,000/total amount of mapped reads. The coverage distribution for each sample was evaluated and the cut off set to 5 . Lineage specific (LS) regions, here defined as genomic regions that are only present in $\mathrm{D}$ pathotype strains, were determined and genes localized within these regions were extracted using BEDtools intersect (v2.25) (Quinlan and Hall 2010). To validate the bioinformatic gene prediction in these LS regions, RNA reads that obtained from transcriptome sequencing of cotton plants infected by D pathotype strain V991 were mapped to LS regions using software Tophat v1.4.0 (Trapnell et al., 2010). 


\section{Ceneration of $D$ gene deletion strains}

To generate a $D$ single gene deletion construct, sequence stretches of approximately $1.2 \mathrm{~kb}$ upstream and $1.3 \mathrm{~kb}$ downstream of the $D$ coding sequence were amplified from genomic DNA of $\mathrm{D}$ pathotype strain $\mathrm{CQ} 2$, using primer pairs SKO-D-LBF/LBR and SKO-D-RBF/RBR (Table S3). The amplicons were cloned into vector pRF-HU2 as described previously (Frandsen et al, 2008), and the resulting deletion construct was transformed into CQ2 via Agrobacterium tumefaciensmediated transformation (Santhanam, 2012). Putative deletion transformants were selected on PDA containing $200 \mu \mathrm{g} / \mathrm{mL}$ cefotaxime and $50 \mu \mathrm{g} / \mathrm{mL}$ hygromycin B (Duchefa, Haarlem, The Netherlands) and homologous gene replacement was verified with PCR analysis using outside primer-F and outside primer- $\mathrm{R}$ (Table $\mathrm{S}_{3}$ ). To generate $\mathrm{D}$ double gene deletion mutants, sequence stretches of approximately $1.1 \mathrm{~kb}$ upstream and $1.2 \mathrm{~kb}$ downstream of the $D$ coding sequence were amplified using primer pairs DKO-D-LBF/LBR and DKO-D-RBF/RBR (Table S3). The amplified products were cloned into vector PRF-NU2. Next, the gene replacement construct was transformed into a $D$ gene single deletion mutant. Putative double deletion transformants were selected on PDA containing $50 \mu \mathrm{g} / \mathrm{mL}$ hygromycin B and $15 \mu \mathrm{g} / \mathrm{mL}$ nourseothricin (Sigma-Aldrich Chemie $\mathrm{GmbH}$, Buchs, Switzerland), and were subjected to PCR to confirm genuine double $D$ gene deletions using outside primer-F and outside primer-R (Table S3). Reverse transcription-PCR (RT-PCR) was used to confirm no $D$ gene transcripts in $D$ double deletion mutants using primers D-RT-F) and D-RT-R), and V. dahliae GAPDH (glyceraldehyde-3-phosphate dehydrogenase) gene as an endogenous control (Table $\mathrm{S} 3$ ). Meanwhile, the same $D$ single deletion construct and double deletion construct were used to generate $D$ single and $D$ double deletion mutants in $V$. dahliae strain V150I, which causes defoliation on olive (Collado-Romero et al., 2006).

$D$ gene complementation was performed by using a genomic construct consisting of the $D$ gene coding sequence with $1.1 \mathrm{~kb}$ upstream and $1.2 \mathrm{~kb}$ downstream sequences $(p D:: D)$ using primer pairs D-com-F and D-com-R (Table S3). The amplified products were cloned into GatewayTM compatible vector PCG using a standard BP reaction (Zhou et al., 2013). The gene complementation construct was further transformed into a $D$ single deletion mutant, a $D$ double deletion mutant, a ND pathotype strain JR2, respectively. Putative $D$ gene complementation transformants were selected on PDA supplemented with $200 \mu \mathrm{g} / \mathrm{mL}$ of cefotaxime and $25 \mu \mathrm{g} / \mathrm{mL}$ geneticin (SigmaAldrich Chemie BV, Zwijndrecht, The Netherlands). Reverse transcription-PCR (RT-PCR) was used to examine $D$ gene transcription in these transformants.

\section{Gene expression analysis}

To assess $D$ gene expression in $D$ deletion strains and complementation strains, various $V$. dahliae strains were grown at $22^{\circ} \mathrm{C}$ in liquid Czapek-Dox medium for one week while shaking at $150 \mathrm{rpm}$ and the resulting mycelium and conidia were harvested for RNA extraction. Firststrand cDNA synthesis was performed by using MMLV reverse transcriptase system (Promega, Wisconsin, USA). Reverse transcription-PCR (RT-PCR) was conducted with primers CQ2D-F and CQ2D-R (Table S3) in a total volume of $25 \mu \mathrm{l}$ with $17.9 \mu \mathrm{l}$ sterilized water, $5 \mu \mathrm{l} 5 \mathrm{x}$ PCR buffer, $0.5 \mu \mathrm{l}$ dNTPs, $0.5 \mu$ l of each primer, $0.1 \mu \mathrm{l}$ GoTag DNA polymerase (Promega, Wisconsin, USA) and 1.0 $\mu \mathrm{l}$ of first-strand cDNA (100 ng/ $\mu \mathrm{l})$. The V. dahliae GAPDH gene was used as endogenous loading control. The resulting PCR products were subjected to agarose gel electrophoresis. 


\section{Heterologous production of D effector protein in Pichia pastoris and bioassays on cotton seedlings}

D effector protein was produced in P. pastoris following previously described procedures (Sánchez-Vallet et al., 2013; Kombrink et al., 2017). Briefly, the $D$ gene was cloned into P. pastoris expression vector pPIC9 (Invitrogen) after performing PCR using primers to add the N-terminal His- and FLAG-tag (Table S3) (Kombrink et al., 2017). A pPIC9 vector containing the His-FLAG tagged $D$ gene was transformed into P. pastoris strain GS115. Putative P. pastoris transformants were cultured in a small volume of BMM medium to check D effector protein expression and one clone was selected for culturing in a BioFlo 120 fermenter (Eppendorf AG, Hamburg, Germany) (Kombrink et al., 2017). The His-tagged $\mathrm{D}$ effector protein was purified using a $\mathrm{Ni}^{\mathrm{i}^{+}-}$ NTA Superflow column (Qiagen). After elution from the column, the protein was dialysed against $100 \mathrm{mM} \mathrm{NaCl}$ and the concentration was determined using absorbance at $280 \mathrm{~nm}$. The purified protein was analysed by SDS-PAGE and Western blotting using primary Mouse-anti-His mAb antibody (Sánchez-Vallet et al., 2013; Kombrink et al., 2017).

To assess the effect of treatment with the $\mathrm{D}$ effector protein, three-week-old cotton seedlings were uprooted from soil and carefully rinsed with tap water. Next, the roots were placed into $10 \mathrm{~mL} D$ protein solution $(8.96 \mu \mathrm{M})$. Treatments with water and V. dahliae chitin binding Vd2LysM effector protein $(8.96 \mu \mathrm{M})$ (Kombrink et al., 2017) were used as negative controls. The cotton seedlings were incubated in a growth chamber at $21^{\circ} \mathrm{C} / 19^{\circ} \mathrm{C}$ during $16 / 8$ hours day/night periods, respectively, with $70 \%$ relative humidity for 16 days and regularly inspected for the occurrence of symptoms.

\section{Results}

\section{V. dahliae inoculation on cotton}

Various strains of $V$. dahliae have been sequenced during the last years, including several previously characterized D pathotype strains (V991, T9, V117 and TM6), as well as ND pathotype strains (BP2, V4, cd3 and HN) (Schnathorst and Mathre 1966; López-Escudero et al., 2010; Zhang et al., 2012; Xu et al., 2012; Liu et al., 2014). In order to select additional D and ND strains to increase the robustness of the comparative genome analysis, we generated a phylogenetic tree of all in house-sequenced V. dahliae strains (Table S1) (Figure S1). This phylogenetic analysis revealed that six additional strains clustered with previously characterized D pathotype strains, while other strains were more related to previously characterized ND strains (Figure S1). Interestingly, four strains (V574, V700, v679, and Vd39) are relatively closely related to the D pathotype strains, yet phylogenetically distinct. In order to assign these four strains to the correct pathotype and use them in our comparative genomics study, we performed disease assays to evaluate their ability to cause defoliation on cotton. Additionally, we included the presumed D strains V76, V117, CQ2 and ST100 and the presumed ND strains JR2 and VdLs17. The disease assay confirmed that V76, V117, CQ2 and ST100 belong to the D pathotype (Figure 1), while all other strains (JR2, VdLs17, V574, V700 and Vd39) classified as ND pathotype strains (Figure 1). 


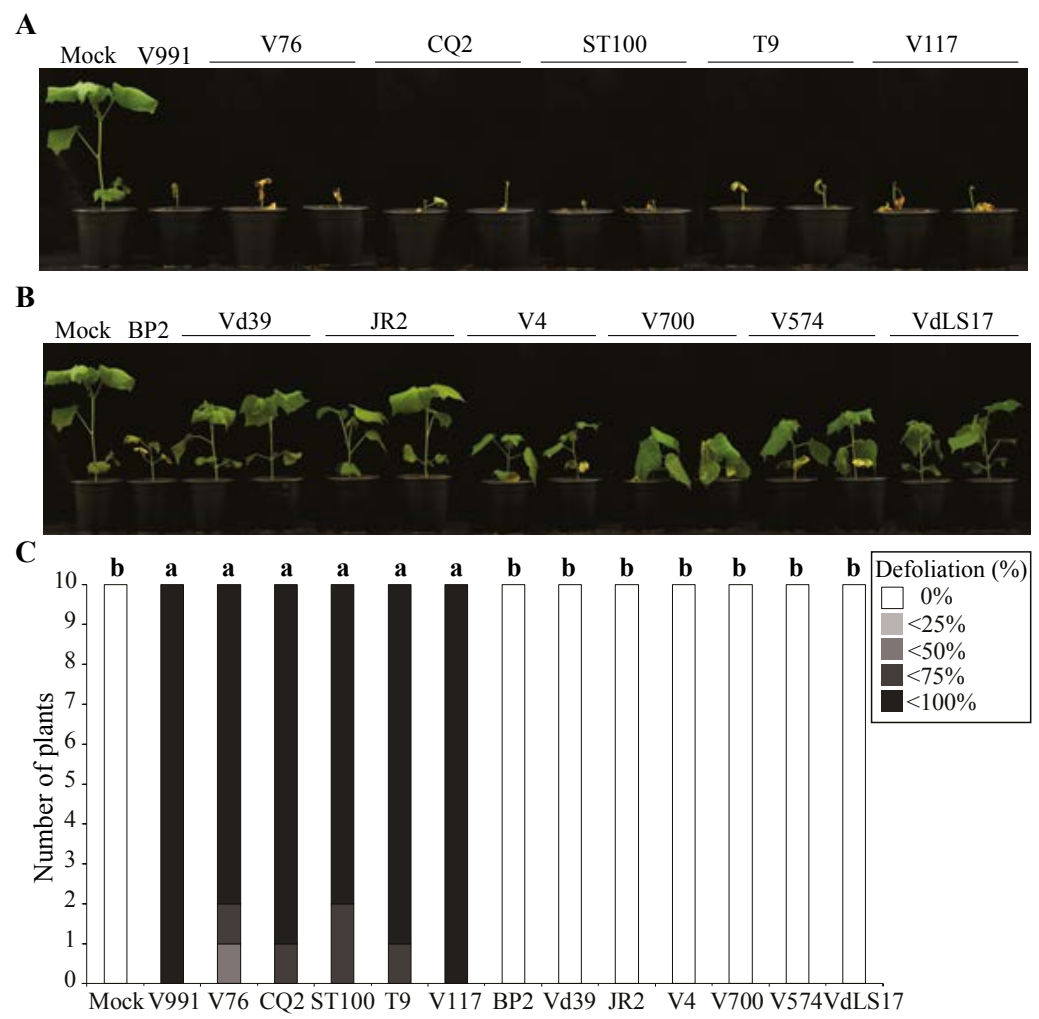

Figure 1. Phenotype of cotton plants inoculated with various sequenced Verticillium dahliae strains. (A) Typical phenotype of cotton plants (cv. Xinluzao63) upon mock-inoculation or inoculation with V. dahliae strains V991, V76, CQ2, ST100, T9 and V117 at 28 days post inoculation (dpi). Previously characterized D pathotype strain V991 used as inoculation control. (B) Typical phenotype of cotton plants upon mock-inoculation or inoculation with V. dahliae strains BP2, Vd39, JR2, V4, V574, V700, VdLS17 at 28 (dpi). Previously characterized ND pathotype strain BP2 used as inoculation control. (C) Defoliation were classified as o ( $0 \%$ leaf drop off), 1 (<25\% leaf drop off), 2 ( $<50 \%$ leaf drop off), 3 ( $<75 \%$ leaf drop off) and 4 ( $<100 \%$ leaf drop off) at 28 dpi. Significance levels were calculated based on 5,000 bootstrap replicates of the median difference between random scores of two treatments and different letter labels indicate statistically significant differences $(P<0.05)$. Inoculation experiments were performed with ten plants for each fungal strain and repeated twice independently with similar results.

\section{Comparative genomics identifies $D$ pathotype-specific effector genes}

The genome of the D pathotype strain CQ2 was sequenced with PacBio technology and used as a reference in a comparative genomics approach that used eight D pathotype strains (V991, T9, V117, TM6, V76, 463, CQ2 and ST100) and nine ND pathotype strains (BP2, V4, HN, cd3, JR2, VdLs17, $\mathrm{V} 574, \mathrm{V700}$ and $\mathrm{Vd} 39$ ) to identify $\sim 200 \mathrm{~kb}$ of D pathotype-specific sequence, encoding $\sim 30$ genes. In order to reduce the interval of interest, and thus the number of candidate genes, sequences of seventy-two additional $V$. dahliae strains were mined. Strain BGI_32 caught our special attention as it clustered neither with the D pathotype strains nor with the ND pathotype strains (Figure S2). As subsequent disease assays assigned this isolate to the ND pathotype (Figure $\mathrm{S} 3$ ), we were able to limit the $\mathrm{D}$-specific region to $\sim 24 \mathrm{~kb}$ with only seven predicted genes (Table $\mathrm{S} 2$ ). 
A

Unitig_28

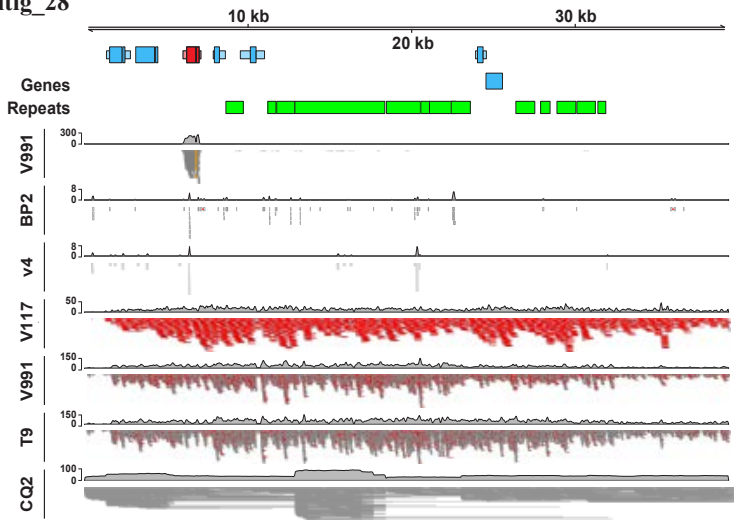

B

Unitig_8

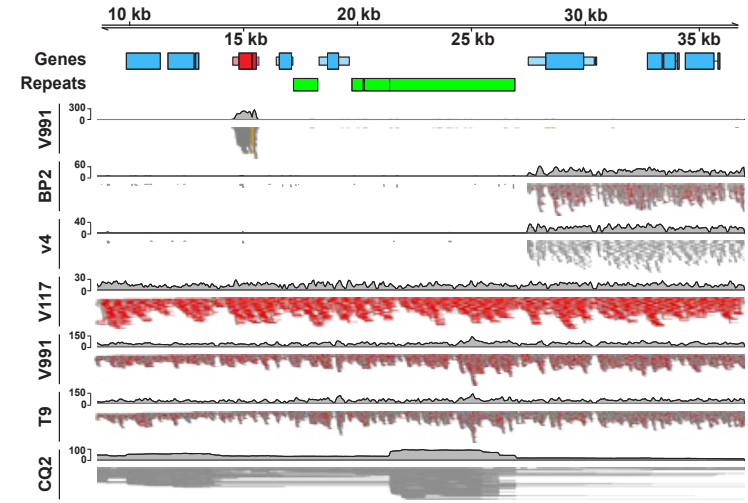

C

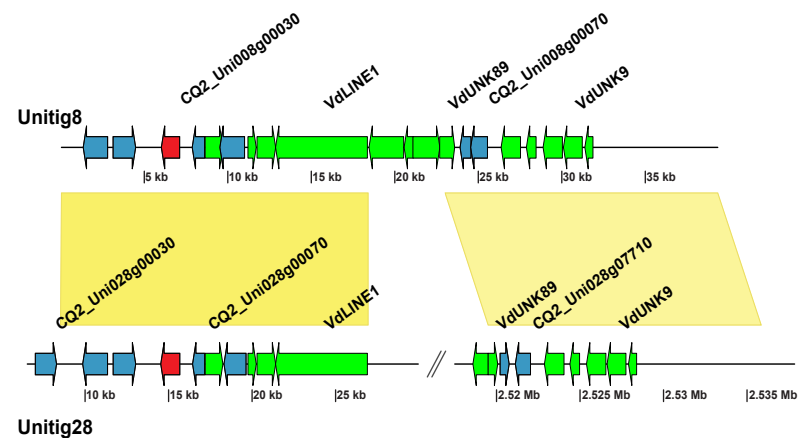

Figure 2. Two identical copies of effector gene generated by segmental duplication. (A-B) Schematic representation of genomic region (Unitig_28 and Unitig_8) where two candidate effector genes located. Gene models shown in blue, the candidate effector genes displayed in red, while repetitive elements displayed in green. RNA reads from cotton plants infected by a D pathotype strain (V991) that only mapped to candidate gene are showed in dark grey. Reads from DNA-seq of ND pathotype strains (V4 and BP2) and D pathotype strains (V117, V991 and T9) mapped onto $\mathrm{CQ}_{2}$ genome. The reads are showed as coverage plot and the depth of DNA reads coverage indicated in red. (C) Syntenic assignment of Unitig_28 and Unitig_8, the extensive synteny (yellow blocks indicate $100 \%$ sequence identity) points towards a segmental duplication. Gene models shown in blue, the candidate effector gene displayed in red, while repetitive elements displayed in green. 
In order to characterize the seven D-specific genes, interproscan analysis (Finn et al., 2017) was conducted, showing that two genes (CQ2_Unio28g00060 and CQ2_Unio08g00030) are predicted to be secreted. Expression analysis using deep transcriptome sequencing of a time course of cotton plants inoculated with D pathotype strain V991 showed that these two genes are highly expressed (Figure S4). Surprisingly, the two genes share $100 \%$ sequence identity, despite being located on separate contigs, namely Unitig_28 and Unitig_8 (Figure 2A-B). Moreover, alignment of contigs Unitig_28 and Unitig_8 revealed that genomic regions surrounding the two genes are completely identical as well (Figure $2 \mathrm{C}$ ), suggesting that these arose by a segmental duplication. We tentatively named these two candidates $D$ gene, for potentially mediating defoliation (D) on cotton.

\section{The $\mathrm{D}$ effector is responsible for cotton defoliation.}

To further examine the role of the $\mathrm{D}$ effector in pathogenicity on cotton plants, targeted gene deletions of the two gene copies were performed in D pathotype strain CQ2 by homologous recombination (Figure S5A). To this end, we first generated single gene copy deletion mutants followed by another round of transformation to remove the second gene copy. Single $(\Delta \mathrm{D})$ and double $(\Delta \Delta \mathrm{D}) \mathrm{D}$ gene deletions were confirmed by PCR (Figure $\mathrm{S} 5 \mathrm{~B}$ ).

We inoculated cotton seedlings with wild type strain CQ2, single $D$ gene deletion mutants $(\triangle D \# 1$ and $\Delta D \# 2)$, double $D$ gene deletion mutants $(\Delta \Delta D \# 1$ and $\Delta \Delta D \# 2)$ and monitored disease progression. While the wild type strain $\mathrm{CQ} 2$ caused severe defoliation symptoms on cotton plants at 28 days post inoculation (dpi) (Figure $3 \mathrm{~A}-\mathrm{B}$ ), $\Delta \mathrm{D}$ mutants displayed significantly compromised aggressiveness with clearly less defoliation symptoms (Figure 3A-B). Importantly, $\Delta \Delta \mathrm{D}$ mutants appeared to be unable to cause disease on cotton, as plants inoculated with $\Delta \Delta \mathrm{D}$ mutants showed no defoliation (Figure $3 \mathrm{~A}-\mathrm{B}$ ). Moreover, no fungal biomass could be recorded in $\Delta \Delta \mathrm{D}$ mutantsinoculated plants with real-time PCR, confirming that the D effector acts as pathogenicity factor (Figure $3 \mathrm{C}$ ). Complementation of single and double deletion mutants with a genomic fragment comprising the $D$ gene coding sequence $(p D:: D$ ) restored the aggressiveness, leading to defoliation symptoms on cotton (Figure 3). Interestingly, introduction of the genomic fragment comprising the $D$ gene coding sequence $(p D:: D)$ into the ND pathotype strain JR2 enhanced aggressiveness on cotton plants, resulting in severe stunting and the induction of defoliation (Figure 4). These results demonstrate that the $\mathrm{D}$ effector is a pathogenicity factor of $V$. dahliae $\mathrm{D}$ pathotype strain and responsible for defoliation symptoms on cotton. 
A

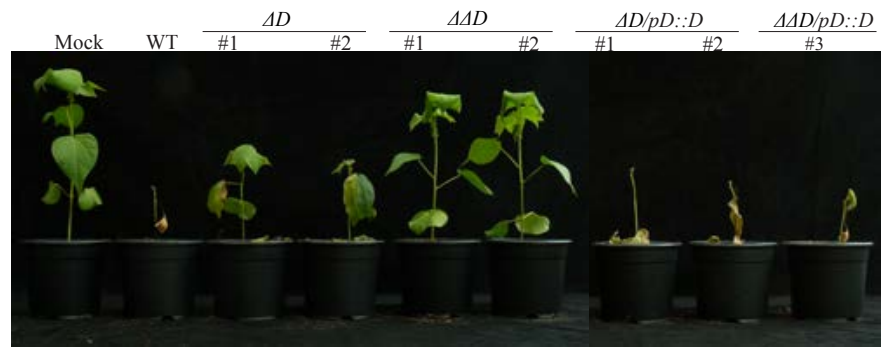

B

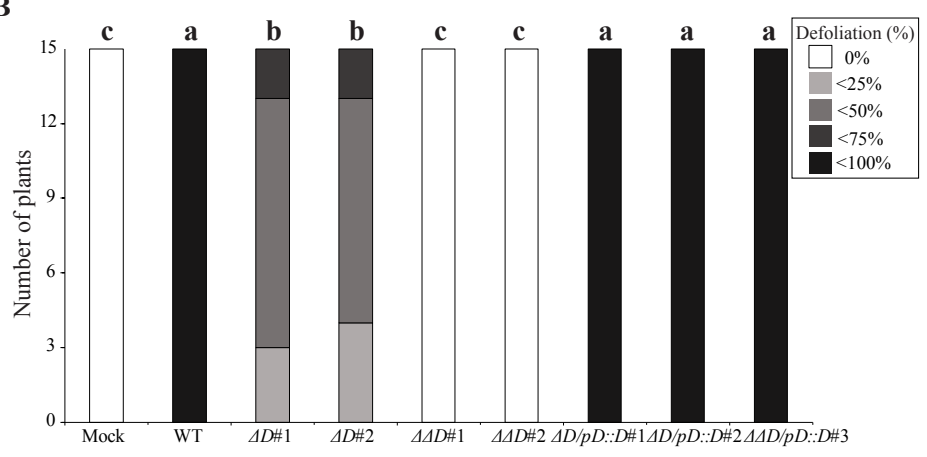

C

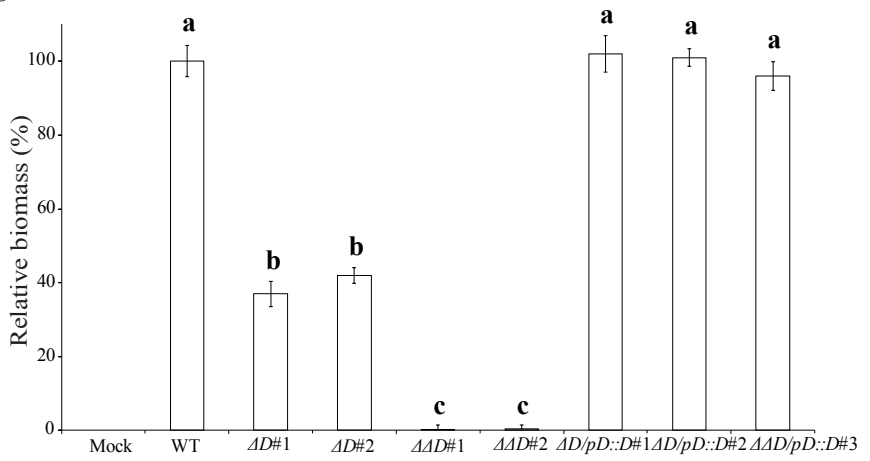

Figure 3. D effector is responsible for cotton defoliation. (A) Typical phenotype of cotton (cv. Xinluzao63) upon mock-inoculation or inoculation with wild type strain CQ2 (WT), two $\Delta \mathrm{D}$ mutants $(\Delta \mathrm{D} \# 1$ and $\Delta \mathrm{D} \# 2)$, two $\Delta \Delta \mathrm{D}$ mutants $(\Delta \Delta \mathrm{D} \# 1$ and $\Delta \Delta \mathrm{D} \# 2)$, two $\Delta D$ complementary strains $\left(\Delta \mathrm{D} / p D:: D \#_{1}\right.$ and $\left.\Delta \mathrm{D} / p D:: D \# 2\right)$ and one $\Delta \Delta \mathrm{D}$ complementary strain $(\Delta \Delta \mathrm{D} / p D:: D \# 3)$ at 28 days post inoculation (dpi). (B) Defoliation were classified as 0 (०\% leaves drop off), 1 ( $<25 \%$ leaves drop off), 2 ( $<50 \%$ leaves drop off), 3 ( $<75 \%$ leaves drop off) and 4 ( $<100 \%$ leaves drop off) at $28 \mathrm{dpi}$. In total, 15 plants were assessed for every treatment and the data represent one of two experiments. Significance levels were calculated based on 5,000 bootstrap replicates of the median difference between random scores of two treatments and different letter labels indicate statistically significant differences $(P<0.05)$. (C) Fungal biomass as determined with real-time PCR at 28 dpi. Bars represent $V$. dahliae ITS levels relative to cotton ubiquitin (GhUB) levels (for equilibration) with standard deviation in a sample of five pooled plants. The fungal biomass in cotton plants upon inoculation with the wild type CQ2 is set to 100\%. Different letter labels indicate statistically significant differences (Student's $t$-test; $P<0.05$ ). Experiments were repeated twice independently with similar results. 

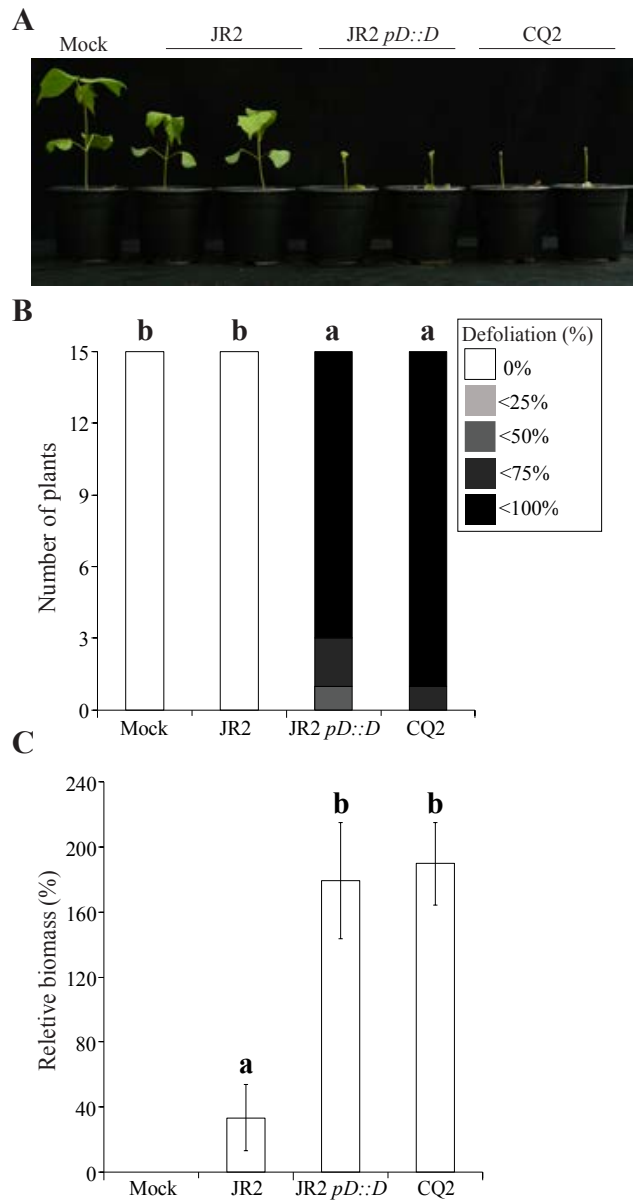

Figure 4. Introduction of $D$ gene in ND pathotype strain resulted in defoliation symptoms. (A) Typical phenotype of cotton (cv. Xinluzao63) plants that were mock-inoculated or inoculated with ND pathotype strain JR2, one $D$ expression transformant of JR2 (JR2 $p D:: D$ ) and D pathotype strain $\mathrm{CQ}_{2}$ at 28 days post inoculation (dpi). (B) Defoliation were classified as o ( $0 \%$ leaves drop off), 1 ( $<25 \%$ leaves drop off), 2 ( $<50 \%$ leaves drop off), 3 ( $<75 \%$ leaves drop off) and 4 (<100\% leaves drop off) at 28 dpi. In total, 15 plants were assessed for every treatment and the data represent one of two experiments. Significance levels were calculated based on 5,000 bootstrap replicates of the median difference between random scores of two treatments and different letter labels indicate statistically significant differences $(P<0.05)$. (C) Fungal biomass as determined with real-time PCR at $28 \mathrm{dpi}$. Bars indicate the $V$. dahliae biomass relatively to the cotton biomass. Significant differences were calculated with the Mann-Whitney $\mathrm{U}$ test $(P<0.05)$ and depicted by different letter labels. Error flags represent the standard error.

\section{The $D$ effector is responsible for olive defoliation}

Since we observed that the $\mathrm{D}$ effector is responsible for defoliation symptoms on cotton, we further examined whether $V$. dahliae strains that cause olive defoliation carry the $D$ gene. We confirmed the presence of the $D$ gene in the previously characterized D pathotype strains V150I, V641I, V356I and V403II (Collado-Romero et al., 2006; Maldonado-González et al., 2015), while olive-pathogenic strain 812 I that belongs to ND pathotype (Maldonado-González et al., 2015) does not carry the $D$ gene (Figure S8). 
Table 1. Infection assay of $D$ gene deletion strains on olive.

\begin{tabular}{llllll}
\hline \multirow{2}{*}{ Treatments } & \multicolumn{5}{c}{ Disease parameters } \\
\cline { 2 - 6 } & AUDPC $^{\mathrm{a}}$ & Final DI (\%) $^{\mathbf{b}}$ & Final DII $^{\mathbf{c}}$ & $\mathbf{M ~ ( \% ) ~}^{\mathbf{d}}$ & $\mathbf{S}^{\mathbf{e}}$ \\
\hline $\mathrm{V}-150 \mathrm{I}(\mathrm{WT})$ & $70.5 \mathrm{a}$ & 44.4 & 0.33 & 11.1 & 1.31 \\
$\Delta \Delta \mathrm{D} \# 5$ & $1.6 \mathrm{~b}$ & 22.2 & 0.02 & 0 & 0.08 \\
$\Delta \Delta \mathrm{D} \# 7$ & $\mathrm{ob}$ & 0 & 0 & 0 & 0 \\
$\Delta \Delta \mathrm{D} \# 8$ & $\mathrm{ob}$ & 0 & 0 & 0 & 0 \\
Control & $\mathrm{ob}$ & 0 & 0 & 0 & 0 \\
\hline
\end{tabular}

${ }^{a}$ AUDPC, area under the disease progress curve over time up to 132 days post inoculation (dpi). ${ }^{\text {bFinal DI, final }}$ disease incidence (\%). 'Final DII, disease intensity index was calculated from data on incidence and severity of symptoms recorded at 132 (dpi). ${ }^{\mathrm{d}} \mathrm{M}$, dead plants (\%) at 132 (dpi). ${ }^{e}$, mean of disease severity symptoms at 132 (dpi). Different letter labels indicate statistically significant differences $(P<0.05)$. Inoculation experiments were repeated twice independently with similar results.

To further investigate whether the $\mathrm{D}$ effector is also responsible for olive defoliation, targeted gene deletions were generated by deletion of the two $D$ gene copies in strainV150I (Figure S5A, C). Subsequently, we inoculated olive plants with three double $D$ gene deletion mutants $(\triangle \Delta D \# 5$, $\Delta \Delta \mathrm{D} \# 7$ and $\Delta \Delta \mathrm{D} \# 8$ ) along with the corresponding wild type strain V150I and evaluated disease symptom development. While wild type strain V150I caused severe disease symptoms, including severe defoliation and eventually plant death, $\Delta \Delta \mathrm{D}$ mutants displayed severely compromised pathogenicity (Table 1). Thus, our results demonstrate that the $\mathrm{D}$ effector, besides cotton defoliation, is also responsible for olive defoliation.

\section{The $\mathrm{D}$ effector is a pathogenicity factor on Nicotiana benthamiana and Arabidopsis thaliana}

To investigate whether the observed role of $\mathrm{D}$ effector in pathogenicity is confined to cotton and olive, or also extends to other host species that do not normally respond to V. dahliae infection with defoliation, we inoculated the $D$ deletion mutants $(\Delta \mathrm{D}$ and $\Delta \Delta \mathrm{D})$ on the model plants $N$. benthamiana and $A$. thaliana. Compared with the wild-type strain, $\Delta \mathrm{D}$ mutants showed markedly reduced aggressiveness on $N$. benthamiana, demonstrated by increased canopy (foliage) area and a significant reduction of fungal biomass in planta (Figure 5A, C, D).

Furthermore, $\Delta \Delta \mathrm{D}$ mutants failed to cause disease on $N$. benthamiana, as the inoculated plants did not show any disease symptoms throughout the assay (Figure $5 \mathrm{~A}, \mathrm{C}$ ). As no fungal biomass could be detected in $\Delta \Delta \mathrm{D}$ mutants-inoculated plants (Figure $5 \mathrm{D}$ ), we conclude that the $\mathrm{D}$ effector acts as a pathogenicity factor on $N$. benthamiana. Similarly, $\Delta \mathrm{D}$ mutants exhibited clearly compromised aggressiveness on $A$. thaliana plants when compared with wild type strain, evidenced by increased A. thaliana rosette leaves area and the reduction in fungal biomass (Figure 5B, E, F). Moreover, $\Delta \Delta \mathrm{D}$ mutants appeared to be non-pathogenic on A. thaliana plants as well, as plants inoculated with $\Delta \Delta \mathrm{D}$ mutants did not show disease symptoms (Figure $5 \mathrm{~B}, \mathrm{E}$ ) or accumulation of fungal biomass (Figure 5F). Collectively, it can be concluded that, besides for pathogenicity on cotton and olive, the $\mathrm{D}$ effector is required for pathogenicity on $N$. benthamiana and A. thaliana. 
A

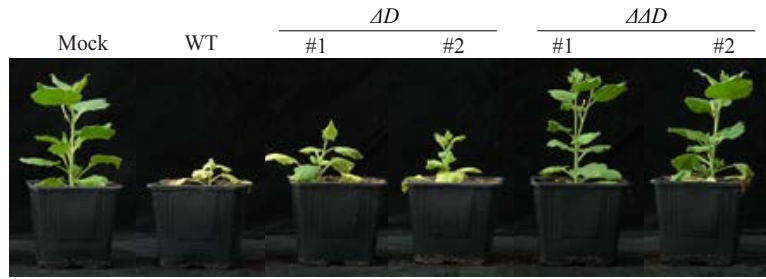

B

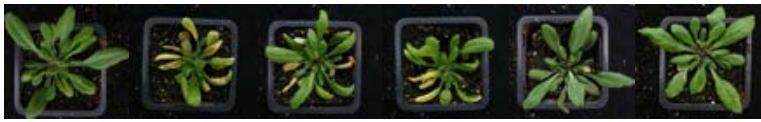

C

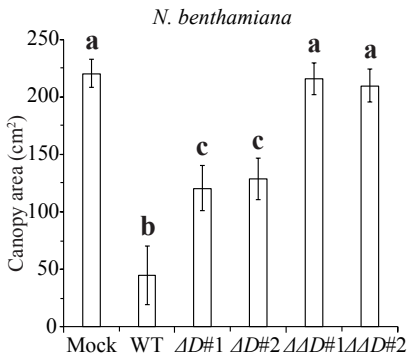

$\mathbf{E}$

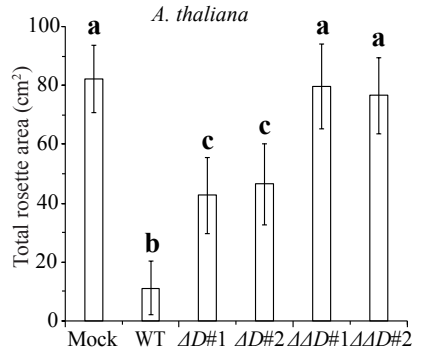

D

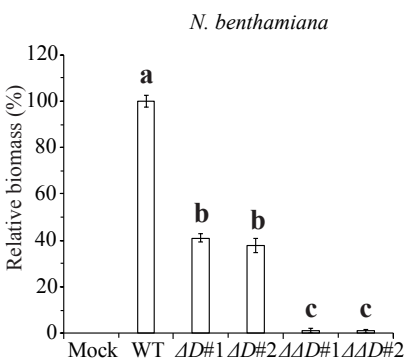

F

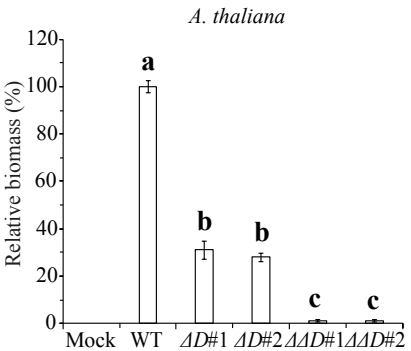

Figure 5. D effector is a pathogenicity factor on Nicotiana benthamiana and Arabidopsis thaliana. (A) Typical phenotype of $N$. benthamiana plants that were mock-inoculated or inoculated with wild type strain CQ2 (WT), two $\Delta \mathrm{D}$ mutants (\#1 and \#2), two $\Delta \Delta \mathrm{D}$ mutants (\#1 and \#2) at 21 days post inoculation (dpi). (B) Typical phenotype of $A$. thaliana (Col-o) plants that were mock-inoculated or inoculated with indicated fungal strains in panel A at 21 (dpi). (C) Quantification of the canopy area of N. benthamiana at 21 dpi. Bars represent the average canopy area of five plants with standard deviation. (D) Fungal biomass as determined with real-time PCR at 21 dpi. Bars represent $V$. dahliae ITS levels relative to $\mathrm{NbRuBisCo}$ (for equilibration) with standard deviation in a sample of five pooled plants. The fungal biomass in N. benthamiana plants upon inoculation with the wild type CQ2 is set to $100 \%$. Different letter labels indicate statistically significant differences (Student's $t$-test; $P<0.05$ ). (E) Quantification of the rosette area of five A. thaliana plants at 21 dpi. Bars represent the average rosette area of five plants with standard deviation. (F) Fungal biomass as determined with real-time PCR at 21 dpi. Bars represent $V$. dahliae ITS levels relative to AtRuBisCo (for equilibration) with standard deviation in a sample of five pooled plants. The fungal biomass in $A$. thaliana plants upon inoculation with the wild type CQ2 is set to $100 \%$. Different letter labels indicate statistically significant differences (Student's $t$-test; $P<0.05$ ). $N$. benthamiana and $A$. thaliana inoculation experiments were performed with five plants for each fungal strain and repeated twice independently with similar results. 


\section{The $D$ effector protein induces defoliation}

To test whether the D effector protein is able to induce symptoms of Verticillium wilt disease, cotton seedlings were treated with the D effector protein $(8.96 \mu \mathrm{M})$ and monitored for symptom development, while treatments with water and the $V$. dahliae chitin-binding effector protein Vd2LysM $(8.96 \mu \mathrm{M})$ were used as negative controls (Kombrink et al., 2017). Intriguingly, application of the $\mathrm{D}$ effector protein induced wilting, slight chlorosis and the first detachment of cotton cotyledons after 10 days (Figure 6A-B), while severe chlorosis and detachment of more than half of the leaves $(55 \pm 6.45 \%$ ) were observed after 16 days (Figure $6 \mathrm{C}$-E). In contrast, treatment with water or Vd2LysM effector protein induced no visible effect on cotton plants throughout the assay. These results suggest that the effector protein itself, rather than extensive fungal proliferation in the xylem vessels, is responsible for the defoliation symptoms.

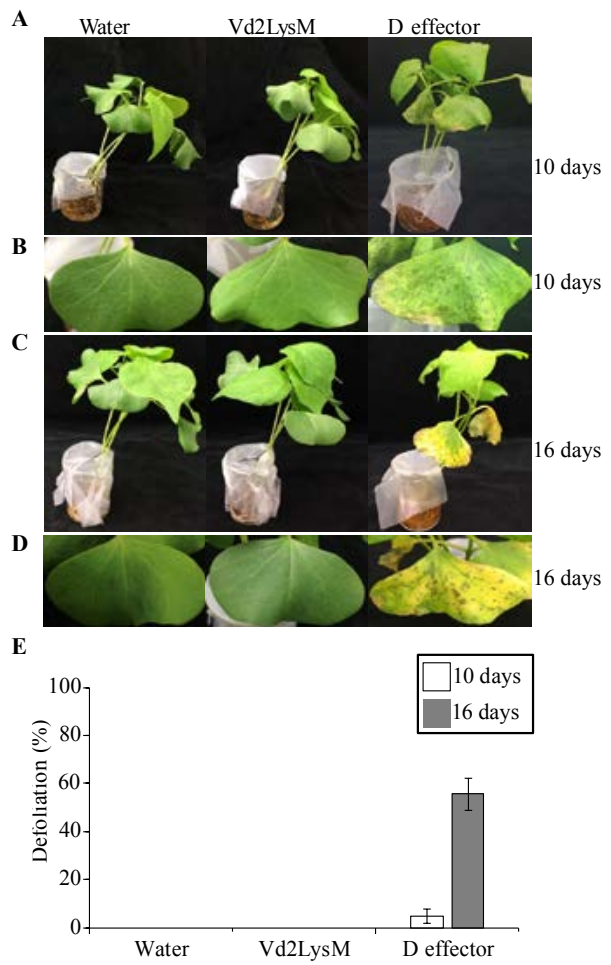

Figure 6. D effector protein induces cotton defoliation in vitro. (A-B) Typical appearance of cotton seedlings (cv. Xinluzao63) applied with D effector protein at 10 days. Note, marginal chlorosis and wilting symptoms occurred on cotyledons. (C-D) Typical appearance of cotton seedlings applied with D effector protein at 16 days. Cotyledons became severe chlorosis, meanwhile more cotyledons and true leaves dropped off. (E) The bar graph showed the defoliation (\%) at 10 and 16 days. Bars represent the average defoliation of two biological replicates with standard deviation. Experiments were repeated twice independently with similar results. 


\section{Discussion}

The ability of a plant pathogen to cause disease on plants is often linked to the presence of specific pathogenicity genes within its genome (van der Does and Rep, 2007). There is mounting evidence that pathogenicity of a plant pathogens is mediated by so-called effector molecules that are secreted by the pathogen during host infection (Jones and Dangl, 2006; de Jonge et al., 2011; Rovenich et al., 2014; Rodriguez-Moreno et al., 2018). It is generally observed that effector activities are redundant and that the contribution of a single effector to disease establishment is dispensable. However, a number of studies have shown that a single effector is able to govern pathogenicity and therefore enable to cause disease on particular host plants. For example, the transcriptional activator-like effector protein PthA has been shown to be essential for pathogenicity of the bacterial citrus pathogen Xanthomonas citri, as transfer of the pthA gene into non-pathogenic strains confers the ability to cause citrus disease (Swarup et al., 1991, 1992; Duan et al., 1999). Similarly, the necrotrophic effector SnTox1 is sufficient to enable the wheat pathogen Parastagonospora nodorum to establish disease on wheat lines that carry the corresponding susceptibility gene SnnI (Liu et al., 2012, 2016).

Despite the observation that $V$. dahliae strains are collectively characterized by their broad host range, pathogenicity and the severity of symptoms that are induced can vary considerably between individual strains (Bhat and Subbarao, 1999; Fradin and Thomma, 2006). Defoliating (D) and non-defoliating (ND) pathotypes have been described already decades ago for oliveand cotton-infecting V. dahliae strains (Schnathorst and Mathre, 1966; Schnathorst and Sibbett, 1971a), but the genetic factor(s) that are responsible for the ability of D pathotype strains to cause defoliation symptoms remained elusive. In this study, we show that a single effector, named $\mathrm{D}$ effector, governs pathogenicity of $\mathrm{D}$ pathotype strains on cotton and olive, as deletion of both copies of the $D$ effector gene resulted in loss of the ability to cause defoliation symptoms. Moreover, introduction of this effector gene into a ND pathotype isolate was accompanied by an acquisition of the ability to cause defoliation. Furthermore, application of heterologously produced effector protein to cotton seedlings induced defoliation, showing that the effector protein is directly responsible for defoliation symptoms. Thus, we demonstrate that a single effector is sufficient to cause disease establishment.

While mating type-related genes have been found in the $V$. dahliae genome, $V$. dahliae is considered to be a strictly asexual species that propagates clonally since a sexual cycle has never been observed and the mating type distribution is skewed towards one of the two (Usami et al., 2008, 2009; Atallah et al., 2010). Such asexual reproduction results in offspring that is genetically highly identical to each other and to the parent, and thus V. dahliae has a highly clonal population structure (Klosterman et al., 2009; Milgroom et al., 2014, 2016; Rafiei et al., 2017). The clonal population structure in $V$. dahliae was first described as vegetative compatibility groups (VCGs) (Joaquim and Rowe, 1990; Strausbaugh, 1993), as vegetatively compatible V. dahliae isolates that form stable heterokaryons are assigned to the same VCG (Rowe, 1995; Katan, 2000). Consequently, isolates within the same VCG are genetically similar to each other, while isolates between different VCGs were thought to be genetically different populations that may vary in 
many traits, including those related to pathogenicity (Katan, 2000). Clonal lineages defined by VCGs were later well supported by molecular genetic markers (Collado-Romero et al., 2006; Milgroom et al., 2014). Interestingly, clonal lineages that are characterized by VCGs and molecular markers are also well associated with particular V. dahliae pathotypes (Collado-Romero et al., 2006; Collins et al., 2005 Jiménez et al., 2011). For instance, isolates in clonal lineage VCG1A have been shown to belong to the highly virulent $\mathrm{D}$ pathotype, whereas the ND pathotype strains were found in all other lineages (Daayf et al., 1995; Hiemstra and Rataj-Guranowska, 2003; ColladoRomero et al., 2006; Dervis et al., 2007; Korolev et al., 2008). It has been proposed that D pathotype strains arose from North America and subsequently dispersed clonally to widespread geographic locations (Bell, 1992). A single nucleotide polymorphism (SNP) genotyping study of a worldwide collection of $V$. dahliae from diverse hosts revealed that $\mathrm{D}$ pathotype strains from Europe, North America and China all belong to VCG1A group and have nearly identical SNP haplotypes, which further supports the hypothesis that $V$. dahliae $\mathrm{D}$ pathotype strains arose from a single origin and subsequently dispersed to other continents (Milgroom et al., 2014, 2016). Since our study showed that the $\mathrm{D}$ effector is responsible for defoliation symptoms, the $\mathrm{D}$ effector gene does not only serve as an ideal molecular marker to accurately differentiate $\mathrm{D}$ and ND pathotype strains, but can also be used as a probe to monitor the spread of highly virulent $\mathrm{D}$ pathotype strains worldwide.

Plant pathogens have to continuously adapt their effector repertoire to escape host immunity and maintain aggressiveness (Rovenich et al., 2014; Rodriguez-Moreno et al., 2018). The emergence of novel effector genes can increase virulence or lead to host range expansion (Friesen et al., 2006; Raffaele et al., 2010). Various mechanisms, such as genome hybridization (Stukenbrock et al., 2012), gene duplication (Dutheil et al., 2016), and horizontal gene transfer (HGT) (Friesen et al., 2006; de Jonge et al., 2012) have been described that can facilitate the development of effector gene repertoires in pathogenic microbes. It has been suggested that the well-characterized V. dahliae LS effector Ave1 has been acquired from plants via HGT (de Jonge et al., 2012). Comparisons of gapless genome assemblies of two V. dahliae strains have revealed that segmental genomic duplications are enhanced in highly variable lineage-specific (LS) genomic regions (Faino et al., 2016). Interestingly, these regions are enriched for in planta-expressed effector genes that contribute to fungal virulence, suggesting that gene duplications contribute to evolution of pathogen virulence (de Jonge et al., 2013; Faino et al., 2016). In the present study, we found that two identical copies of the $D$ effector gene arose by a segmental duplication, and the high level of similarity between flanking sequences of the $D$ effector gene suggests that this duplication occurred rather recently (Figure $2 \mathrm{C}$ ). The relevance of the occurrence of two copies of the $D$ effector gene and their impact on fungal adaption remains unknown at this point. Possibly, the emergence of two copies of the $D$ effector gene is relevant to maintain highly aggressiveness of $\mathrm{D}$ pathotype strains on diverse host plants. In filamentous pathogens, effector genes that arose from gene duplication events typically evolve in a so called "duplication-divergence" pattern: following a gene duplication event, one gene copy diverges to some extent due to functional redundancy and evolves a distinct function (Plissonneau et al., 2017). For example, a large number of Crinklers (CRN) effector genes of oomycete pathogen Phytophthora sojae underwent sequence diversification after gene duplication (Shen et al., 2013). Similarly, gene duplications followed by sequence divergence were proposed to be responsible for the generation of novel effector genes 
in the smut fungus Ustilago maydis (Dutheil et al., 2016). In addition to experiencing functional diversification, the recent duplications of effector genes may also be subject to differential loss of the duplicated gene copies (Dong et al., 2015; Pedersen et al., 2012). Frequent effector gene losses after segmental duplications have been proposed to occur in the powdery mildew fungus Blumeria graminis, which contribute to the diversity of the effector repertoires of the pathogen (Wicker et al., 2013; Menardo et al., 2017). Possibly, selective forces from host immune systems contribute to this process. However, it is unclear whether the two copies of the $D$ effector gene will experience sequence divergence or gene loss over time.

To date, a number of $V$. dahliae effectors have been shown to facilitate fungal aggressiveness and promote host colonization. For example, the V. dahliae LysM-containing-effector Vd2LysM is a chitin-binding protein that can suppress chitin-induced immune responses and protects fungal hyphae against hydrolysis by plant hydrolytic enzymes (Kombrink et al., 2017). In addition, $V$. dahliae effector protein VdSCP41 has been shown to interact with Arabidopsis transcription factors CBP6og and SARD1, two master immune regulators, to modulate plant immunity (Qin et al., 2018). Moreover, the race 1 strain-specific effector Ave1 contributes to $V$. dahliae virulence not only on tomato plants that lack resistance gene Ve1, but also on A. thaliana, tobacco as well as on cotton (de Jonge et al., 2012; Song et al., 2018). However, to date the exact function of Ave1 during plant colonization remains unknown. In the present study, we show that the D effector acts as a pathogenicity determinant not only on cotton, olive, but also on $N$. benthamiana and A. thaliana (Figure 3; Table 1; Figure 5). Although the intrinsic function of the D effector remains unknown at this point, the finding that the $\mathrm{D}$ effector mediates pathogenicity on various plant hosts implies that the molecular target(s) of this effector might be broadly conserved in the plant kingdom.

Plant hormones such as salicylic acid (SA), abscisic acid (ABA), and ethylene (ET) are key signalling molecules that regulate multiple aspects of plant growth, development, and defense (Kazan and Lyons, 2014; Pieterse et al., 2012; Fu and Dong, 2013). Various pathogens independently evolved effectors to target the these hormones pathway to promote disease (Kazan and Lyons, 2014; Ma and $\mathrm{Ma}$, 2016). Accumulating evidence has shown that $V$. dahliae can secrete effectors to interfere with plant hormone homeostasis or signalling pathways to modulate plant physiological processes and ultimately facilitate pathogen dissemination (Liu et al., 2014; Tanaka et al., 2015). For instance, the V. dahliae effector VdIsc1 suppresses SA accumulation to facilitate host infection (Liu et al., 2014). Wiese and DeVay (1970) previously reported that the concentration of ABA in cotton plants infected by a $\mathrm{D}$ pathotype strain was twice as high as in healthy plants, whereas the ABA concentration in ND pathotype strain-infected cotton plants was unaffected. While ET production in ND straininfected plants was consistently higher than in healthy plants, ET production in D pathotype strain infected-cotton plants was two times higher than in ND strain-infected plants (Wiese and DeVay, 1970). Therefore, it is tempting to speculate that $\mathrm{D}$ pathotype strains may employ the $\mathrm{D}$ effector to manipulate plant hormone levels (e.g. ABA or ET) and their signalling pathways to enable disease establishment, but this remains to be demonstrated.

Currently, there is no effective fungicide commercially available to control Verticillium wilt once crops have been infected (Fradin and Thomma, 2006). Although biocontrol measures and cultivation practices have been applied to combat Verticillium wilt diseases, the control efficiency 
largely depends on field conditions (Fradin and Thomma, 2006; Inderbitzin and Subbarao, 2014). Thus, development of resistance cultivars has been considered the most desirable strategy for the control of Verticillium wilt in various crops (Fradin and Thomma, 2006; Klosterman et al., 2009). Despite the devastating impact of the highly virulent $D$ pathotype strains on cotton and olive plantations, there is presently no resistance $(R)$ gene against D pathotype strains in either of these plant hosts (López-Escudero and Mercado-Blanco, 2011; Shaban et al., 2018). Since effectors are important virulence molecules of pathogens that can be potentially recognized by host plants, microbial effectors have been exploited as probes to identify $R$ genes in resistance breeding (Laugé et al., 1998; Vleeshouwers and Oliver, 2014). Plant germplasm is screened for $R$ genes that trigger robust responses, including a hypersensitive response, upon transient expression of the effector gene in planta or infiltration of purified effector protein (Takken et al., 1999; Vleeshouwers et al., 2011). After the detection of effector-responding genotypes, the corresponding $R$ genes can be genetically mapped in populations derived from crosses between responding and non-responding genotypes (Laugé et al., 1998; Vleeshouwers et al., 2011). This effector-assisted breeding has been successfully used for identifying a number of $R$ genes in wild tomato species against the leaf mould pathogen Cladosporium fulvum (Laugé et al., 1998; Takken et al., 1999; de Wit, 2016), as well as against the late blight pathogen Phytophthora infestans in potato (Du et al., 2015; Vleeshouwers and Oliver, 2014). Thus, we propose that the D effector can be used as a probe to screen cotton and olive germplasm, but also the germplasm of other plant species, for the occurrence of $R$ gene-mediated recognition.

\section{Acknowledgements}

J.L. acknowledges a PhD fellowship from the China Scholarship Council (CSC). B.P.H.J.T. is supported by a Vici grant of the Research Council for Earth and Life sciences (ALW) of the Netherlands Organization for Scientific Research (NWO). We thank Jieyin Chen (Chinese Academy of Agricultural Sciences, China) and Michael G. Milgroom (Cornell University, USA) for providing V. dahliae strains. 


\section{References}

Atallah ZK, Maruthachalam K, du Toit L, Koike ST, Michael Davis R, Klosterman SJ, Hayes RJ, Subbarao KV (2010) Population analyses of the vascular plant pathogen Verticillium dahliae detect recombination and transcontinental gene flow. Fungal Genet Biol 47: 416-422.

Bell, AA (1992) Verticillium wilt. Page 87-126 in: Cotton Diseases. R. J. Hillocks, ed. CAB International, Wallingford, UK.

Bertels F, Silander OK, Pachkov M, Rainey PB, van Nimwegen E (2014) Automated reconstruction of wholegenome phylogenies from short-sequence reads. Mol Biol Evol 31: 1077-1188.

Bhat RG, Subbarao KV (1999) Host range specificity in Verticillium dahliae. Phytopathology 89: 1218-1225.

Böhnert HU, Fudal I, Dioh W, Tharreau D, Notteghem JL, Lebrun MH (2004) A putative polyketide synthase/ peptide synthetase from Magnaporthe grisea signals pathogen attack to resistant rice. Plant Cell 16: 2499-2513.

Campbell CL, Madden LV (1990) Introduction to plant disease epidemiology. John Wiley \& Sons, New York, NY, USA.

Chin CS, Alexander DH, Marks P, Klammer AA, Drake J, Heiner C, Clum A, Copeland A, Huddleston J, Eichler EE, Turner SW, et al. (2013) Nonhybrid, finished microbial genome assemblies from long-read SMRT sequencing data. Nat Methods 10: 563-569.

Collado-Romero M, Mercado-Blanco J, Olivares-García C, Valverde-Corredor A, Jiménez-Díaz RM (2006) Molecular variability within and among verticillium dahliae vegetative compatibility groups determined by fluorescent amplified fragment length polymorphism and polymerase chain reaction markers. Phytopathology 96: 485-495.

Collins A, Mercado-Blanco J, Jiménez-Díaz RM, Olivares C, Clewes E, Barbara DJ (2005) Correlation of molecular markers and biological properties in Verticillium dahliae and the possible origins of some isolates. Plant Patho 54: 549-557.

Cook DE, Mesarich CH, Thomma BPHJ (2015) Understanding plant immunity as a surveillance system todetect invasion. Annu Rev Phytopathol 53: 541-563.

Daayf F, Nicole M, Geiger, JP (1995) Differentiation of Verticillium dahliae populations on the basis of vegetative compatibility and pathogenicity on cotton. Eur J Plant Pathol 101: 69-79.

de Jonge R, Bolton MD, Thomma BPHJ (2011) How filamentous pathogens co-opt plants: the ins and outs of fungal effectors. Curr Opin Plant Biol 14: 400-406.

de Jonge R, van Esse HP, Kombrink A, Shinya T, Desaki Y, Bours R, van der Krol S, Shibuya N, Joosten MH, Thomma BPHJ (2010) Conserved fungal LysM effector Ecp6 prevents chitin-triggered immunity in plants. Science 329: 953-955.

de Jonge R, van Esse HP, Maruthachalam K, Bolton MD, Santhanam P, Saber MK, Zhang Z, Usami T, Lievens B, Subbarao KV, et al. (2012) Tomato immune receptor Ve1 recognizes effector of multiple fungal pathogens uncovered by genome and RNA sequencing. Proc Natl Acad Sci USA 109: 5110-5115.

de Jonge R, Thomma BPHJ (2009) Fungal LysM effectors - extinguishers of host immunity? Trends Microbiol 17: 151-157.

Dervis S, Mercado-Blanco J, Erten L, Valverde-Corredor A, Pérez-Artés E (2010) Verticillium wilt of olive in Turkey: a survey on disease importance, pathogen diversity and susceptibility of relevant olive cultivars. Eur J Plant Pathol 127: 287-301.

de Wit PJ (2016) Cladosporium fulvum Effectors: Weapons in the Arms Race with Tomato. Annu Rev Phytopathol. 54: $1-23$.

Du J, Verzaux E, Chaparro-Garcia A, Bijsterbosch G, Keizer LC, Zhou J, Liebrand TW, Xie C, Govers F, Robatzek S, et al. (2015) Elicitin recognition confers enhanced resistance to Phytophthora infestans in potato. Nat Plants 1: 15034 .

Duan YP, Castañeda A, Zhao G, Erdos G and Gabriel DW (1999) Expression of a single, host-specific, bacterial pathogenicity gene in plant cells elicits division, enlargement, and cell death. Mol Plant-Microbe Interact 12: $556-560$. 
Dutheil JY, Mannhaupt G, Schweizer G, MK Sieber C, Münsterkötter M, Güldener U, Schirawski J, Kahmann RA (2016) A tale of genome compartmentalization: the evolution of virulence clusters in smut fungi. Genome Biol Evol 8: 681-704.

Faino L, Seidl MF, Datema E, van den Berg GC, Janssen A, Wittenberg AH, Thomma BPHJ (2015) Single-molecule real-time sequencing combined with optical mapping yields completely finished fungal genome. mBio 6: e00936-00915.

Faino L, Seidl MF, Shi-Kunne X, Pauper M, van den Berg GC, Wittenberg AH, Thomma BPHJ (2016) Transposons passively and actively contribute to evolution of the two-speed genome of a fungal pathogen. Genome Res 26: $1091-1100$.

Finn RD, Attwood TK, Babbitt PC, Bateman A, Bork P, Bridge AJ, Chang HY, Dosztányi Z, El-Gebali S, Fraser M, et al. (2017) InterPro in 2017-beyond protein family and domain annotations. Nucleic Acids Res. 45: 190-199.

Fradin EF, Thomma BPHJ (2006) Physiology and molecular aspects of Verticillium wilt diseases caused by V. dahliae and V. albo-atrum. Mol Plant Pathol 7: 71-86.

Fradin EF, Zhang Z, Ayala JCJ, Castroverde CD, Nazar RN, Robb J, Liu C-M, Thomma BPHJ (2009) Genetic dissection of Verticillium wilt resistance mediated by tomato Ve1. Plant Physiol 150: 320-332.

Frandsen RJ, Andersson JA, Kristensen MB, Giese H (2008) Efficient four fragment cloning for the construction of vectors for targeted gene replacement in filamentous fungi. BMC Mol Biol 9: 70.

Friesen TL, Stukenbrock EH, Liu Z, Meinhardt S, Ling H, Faris JD, Rasmussen JB, Solomon PS, McDonald BA, Oliver RP (2006) Emergence of a new disease as a result of interspecific virulence gene transfer. Nat Genet 38: $953-956$.

Fudal I, Ross S, Gout L, Blaise F, Kuhn M, Eckert M, Cattolico L, Bernard-Samain S, Balesdent M, Rouxel T (2007) Heterochromatin-like regions as ecological niches for avirulence genes in the Leptosphaeria maculans genome: map-based cloning of AvrLm6. Mol Plant-Microbe Interact 20: 459-470.

Fu ZQ Dong X (2013) Systemic acquired resistance: turning local infection into global defense. Annu Rev Plant Biol 64: 839-863.

Gao W, Long L, Zhu LF, Xu L, Gao WH, Sun LQ Liu LL, Zhang XL (2013) Proteomic and virus-induced gene silencing (VIGS) Analyses reveal that gossypol, brassinosteroids, and jasmonic acid contribute to the resistance of cotton to Verticillium dahliae. Mol Cell Proteomics 12: 3690-703.

Gibriel HA, Thomma BPHJ, Seidl MF (2016) The age of effectors: genome-based discovery and applications. Phytopathology 106: 1206-1212.

Gómez-Lama Cabanás C, Legarda Cristóbal G, Ruano-Rosa D, Pizarro-Tobías P, Valverde-Corredor A, Niqui Arroyo, JL, Triviño JC, Roca Hernández A, Mercado-Blanco J (2018) Indigenous Pseudomonas spp. strains from the olive (Olea europaea L.) rhizosphere as effective biocontrol agents against Verticillium dahliae: from the host roots to the bacterial genomes. Front Microbiol 9: 277.

Hadizadeh I, Banihashemi Z (2007) Vegetative compatibility grouping of Verticillium dahliae from pistachio in Iran. Phytopathol Mediterr 46: 272-284.

Hiemstra JA, Rataj-Guranowska M (2003) Vegetative compatibility groups in Verticillium dahliae isolates from the Netherlands as compared to VCG diversity in Europe and in the USA. Eur J Plant Pathol 109: 827-839.

Holt C, Yandell M (2011) MAKER2: an annotation pipeline and genome-database management tool for secondgeneration genome projects. BMC Bioinformatics 12: 491.

Hu B, Xie G, Lo CC, Starkenburg SR, Chain PS (2011) Pathogen comparative genomics in the next-generation sequencing era: genome alignments, pangenomics and metagenomics. Brief Funct Genomics 10: 322-333.

Inderbitzin P, Subbarao KV (2014) Verticillium systematics and evolution: how confusion impedes Verticillium wilt management and how to resolve it. Phytopathology 104: 564-574.

Jiménez-Díaz RM, Olivares-García C, Landa BB, del Mar Jiménez-Gasco M, Navas-Cortés JA (2011) Regionwide analysis of genetic diversity in Verticillium dahliae populations infecting olive in southern Spain and agricultural factors influencing the distribution and prevalence of vegetative compatibility groups and pathotypes. Phytopathology 101: 304-315.

Jiménez-Díaz RM, Olivares-García C, Trapero-Casas JL, Jiménez-Gasco MM, Navas-Cortés JA, Landa BB, Milgroom MG (2017) Variation of pathotypes and races and their correlations with clonal lineages in Verticillium dahliae. Plant Pathol 66: 651-666. 
Joaquim TR, Rowe RC (1990) Reassessment of vegetative compatibility relationships among strains of Verticillium dahliae using nitrate nonutilizing mutants. Phytopathology 80: 160-166.

Jones JD, Dangl JL (2006) The plant immune system. Nature 444: 323.

Kazan K, Lyons R (2014) Intervention of phytohormone pathways by pathogen effectors. Plant Cell 26: 2285-2309.

Katan T (2000) Vegetative compatibility in populations of Verticillium-an overview. In: Advances in Verticillium research and disease management. Eds Tjamos EC, Rowe RC, Heale JB and Fravel RD, APS Press, St. Paul, MN, USA, 69-86.

Klosterman SJ, Atallah ZK, Vallad GE, Subbarao KV (2009) Diversity, pathogenicity, and management of Verticillium species. Annu Rev Phytopathol 47: 39-62.

Klosterman SJ, Subbarao KV, Kang S, Veronese P, Gold SE, Thomma BPHJ, Chen Z, Henrissat B, Lee YH, Park J (2011) Comparative genomics yields insights into niche adaptation of plant vascular wilt pathogens. PLOS Pathog 7: e1002137.

Kombrink A, Rovenich H, Shi-Kunne X, Rojas-Padilla E, van den Berg G, Domazakis E, De Jonge R, Valkenburg DJ, Sanchez-Vallet A, Seidl MF, et al. (2017) Verticillium dahliae LysM effectors differentially contribute to virulence on plant hosts. Mol Plant Pathol 18: 596-608.

Korolev N, Pérez-Artés E, Mercado-Blanco J, Bejarano-Alcázar J, Rodríguez-Jurado D, Jiménez-Díaz RM, Katan T, Katan J (2008) Vegetative compatibility of cotton defoliating Verticillium dahliae in Israel and its pathogenicity to various hosts. Eur J Plant Pathol 122: 603-617.

Langmead B, Salzberg SL (2012) Fast gapped-read alignment with Bowtie 2. Nat Methods 9: 357-359.

Laugé R, Joosten MHAJ, Haanstra JPW, Goodwin PH, Lindhout P, De Wit PJGM (1998) Successful search for a resistance gene in tomato targeted against a virulence factor of a fungal pathogen. Proc Natl Acad Sci USA 95: 9014-9018.

Leyva-Pérez Mdlo, Jiménez-Ruiz J, Gómez-Lama Cabanás C, Valverde-Corredor A, Barroso JB, Luque F, MercadoBlanco J (2017) Tolerance of olive (Olea europaea) cv Frantoio to Verticillium dahliae relies on both basal and pathogen-induced differential transcriptomic responses. New Phytol 217: 671-686.

Li H, Durbin R (2010) Fast and accurate long-read alignment with Burrows-Wheeler transform. Bioinformatics 26: 589-595.

Liu T, Song T, Zhang X, Yuan H, Su L, Li W, Xu J, Liu S, Chen L, Chen T, et al. (2014) Unconventionally secreted effectors of two filamentous pathogens target plant salicylate biosynthesis. Nat Commun 5:4686.

Liu Z, Gao Y, Kim YM, Faris JD, Shelver WL, de Wit PJ, Xu SS, Friesen TL (2016) SnTox1, a Parastagonospora nodorum necrotrophic effector, is a dual-function protein that facilitates infection while protecting from wheatproduced chitinases. New Phytol 211: 1052-1064.

Liu Z, Zhang Z, Faris JD, Oliver RP, Syme R, McDonald MC, McDonald BA, Solomon PS, Lu S, Shelver WL, et al. (2012) The cysteine rich necrotrophic effector SnToxi produced by Stagonospora nodorum triggers susceptibility of wheat lines harboring Snn1. PLoS Pathog 8: e1002467.

López-Escudero FJ, del Río C, Caballero JM, Blanco-López MA (2004) Evaluation of olive cultivars for resistance to Verticillium dahliae. Eur J Plant Pathol 110: 79-85.

López-Escudero FJ, Mercado-Blanco J (2011) Verticillium wilt of olive: a case study to implement an integrated strategy to control a soil-borne pathogen. Plant and Soil 344: 1-50.

López-Escudero FJ, Mercado-Blanco J, Roca JM, Valverde-Corredor A, Blanco-López MA (2010) Verticillium wilt of olive in the Guadalquivir Valley (southern Spain): relations with some agronomical factors and spread of Verticillium dahliae. Phytopathol Mediterr 49: 370-380.

Ma KW, Ma W (2016) Phytohormone pathways as targets of pathogens to facilitate infection. Plant Mol Biol 91: $713-725$.

Maldonado-González MM, Schilirò E, Prieto P, Mercado-Blanco J (2015) Endophytic colonization and biocontrol performance of Pseudomonas fluorescens PICF7 in olive (Olea europaea L.) are determined neither by pyoverdine production nor swimming motility. Environ Microbiol 17: 3139-3153.

Marshall R, Kombrink A, Motteram J, Loza-Reyes E, Lucas J, Hammond-Kosack KE, Thomma BPHJ, Rudd J (2011) Analysis of two in planta expressed LysM effector homologues from the fungus Mycosphaerella graminicola reveals novel functional properties and varying contributions to virulence on wheat. Plant. Physiol. 156: 756-769. 
Mentlak TA, Kombrink A, Shinya T, Ryder LS, Otomo I, Saitoh H, Terauchi R, Nishizawa Y, Shibuya N, Thomma BPHJ, et al. (2012) Effector-mediated suppression of chitin-triggered immunity by Magnaporthe oryzae is necessary for rice blast disease. Plant Cell 24: 322-335.

Mercado-Blanco J, Rodríguez-Jurado D, Parrilla-Araujo S, Jiménez-Díaz, RM (2003) Simultaneous detection of the defoliating and non-defoliating Verticillium dahliae pathotypes in infected olive plants by duplex, nested polymerase chain reaction. Plant Dis 87: 1487-1494.

Mercado-Blanco J, Rodríguez-Jurado D, Pérez-Artés E, Jiménez-Díaz, RM (2002) Detection of the defoliating pathotype of Verticillium dahliae in infected olive plants by nested PCR. Eur J Plant Pathol 108: 1-13.

Milgroom MG, Jiménez-Gasco Mdel M, Olivares García C, Drott MT, Jiménez-Díaz RM (2014) Recombination between clonal lineages of the asexual fungus Verticillium dahliae detected by genotyping by sequencing. PLoS One 9: e106740.

Milgroom MG, Jiménez-Gasco MM, Olivares-García C, Jiménez-Díaz RM (2016) Clonal expansion and migration of a highly virulent, defoliating lineage of Verticillium dahliae. Phytopathology 106: 1036-1046.

Mitchum MG, Hussey RS, Baum TJ, Wang X, Elling AA, Wubben M, Davis EL (2013) Nematode effector proteins: an emerging paradigm of parasitism. New Phytol 199: 879-894.

Pérez-Artés E, García-Pedrajas MD, Bejarano-Alcázar J, Jiménez-Díaz RM (2000) Differentiation of cottondefoliating and non-defoliating pathotypes of Verticillium dahliae by RAPD and specific PCR analyses. Eur J Plant Pathol 106: 507-517.

Pieterse CM, Van der Does D, Zamioudis C, Leon-Reyes A, Van Wees SC (2012) Hormonal modulation of plant immunity. Annu Rev Cell Dev Biol 28: 489-521.

Plissonneau C, Benevenuto J, Mohd-Assaad N, Fouché S, Hartmann FE, Croll D (2017) Using population and comparative genomics to understand the genetic basis of effector-driven fungal pathogen evolution. Front Plant Sci 8: 119.

Qin J, Wang K, Sun L, Xing H, Wang S, Li L, Chen S, Guo HS, Zhang J (2018) The plant-specific transcription factors CBP60g and SARD1 are targeted by a Verticillium secretory protein VdSCP41 to modulate immunity. eLife 7: e34902.

Quinlan AR, Hall IM (2010) BEDTools: a flexible suite of utilities for comparing genomic features. Bioinformatics 26: 841-842.

Raffaele S, Farrer RA, Cano LM, Studholme DJ, MacLean D, Thines M, Jiang RH, Zody MC, Kunjeti SG, Donofrio NM, et al. (2010) Genome evolution following host jumps in the Irish potato famine pathogen lineage. Science 330: 1540-1543.

Rafiei V, Banihashemi Z, Jiménez-Díaz RM, Navas-Cortés JA, Landa BB, Jiménez-Gasco MM, Turgeon BG, Milgroom MG (2018) Comparison of genotyping by sequencing and microsatellite markers for unravelling population structure in the clonal fungus Verticillium dahliae. Plant Pathol 67: 76-86.

Rodriguez-Moreno L, Ebert MK, Bolton MD, Thomma BPHJ (2018) Tools of the crook-infection strategies of fungal plant pathogens. Plant J 93: 664-674.

Rovenich H, Boshoven JC, Thomma BPHJ (2014) Filamentous pathogen effector functions: of pathogens, hosts and microbiomes. Curr Opin Plant Biol 20: 96-103.

Rowe RC (1995) Recent progress in understanding relationships between Verticillium species and subspecific groups. Phytoparasitica 23: 31-38.

Sánchez-Vallet A, Saleem-Batcha R, Kombrink A, Hansen G, Valkenburg D-J, Thomma BPHJ, Mesters JR (2013) Fungal effector Ecp6 outcompetes host immune receptor for chitin binding through intrachain LysM dimerization. eLife 2: e00790.

Santhanam P (2012) Random insertional mutagenesis in fungal genomes to identify virulence factors. Plant Fungal Pathogens Springer (Methods and Protocols) 835: 509-517.

Santhanam P, van Esse HP, Albert I, Faino L, Nürnberger T, Thomma BPHJ (2013) Evidence for functional diversification within a fungal NEP1-like protein family. Mol Plant-Microbe Interact 26: 278-286.

Schirawski J, Mannhaupt G, Munch K, Brefort T, Schipper K, Doehlemann G, Di Stasio M, Rossel N, MendozaMendoza A, Pester D, et al (2010) Pathogenicity determinants in smut fungi revealed by genome comparison. Science 330: 1546-1548. 
Schnathorst WC, Mathre D (1966) Host range and differentiation of a severe form of Verticillium albo-atrum in cotton. Phytopathology 56: 1155-1161.

Schnathorst WC, Sibbett GS (1971a) T-1 Verticillium strain: major factor in cotton and olive wilt. Calif Agric 25: 3-5.

Schnathorst WC, Sibbett GS (1971b) The relation of strains of Verticillium albo-atrum to severity of Verticillium wilt in Gossypium hirsutum and Olea europaea in California. Plant Dis Reptr 9: 780-782.

Shaban M, Miao Y, Ullah A, Khan AQ, Menghwar H, Khan AH, Ahmed MM, Tabassum MA, Zhu L (2018) Physiological and molecular mechanism of defense in cotton against Verticillium dahliae. Plant Physiol Biochem 125: 193-204.

Shen D, Liu T, Ye W, Liu L, Liu P, Wu Y, Wang Y, Dou D (2013) Gene duplication and fragment recombination drive functional diversification of a superfamily of cytoplasmic effectors in Phytophthora sojae. PLoS One 8: e70036.

Song Y, Liu L, Wang Y, Valkenburg DJ, Zhang X, Zhu L, Thomma BPHJ (2018) Transfer of tomato immune receptor Ve1 confers Ave1-dependent Verticillium resistance in tobacco and cotton. Plant Biotechnol J 16: 638-648.

Stamatakis A (2014) RAxML version 8: a tool for phylogenetic analysis and post-analysis of large phylogenies. Bioinformatics 30: 1312-1313.

Strausbaugh, CA (1993) Assessment of vegetative compatibility and virulence of Verticillium dahliae isolates from Idaho potatoes and tester strains. Phytopathology 83: 1253-1258.

Stukenbrock EH, Christiansen FB, Hansen TT, Dutheil JY, Schierup MH (2012) Fusion of two divergent fungal individuals led to the recent emergence of a unique widespread pathogen species. Proc Natl Acad Sci USA 109: 10954-10959.

Swarup S, De Feyter R, Brlansky RH, Gabriel DW (1991) A pathogenicity locus from Xanthomonas citri enables strains from several pathovars of X. campestris to elicit canker like lesions on citrus. Phytopathology 81: 802-809.

Swarup S, YangY, Kingsley MT and Gabriel DW (1992) An Xanthomonas citri pathogenicity gene, pthA, pleiotropically encodes gratuitous avirulence on non-hosts. Mol Plant-Microbe Interact 5: 204-213.

Takahara H, Hacquard S, KombrinkA, Hughes HB, HalderV, Robin GP, Hiruma K, Neumann U, Shinya T, Kombrink E, et al. (2016) Colletotrichum higginsianum extracellular LysM proteins play dual roles in appressorial function and suppression of chitin-triggered plant immunity. New Phytol 211: 1323-1337.

Takken FL, Thomas CM, Joosten MH, Golstein C, Westerink N, Hille J, Nijkamp HJ, de Wit PJ, Jones JD (1999) A second gene at the tomato Cf-4 locus confers resistance to Cladosporium fulvum through recognition of a novel avirulence determinant. Plant J 20: 279-288.

Tanaka S, Han X and Kahmann R (2015) Microbial effectors target multiple steps in the salicylic acid production and signaling pathway. Front. Plant Sci 6: 349.

Thomma BPHJ, Seidl MF, Shi-Kunne X, Cook DE, Bolton MD, van Kan JA, Faino L (2016) Mind the gap; seven reasons to close fragmented genome assemblies. Fungal Genet Biol 90: 24-30.

Trapnell C, Williams BA, Pertea G, Mortazavi A., Kwan G, vanBaren MJ, Salzberg SL, Wold BJ, Pachter L (2010) Transcript assembly and quantification by RNA-Seq reveals unannotated transcripts and isoform switching during cell differentiation. Nat. Biotechnol 28: 511-515.

Usami T, Itoh M, Amemiya Y (2008) Mating type gene MAT1-2-1 is common among Japanese isolates of Verticillium dahliae. Physiol Mol Plant Pathol 73: 133-137.

Usami T, Itoh M, Amemiya Y (2009) Asexual fungus Verticillium dahliae is potentially heterothallic. J Gen Plant Pathol 75: 422-427.

van der Does HC, Rep M (2007) Virulence genes and the evolution of host specificity in plant-pathogenic fungi. Mol Plant Microbe Interact 20: 1175-1182.

Vleeshouwers VG, Oliver RP (2014) Effectors as tools in disease resistance breeding against biotrophic, hemibiotrophic, and necrotrophic plant pathogens. Mol Plant-Microbe Interact 27: 196-206.

Vleeshouwers VG, Raffaele S, Vossen JH, Champouret N, Oliva R, Segretin ME, Rietman H, Cano LM, Lokossou A, Kessel G, et al. (2011) Understanding and exploiting late blight resistance in the age of effectors. Annu Rev Phytopathol 49: 507-531.

Wiese MV, Devay JE (1970) Growth regulator changes in cotton associated with defoliation caused by Verticillium albo-atrum. Plant Physiology 45: 304-309. 
Xu F, Yang L, Zhang J, Guo X, Zhang X, Li G (2012) Prevalence of the defoliating pathotype of Verticillium dahliae on cotton in central China and virulence on selected cotton cultivars. J Phytopathol 160: 369-376.

Zhang B, Yang Y, Chen T, Yu W, Liu T, Li H, Fan X, Ren Y, Shen D, Liu L, et al. (2012) Island cotton Gbve1 gene encoding a receptor-like protein confers resistance to both defoliating and non-defoliating isolates of Verticillium dahliae. PLOS ONE 7: e51091.

Zhang L, Ni H, Du X, Wang S, Ma XW, Nürnberger T, Guo HS, Hua C (2017) The Verticillium-specific protein VdSCP7 localizes to the plant nucleus and modulates immunity to fungal infections. New Phytol 215:368-381.

Zhou L, Zhao J, Guo W, Zhang T (2013) Functional analysis of autophagy genes via Agrobacterium-mediated transformation in the vascular Wilt fungus Verticillium dahliae. J Genet Genomics 40: 421-431. 


\section{Supplemental information}

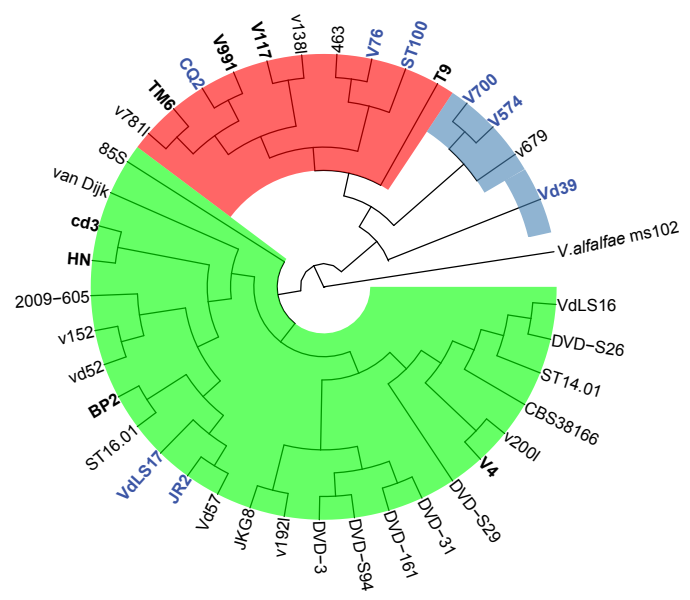

Figure S1. Phylogenetic tree of in housesequenced V. dahliae strains. V. dahliae strains clustering with known $\mathrm{D}$ pathotype strains (TM6, V991, V117 and T9) are showed in lightred, while strains clustering with known ND pathotype strains ( $\mathrm{V}_{4}, \mathrm{BP} 2, \mathrm{~cd}_{3}$ and $\left.\mathrm{HN}\right)$ are showed in light-green. Strains that distinct from the $\mathrm{D}$ and ND pathotype groups are showed in light-blue. Strains that used for phenotypic characterization in this work are display in bold with blue color. Phylogenetic relationship between sequenced $V$. dahliae strains was inferred using RealPhy (Bertels et al., 2014) and $V$. dahliae strain JR2 used as reference. V. alfalfae ms102 was used as root of the tree.

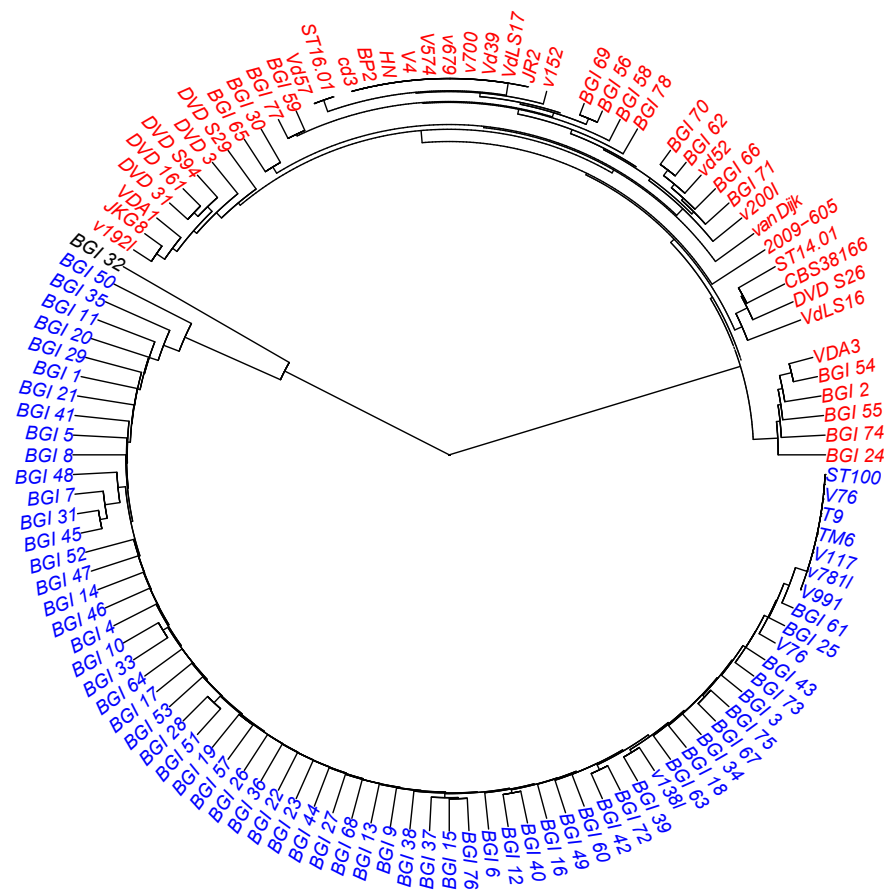

Figure S2. Clustering analysis of seventy-two sequenced V. dahliae strains. Sequences of seventy-two V. dahliae strains were aligned on the assembled genome of $\mathrm{CQ}_{2}$ and clustered in three groups based on presence/absence polymorphism. Strains clustering with known D pathotype strains are displayed in blue, while strains clustering with ND pathotype strains are showed in red. Strain BGI_32 that is the most divergent from the two groups showed in black. 


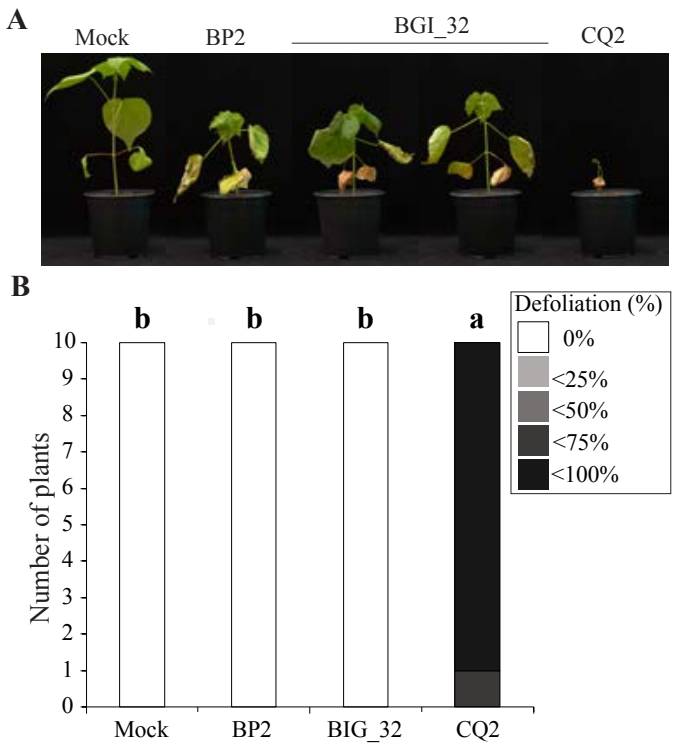

Figure S3. Phenotype of cotton plants inoculated with V. dahliae strain BGI_32. (A) Typical phenotype of cotton plants(cv. Xinluza063) upon mock-inoculation or inoculation with BP2, BGI_32 and CQ2 at 28 days post inoculation (dpi). ND pathotype strain BP2 and D pathotype strain CQ2 were used as inoculation control. (B) Defoliation were classified as O ( $0 \%$ leaves drop off), 1 ( $<25 \%$ leaf drop off), 2 ( $<50 \%$ leaf drop off), 3 ( $<75 \%$ leaf drop off) and 4 ( $<100 \%$ leaf drop off) at 28 dpi. Significance levels were calculated based on 5,000 bootstrap replicates of the median difference between random scores of two treatments and different letter labels indicate statistically significant differences $(P<0.05)$. Inoculation experiments were performed with ten plants for each fungal strain and repeated twice independently with similar results.
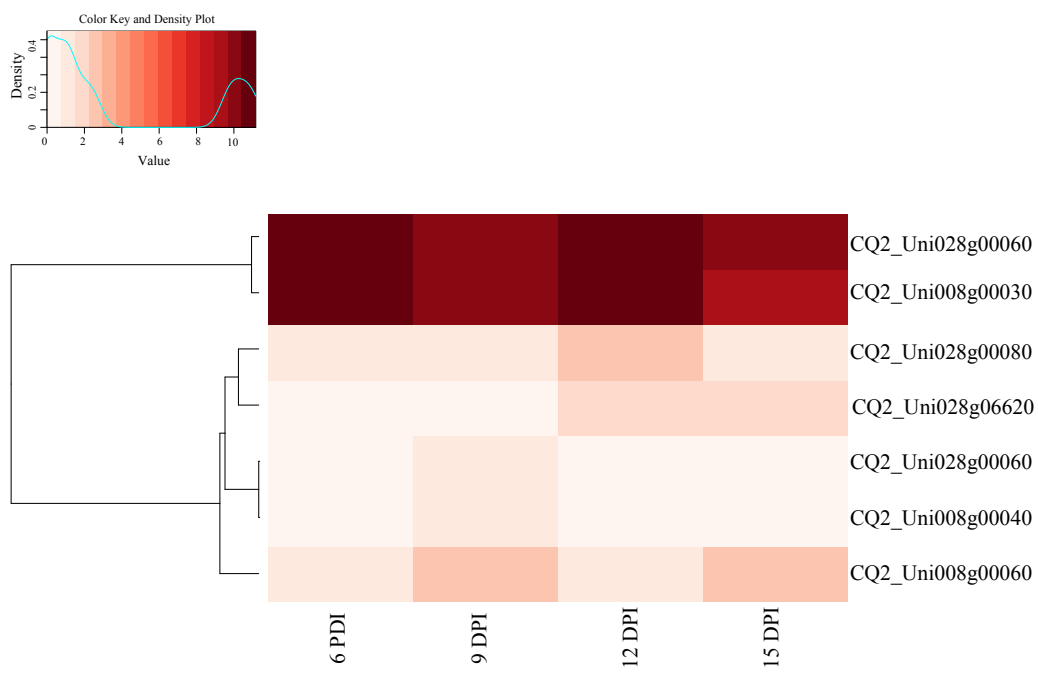

Figure S4. Expression analysis of the seven candidate genes. The heatmap showed the expression level of each gene during a time course of cotton infected by D pathotype strain V991 at 6, 9, 12 and 15 days post inoculation (DPI). The scaled expression values are color-coded according to scale bar at left corner. 
A

Single deletion

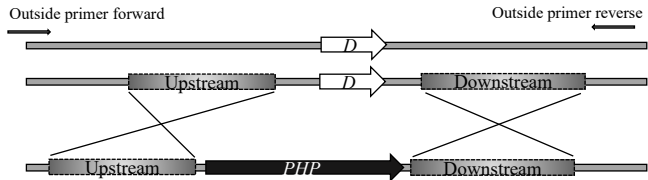

Double deletion

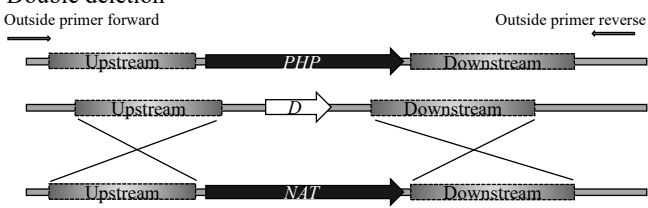

B

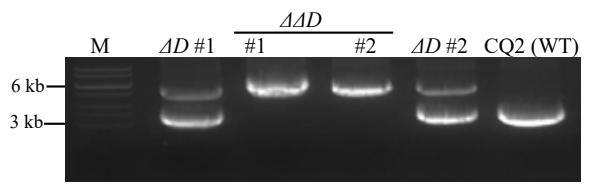

C

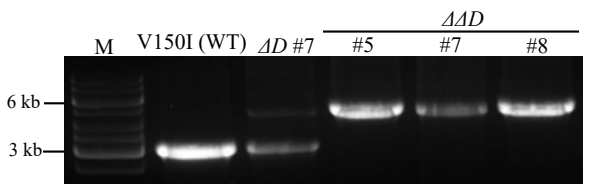

Figure S5. Construction and verification of $\boldsymbol{D}$ single deletion and double deletion mutants. (A) Schematic representation of the homologous recombination events to establish targeted replacement of $D$ gene with phosphotransferase $(H P H)$ and the nourseothricin resistance gene cassette (NAT). (B) Verification of $D$ single deletion $(\Delta \mathrm{D})$ and double deletion mutants $(\Delta \Delta \mathrm{D})$ in $V$. dahliae cotton defoliating strain CQ2 by PCR. Amplicons generated with outside primers indicated in panel A are shown for wild type strain CQ2 (WT), two $\Delta \mathrm{D}$ mutants (\#1 and \#2) and two $\Delta \Delta \mathrm{D}$ mutants (\#1 and \#2). (C) Verification of $D$ single deletion $(\Delta D)$ and double deletion mutants $(\Delta \Delta \mathrm{D})$ in V. dahliae olive defoliating strain V150I by PCR. Amplicons generated with outside primers indicated in panel A are shown for wild-type strain V150I (WT), one $\Delta D$ mutant (\#7) and three $\Delta \Delta \mathrm{D}$ mutants (\#5, \#7 and \#8).

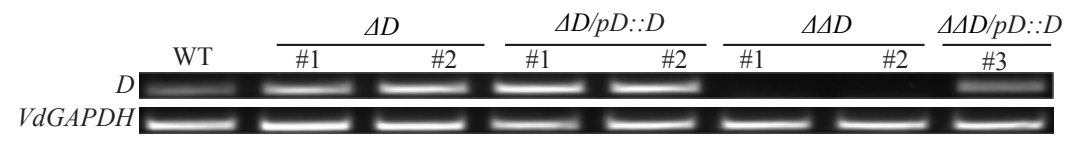

Figure S6. Detection of $\boldsymbol{D}$ gene transcripts in various $\boldsymbol{D}$ deletion and complementation strains. Amplification of $D$ gene fragment (from left to right) from cDNA in wild type strain CQ2 (WT), two $\triangle \mathrm{D}$ strains (\#1 and \#2), two $\triangle \mathrm{D}$ complementation strains $(\Delta \mathrm{D} / \mathrm{pD}:: \mathrm{D} \# 1$ and \#2), two $\Delta \Delta \mathrm{D}$ strains (\#1 and \#2) and one $\Delta \Delta \mathrm{D}$ complementation strain $(\triangle \triangle \mathrm{D} / \mathrm{pD}:: \mathrm{D} \# 3)$. V. dahliae GAPDH gene used as endogenous control.

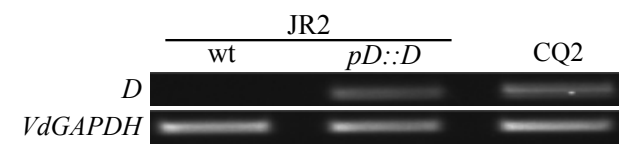

Figure S7. Expression of $D$ gene $(p D:: D)$ in ND pathotype strain JR2. Amplification of $D$ gene fragment (from left to right) from cDNA in wild type strain JR2, one $D$ expression ( $p D:: D)$ transformant of JR2 and CQ2 (used as positive control). V. dahliae GAPDH gene used as endogenous control.

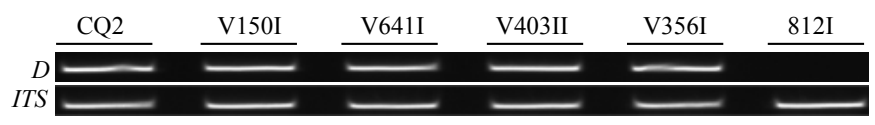

Figure S8. PCR detection of $D$ gene in V. dahliae strains. Amplification of $D$ gene fragment (from left to right) from genomic DNA in CQ2, V150I, V641I, V403I, V356I, 812I. As an endogenous control, a fragment of the Verticillium ITS region was amplified. 


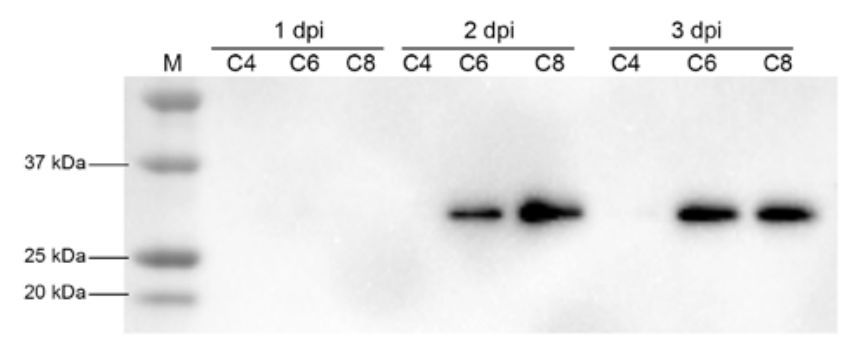

Figure S9. Detection of $\mathbf{D}$ effector protein expressed in the Pichia pastoris. Protein samples were collected from three putative $\mathrm{D}$-expression P. pastoris transformants (named as $\mathrm{C} 4, \mathrm{C} 6$ and $\mathrm{C} 8$ ) at 1,2 and 3 days post inoculation (dpi) in BMM medium, and were subjected to immunoblotted. Monoclonal antibody of His ${ }_{6}$ epitope-tag was used to detect His-tagged $\mathrm{D}$ effector proteins (predicted molecular weight of $32 \mathrm{kDa}$ ). Note that $P$. pastoris transformants C6, C8 expressed D effector protein properly while $\mathrm{C}_{4}$ failed to produce $\mathrm{D}$ effector protein. 
Table S1. V. dahliae strains used in this study.

\begin{tabular}{|c|c|c|c|c|}
\hline Strain & Sequencing platform & Reference & Origin & Geographical location \\
\hline $\mathrm{HN}$ & Illumina & Xu et al., 2012 & Cotton & China \\
\hline $\mathrm{cd}_{3}$ & Illumina & $\mathrm{Xu}$ et al., 2012 & Cotton & China \\
\hline VdLs17 & PacBio & Faino et al., 2015 & Lettuce & USA \\
\hline JR2 & PacBio & Faino et al., 2015 & Tomato & Canada \\
\hline $\operatorname{Vd} 57$ & Illumina & This study & Strawberry & Germany \\
\hline V152 & Illumina & Kombrink et al., 2017 & Oak & Hungary \\
\hline $\mathrm{Vd}_{52}$ & Illumina & Kombrink et al., 2017 & Pepper & Austria \\
\hline van Dijk & Illumina & Kombrink et al., 2017 & Chrysanthemum & The Netherlands \\
\hline $\mathrm{BP} 2$ & Illumina & Zhang et al., 2012 & Cotton & China \\
\hline ST16.01 & Illumina & This study & Cotton & Syria \\
\hline $2009-605$ & Illumina & This study & Bell pepper & Ukraine \\
\hline $\mathrm{V}_{4}$ & Illumina & Keykhasaber, 2017 & Olive & Spain \\
\hline V200I & Illumina & This study & Strawberry & Germany \\
\hline CBS38166 & Illumina & de Jonge et al., 2012 & Tomato & Canada \\
\hline DVD-S26 & Illumina & de Jonge et al., 2012 & Soil & Canada \\
\hline VdLS16 & Illumina & de Jonge et al., 2012 & Lettuce & USA \\
\hline ST14.01 & Illumina & de Jonge et al., 2012 & Pistachio & USA \\
\hline DVD-S29 & Illumina & de Jonge et al., 2012 & Soil & Canada \\
\hline DVD-31 & Illumina & de Jonge et al., 2012 & Tomato & Canada \\
\hline DVD-161 & Illumina & de Jonge et al., 2012 & Tomato & Canada \\
\hline DVD-S94 & Illumina & de Jonge et al., 2012 & Soil & Canada \\
\hline DVD-3 & Illumina & de Jonge et al., 2012 & Potato & Canada \\
\hline V192I & Illumina & This study & Cotton & Spain \\
\hline JKG8 & Illumina & Kombrink et al., 2017 & Potato & The Netherlands \\
\hline $85 \mathrm{~S}$ & PacBio & This study & Sunflower & France \\
\hline $\operatorname{Vd} 39$ & Illumina & This study & Sunflower & Germany \\
\hline V574 & Illumina & Milgroom et al., 2014 & Artichoke & Spain \\
\hline v700 & Illumina & Milgroom et al., 2014 & Artichoke & Spain \\
\hline v679 & Illumina & Milgroom et al., 2014 & Artichoke & Spain \\
\hline T9 & Illumina & Keykhasaber, 2017 & Cotton & USA \\
\hline V781I & Illumina & This study & Olive & Spain \\
\hline V138I & Illumina & This study & Cotton & Spain \\
\hline TM6 & Illumina & Keykhasaber, 2017 & Cotton & China \\
\hline V117 & Illumina & Keykhasaber, 2017 & Olive & Spain \\
\hline V991 & Illumina & Zhang et al., 2012 & Cotton & China \\
\hline $\mathrm{CQ}_{2}$ & PacBio & This study & Cotton & China \\
\hline ST100 & Illumina & de Jonge et al., 2012 & Soil & Belgium \\
\hline V76 & Illumina & This study & Cotton & Mexico \\
\hline 463 & Illumina & This study & Cotton & Mexico \\
\hline
\end{tabular}


Table S2. D pathotype-specific (D-LS) regions identified by comparative genomics.

\begin{tabular}{|c|c|c|c|}
\hline Contig Names & Start (bp) & End (bp) & Size (bp) \\
\hline unitig_2_complete & $1,030,380$ & $1,031,982$ & 1,602 \\
\hline unitig_2_complete & $1,052,304$ & $1,053,244$ & 940 \\
\hline unitig_8_Part_Chr & 6,022 & 7,117 & 1,095 \\
\hline unitig_8_Part_Chr & 7,869 & 8,611 & 742 \\
\hline unitig_8_Part_Chr & 9,525 & 11,004 & 1,479 \\
\hline unitig_26_Part_Chr & 52,257 & 54,090 & 1,833 \\
\hline unitig_26_Part_Chr & 54,284 & 55,934 & 1,650 \\
\hline unitig_26_Part_Chr & 151,504 & 151,944 & 440 \\
\hline unitig_26_Part_Chr & 152,148 & 153,466 & 1,318 \\
\hline unitig_26_Part_Chr & 154,179 & 154,941 & 762 \\
\hline unitig_26_Part_Chr & 154,815 & 156,521 & 1,706 \\
\hline unitig_26_Part_Chr & 156,881 & 159,404 & 2,523 \\
\hline unitig_26_Part_Chr & 159,772 & 161,414 & 1,642 \\
\hline unitig_26_Part_Chr & 162,174 & 163,225 & 1,051 \\
\hline unitig_26_Part_Chr & 165,628 & 166,710 & 1,082 \\
\hline unitig_26_Part_Chr & 166,846 & 167,777 & 931 \\
\hline unitig_26_Part_Chr & 191,563 & 192,205 & 642 \\
\hline unitig_26_Part_Chr & 198,885 & 200,078 & 1,193 \\
\hline unitig_26_Part_Chr & 199,987 & 200,815 & 828 \\
\hline unitig_26_Part_Chr & 203,274 & 203,828 & 554 \\
\hline unitig_26_Part_Chr & 204,157 & 204,774 & 617 \\
\hline unitig_26_Part_Chr & 212,513 & 213,631 & 1,118 \\
\hline unitig_26_Part_Chr & 216,642 & 219,899 & 3,257 \\
\hline unitig_26_Part_Chr & 317,134 & 317,938 & 804 \\
\hline unitig_26_Part_Chr & 318,784 & 319,771 & 987 \\
\hline unitig_28_Part_Chr & 14,530 & 15,671 & 1,141 \\
\hline unitig_28_Part_Chr & 16,435 & 17,160 & 725 \\
\hline unitig_28_Part_Chr & 18,315 & 19,638 & 1,323 \\
\hline unitig_28_Part_Chr & $2,218,774$ & $2,220,207$ & 1,433 \\
\hline unitig_28_Part_Chr & $2,220,360$ & $2,221,215$ & 855 \\
\hline unitig_28_Part_Chr & $2,229,134$ & $2,229,758$ & 624 \\
\hline unitig_28_Part_Chr & $2,504,628$ & $2,505,000$ & 372 \\
\hline
\end{tabular}


Table S3. Primers used in this study.

\begin{tabular}{|c|c|c|}
\hline Primer name & Oligonucleotide sequence $\left(5^{\prime} \rightarrow 3^{\prime}\right)$ & Description \\
\hline SKO-D-LBF & GGTCTTAAUAATCCCATAAAAGCGCTGAA & $\begin{array}{l}\text { For single } D \text { deletion generation, left border, } \\
\text { forward }\end{array}$ \\
\hline SKO-D-LBR & GGCATTAAUCTGTCGTTTGCTCAGTTGGA & $\begin{array}{l}\text { For single } D \text { deletion generation, left border, } \\
\text { reverse }\end{array}$ \\
\hline SKO-D-RBF & $\frac{\text { GGACTTAAUGATGG- }}{\text { TAGGGGGAAGGAGAG }}$ & $\begin{array}{l}\text { For single } D \text { deletion generation, right border, } \\
\text { forward }\end{array}$ \\
\hline SKO-D-RBR & GGGTTTAAUGCACCATGCATAAAACGATG & $\begin{array}{l}\text { For single } D \text { deletion generation, right border, } \\
\text { reverse }\end{array}$ \\
\hline DKO-D-LBF & GGTCTTAAUCGACAGACAGGAGGATGTCA & $\begin{array}{l}\text { For double } D \text { deletion generation, left border, } \\
\text { forward }\end{array}$ \\
\hline DKO-D-LBR & GGCATTAAUGCGGCTCGAACTCTCTAAAC & $\begin{array}{l}\text { For double } D \text { deletion generation, left border, } \\
\text { reverse }\end{array}$ \\
\hline DKO-D-RBF & GGACTTAAUCTATTCGCATTTTCGCGACT & $\begin{array}{l}\text { For double } D \text { deletion generation, right border, } \\
\text { forward }\end{array}$ \\
\hline DKO-D-RBR & GGGTTTAAUTGAACAGCAGACCAACAGGA & $\begin{array}{l}\text { For double } D \text { deletion generation, right border, } \\
\text { reverse }\end{array}$ \\
\hline outside primer-F & CTTCGATTGCTGTCACTGGA & Verification of $D$ deletion mutants \\
\hline outside primer- $\mathrm{R}$ & TGAACAGCAGACCAACAGGA & Verification of $D$ deletion mutants \\
\hline $\mathrm{D}$-com-F & $\begin{array}{l}\text { ggggacagctttcttgtacaaagtg- } \\
\text { gaaAAAATCCCATAAAAGCGCTGAA }\end{array}$ & Complementation of $D$ gene, forward \\
\hline D-com-R & $\begin{array}{l}\text { ggggacaactttgtataataaagttgtTTCCGCG- } \\
\text { CATAATGAACTCG }\end{array}$ & Complementation of $D$ gene, reverse \\
\hline $\mathrm{D}-\mathrm{F}(\mathrm{RT})$ & CGACTTGACGCATTTGGTTA & V. dahliae D, RT-PCR \\
\hline $\mathrm{D}-\mathrm{R}(\mathrm{RT})$ & CTGAGAACGACTTTCTCAT & V. dahliae D, RT-PCR \\
\hline D-Pich-F & $\begin{array}{l}\text { CGGTATGAATTCATTGCCATCCCGCAATC- } \\
\text { CGATAC }\end{array}$ & D effector protein expression in pichia pastoris \\
\hline D-Pich-R & $\begin{array}{l}\text { CGGTATGCGGCCGCTTATTATCAAAGCTG- } \\
\text { GCCTGCGTCAAAAGA }\end{array}$ & D effector protein expression in pichia pastoris \\
\hline ITS-F & AAAGTTTTAATGGTTCGCTAAGA & $\begin{array}{l}\text { Verticillium ribosomal internal transcribed } \\
\text { spacer region (ITS), fungal biomass } \\
\text { quantification }\end{array}$ \\
\hline ITS-R & CTTGGTCATTTAGAGGAAGTAA & $\begin{array}{l}\text { Verticillium ribosomal internal transcribed } \\
\text { spacer region (ITS), fungal biomass } \\
\text { quantification }\end{array}$ \\
\hline VdGAPDH-F & CGAGTCCACTGGTGTCTTCA & V. dahliae GAPDH, RT PCR \\
\hline VdGAPDH-R & CСCTCAACGATGGTGAACTT & V. dahliae GAPDH, RT PCR \\
\hline GhUb-F & GAAGGCATTCCACCTGACCAAC & $\begin{array}{l}\text { Cotton ubiquitin gene, fungal biomass } \\
\text { quantification }\end{array}$ \\
\hline GhUb-R & CAAAACTCCAAAATCATACCCAAAG & $\begin{array}{l}\text { Cotton ubiquitin gene, fungal biomass } \\
\text { quantification }\end{array}$ \\
\hline AtRubisco-F & GCAAGTGTTGGGTTCAAAGCTGGTG & $\begin{array}{l}\text { Arabidopsis Rubisco gene, fungal biomass } \\
\text { quantification }\end{array}$ \\
\hline AtRubisco-R & CCAGGTTGAGGAGTTACTCGGAATGCTG & $\begin{array}{l}\text { Arabidopsis Rubisco gene, fungal biomass } \\
\text { quantification }\end{array}$ \\
\hline
\end{tabular}




\begin{tabular}{lll}
\hline Primer name & oligonucleotide sequence $\left(\mathbf{5}^{\prime} \rightarrow \mathbf{3}^{\prime}\right)$ & Description \\
\hline NbRubisco-F & TCCGGGTATTAGGAAAGCGT & $\begin{array}{l}\text { N. benthamiana Rubisco gene, fungal biomass } \\
\text { quantification }\end{array}$ \\
\hdashline NbRubisco-R & CCCAAGATCTGGGTCAGAGC & $\begin{array}{l}\text { N. benthamiana Rubisco gene, fungal biomass } \\
\text { quantification }\end{array}$ \\
\hline
\end{tabular}

${ }^{\mathrm{a}}$ USER cloning sites present in primer sequence are underlined; Gateway cloning sites present in primer sequence are indicated in lower case letter. RT-PCR: Reverse Transcription-PCR.

\section{References}

de Jonge R, van Esse HP, Maruthachalam K, Bolton MD, Santhanam P, Saber MK, Zhang Z, Usami T,Lievens B, Subbarao KV, Thomma BPHJ (2012) Tomato immune receptor Ve1 recognizes effector of multiple fungal pathogens uncovered by genome and RNA sequencing. Proc Natl Acad Sci USA 109:5110-5115.

Faino L, Seidl MF, Datema E, van den Berg GC, Janssen A, Wittenberg AH, Thomma BPHJ (2015) Single-molecule real-time sequencing combined with optical mapping yields completely finished fungal genome. mBio 6: e00936-00915.

Keykhasaber M (2017) Unravelling aspects of spatial and temporal distribution of Verticillium dahliae in olive, maple and ash trees and improvement of detection methods Wageningen University \& Research PhD thesis.

Kombrink A, Rovenich H, Shi-Kunne X, Rojas-Padilla E, van den Berg G, Domazakis E, De Jonge R, Valkenburg DJ, Sanchez-Vallet A, Seidl MF, et al. (2017) Verticillium dahliae LysMeffectors differentially contribute to virulence on plant hosts. Mol Plant Pathol 18: 596-608.

Milgroom MG, Jiménez-Gasco MM, Olivares-García C, Jiménez-Díaz RM (2016) Clonal expansion and migration of a highly virulent, defoliating lineage of Verticillium dahliae. Phytopathology 106: 1036-1046.

Xu F, Yang L, Zhang J, Guo X, Zhang X, Li G (2012) Prevalence of the defoliating pathotype of Verticillium dahliae on cotton in central China and virulence on selected cotton cultivars. J Phytopathol 160: 369-376.

Zhang B, Yang Y, Chen T, Yu W, Liu T, Li H, Fan X, Ren Y, Shen D, Liu L, Liu L, Dou D, ChangY (2012) Island cotton Gbver gene encoding a receptor-like protein confers resistance to both defoliating and non-defoliating isolates of Verticillium dahliae. PLOS ONE 7: e51091. 


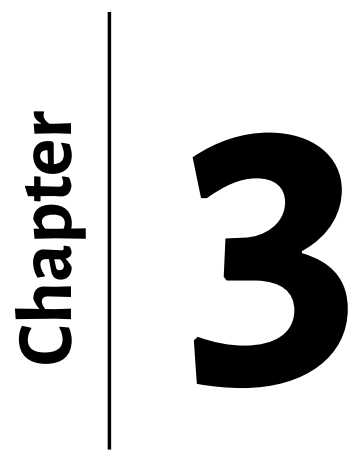

\section{A single effector mediates pathogenicity of Verticillium dahliae on tomato}

Jinling Li' ${ }^{15}$, Luigi Faino's and Bart P.H.J. Thomma ${ }^{1 "}$ 


\section{Abstract}

In order to establish disease, many plant pathogens secrete so-called effector molecules to support host colonization, frequently through the modulation of host physiology. Accordingly, many effector molecules have been shown to be pivotal for microbial pathogenesis. Verticillium dahliae is a xylem-invading fungal pathogen that causes devastating vascular wilt disease on hundreds of plant species, including the economically important crop tomato (Solanum lycopersicum). Although individual strains are typically characterized by their broad host range, differential pathogenicity occurs on nearly all hosts. Currently, the molecular basis underlying differences in pathogenicity between $V$. dahliae strains remains unknown. In this study, we used comparative genomics to identify $V$. dahliae genes that confer pathogenicity on tomato plants. While genome analysis of tomato-pathogenic and non-pathogenic $V$. dahliae strains revealed five effector candidate genes that specifically occur in pathogenic strains, only one of them was expressed during host colonization. Functional analyses showed that this single effector governs pathogenicity of $V$. dahliae on tomato, as deletion of the effector gene resulted in loss of the ability to colonize tomato plants. Furthermore, transfer of this effector gene into a non-pathogenic $V$. dahliae isolate resulted in the ability to cause disease on tomato. Moreover, introduction of the gene in the non-pathogenic, saprophytic, sister species V. tricorpus and V. nubilum similarly resulted in tomato disease. Thus, we demonstrate that a single effector, named Tom1, mediates pathogenicity of $V$. dahliae on tomato. 


\section{Introduction}

Verticillium is a relatively small genus of Ascomycete fungi that consists of ten soil-borne, asexual species with different lifestyles that range from saprophytic to pathogenic (Klosterman et al., 2009; Inderbitzin and Subbarao, 2014; Klimes et al., 2015). Among these species, V. isaacii, $V$. klebahnii, V. zaregamsianum, $V$. tricorpus and $V$. nubilum are considered to be saprophytes that occasionally cause opportunistic infections on plants that have been weakened by other stresses (Inderbitzin et al., 2011; Gurung et al., 2015; Seidl et al., 2015; Shi-Kunne et al., 2018). The remaining Verticillium species, V. dahliae, V. albo-atrum, V. alfalfae, V. nonalfalfae and V. longisporum, can cause vascular wilt diseases on economically important crops (Pegg and Brady, 2002; Fradin and Thomma, 2006; Inderbitzin et al., 2011; Depotter et al., 2016). However, despite the fact that the latter five species are all pathogenic, they differ significantly in host range. V. dahliae is the most notorious plant pathogen that can infect over 200 plant species (Fradin and Thomma, 2006). In contrast, other pathogenic Verticillium species have more restricted host ranges as, for instance, V. albo-atrum mainly infects hop, soybean, tomato and potato (Fradin and Thomma, 2006), while $V$. longisporum mainly causes diseases on brassicaceous plant hosts such as oilseed rape and cauliflower (Depotter et al., 2016), and V. alfalfae only infects lucerne (Inderbitzin et al., 2011). It has been estimated that the economic losses caused by Verticillium wilt diseases on the 20 most affected hosts collectively amount up to $€ 3$ billion worldwide (Depotter et al., 2016).

Verticillium wilt diseases are difficult to control due to the long viability of the resting structures, the scarcity of disease resistance in host germplasms, and the inability of fungicides to eliminate the pathogens once they have entered host plant xylem tissues (Fradin and Thomma, 2006; Klosterman et al., 2011). The high economic impact of Verticillium wilt diseases, combined with the absence of curative treatments, substantiates the need for developing novel disease control strategies.

Unravelling the mechanisms by which microbial pathogens cause diseases on plants is of fundamental importance to combat pathogen infections and control crop losses. Over the years, accumulating evidence has shown that the pathogenicity of a plant pathogen is largely mediated by so-called effector molecules that are secreted by the pathogen during host infection (Jones and Dangl, 2006; de Jonge et al., 2011; Rovenich et al., 2014; Rodriguez-Moreno et al., 2018). Most of secreted effector molecules are involved in suppression of plant immune responses or manipulation of host physiology to enable successful host colonization (Rovenich et al., 2014; Rodriguez-Moreno et al., 2018). It is generally observed that effector activities are redundant and single effectors are dispensable for virulence of the pathogens. As effectors are crucial for establishing parasitic symbiosis, the identification and functional characterization of effectors is important for a mechanistic understanding of microbial pathogenesis that ultimately provides valuable knowledge to develop effective disease management strategies (Gibriel et al., 2016).

Recent advances in genomic sequencing technologies and the rapid development of new bioinformatics algorithms, pipelines, and effector identification methods enable genomicsbased discovery of effector candidates from various plant pathogens (Faino and Thomma, 2014; Thomma et al., 2015; Gibriel et al., 2016). Moreover, facilitated by the wealth of publically available genome sequences of multiple plant pathogens, comparative genomics approaches 
have been applied to discover effectors by inferring differences in gene content or gene presence/ absence polymorphisms between closely related pathogens, or different strains of the same species (Thomma et al., 2015; Gibriel et al., 2016). For instance, genome analysis of the cereal pathogens Fusarium graminearum and F. verticillioides, and the tomato pathogen F. oxysporum $f$. sp. lycopersici permitted the identification of four dispensable chromosomes that are specific to tomato-infecting F. oxysporum f. sp. lycopersici (Ma et al., 2010). Interestingly, pathogenicity of F. oxysporum f. sp. lycopersici on tomato could be specifically attributed to one dispensable chromosome that contains a number of effector genes (Ma et al., 2010). Comparative genome studies of $V$. dahliae isolates revealed that extensive genome rearrangements established highly variable lineage-specific (LS) genomic regions that only occur in part of the $V$. dahliae population (de Jonge et al., 2013; Faino et al., 2016). Interestingly, these LS genomic regions are greatly enriched for in planta-expressed effector genes, some of which have shown to be important for fungal aggressiveness (de Jonge et al., 2012, 2013; Kombrink et al., 2017). For instance, the most well-characterized LS effector is the race-specific effector Aver that is recognized by the tomato immune receptor Ve1 (Fradin et al., 2009; de Jonge et al., 2012). Interestingly, Ave1 is a potent virulence factor on tomato plants that lack resistance gene Ve1, Arabidopsis, tobacco and cotton (de Jonge et al., 2012; Song et al., 2018). Comparative genomics has further identified LS effectors that are important for virulence (de Jonge et al., 2013), including Vd2LysM, a chitinbinding effector that contributes to virulence on tomato through suppression of chitin-triggered host immunity (Kombrink et al., 2017). More recently, the V. dahliae D (for defoliating) effector that is responsible for causing defoliation symptoms on cotton and olive was identified through comparative genomics of strains that belong to the defoliating (D) and the non-defoliating (ND) pathotype V. dahliae (Chapter 2).

Tomato is considered one of the most important vegetable crops worldwide, with a net economic value exceeding 58 billion dollars (Vincent et al., 2013). Genetic resistance against V. dahliae has been characterized in tomato, as the tomato immune receptor Ve1 mediates resistance to race 1 strains of $V$. dahliae by recognition of the race1-specific effector Ave1 (Fradin et al., 2009; de Jonge et al., 2012). However, race 2 isolates that have overcome Ve1-mediated recognition by omission of the Ave1 effector gene arose (Dobinson et al., 1996; de Jonge et al., 2012). Besides race 1 and race 2 strains that have the ability to cause disease on particular tomato genotypes, strains that are unable to cause disease on tomato occur as well. In this study, we aimed to identify the molecular basis underlying V. dahliae pathogenicity on tomato by using comparative genomics.

\section{Materials and methods}

\section{Pathogenicity assays}

Pathogenicity assays were performed on twelve-day-old tomato seedlings of susceptible tomato (cv. Moneymaker) using the root-dipping inoculation method as previously described (Fradin et al., 2009). The disease symptoms were scored up to 21 days post inoculation (dpi). V. dahliae stem section outgrowth assays, canopy area measurements and fungal biomass quantifications were performed as previously described (Fradin et al., 2009; Santhanam et al., 2013; Song et al., 2018). 


\section{Phylogenetic analysis of sequenced $V$. dahliae strains}

A phylogenetic tree of the $V$. dahliae strains was generated by REALPHY (version 1.12) (Bertels et al., 2014) using Bowtiez (Langmead and Salzberg, 2012) to map genomic reads against the reference genome of $V$. dahliae strain JR2 for which a gapless genome assembly is available (Faino et al., 2015). A maximum likelihood phylogenetic tree was inferred using RAxML (version 8.2.8) with the GTRGAMMA model and 500 bootstrap replicates (Stamatakis, 2014). The genome sequence of $V$. alfalfae strain msio2 was used to root the tree.

\section{V. dahliae comparative genomics}

In order to identify $V$. dahliae genes that mediate pathogenicity on tomato, the whole-genome assembly of $V$. dahliae strain JR2 (Faino et al., 2015) was used as a reference. Next, short reads from pathogenic and non-pathogenic $V$. dahliae strains were mapped onto the reference using BWA software (Li and Durbin, 2010) with default options. The presence/absence analysis was performed using $\mathrm{R}$ scripts, and genomic regions were considered present if the breadth of coverage was $\geq 5 \mathrm{x}$, while those with breadth of coverage $<5 \mathrm{x}$ were considered absent. Genomic regions that are only present in tomato-pathogenic strains were determined and genes localized within these regions were extracted using an R script. To further characterize potential effector genes, SignalP (version 4.1) (Petersen et al., 2011) software was used to identify secretion signal peptides at the $\mathrm{N}$-termini of the encoded proteins. Subsequently, the machine-learning approach applied in EffectorP (version 1.0) (default parameters) was used to identify potential effector genes (Sperschneider et al., 2016).

\section{Gene expression analysis}

To determine expression profiles of effector candidate genes during V. dahliae infection of tomato, two week-old tomato (cv. Moneymaker) seedlings were inoculated with $V$. dahliae strain JR2 and stems were harvested at 4, 8, 12, 16 and 18 days post inoculation (dpi). Total RNA extraction and cDNA synthesis were performed as previously described (Santhanam et al., 2013). Quantitative real time-PCR (qRT-PCR) was performed with primers listed in Table S3, using the V. dahliae GAPDH (GAPDH, glyceraldehyde-3-phosphate dehydrogenase) gene as an endogenous control (Table S3).

\section{Generation of Tom gene deletion strains and complementation strains}

To generate a Tom 1 gene deletion construct, sequences that flank the Tom 1 coding sequence were amplified from genomic DNA of $V$. dahliae strain JR2 using the primers KO-Tom1-LBF and KO-Tom1-LBR, and primers KO-Tom1-RBF and KO-Tom1-RBR (Table S3), and cloned into the binary vector pRF-HU2 (Frandsen et al, 2008). The resulting Tom1 gene deletion construct was used to transform V. dahliae strain JR2 as previously described (Santhanam et al., 2013). The putative deletion transformants were selected on PDA containing cefotaxime $(200 \mu \mathrm{g} / \mathrm{mL})$ and hygromycin B (50 $\mu \mathrm{g} / \mathrm{mL})$ (Duchefa, Haarlem, the Netherlands), and the absence of the Tom gene was verified with PCR. 
To generate the Tom 1 complementation construct, a genomic fragment consisting of the Tom 1 coding sequence plus $1.2 \mathrm{~kb}$ upstream and $1.1 \mathrm{~kb}$ downstream ( $p$ Tom1::Tom1) were amplified using primers Tom1-com-F and Tom1-com-R (Table S3) and cloned into the Gateway ${ }^{\mathrm{TM}}$ compatible $^{-}$ vector PCG using a standard BP reaction (Zhou et al., 2013). The resulting complementation construct was transformed into the Tomı deletion mutant, V. dahliae strain ST10o, V. tricorpus strain MUCL9792, and V. nubilum strain PD397, respectively. Putative Tom1 complementation transformants were selected on PDA supplemented with cefotaxime $(200 \mu \mathrm{g} / \mathrm{mL})$ and geneticin $(25 \mu \mathrm{g} / \mathrm{mL})$ (Sigma-Aldrich Chemie BV, Zwijndrecht, The Netherlands) and successful transformation was confirmed with PCR.

\section{Results}

\section{Verticillium dahliae inoculations on susceptible tomato plants}

Previously, various $V$. dahliae strains have been sequenced in our lab, of which strains JR2, VdLs17, 2009-605, DVD3, DVD-S161, DVD-31, DVD-S26, DVD-S29, DVD-S94, V4 and CBS38166 were known to be able to cause disease on tomato, while strain ST1oo lacks the ability to infect tomato (de Jonge et al., 2012, 2013; Faino et al., 2015). In order to identify additional tomato nonpathogenic strains, we generated a phylogenetic tree of all sequenced V. dahliae strains (Table S1), revealing that $V$. dahliae strains v781I, TM6, CQ2, V991, V117, V1381I, 463, V76 and T9 clustered with the tomato non-pathogenic strain ST100, while the remaining strains were found to be more related to previously characterized tomato-pathogenic strains (Figure 1).

Of particular interest are strains V574, V700, V679 and Vd39 that are phylogenetically the most distinct under the close relatives of ST100 (Figure 1). Thus, we selected V991, V117, T9, V574 and $\mathrm{Vd} 39$ to evaluate their capacity to cause disease on tomato. In contrast to JR2, which induced clear stunting and significant reduction in canopy area development on inoculated tomato plants, all of these strains failed to cause any visible tomato disease symptoms just like ST100 (Figure 2AB). This finding was further corroborated by fungal recovery assays, as plating stem sections of the inoculated plants on agar medium resulted in fungal outgrowth from all sections of JR2inoculated plants, while no fungal growth was recovered from stem sections of plants inoculated with any of the other strains (Figure $2 \mathrm{C}$ ). Collectively, these data demonstrate that stains ST100, V991, V117, T9, Vd39 and V574 are non-pathogenic on tomato. 


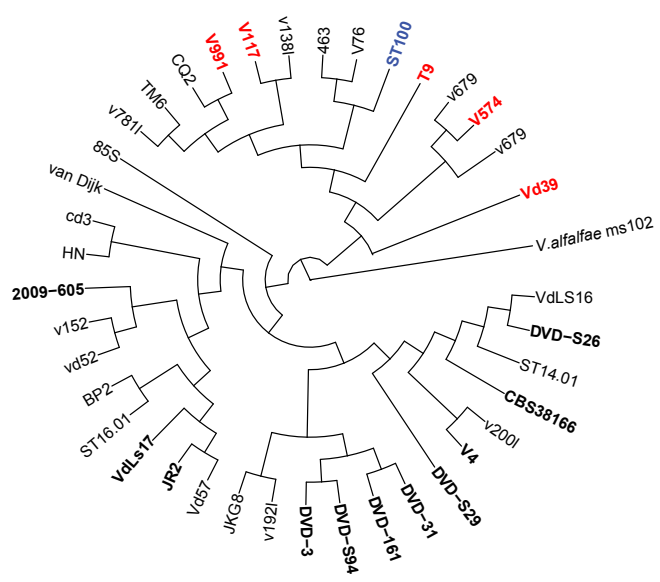

Figure 1. Phylogenetic tree of sequenced V. dahliae strains. Previously characterized tomato-pathogenic and nonpathogenic strains are shown in bold black and blue font, respectively. Strains that were selected for phenotypic characterization in this study are shown in red font. Phylogenetic relationships between sequenced $V$. dahliae strains are inferred using RealPhy (Bertels et al., 2014). V. alfalfae strain ms102 was used to root the tree.

$\mathbf{A}$

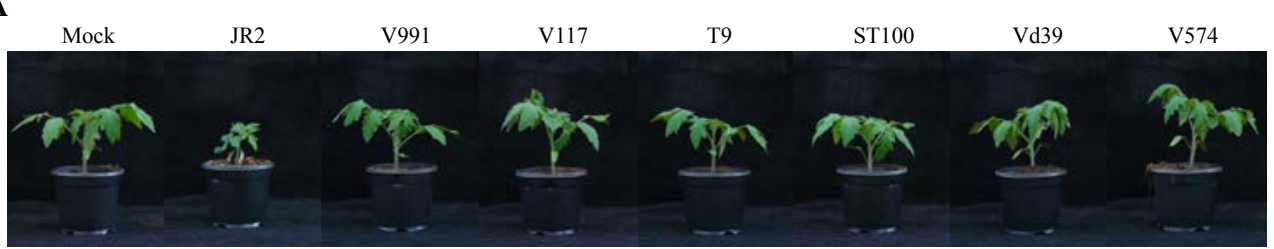

B

C
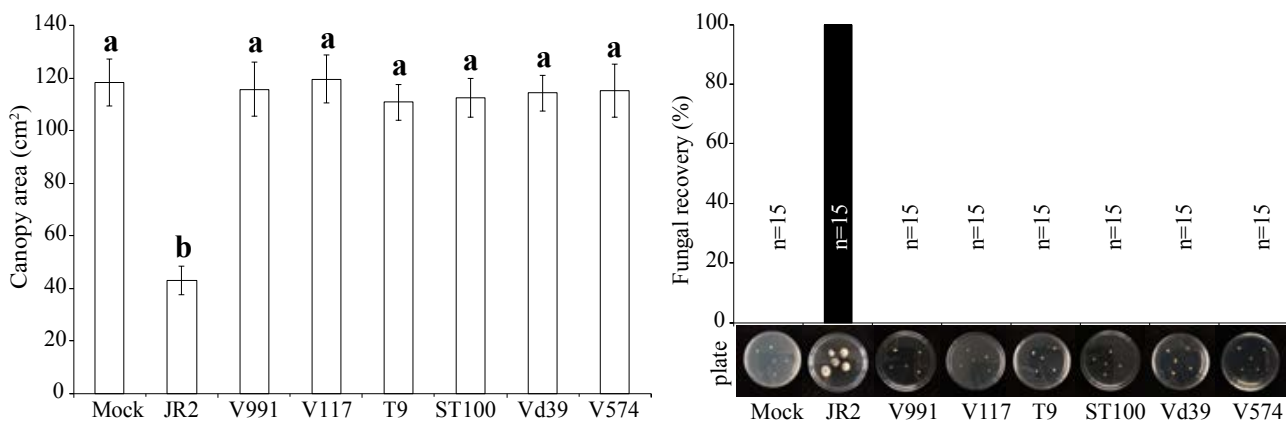

Figure 2. Disease assays of selected V. dahliae strains on tomato. (A) Typical appearance of tomato (cv. Moneymaker) plants upon mock-inoculation or inoculation with V. dahliae strain JR2, V991, V117, T9, ST100, Vd39 and V574 at 21 days post inoculation (dpi). (B) Average canopy area with standard deviations of five tomato plants inoculated with the various $V$. dahliae strains or upon mock-inoculation. Different letters indicate statistically significant differences (Student's $t$-test; $P<0.05$ ). (C) Fungal outgrowth at 10 days after plating of 15 stem sections on PDA medium. All experiments have been repeated three times and similar results were observed. 


\section{Comparative genomics identifies pathogenicity effector candidates}

Recently, a gapless, complete whole-genome assembly of tomato-pathogenic strain JR2 was generated (Faino et al., 2015) and used for the reference genome. Here, we used the genome sequences of eleven pathogenic strains (JR2, VdLs17, 2009-605, DVD3, DVD-S161, DVD-31, DVD-S26, DVD-S29, DVD-S94, V4 and CBS38166) and six non-pathogenic strains (ST100, V991, V117, T9, Vd39 and V574) for comparative genome analysis and identified $\sim 133 \mathrm{~kb}$ of sequence that is shared by all pathogenic strains and absent from all non-pathogenic strains, collectively encoding thirty-four genes. Five of these thirty-four genes encode putative effectors based on EffectorP (Sperschneider et al., 2016) (Table S2). Real-time PCR revealed that one of the five effector candidate genes (VDAG_JR2_Chr3g13460) is expressed during host colonization, with a peak in expression at 12 days post inoculation, while the remaining four effector candidates are not expressed (Figure 3).

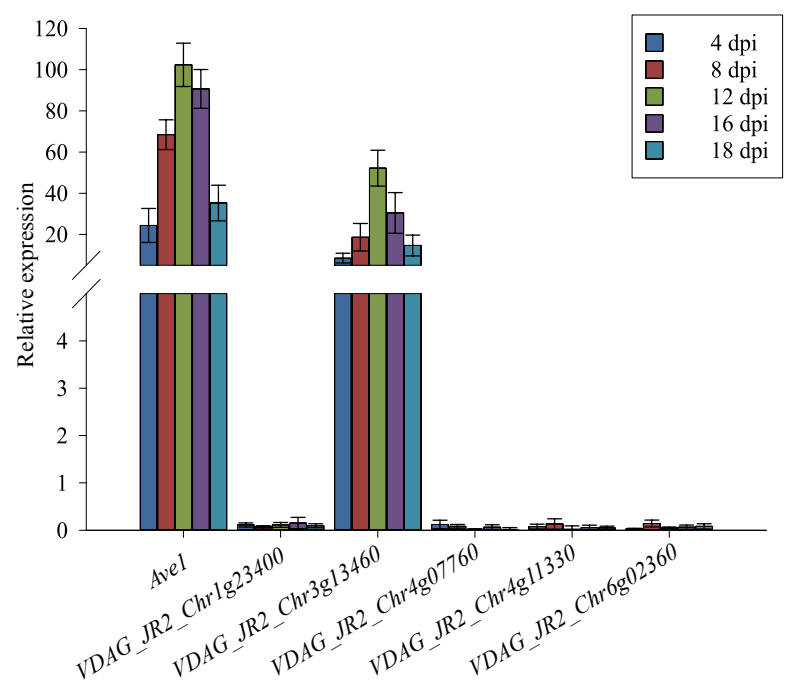

Figure 3. Expression of five candidate genes during V. dahliae tomato colonization. Twelve day-old tomato (cv. Moneymaker) seedlings were root-inoculated with $V$. dahliae strain JR2 and plants were harvested at intervals between 4 and 18 days post inoculation (dpi). Quantitative real-time PCR was performed to determine the relative expression of the five candidate genes using the V. dahliae GAPDH gene as a reference. The previously characterized effector gene Ave1 (de Jonge et al., 2012) was used as a positive control. Bars represent averages with standard deviation of two biological repeats.

Thus, we tentatively named this in planta-expressed effector gene as Tomi gene, for potentially mediating V. dahliae pathogenicity on tomato. The Tom 1 gene encodes a secreted protein of 127 amino acids, with no predicted functional domains as determined with InterPro analysis (Finn et al., 2017). To analyse potential Tom 1 gene diversity, we mined the genomes of 39 sequenced $V$. dahliae strains for Tom1 gene sequence variation. Intriguingly, only one single nucleotide polymorphism (SNP) was identified in one pathogenic strain, which results in a synonymous substitution that does not affect the sequence of the encoded protein. 


\section{The Tom1 effector is essential for V. dahliae pathogenicity on tomato}

To investigate the role of Tom 1 in pathogenicity of $V$. dahliae on tomato, we generated Tom 1 deletion mutants (Figure S1A) in V. dahliae strain JR2 and inoculated these on susceptible tomato plants. Compared to the wild type strain, Tom 1 deletion strains ( $\Delta \mathrm{Tom} \# 1$ and $\Delta \mathrm{Tom} \# 2$ ) appeared to have lost their ability to infect tomato, as no disease symptoms were observed (Figure 4A). This finding was corroborated by measurements of canopy area development, as $\Delta$ Tomi-inoculated plants developed a similar canopy area as mock-inoculated plants, while JR2-inoculated plants displayed significantly less canopy area development (Figure 4B). Moreover, fungal recovery assays showed that no fungus could be recovered from stem sections of $\Delta$ Tomi-inoculated plants, in contrast to the abundant fungal outgrowth that was monitored from JR2-inoculated plants (Figure 4C). Importantly, the loss of pathogenicity displayed by Tomi deletion strains can be restored upon introduction of a genomic construct that encodes the Tom 1 gene (Figure 4). Collectively, these data show that Tom 1 encodes a pathogenicity effector that is crucial for colonization of tomato plants.

\section{A}

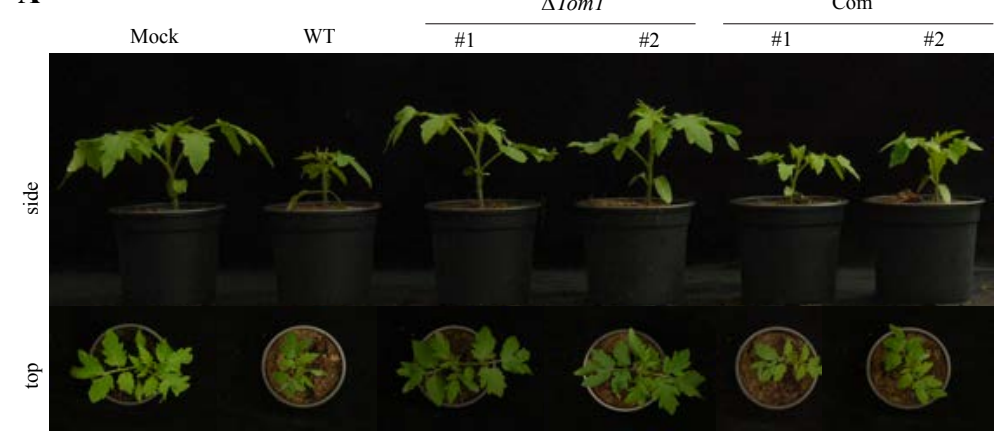

B

C
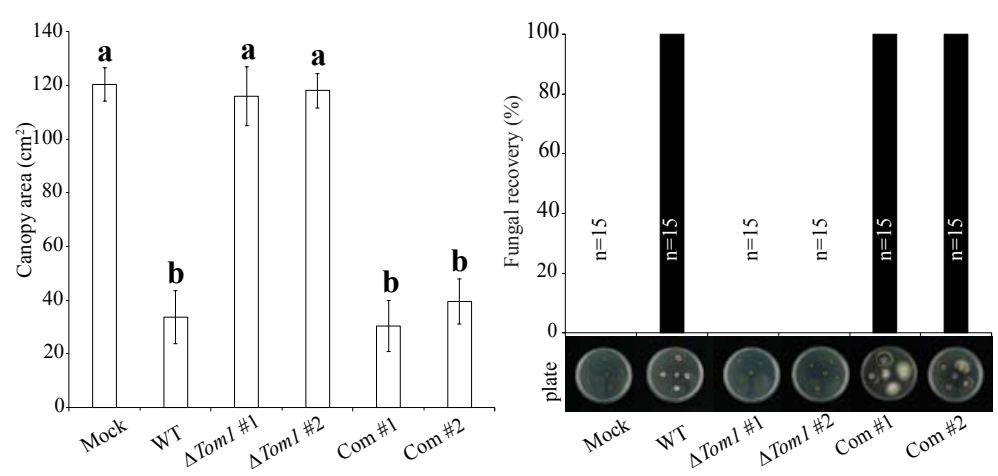

Figure 4. The Tomı gene is required for pathogenicity on tomato. (A) Typical appearance of tomato (cv. Moneymaker) plants upon mock-inoculation or inoculation with wild type strain JR2 (WT), two independent Tom 1 deletion strains ( $\Delta \mathrm{TomI} \# 1$ and $\Delta \mathrm{Tom} 1 \# 2$ ) and two independent Tom1 complementation strains (Com \#1 and Com \#2) at 21 days post inoculation (dpi). (B) Average canopy area with standard deviations of five tomato plants inoculated with the different $V$. dahliae strains or upon mock-inoculation. Different letters indicate statistically significant differences (Student's $t$-test; $P<0.05$ ). (C) Fungal outgrowth at 10 days after plating of 15 stem sections on PDA medium. All experiments have been repeated three times and similar results were observed. 


\section{Tom1 introduction is sufficient to cause pathogenicity on tomato}

Whilst not pathogenic on tomato, $V$. dahliae strain ST1oo is pathogenic on a diversity of other plant hosts, and thus likely possesses a complement of effector genes to subvert plant immunity (Chapter 2). To investigate whether the Tom1 gene is not only required, but perhaps even sufficient to mediate pathogenicity on tomato, we introduced the gene into the tomato non-pathogenic $V$. dahliae strain ST100 (Figure S1B).

Interestingly, Tom1-expressing V. dahliae ST10o strains gained the ability to infect tomato, as tomato plants inoculated with the Tom 1 expression strains showed a clear reduction in canopy area development when compared with plants that were inoculated with the wild-type ST1oo strain (Figure 5A-B). Fungal outgrowth assays confirmed that the Tom 1 expression strains colonized tomato plants while the wild-type ST10o strain was not able to do so, confirming that the transformants gained tomato pathogenicity (Figure $5 \mathrm{C}$ ).

Previous studies have shown that the Verticillium species V. tricorpus and V. nubilum have a saprophytic, rather than a pathogenic, lifestyle (Inderbitzin et al., 2011; Seidl et al., 2015). Thus, we tested whether V. tricorpus strain MUCL9792 and V. nubilum strain PD397 can gain tomato pathogenicity upon introduction of the Tom 1 gene (Figure S1C, D). As anticipated, tomato plants inoculated with the wild type $V$. tricorpus and $V$. nubilum strains showed no disease symptoms (Figure 6A, 7A). In contrast, Tom1-expressing transformants of both species gained the ability to infect tomato, as evidenced by significant reductions in canopy area development (Figure 6B, 7B), as well as by fungal recovery assays (Figure $6 \mathrm{C}, 7 \mathrm{C}$ ). Taken together, our data show that the Tom 1 effector is necessary and sufficient to cause Verticillium wilt disease on tomato. 
$\mathbf{A}$

A

V. dahliae ST100

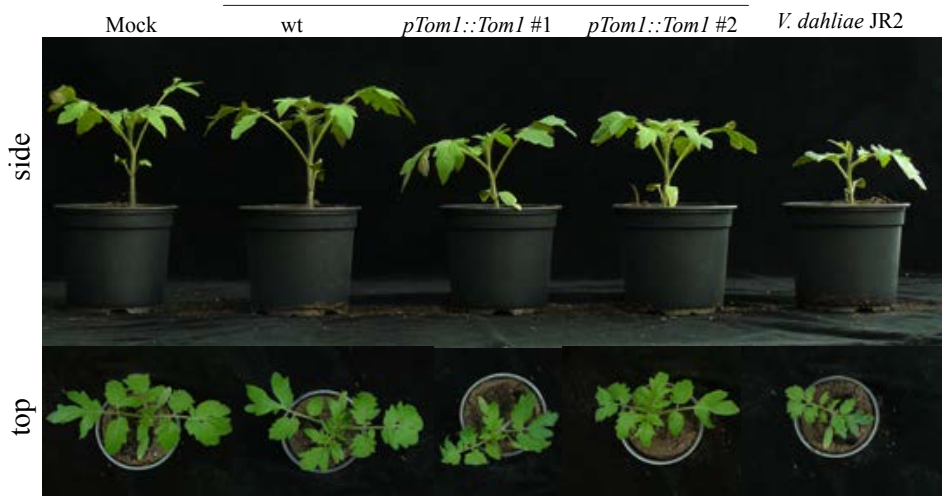

B

C
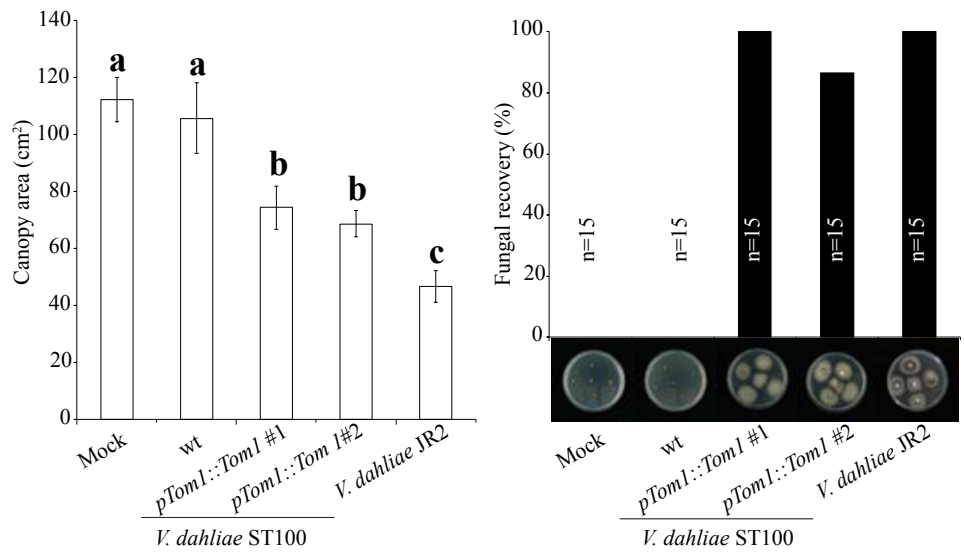

Figure 5. Introduction of Tom I into the non-pathogenic V. dahliae strain ST100 results pathogenicity on tomato.

(A) Typical appearance of tomato plants (cv. Moneymaker) upon mock-inoculation or inoculation with wild type strain ST100 (wt), two independent Tom1 expression transformants ( $\Delta \mathrm{Tom1} \# 1$ and $\Delta \mathrm{TomI} \# 2)$ and V. dahliae strain JR2 at 21 days post inoculation (dpi). (B) Average canopy area with standard deviations of five tomato plants inoculated with the various $V$. dahliae strains or upon mock-inoculation. Different letters indicate statistically significant differences (Student's $t$-test; $P<0.05$ ). (C) Fungal outgrowth at 10 days after plating of 15 stem sections on PDA medium. All experiments have been repeated three times and similar results were observed. 
A

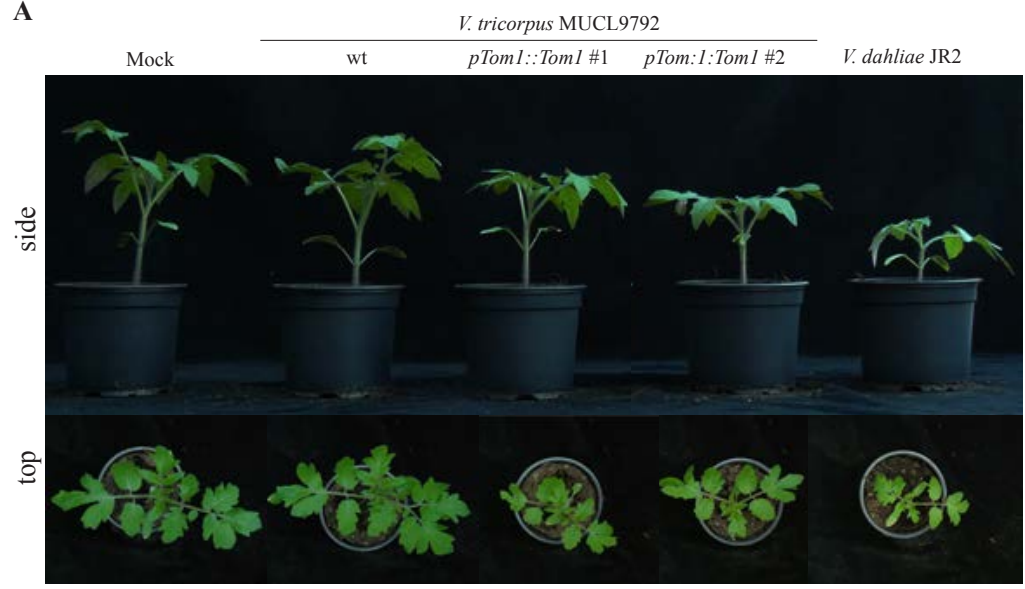

B

C
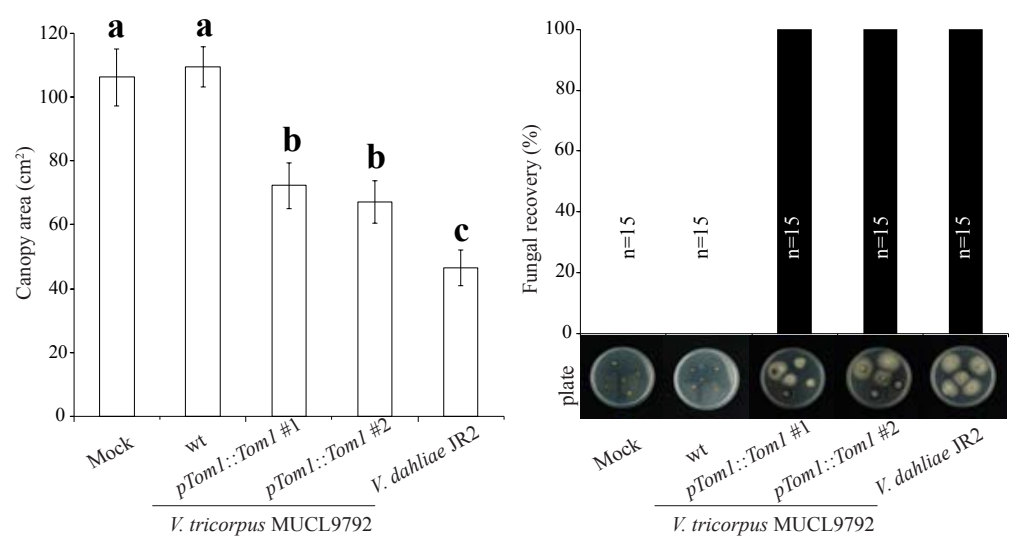

Figure 6. Introduction of Tom 1 into the saprophytic sister species V. tricorpus incites the ability to cause disease on tomato. (A) Typical appearance of tomato plants cv. Moneymaker upon mock-inoculation or inoculation with wild type V. tricorpus strain MUCL9792 (wt), two independent Tom1 expression transformants (pTom1::Tom1 \#1 and pTom1::Tom1 \#2) and V. dahliae strain JR2 at 21 days post inoculation (dpi). (B) Average canopy area with standard deviations of five tomato plants inoculated with the various fungal strains or upon mock-inoculation. Different letters indicate statistically significant differences (Student's $t$-test; $P<0.05$ ). (C) Fungal outgrowth at 10 days after plating of 15 stem sections on PDA medium. 
$\mathbf{A}$

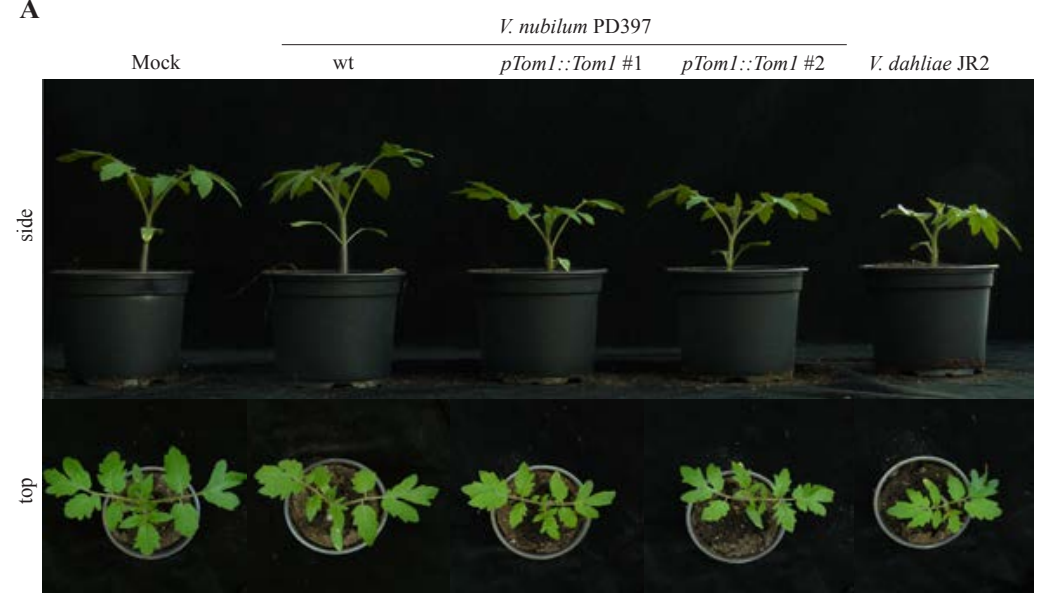

B

C
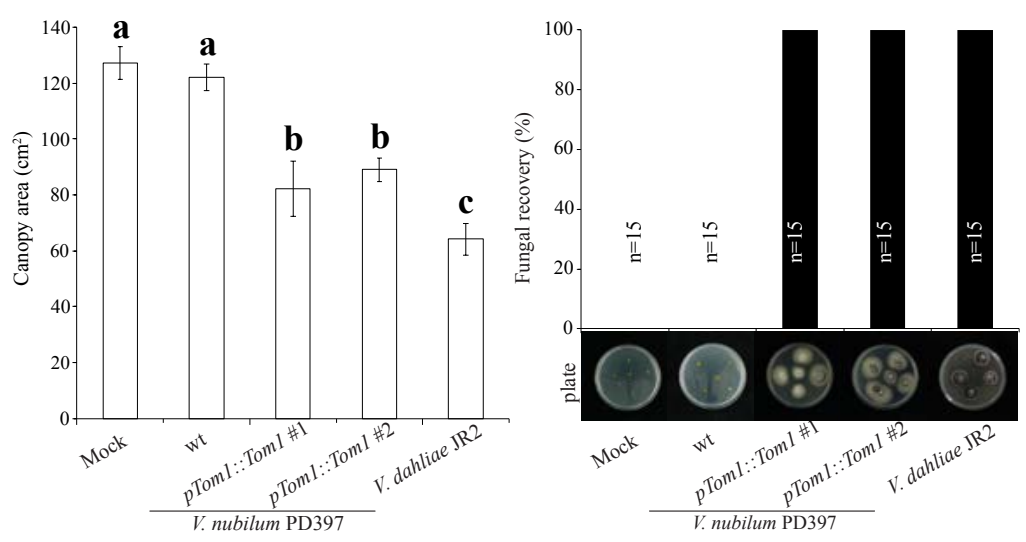

Figure 7. Introduction of Tom 1 into the saprophytic sister species V. nubilum enable to cause disease on tomato. (A) Typical appearance of tomato cv. Moneymaker upon mock-inoculation or inoculation with wild type V. nubilum strain PD397 (wt), two independent Tom1 expression transformants (pTom1::Tom1 \#1 and pTom1::Tom1 \#2) and V. dahliae strain JR2 at 21 days post inoculation (dpi). (B) Average canopy area with standard deviations of five tomato plants inoculated with the various fungal strains or upon mock-inoculation. Different letters indicate statistically significant differences (Student's $t$-test; $P<0.05$ ). (C) Fungal outgrowth at 10 days after plating of 15 stem sections on PDA medium. All experiments have been repeated three times and similar results were observed.

\section{Discussion}

Plant pathogens employ a multitude of effectors to modulate host immunity and promote disease (Rovenich et al., 2014, Toruño et al., 2016). As such, effectors of plant pathogens have been shown to display functional redundancy as mutation or deletion of single effector typically does not result in significant loss of virulence in host plants (de Jonge et al., 2011; Tan et al., 2015; Win et al., 2012). Therefore, individual contributions of single effector to host colonization are often considered to be dispensable. Nevertheless, a number of studies have shown that a single effector molecule is able to govern the pathogenicity of pathogen and enables disease 
establishment. For example, the transcriptional activator-like effector protein PthA has been shown to mediate pathogenicity of bacterial pathogen Xanthomonas citri on citrus (Swarup et al., 1991, 1992; Duan et al., 1999), as introduction of pthA into non-pathogenic strains confers the ability to cause disease symptoms on citrus. Additionally, the necrotrophic effector ToxA confers pathogenicity on wheat lines harbouring the corresponding susceptibility gene Tsn in the fungal wheat pathogens Pyrenophora tritici-repentis and in Parastagonospora nodorum (Friesen et al., 2006). We recently showed that the $\mathrm{D}$ effector confers pathogenicity on cotton, olive, Arabidopsis and Nicotiana benthamiana to V. dahliae strains of the defoliating pathotype (Chapter 2). In the present study, we show that a single effector, named Tom1, is required for pathogenicity of $V$. dahliae on tomato, as deletion of the effector gene leads to loss of the ability to colonize tomato plants (Figure 4). Moreover, introduction of this effector gene into a non-pathogenic $V$. dahliae isolate is sufficient to cause wilt disease on tomato (Figure 5). Thus, our data further reinforce the notion that a single effector can be sufficient to enable disease establishment.

Host specificity refers to the capability of pathogenic microbial species, or members of a species, to cause disease only on a particular range of defined plant hosts (Borah et al., 2018). The basis of host specificity, i.e. the molecular factors that determine the taxonomic range of hosts that a specific pathogenic microbe infects, is largely unknown (Nissan et al., 2006). Over the years, a number of studies have suggested that the host range of the pathogen is governed by the presence of host-specific virulence genes that contribute to disease establishment (van der Does and Rep, 2007). For instance, comparative analysis of the genome sequence of Fusarium oxysporum f.sp. lycopersici, a vascular wilt pathogen of tomato, with those of phylogenetically related Fusarium pathogens revealed that a mobile pathogenicity chromosome that contains various effector genes is responsible for host specificity on tomato, as transfer of this chromosome to non-pathogenic strains can render these pathogenic on tomato (Ma et al., 2010).

Several studies have also shown that even a single pathogenicity effector can act as a pathogen host-specificity determinant. For instance, the necrotrophic toxin effector ToxA not only mediates pathogenicity of the fungal wheat pathogens $P$. tritici-repentis and P. nodorum, but also defines host specificity on particular wheat genotypes (Friesen et al., 2006, 2008). In addition, HsvG, a type III effector of the gall-forming bacterial pathogen Pantoea agglomerans pv. gypsophilae, functions as a pathogenicity effector and determines host specificity on the ornamental plant Gypsophila paniculata L. Gypsophila. Mutations of HsvG abolished the ability of the pathogen to cause disease symptoms on G. paniculata L. Gypsophila, but still retained full pathogenicity on beet (Valinsky et al., 1998; Nissan et al., 2006). While V. dahliae strains are collectively characterized by their broad host range, pathogenic isolates display various levels of host specificity as individual isolates only infect a limited number of plant species (Bhat and Subbarao, 1999). So far, little is known about the genetic basis for host-specificity of $V$. dahliae strains. In this study, we show that the Tom effector enables $V$. dahliae strains to cause wilt disease on tomato. Interestingly, no Tom1 gene expression was observed at any of time points based on RNA-Seq of a time course of V. dahliae-infected Arabidopsis plants (data not shown). RNA-Seq of a time course of V. dahliaeinoculated N. benthamiana plants (Faino et al., 2012) showed that Tom1 is only expressed at 12 days post inoculation (data not shown), when major symptoms of disease, including wilting and 
significant stunting were already. Therefore, it is unlikely that the Tomi effector plays a role on Arabidopsis and N. benthamiana that is as determinant as it is on tomato. Moreover, V. dahliae strains of the D pathotype that lack the Tom 1 effector gene are unable to cause disease on tomato, but can still induce severe disease on Arabidopsis and N. benthamiana as shown in Chapter 2. Thus, we reason that the Tom 1 effector may act as a pathogenicity effector that determines host specificity of $V$. dahliae on tomato, but future experiments need to confirm this hypothesis.

So far, the most sustainable strategy to combat Verticillium wilt disease is the deployment of resistant cultivars (Fradin and Thomma, 2006). Although the tomato resistance $(R)$ gene Ver has been introduced into tomato cultivars to confer resistance to $V$. dahliae race 1 strains (Schaible et al., 1951; Kawchuk et al., 2001; Fradin et al, 2009), race 2 isolates that escape Ve1-mediated recognition through omission of the Aver effector gene arose and have steadily become a threat to tomato production (Pegg and Brady, 2002; Yadeta, 2012). Unfortunately, there is presently no $R$ gene against race 2 isolates on tomato (Yadeta, 2012). As effectors are important virulence molecules of pathogens that can be potentially recognized by plant hosts (Rodriguez-Moreno et al., 2018), they have been used as tools to probe plant germplasm to identify $R$ genes in resistance breeding (Laugé et al., 1998; Vleeshouwers and Oliver, 2014). This can be done by screening plant germplasm for $R$ genes that trigger robust immune responses, such as a hypersensitive response, upon transient expression of effector gene in planta or purified effector protein infiltration (Vleeshouwers et al., 2011). This effector-assisted breeding has been successfully used for identifying a number of $R$ genes in wild tomato species against the leaf mould pathogen Cladosporium fulvum (Laugé et al., 1998; Takken et al., 1999; de Wit, 2016) as well as against the late blight pathogen Phytophthora infestans in potato (Du et al., 2015; Vleeshouwers and Oliver, 2014). It is thus advisable that the Tom effector is used for screening tomato germplasm for $R$ genemediated recognition. Alternatively, host-induced gene silencing (HIGS), which involves host plants expressing double-stranded RNAs to silence essential pathogen genes, can be exploited. HIGS has been recently developed for controlling Verticillium wilt disease in cotton as well as in tomato (Zhang et al., 2016; Song and Thomma, 2016). Song and Thomma (2016) showed that HIGS can be utilized to suppress Verticillium wilt disease by silencing virulence genes of $V$. dahliae in tomato, which can offer an alternative to $R$ genes against $V$. dahliae. In addition, spray-induced gene silencing (SIGS) in which sRNAs are used to treat plants may be pursued as well (Wang et al., 2016; Wang et al., 2017; Wang and Jin, 2017). Since we show that the Tom1 effector mediates $V$. dahliae pathogenicity on tomato, we expect that the Tomi gene is an ideal silencing target for HIGS or SIGS, and thus establishment of Verticillium wilt resistance.

\section{Acknowledgements}

J.L.L acknowledges a PhD fellowship from the China Scholarship Council (CSC). B.P.H.J.T. is supported by a Vici grant of the Research Council for Earth and Life sciences (ALW) of the Netherlands Organization for Scientific Research (NWO). Bert Essenstam is acknowledged for excellent plant care at Unifarm. 


\section{References}

Bertels F, Silander OK, Pachkov M, Rainey PB, van Nimwegen E (2014) Automated reconstruction of wholegenome phylogenies from short-sequence reads. Mol Biol Evol 31: 1077-1088.

Bhat RG, Subbarao KV (1999) Host range specificity in Verticillium dahliae. Phytopathology 89: 1218-1225.

Borah N, Albarouki E, Schirawski J (2018) comparative methods for molecular determination of host-specificity factors in plant-pathogenic fungi. Int J Mol Sci 19: E863.

de Jonge R, Bolton MD, Thomma BPHJ (2011) How filamentous pathogens co-opt plants: the ins and outs of fungal effectors. Curr Opin Plant Biol 14: 400-406.

de Jonge R, Bolton MD, Kombrink A, van den Berg GC, Yadeta KA, Thomma BPHJ (2013) Extensivechromosomal reshuffling drives evolution of virulence in an asexual pathogen. Genome Res 23: 1271-1282.

de Jonge R, van Esse HP, Maruthachalam K, Bolton MD, Santhanam P, Saber MK, Zhang Z, Usami T, Lievens B, Subbarao KV, Thomma BPHJ (2012) Tomato immune receptor Ve1 recognizes effector of multiple fungal pathogens uncovered by genome and RNA sequencing. Proc Natl Acad Sci USA 109: 5110-5115.

Depotter JR, Deketelaere S, Inderbitzin P, Tiedemann AV, Höfte M, Subbarao KV, Wood TA and Thomma BPHJ (2016) Verticillium longisporum, the invisible threat to oilseed rape and other brassicaceous plant hosts. Molecular Plant Pathology 17: 1004-1016.

de Wit PJ (2016) Cladosporium fulvum Effectors: Weapons in the arms race with tomato. Annu Rev Phytopathol 54: $1-23$.

Dobinson K, Tenuta G, Lazarovits G (1996) Occurrence of race 2 of Verticillium dahliae in processing tomato fields in southwestern Ontario. Can J Plant Pathol 18: 55-58.

Duan YP, Castañeda A, Zhao G, Erdos G and Gabriel DW (1999) Expression of a single, host-specific, bacterial pathogenicity gene in plant cells elicits division, enlargement, and cell death. Mol Plant-Microbe Interact 12: 556-560.

Du J, Verzaux E, Chaparro-Garcia A, Bijsterbosch G, Keizer LC, Zhou J, Liebrand TW, Xie C, Govers F, Robatzek S, et al. (2015) Elicitin recognition confers enhanced resistance to Phytophthora infestans in potato. Nat Plants 1: 15034 .

Faino L, de Jonge R, Thomma BP (2012) The transcriptome of Verticillium dahliae-infected Nicotiana benthamiana determined by deep RNA sequencing. Plant Signal Behav 7: 1065-1069.

Faino L, Seidl MF, Datema E, van den Berg GC, Janssen A, Wittenberg AH, Thomma BP (2015) Single-molecule real-time sequencing combined with optical mapping yields completely finished fungal genome. MBio 6: e00936-15.

Faino L, Seidl MF, Shi-Kunne X, Pauper M, van den Berg GC, Wittenberg AH, Thomma BPHJ (2016) Transposons passively and actively contribute to evolution of the two-speed genome of a fungal pathogen. Genome Res 26: $1091-1100$.

Finn RD, Attwood TK, Babbitt PC, Bateman A, Bork P, Bridge AJ, Chang HY, Dosztányi Z, El-Gebali S, Fraser M, ea al. (2017) InterPro in 2017-beyond protein family and domain annotations. Nucleic Acids Res 45: D190-D199.

Fradin EF, Thomma BPHJ (2006) Physiology and molecular aspects of Verticillium wilt diseases caused by V. dahliae and V. albo-atrum. Mol Plant Pathol 7: 71-86.

Fradin EF, Zhang Z, Ayala JCJ, Castroverde CD, Nazar RN, Robb J, Liu C-M, Thomma BPHJ (2009) Genetic dissection of Verticillium wilt resistance mediated by tomato Ve1. Plant Physiol 150: 320-332.

Friesen TL, Faris JD, Solomon PS, Oliver RP (2008) Host-specific toxins: effectors of necrotrophic pathogenicity. Cell Microbiol 10: 1421-1428.

Friesen TL, Stukenbrock EH, Liu Z, Meinhardt S, Ling H, Faris JD, Rasmussen JB, Solomon PS, McDonald BA, Oliver RP (2006) Emergence of a new disease as a result of interspecific virulence gene transfer. Nat Genet 38: $953-956$.

Gaudriault S, Malandrin L, Paulin JP, Barny MA (1997) DspA, an essential pathogenicity factor of Erwinia amylovora showing homology with AvrE of Pseudomonas syringae, is secreted via the Hrp secretion pathway in a DspBdependent way. Mol Microbiol 26: 1057-1069. 
Gibriel HA, Thomma BPHJ, Seidl MF (2016) The age of effectors: Genome-based discovery and applications. Phytopathology 106: 1206-1212.

Gurung S, Short DPG, Hu X, Sandoya GV, Hayes RJ, Koike ST, Subbarao KV (2015) Host range of Verticillium isaacii and Verticillium klebahnii from artichoke, spinach and lettuce. Plant Dis 99: 933-938.

Inderbitzin P, Bostock RM, Davis RM, Usami T, Platt HW, Subbarao KV (2011) Phylogenetics and taxonomy of the fungal vascular wilt pathogen Verticillium, with the descriptions of five new species. PLOS ONE 6: e28341.

Inderbitzin P, Subbarao KV (2014) Verticillium systematics and evolution: how confusion impedes Verticillium wilt management and how to resolve it. Phytopathology 104: 564-574.

Jones JD, Dangl JL (2006) The plant immune system. Nature 444: 323-329.

Kawchuk LM, Hachey J, Lynch DR, Kulcsar F, van Rooijen G, Waterer DR, Robertson A, Kokko E, Byers R, Howard RJ (2001) Tomato Ve disease resistance genes encode cell surface-like receptors. Proc Natl Acad Sci USA 98: 6511-6515.

Klimes A, Dobinson KF, Klosterman SJ, Thomma BPHJ (2015) Genomics spurs rapid advances in ourunderstanding of the basic biology of vascular wilt pathogens in the genus Verticillium. Annu Rev Phytopathol 53: 181-198.

Klosterman SJ, Atallah ZK, Vallad GE, Subbarao KV (2009) Diversity, pathogenicity, and management of Verticillium species. Annu Rev Phytopathol 47: 39-62.

Klosterman SJ, Subbarao KV, Kang S, Veronese P, Gold SE, Thomma BPHJ, Chen Z, Henrissat B, Lee YH, Park J (2011) Comparative genomics yields insights into niche adaptation of plant vascular wilt pathogens. PLOS Pathog 7: e1002137.

Kombrink A, Rovenich H, Shi-Kunne X, Rojas-Padilla E, van den Berg G, Domazakis E, De Jonge R,Valkenburg DJ, Sánchez-Vallet A, Seidl MF, et al. (2017) Verticillium dahliae LysM effectors differentially contribute to virulence on plant hosts. Mol Plant Pathol 18: 596-608.

Laugé, R, Joosten, M HA J, Haanstra, JPW, Goodwin, P H, Lindhout, P, de Wit, PJGM (1998) Successful search for a resistance gene in tomato targeted against a virulence factor of a fungal pathogen. Proc Natl Acad Sci USA 95: 9014-9018.

Langmead B, Salzberg SL (2012) Fast gapped-read alignment with Bowtie 2. Nat Methods 9:357-359.

Li H, Durbin R (2010) Fast and accurate long-read alignment with Burrows-Wheeler transform. Bioinformatics 26: 589-595.

Ma LJ, van der Does HC, Borkovich KA, Coleman JJ, Daboussi MJ, Di Pietro A, Dufresne M, Freitag M, Grabherr M, Henrissat B, et al. (2010) Comparative genomics reveals mobile pathogenicity chromosomes in Fusarium. Nature 464: 367-373.

Nissan G, Manulis-Sasson S, Weinthal D, Mor H, Sessa G, Barash I (2006) The type III effectors HsvG and HsvB of gall-forming Pantoea agglomerans determine host specificity and function as transcriptional activators. Mol Microbiol 61: 1118-1131.

Pegg GF, Brady BL (2002) Verticillium wilts. Wallingord, Oxfordhire: CABI Publishing.

Petersen TN, Brunak S, von Heijne G, Nielsen H (2011) SignalP 4.0: discriminating signal peptides from transmembrane regions Nat Methods 8: 785-786.

Rodriguez-Moreno L, Ebert MK, Bolton MD, Thomma BPHJ (2018) Tools of the crook-infection strategies of fungal plant pathogens. Plant J 93: 664-674.

Rovenich H, Boshoven JC, Thomma BPHJ (2014) Filamentous pathogen effector functions: of pathogens, hosts and microbiomes. Curr Opin Plant Biol 20: 96-103.

Santhanam P, van Esse HP, Albert I, Faino L, Nürnberger T, Thomma BPHJ (2013) Evidence for functional diversification within a fungal NEP1-like protein family. Mol Plant-Microbe Interact 26: 278-286.

Schaible L, Cannon OS, Waddoups V (1951) Inheritance of resistance to Verticillium wilt in a tomato cross. Phytopathology 41: 986-990.

Seidl MF, Faino L, Shi-kunne X, van den Berg GCM, Bolton MD, Thomma BPHJ (2015) The genome of the saprophytic fungus Verticillium tricorpus reveals a complex effector repertoire resembling that of its pathogenic relatives. Mol Plant-Microbe Interact 28: 362-373.

Shi-Kunne X, Faino L, van den Berg GCM, Thomma BPHJ, Seidl MF (2018) Evolution within the fungal genus Verticillium is characterized by chromosomal rearrangement and gene loss. Environ Microbiol 20: 1362-1373. 
Sperschneider J, Gardiner DM, Dodds PN, Tini F, Covarelli L, Singh KB, Manners JM, Taylor JM (2016) EffectorP: predicting fungal effector proteins from secretomes using machine learning. New Phytol 210: 743-761.

Song Y, Liu L, Wang Y, Valkenburg DJ, Zhang X, Zhu L, Thomma BPHJ (2018) Transfer of tomato immune receptor Ve1 confers Ave1-dependent Verticillium resistance in tobacco and cotton. Plant Biotechnol J 16: 638-648.

Song Y, Thomma BPHJ (2016) Host-induced gene silencing compromises Verticillium wilt in tomato and Arabidopsis. Mol Plant Pathol 19: 77-89.

Stamatakis, A (2014) Raxml version 8: a tool for phylogenetic analysis and post-analysis of large phylogenies. Bioinformatics 30: 1312-1313.

Swarup S, De Feyter R, Brlansky RH, Gabriel DW (1991) A pathogenicity locus from Xanthomonas citri enables strains from several pathovars of $X$. campestris to elicit cankerlike lesions on citrus. Phytopathology 81: 802-809.

Swarup S, Yang Y, Kingsley MT and Gabriel DW (1992) An Xanthomonas citri pathogenicity gene, $p$ thA, pleiotropically encodes gratuitous avirulence on nonhosts. Mol Plant-Microbe Interact 5: 204-213.

Takken FL, Thomas CM, Joosten MH, Golstein C, Westerink N, Hille J, Nijkamp HJ, de Wit PJ, Jones JD (1999) A second gene at the tomato $\mathrm{Cf}-4$ locus confers resistance to cladosporium fulvum through recognition of a novel avirulence determinant. Plant J 20: 279-288.

Tan KC, Phan HT, Rybak K, John E, Chooi YH, Solomon PS, Oliver RP (2015) Functional redundancy of necrotrophic effectors-consequences for exploitation for breeding. Front Plant Sci 6: 501.

Thomma BPHJ, Seidl MF, Shi-Kunne X, Cook DE, Bolton MD, van Kan JAL, Faino L (2015) Mind the gap; seven reasons to close fragmented genome assemblies. Fungal Genet Biol 90: 24-30.

Valinsky, L., Manulis, S., Nizan, R., Ezra, D., Barash, I (1998) A pathogenicity gene isolated from the pPATH of Erwinia herbicola pv. gypsophila determines host specificity. Mol Plant Microbe Interact 11: 753-762.

van der Does HC, Rep M (2007) Virulence genes and the evolution of host specificity in plant-pathogenic fungi. Mol Plant-Microbe Interact 20: 1175-1182.

Vincent H, Wiersema J, Kell SP, Dobbie S, Fielder H, Dobbiea S, Castaneda-Alvarez NP, Guarino L, Eastwood R, Leon B, Maxted N (2013) A prioritized crop wild relative inventory to help underpin global food security. Biol Conserv 167: 265-275.

Vleeshouwers VG, Raffaele S, Vossen JH, Champouret N, Oliva R, Segretin ME, Rietman H, Cano LM, Lokossou A, Kessel G, et al. (2011) Understanding and exploiting late blight resistance in the age of effectors. Annu Rev Phytopathol 49: 507-531.

Vleeshouwers VG, Oliver RP (2014) Effectors as tools in disease resistance breeding against biotrophic, hemibiotrophic, and necrotrophic plant pathogens. Mol Plant-Microbe Interact 27: 196-206.

Wang M, Weiberg A, Lin FM, Thomma BPHJ, Huang HD, Jin H (2016) Bidirectional cross-kingdom RNAi and fungal uptake of external RNAs confer plant protection. Nat Plants 19: 16151

Wang M, Thomas N, Jin H (2017) Cross-kingdom RNA trafficking and environmental RNAi for powerful innovative pre-and post-harvest plant protection. Curr Opin Plant Biol 38: 133-141.

Wang M, Jin H (2016) Spray-Induced Gene Silencing: a powerful innovative strategy for crop protection. Trends Microbiol 25: 4-6.

Win J, Chaparro-Garcia A, Belhaj K, Saunders DG, Yoshida K, Dong S, Schornack S, Zipfel C, Robatzek S, Hogenhout SA, Kamoun S (2012) Effector biology of plant-associated organisms: concepts and perspectives. Cold Spring Harb Symp Quant Biol 77: 235-247.

Yadeta, KA (2012) Verticillium wilt resistance in Arabidopsis and tomato: identification and functional characterization. Wageningen University $\mathrm{PhD}$ thesis.

Zhang T, Jin Y, Zhao JH, Gao F, Zhou BJ, Fang YY, Guo HS (2016) Host-induced gene silencing of the target gene in fungal cells confers effective resistance to the cotton wilt disease pathogen Verticillium dahliae. Mol Plant 9: 939-942.

Zhou L, Zhao J, Guo W, Zhang TJ (2013) Functional analysis of autophagy genes via Agrobacterium-mediated transformation in the vascular Wilt fungus Verticillium dahliae. Genet Genomics 40: 421-431. 


\section{Supplemental information}

A

\begin{tabular}{|c|c|c|c|c|c|}
\hline \multirow{2}{*}{\multicolumn{2}{|c|}{ JR2 (wt) }} & \multicolumn{2}{|c|}{$\Delta$ Tom 1} & \multicolumn{2}{|c|}{ Com } \\
\hline & & $\# 1$ & $\# 2$ & $\# 1$ & \#2 \\
\hline Tom 1 & 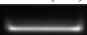 & & & 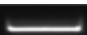 & 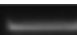 \\
\hline ITS & 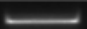 & 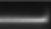 & 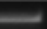 & 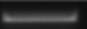 & 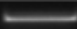 \\
\hline
\end{tabular}

C

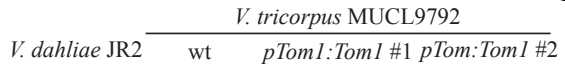

B

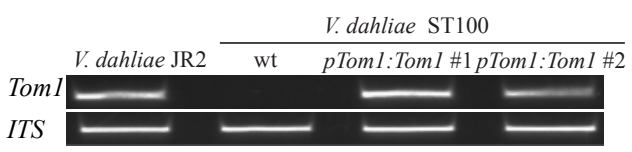

D

V. nubilum PD397

$\operatorname{Tom1}=-$

Figure S1. Verification of Tomı deletion and complementation strains. (A) Amplification of Tomı from genomic DNA of V. dahliae strain JR2, two independent Tom1 deletion strains ( $\Delta$ Tom1 \#1 and $\Delta$ Tom1 \#2) and two Tom1 complementation strains (Com \#1 and Com \#2). As an endogenous control, a fragment of the Verticillium ITS region was amplified. (B) Amplification of Tom 1 from genomic DNA of V. dahliae strain JR2, wild type V. dahliae strain ST10o (wt), and two independent Tom1 expression transformants (pTom1::Tom1 \#1 and pTom1::Tom1 \#2). As an endogenous control, a fragment of the Verticillium ITS region was amplified. (C) Amplification of Tom 1 from genomic DNA of V. dahliae strain JR2, wild type V. tricorpus strain MUCL9792 (wt), and two independent Tom1 expression transformants (pTom1::Tom1 \#1 and pTom1::Tom1 \#2). As an endogenous control, a fragment of the Verticillium ITS region was amplified. (D) Amplification of Tom1 from genomic DNA in V. dahliae strain JR2, wild type V. nubilum strain PD397 (wt), and two independent Tom1 expression transformants (pTom1::Tom1 \#1 and pTom1::Tom1 \#2). As an endogenous control, a fragment of the Verticillium ITS region was amplified. 
Table S1. V. dahliae strains used in this study.

\begin{tabular}{|c|c|c|c|c|}
\hline Strain & Sequencing platform & Reference & Origin & $\begin{array}{c}\text { Geographical } \\
\text { location }\end{array}$ \\
\hline $\mathrm{HN}$ & Illumina & $\mathrm{Xu}$ et al., 2012 & Cotton & China \\
\hline $\mathrm{cd}_{3}$ & Illumina & $\mathrm{Xu}$ et al., 2012 & Cotton & China \\
\hline VdLsi7 & PacBio & Faino et al., 2015 & Lettuce & USA \\
\hline $\mathrm{JR} 2$ & PacBio & Faino et al., 2015 & Tomato & Canada \\
\hline $\mathrm{Vd}_{57}$ & Illumina & Chapter 2 of this thesis & Strawberry & Germany \\
\hline V152 & Illumina & Kombrink et al., 2017 & Oak & Hungary \\
\hline $\mathrm{Vd}_{52}$ & Illumina & Kombrink et al., 2017 & Pepper & Austria \\
\hline van Dijk & Illumina & Kombrink et al., 2017 & Chrysanthemum & The Netherlands \\
\hline $\mathrm{BP} 2$ & Illumina & Zhang et al., 2012 & Cotton & China \\
\hline ST16.01 & Illumina & Chapter 2 of this thesis & Cotton & Syria \\
\hline $2009-605$ & Illumina & Chapter 2 of this thesis & Bell pepper & Ukraine \\
\hline $\mathrm{V} 4$ & Illumina & Keykhasaber, 2017 & Olive & Spain \\
\hline V200I & Illumina & Chapter 2 of this thesis & Strawberry & Germany \\
\hline $\mathrm{CBS} 38166$ & Illumina & de Jonge et al., 2012 & Tomato & Canada \\
\hline DVD-S26 & Illumina & de Jonge et al., 2012 & Soil & Canada \\
\hline VdLS16 & Illumina & de Jonge et al., 2012 & Lettuce & USA \\
\hline ST14.01 & Illumina & de Jonge et al., 2012 & Pistachio & USA \\
\hline DVD-S29 & Illumina & de Jonge et al., 2012 & Soil & Canada \\
\hline DVD-31 & Illumina & de Jonge et al., 2012 & Tomato & Canada \\
\hline DVD-161 & Illumina & de Jonge et al., 2012 & Tomato & Canada \\
\hline DVD-S94 & Illumina & de Jonge et al., 2012 & Soil & Canada \\
\hline DVD-3 & Illumina & de Jonge et al., 2012 & Potato & Canada \\
\hline V192I & Illumina & Chapter 2 of this thesis & Cotton & Spain \\
\hline JKG8 & Illumina & Kombrink et al., 2017 & Potato & The Netherlands \\
\hline $85 S$ & PacBio & Chapter 2 of this thesis & Sunflower & France \\
\hline Vd39 & Illumina & Chapter 2 of this thesis & Sunflower & Germany \\
\hline$V_{574}$ & Illumina & Milgroom et al., 2014 & Artichoke & Spain \\
\hline v700 & Illumina & Milgroom et al., 2014 & Artichoke & Spain \\
\hline v679 & Illumina & Milgroom et al., 2014 & Artichoke & Spain \\
\hline T9 & Illumina & Keykhasaber, 2017 & Cotton & USA \\
\hline V781I & Illumina & Chapter 2 of this thesis & Olive & Spain \\
\hline V138I & Illumina & Chapter 2 of this thesis & Cotton & Spain \\
\hline TM6 & Illumina & Keykhasaber, 2017 & Cotton & China \\
\hline V117 & Illumina & Keykhasaber, 2017 & Olive & Spain \\
\hline V991 & Illumina & Zhang et al., 2012 & Cotton & China \\
\hline $\mathrm{CQ}_{2}$ & PacBio & Chapter 2 of this thesis & Cotton & China \\
\hline ST100 & Illumina & de Jonge et al., 2012 & Soil & Belgium \\
\hline V76 & Illumina & Chapter 2 of this thesis & Cotton & Mexico \\
\hline 463 & Illumina & Chapter 2 of this thesis & Cotton & Mexico \\
\hline
\end{tabular}


Table S2. Tomato-pathogenic strain-specific genes identified by comparative genomics.

\begin{tabular}{|c|c|}
\hline Gene ID & Effector P (Yes/No) \\
\hline VDAG_JR2_Chrigo1610 & No \\
\hline VDAG_JR2_Chr1go1620 & No \\
\hline VDAG_JR2_Chr1g07050 & No \\
\hline VDAG_JR2_Chr1g07060 & No \\
\hline VDAG_JR2_Chr1g12270 & No \\
\hline VDAG_JR2_Chr1g13280 & No \\
\hline VDAG_JR2_Chr1g23400 & Yes \\
\hline VDAG_JR2_Chr2g00380 & No \\
\hline VDAG_JR2_Chr2g00780 & No \\
\hline VDAG_JR2_Chr2g03850 & No \\
\hline VDAG_JR2_Chr2g03860 & No \\
\hline VDAG_JR2_Chr2g12810 & No \\
\hline VDAG_JR2_Chr3g06060 & No \\
\hline VDAG_JR2_Chr3g09230 & No \\
\hline VDAG_JR2_Chr3g09240 & No \\
\hline VDAG_JR2_Chr3g09250 & No \\
\hline VDAG_JR2_Chr3g13460 & Yes \\
\hline VDAG_JR2_Chr4go2130 & No \\
\hline VDAG_JR2_Chr4go7760 & Yes \\
\hline VDAG_JR2_Chr4g11330 & Yes \\
\hline VDAG_JR2_Chr5g02370 & No \\
\hline VDAG_JR2_Chr5g08390 & No \\
\hline VDAG_JR2_Chr6go2360 & Yes \\
\hline VDAG_JR2_Chr6go2370 & No \\
\hline VDAG_JR2_Chr6go3370 & No \\
\hline VDAG_JR2_Chr6g03410 & No \\
\hline VDAG_JR2_Chr7g03300 & No \\
\hline VDAG_JR2_Chr7g05290 & No \\
\hline VDAG_JR2_Chr8go6110 & No \\
\hline VDAG_JR2_Chr8go6120 & No \\
\hline VDAG_JR2_Chr8go8950 & No \\
\hline VDAG_JR2_Chr8g09620 & No \\
\hline VDAG_JR2_Chr8g09630 & No \\
\hline VDAG_JR2_Chr8g09640 & No \\
\hline
\end{tabular}


Table S3. Primers used in this study.

\begin{tabular}{|c|c|c|}
\hline Primer name & Oligonucleotide sequence $\left(5^{\prime} \rightarrow 3^{\prime}\right)$ & Description $^{a}$ \\
\hline VdAve1-F & AGCTTTCTACGCTTGGA & qRT-PCR \\
\hline VdAve1-R & TTGGCTGGGATTGCT & qRT-PCR \\
\hline VDAG_JR2_Chrig23400-F & ACTGGAAGGTGACGATGTCC & qRT-PCR \\
\hline VDAG_JR2_Chr1g23400-R & GGGGTACGCTACCTTCTTCC & qRT-PCR \\
\hline VDAG_JR2_Chr3g13460-F & GCTTCACTGTGTCCGCTGTA & qRT-PCR \\
\hline VDAG_JR2_Chr3g13460-R & TCCATATCTTCCCAGGTTGG & qRT-PCR \\
\hline VDAG_JR2_Chr4go7760-F & ACCATGTAAGACTTGAGGCCA & qRT-PCR \\
\hline VDAG_JR2_Chr4go7760-R & AGCGCTCCTGACTGTTATGA & qRT-PCR \\
\hline VDAG_JR2_Chr4g11330-F & GCGTACCTCGATTCTCTTCG & qRT-PCR \\
\hline VDAG_JR2_Chr4g11330-R & TTCCGTAAGGTGGCTGAGAT & qRT-PCR \\
\hline VDAG_JR2_Chr6go2360-F & TTAACATGACGGACCACGAA & qRT-PCR \\
\hline VDAG_JR2_Chr6go2360-R & ACCCTGAAGCACAGCTTCTC & qRT-PCR \\
\hline Tomı-LBF & $\underline{\text { GGTCTTAAUTGTAATCGGCGATAGGAAGG }}$ & For Tomi deletion, left border, forward \\
\hline Tom1-LBR & GGCATTAAUGACTTTGGCAACATGGTGAA & For Tomı deletion, left border, reverse \\
\hline Tomi-RBF & GGACTTAAUAGATCACCCACCTGACCTTG & For TomI deletion, right border, forward \\
\hline TomI-RBR & GGGTTTAAUCGCGACTCTGCCTTCTTAAC & For TomI deletion, right border, reverse \\
\hline Tomi-com-F & $\begin{array}{l}\text { ggggacagctttcttgtacaaagtggaaTGTAATCG- } \\
\text { GCGATAGGAAGG }\end{array}$ & For Tom 1 complementation, forward \\
\hline Tom1-com-R & $\begin{array}{l}\text { ggggacaactttgtataataaagttgtCGCGACTCT- } \\
\text { GCCTTCTTAAC }\end{array}$ & For Tomi complementation, reverse \\
\hline ITS-F & AAAGTTTTAATGGTTCGCTAAGA & Fungal biomass quantification \\
\hline ITS-R & CTTGGTCATTTAGAGGAAGTAA & Fungal biomass quantification \\
\hline SI-RUB-F & GAACAGTTTCTCACTGTTGAC & Tomato rubisco gene \\
\hline SI-RUB-R & CGTGAGAACCATAAGTCACC & Tomato rubisco gene \\
\hline VdGAPDH-F & CGAGTCCACTGGTGTCTTCA & V. dahliae GAPDH, qRT-PCR \\
\hline VdGAPDH-R & CCCTCAACGATGGTGAACTT & V. dahliae GAPDH, qRT-PCR \\
\hline
\end{tabular}

${ }^{a}$ USER cloning sites in primer sequences are underlined; Gateway cloning sites in primer sequences are in lower cases. QRT-PCR: Quantitative Real Time-PCR. 


\section{References}

de Jonge R, van Esse HP, Maruthachalam K, Bolton MD, Santhanam P, Saber MK, Zhang Z, Usami T,Lievens B, Subbarao KV, Thomma BPHJ (2012) Tomato immune receptor Ve1 recognizes effector of multiple fungal pathogens uncovered by genome and RNA sequencing. Proc Natl Acad Sci USA 109:5110-5115.

Faino L, Seidl MF, Datema E, van den Berg GC, Janssen A, Wittenberg AH, Thomma BPHJ (2015) Single-molecule real-time sequencing combined with optical mapping yields completely finished fungal genome. mBio 6: e00936-00915.

Keykhasaber M (2017) Unravelling aspects of spatial and temporal distribution of Verticillium dahliae in olive, maple and ash trees and improvement of detection methods Wageningen University \& Research PhD thesis.

Kombrink A, Rovenich H, Shi-Kunne X, Rojas-Padilla E, van den Berg G, Domazakis E, De Jonge R, Valkenburg DJ, Sanchez-Vallet A, Seidl MF, et al. (2017) Verticillium dahliae LysMeffectors differentially contribute to virulence on plant hosts. Mol Plant Pathol 18: 596-608.

Milgroom MG, Jiménez-Gasco MM, Olivares-García C, Jiménez-Díaz RM (2016) Clonal expansion and migration of a highly virulent, defoliating lineage of Verticillium dahliae. Phytopathology 106: 1036-1046.

Xu F, Yang L, Zhang J, Guo X, Zhang X, Li G (2012) Prevalence of the defoliating pathotype of Verticillium dahliae on cotton in central China and virulence on selected cotton cultivars. J Phytopathol 160: 369-376.

Zhang B, Yang Y, Chen T, Yu W, Liu T, Li H, Fan X, Ren Y, Shen D, Liu L, Liu L, Dou D, ChangY (2012) Island cotton Gbve1 gene encoding a receptor-like protein confers resistance to both defoliating and non-defoliating isolates of Verticillium dahliae. PLOS ONE 7: e51091. 



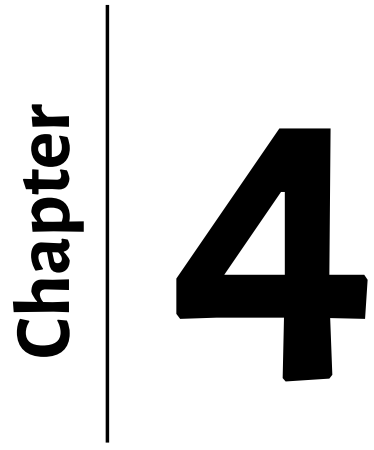

\section{The Verticillium dahliae effector Sun1 quantitatively contributes to virulence on sunflower}

Jinling Li ${ }^{1 \$}$, Hesham Gibriel'\$, Hélène Missonnier², Luigi Faino', Xiaoqian Shi-Kunne', Michael F. Seidl', Alban Jacques ${ }^{2 *}$, and Bart P.H.J. Thomma ${ }^{1 *^{*}}$ 


\begin{abstract}
Plant pathogens employ effector molecules to manipulate host physiology and establish themselves within their hosts. Verticillium dahliae is a highly destructive xylem-colonizing fungal pathogen that causes vascular wilt disease on diverse crops, such as tomato (Solanum lycopersicum), cotton (Gossypium hirsutum), and sunflower (Helianthus annuus). In this study, we show that only particular $V$. dahliae strains cause vascular wilt disease on sunflower. Based on comparative genomics of a sunflower pathogenic strain with a diversity of non-pathogenic strains, we identified two candidate effector genes that occur in the sunflower-pathogenic strain $85 \mathrm{~S}$ and that are highly expressed during host colonization. Intriguingly, these two candidate effector genes appeared to be identical copies that arose by a segmental duplication. Moreover, we show that this duplicated effector gene quantitatively contributes to V. dahliae virulence on sunflower but not on Nicotiana benthamiana or Arabidopsis thaliana.
\end{abstract}




\section{Introduction}

Plants and microbes engage in a diverse array of symbiotic relationships, ranging from pathogenic to mutualistic. Pathogenic interactions between plants and microbial pathogens have been described as ongoing arms races in which plants try to halt microbial ingress while pathogens attempt to continue symbiosis (Jones and Dangl, 2006; Thomma et al., 2011; Cook et al., 2015; Rovenich et al., 2014). In these arms races, plants have developed various types of immune receptors to detect invading pathogens through sensing various pathogen-derived or pathogen-induced molecular patterns, so-called invasion patterns, that betray microbial invasion to activate appropriate immune responses (Cook et al., 2015; Rodriguez-Moreno et al., 2017). In turn, to enable a parasitic life on their hosts, microbial pathogens secrete so-called effector molecules to deregulate host immune responses and support successful host infection (Jones and Dangl, 2006; Rovenich et al., 2014; Cook et al., 2015). Whereas most extensively studied effectors are proteinaceous molecules, other types of microbially secreted molecules, such as secondary metabolites and small RNAs, have also been described as non-canonical effectors (Wang et al., 2015; Rodriguez-Moreno et al., 2018). Interestingly, ongoing research has revealed that effectors are not exclusively secreted by plant pathogens but other types of symbionts such as endophytes and mutualists similarly employ effectors to establish host interactions (Rovenich et al., 2014). For instance, the mutualistic fungus Laccaria bicolor secretes the effector protein MiSSP7 to interact with jasmonic acid (JA) signalling components of the host and facilitate symbiosis by suppressing host immunity (Plett et al., 2014). Moreover, as all symbionts establish themselves in environments that comprise other microbes including antagonists, effector molecules may also act in self-defense and competition with microbiome co-inhabitants (Rovenich et al., 2014; Snelders et al., 2018).

Vascular wilts caused by soil-borne fungal species of the Verticillium genus are among the most devastating plant diseases worldwide with an estimated annual loss of $€ 3$ billion in the 20 most affected hosts (Depotter et al., 2016). Within the Verticillium genus, V. dahliae is the most notorious pathogenic species that has the ability to infect over 200 plant species including highvalue crops such as tomato (Solanum lycopersicum), cotton (Gossypium hirsutum), and sunflower (Helianthus annuus) (Inderbitzin and Subbarao, 2014). V. dahliae invades plants via roots and then colonizes the water-conducting xylem vessels, which disrupts water transport and causes the characteristic wilting symptoms (Fradin and Thomma, 2006; Klosterman et al., 2011). Verticillium wilt disease management is notoriously challenging since conventional fungicides are generally ineffective to eradicate the pathogen once it has entered the xylem tissues (Fradin and Thomma, 2006; Klosterman et al., 2009). Moreover, due to the broad host range of the pathogen and long viability of the resting structures in the soil, cultivation practices such as crop rotation do not result in efficient disease management (Pegg and Brad, 2002; Fradin and Thomma, 2006). Although genetic resistance has been considered as a preferred strategy for disease control, only few Verticillium wilt resistance genes have been identified so far (Schaible et al., 1951; Simko et al., 2004; Fradin and Thomma, 2006). For example, in tomato, immune receptor Ve1 confers resistance to race $1 \mathrm{~V}$. dahliae and Verticillium albo-atrum strains through recognition of the race 1-specific effector protein Ave1 (Fradin et al., 2009; de Jonge et al., 2012). Transfer of tomato Ve1 
into other crop species like tobacco and cotton can provide resistance against race 1 Verticillium strains (Song et al., 2018). The high economic impact of Verticillium wilt disease, combined with the absence of curative treatments, substantiates the need for developing novel disease control strategies. Recently, host-induced gene silencing (HIGS), which involves host expression of double-stranded RNAs to target and silence essential pathogen genes to confer host resistance, has been developed for controlling Verticillium wilt disease in cotton and tomato (Song and Thomma, 2016; Zhang et al., 2016).

To design novel control strategies to combat Verticillium wilt disease, a thorough understanding of molecular mechanisms underlying pathogenesis of $V$. dahliae is of fundamental importance (Fradin and Thomma, 2006). Over the past years, forward genetic approaches such as random mutagenesis and proteomic techniques have been performed to identify a number of pathogenicity and virulence factors of V. dahliae (El-Bebany et al., 2010; Santhanam, 2014; Chen et al., 2016; Zhang et al., 2017). The ease and low cost of present-day genome sequencing (Faino and Thomma, 2014) have made it possible to sequence multiple $V$. dahliae isolates from various host niches. Using comparative population genomics, we previously identified the $V$. dahliae race-specific effector Ave1 that is crucial for fungal aggressiveness during tomato colonization (de Jonge et al., 2012). Subsequently, Ave1 was demonstrated to contribute to fungal virulence not only on tomato plants that lack the Ver resistance gene, but also on tobacco, A. thaliana, as well as on cotton (de Jonge et al., 2012; Song et al., 2018). More recently, we applied comparative genomics to identify the $V$. dahliae defoliating (D) pathotype-specific effector (named D effector) that is responsible for defoliation symptoms on cotton and olive (Chapter 2). Interestingly, we found that the $\mathrm{D}$ effector acts as a pathogenicity determinant of $V$. dahliae on diverse host species (Chapter 2). Using a similar approach, we uncovered a $V$. dahliae effector (named Tom1) that mediates pathogenicity of $V$. dahliae on tomato (Chapter 3).

Sunflower is a worldwide planted oil crop that is known to maintain stable yields across a wide variety of environmental conditions (Kane and Rieseberg, 2007; Badouin et al., 2017). However, Verticillium wilt disease constitutes an important constraint for the production of sunflower (Yao et al., 2011; Guo et al., 2017). Despite huge yield losses caused by V. dahliae, so far relatively little is known about how the pathogen causes disease on sunflower. In this study, comparative genome analysis of a sunflower pathogenic strain with multiple non-pathogenic strains was performed to identify $V$. dahliae effector gene candidates that are essential for virulence on sunflower.

\section{Materials and methods}

\section{Fungal strains and plant materials}

Verticillium dahliae strains (Table S1) were grown on potato dextrose agar (PDA) at $22^{\circ} \mathrm{C}$. Sunflower (H. annuus cv. Tutti), Nicotiana benthamiana, cotton (G. hirsutum cv. Simian3), tomato (S. lycopersicum cv. Moneymaker), and Arabidopsis thaliana (Col-o) plants were grown under controlled greenhouse conditions (Unifarm, Wageningen, The Netherlands) at $21^{\circ} \mathrm{C} / 19^{\circ} \mathrm{C}$ during 16/8 hours day/night periods, respectively, with 70\% relative humidity ${ }^{2}$. 


\section{V. dahliae genome sequences and phylogenetic tree construction}

Genomes of the four V. dahliae strains (JR2, VdLs17, CQ2, and 85S) were sequenced using SingleMolecule Real-Time (SMRT) sequencing technology (Faino et al., 2015; Depotter et al., 2018) (Table S1). Additionally, genomes of V. dahliae strains V574 and BP2 were sequenced using the Illumina HiSeq 2000 (Chapter 2 of this thesis) (Table S1). A phylogenetic tree of the $V$. dahliae strains was generated with REALPHY (version 1.12) (Bertels et al., 2014) using Bowtie2 (Langmead and Salzberg, 2012) to map genomic reads against the reference $V$. dahliae strain JR2. A maximum likelihood phylogenetic tree was inferred using RAxML (version 8.2.8) with the GTRGAMMA model and 500 bootstrap replicates (Stamatakis, 2014).

\section{V. dahliae strain $85 \mathrm{~S}$ effector identification}

In order to identify effector genes of $V$. dahliae strain $85 \mathrm{~S}$ that mediate aggressiveness on sunflower plants, we mapped DNA reads from non-pathogenic strains to the genome assembly of $V$. dahliae strain $85 \mathrm{~S}$ using BWA (BWA-mem algorithm) (vo.7.12) (Li and Durbin, 2010). Read coverage mapping of all $V$. dahliae strains over the $85 \mathrm{~S}$ reference genome was calculated in 100 bp windows using BEDTools coverage (v2.25) (Quinlan and Hall, 2010). Genomic regions were considered present if the breadth of coverage $\geq 50 \%$, while those with breadth of coverage $<50 \%$ were considered absent. lineage-specific (LS) genomic regions, here defined as genomic regions that are only present in $V$. dahliae strain $85 \mathrm{~S}$ and absent in all other non-pathogenic $V$. dahliae strains, were determined and genes localized within these LS regions were extracted using BEDtools intersect (v2.25) (Quinlan and Hall, 2010).

A gene annotation for $V$. dahliae strain $85 \mathrm{~S}$ was generated using the Maker2 pipeline (Holt and Yandell, 2011). To identify potential effector genes of strain $85 \mathrm{~S}, \mathrm{~N}$-terminal signal peptides were first predicted with SignalP (version 4.1) (Petersen et al., 2011). Subsequently, the machinelearning approach applied in EffectorP (version 1.0) (default parameters) was used (Sperschneider et al., 2016). Effector genes localized within LS regions were extracted using BEDtools intersect (Quinlan and Hall, 2010). Syntenies between effector gene copies was analysed using NUCmer (version 3.1) (-- maxmatch), which is part of the MUMer package (Kurtz et al., 2004), and visualized using R package genoPlotR (vo.8.6) (Guy et al., 2010).

\section{Gene expression analysis}

To determine expression of Sun1 in planta, 12-day-old sunflower seedlings were root-inoculated with conidiospores of $V$. dahliae strain $85 \mathrm{~S}$ as described previously (Fradin et al., 2009). Stems of inoculated sunflower plants were harvested at $9,16,24,32$ and 40 days post inoculation (dpi), flash frozen in liquid nitrogen and stored at $-80^{\circ} \mathrm{C}$ for total RNA extraction. Total RNA extraction and cDNA synthesis were performed as described previously (Song et al., 2018). Quantitative real time PCR was preformed to detect the expression of Sun1 using primers Sun1-F(RT-PCR) and Sun1-R(RT-PCR), whereas the V. dahliae GAPDH (glyceraldehyde-3-phosphate dehydrogenase) gene served as an endogenous control (Table S2). 


\section{Generation of Sun1 deletion strains}

To generate single Sunı gene deletion constructs, sequence stretches of approximately $1.1 \mathrm{~kb}$ upstream and $1.2 \mathrm{~kb}$ downstream of the Sun1 coding sequence were amplified from genomic DNA of $V$. dahliae strain $85 \mathrm{~S}$ using primer pairs SKO-Sun1-LBF/LBR and SKO-Sun1-RBF/RBR (Table $\mathrm{S} 2$ ). The amplicons were cloned into the pRF-HU2 vector as described previously (Frandsen et al., 2008) and the resulting deletion construct was transformed into strain $85 \mathrm{~S}$ via Agrobacterium tumefaciens-mediated transformation as described earlier (Santhanam, 2012). Putative deletion transformants were selected on PDA supplemented with cefotaxime $(200 \mu \mathrm{g} / \mathrm{mL})$ and hygromycin $\mathrm{B}(50 \mu \mathrm{g} / \mathrm{mL})$ and homologous gene replacement was verified by PCR analysis using outsider primer $\mathrm{F}$ and outsider primer $\mathrm{R}$ (Table $\mathrm{S} 2$ ).

To generate Sunı double deletion mutants, sequence stretches of approximately $1.3 \mathrm{~kb}$ upstream and $1.1 \mathrm{~kb}$ downstream of the Sun1 coding sequence were amplified using primer pairs DKOSun1-LBF/LBR and DKO-Sun1-RBF/RBR (Table S2). The amplified products were cloned into vector pRF-NU2. Next, the gene replacement construct was transformed into a Sun1 single deletion mutant. Putative double deletion transformants were selected on PDA supplemented with nourseothricin $(15 \mu \mathrm{g} / \mathrm{mL})$ and hygromycin B $(50 \mu \mathrm{g} / \mathrm{mL})$ and confirmed by PCR analysis using outsider primer $\mathrm{F}$ and outsider primer $\mathrm{R}$ (Table $\mathrm{S} 2$ ).

\section{Pathogen inoculations and fungal recovery assays}

Inoculations were performed on sunflower, cotton, tomato, $N$. benthamiana, and A. thaliana plants as previously described (Fradin et al., 2009). Disease symptoms were scored up to 21 (tomato, $A$. thaliana, and N. benthamiana), 28 (cotton), or 45 (sunflower) days post inoculation (dpi). Plants were photographed and Image $J$ was used to determine the canopy areas of tomato while a rectilinear scale was used to measure plant height of sunflower. Fungal biomass in A. thaliana, $N$. benthamiana, and sunflower were determined as previously described (Song et al., 2018). Real-time quantitative PCR (qPCR) was conducted to quantify fungal colonization (Ellendorff et al., 2009) using the fungus-specific primers ITS-F and ITS-R (Table S2). Primers targeting the sunflower elongation factor 1-alpha (EF-1 $\alpha$ ) gene, A. thaliana RuBisCo, and N. benthamiana RuBisCo gene were used as endogenous plant controls as described earlier (Table S2) (Song et al., 2018).

Fungal recovery assays were conducted to detect $V$. dahliae strains in planta as previously described (Fradin et al., 2009). Stem sections were harvested at 45 days post inoculation (dpi), surface-sterilized and sliced into small discs. For each V. dahliae strain, 12 to 15 stem slices from five pooled plants transferred onto PDA supplemented with chloramphenicol $(35 \mu \mathrm{g} / \mathrm{mL})$ and incubated at $22^{\circ} \mathrm{C}$ for 7 days. 


\section{Results}

\section{Verticillium dahliae inoculations on sunflower}

Various strains of $V$. dahliae have been sequenced in our laboratory but their capacity to infect sunflower remained unknown (Klosterman et al., 2011; de Jonge et al., 2013; Thomma unpublished data). Therefore, in addition to the sunflower-pathogenic $V$. dahliae strain $85 \mathrm{~S}$, five strains of which the genome has been sequenced were tested for their ability to infect sunflower. These comprise JR2 and VdLs17, for which a gapless genome assembly has previously been generated (Faino et al., 2015) and that are known to cause Verticillium wilt on tomato and lettuce, respectively, and three V. dahliae strains that are phylogenetically distant from JR2 and VdLs17, namely the cottonpathogenic strains CQ2, BP2 and V574 (Figure S1). Interestingly, in contrast to strain $85 \mathrm{~S}$ that induced clear stunting, chlorosis and wilting on inoculated sunflower plants, JR2, CQ2, VdLs17, BP2 and V574 failed to cause visible disease symptoms, suggesting that these strains do not have the capacity to infect sunflower (Figure $1 \mathrm{~A}-\mathrm{B}$ ).

This finding was further corroborated by fungal recovery assays, as plating of stem sections of the inoculated plants on agar medium resulted in fungal outgrowth from all sections of $85 \mathrm{~S}$-inoculated plants while no fungal growth was recovered from stem sections of plants inoculated with any of the other strains (Figure $1 C$ ). Thus, except for V. dahliae strain $85 \mathrm{~S}$ that can be classified as a sunflower pathogenic strain, all other strains (JR2, CQ2, VdLs17, BP2 and V574) were classified as non-pathogenic on sunflower.

\section{Comparative genomics identifies the effector gene Sun1}

We aimed to identify effectors that mediate aggressiveness on sunflower plants by comparative genomics of pathogenic strain $85 \mathrm{~S}$ and the non-pathogenic strains JR2, VdLs17, CQ2, BP2, and V574. To this end, the genomes of V. dahliae strains 85S, CQ2, VdLs17, as well as JR2 were sequenced with PacBio technology (Faino et al., 2015; Depotter et al., 2018). In addition, the genomes of BP2 and V574 were sequenced by using the Illumina HiSeq 2000 (Chapter 2 of this thesis). Gene annotation for V. dahliae strain $85 \mathrm{~S}$ using the Maker2 pipeline (Holt and Yandell, 2011) yielded a total of 10,580 protein-coding genes. Of these genes, 1,062 genes were predicted to encode putative secreted proteins. Subsequently, we used the machine-learning approach applied in EffectorP (Sperschneider et al., 2016) to identify 174 candidate effectors for V. dahliae strain 85S. To identify $85 \mathrm{~S}$-specific effector genes, a reference-based alignment strategy was used. All reads of the non-pathogenic $V$. dahliae strains were mapped onto the genome assembly of strain $85 \mathrm{~S}$ and lineage specific (LS) regions for which no synteny occurred in any of the non-pathogenic strains were extracted. This comparative analysis revealed 6,924 LS sequences of $100 \mathrm{bp}$ in size, collectively comprising 159 genes including five that encode secreted proteins. Of these five genes, two were classified as effector genes based on EffectorP. Remarkably, both effector genes were found to encode a putative effector of 125 amino acids and share $100 \%$ sequence identity, despite the observation that they are located on two different contigs, namely unitig_14 and unitig_4 (Figure 2A). Moreover, alignment of unitig_14 and unitig_4 revealed that genomic regions surrounding the two genes are completely identical as well (Figure $2 \mathrm{~B}$ ), suggesting that these 
arose by a segmental duplication. We named the putative effector genes Sun1, as candidates for mediating virulence on sunflower. Similar to most fungal effectors reported so far (Stergiopoulos and de Wit, 2009; de Jonge et al., 2011), no Sunı homologs were found in other species.

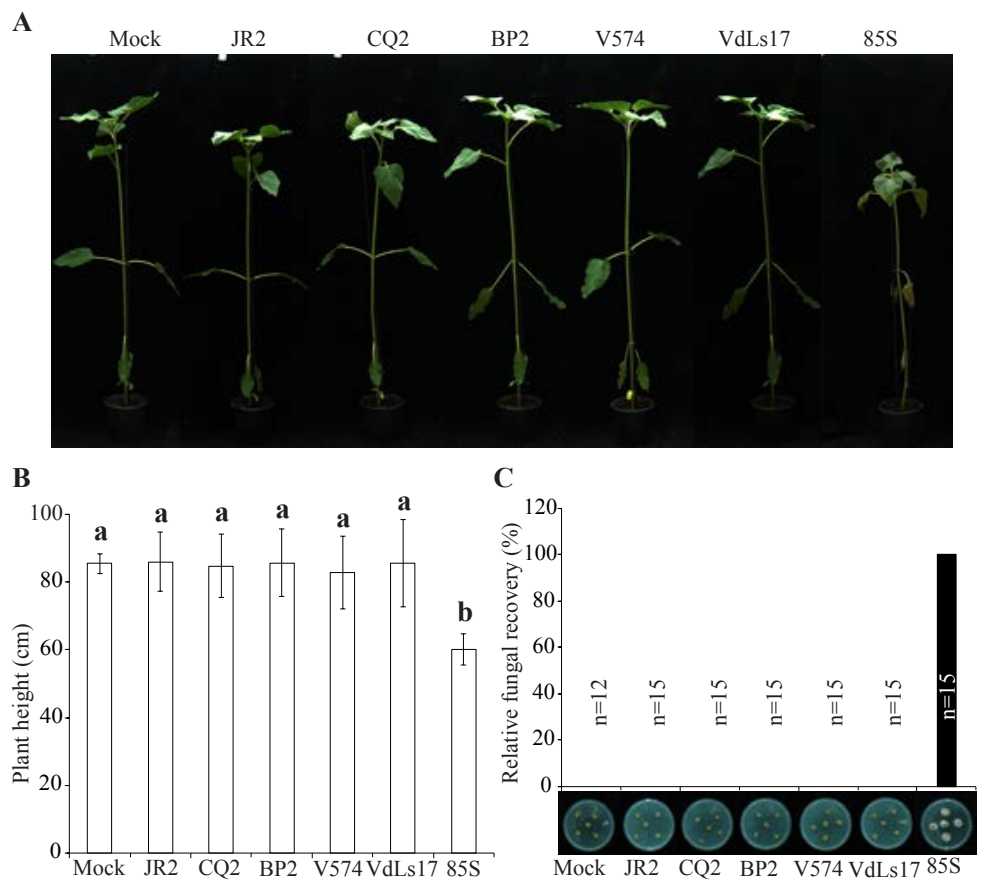

Figure 1. Phenotypes of sunflower plants inoculated with sequenced Verticillium dahliae strains. (A) Side view of sunflower (cv. Tutti) plants upon mock-inoculation or inoculation with V. dahliae strains JR2, CQ2, BP2, V574, VdLs17 and $85 \mathrm{~S}$ at 45 days post inoculation (dpi). Besides the stunting, the plant inoculated with strain $85 \mathrm{~S}$ also displays chlorosis and wilting symptoms. (B) Quantification of $V$. dahliae-induced plant stunting at 45 days post inoculation (dpi). Bars represent the average height of five plants with standard deviation. Different letter labels indicate statistically significant differences (Student's $t$-test; $P<0.05$ ). (C) Fungal outgrowth at 10 days after plating of sunflower stem sections harvested at 45 (dpi) with various $V$. dahliae strains. The bar graph shows the percentage of stem section slices from which fungal outgrowth was observed. Inoculation experiments were performed with five plants for each fungal strain and independently repeated twice with similar results. 
A

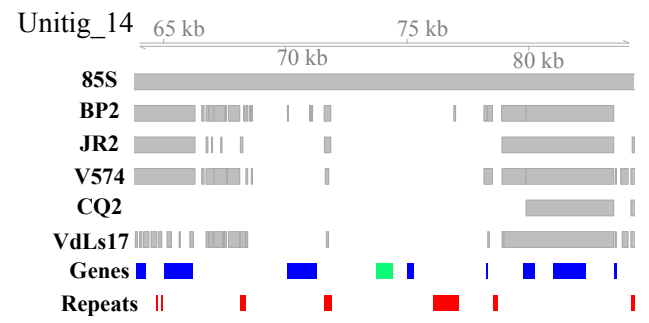

Unitig_4

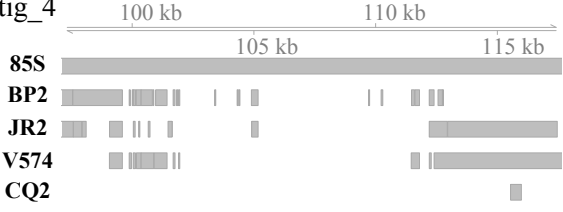

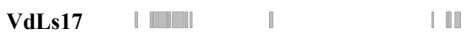

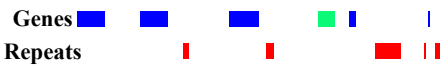

B

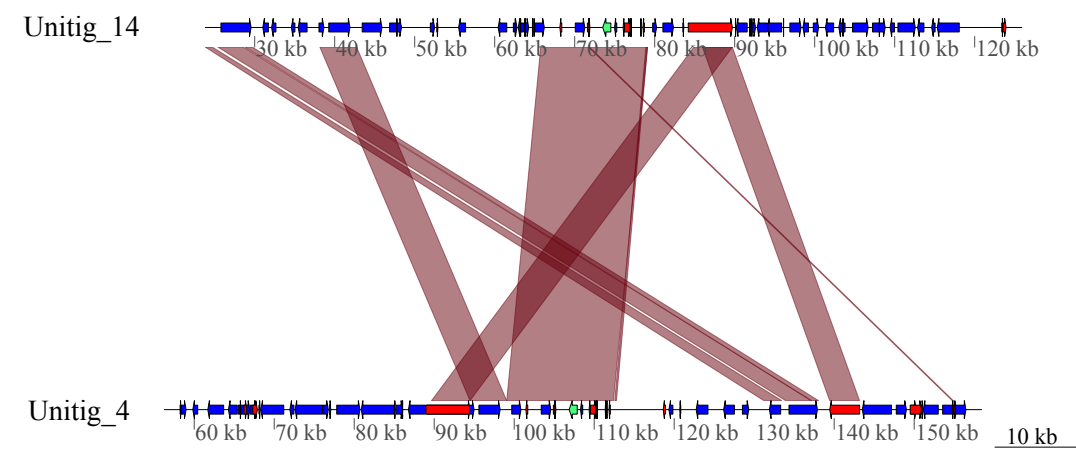

Figure 2. Comparative genomics of V. dahliae strains identifies the Sun1 effector gene. (A) The alignment of reads derived from non-pathogenic V. dahliae strains to the sunflower-pathogenic V. dahliae strain $85 \mathrm{~S}$ reveals two LS regions of $\sim 4 \mathrm{~kb}$ on contigs unitig_14 and unitig_4. Note, besides other genes (blue), these two LS regions harbor the effector gene Sun (green) that is flanked by repeats (red), and solely present in the strain $85 \mathrm{~S}$. (B) Synteny analyses of unitig_4 and unitig_14 harboring the Sunı effector gene. A region encompassing $50 \mathrm{~kb}$ upstream and downstream of Sunt effector gene is shown. Highly syntenic regions (>xx\% identity) upstream and downstream of this effector gene on unitig_14 and unitig_4 are indicated with red ribbons.

To further assess the potential of Sun1 as a virulence effector on sunflower, the transcript level of Sun1 during infection of $V$. dahliae strain $85 \mathrm{~S}$ on sunflower was investigated using real-time PCR in a time course experiment up to 40 days post inoculation (dpi). This analysis revealed that Sun1 increased significantly at 9 days post-inoculation (dpi), with a peak in expression at $16 \mathrm{dpi}$ and remained relatively high at later time points (Figure 3 ).

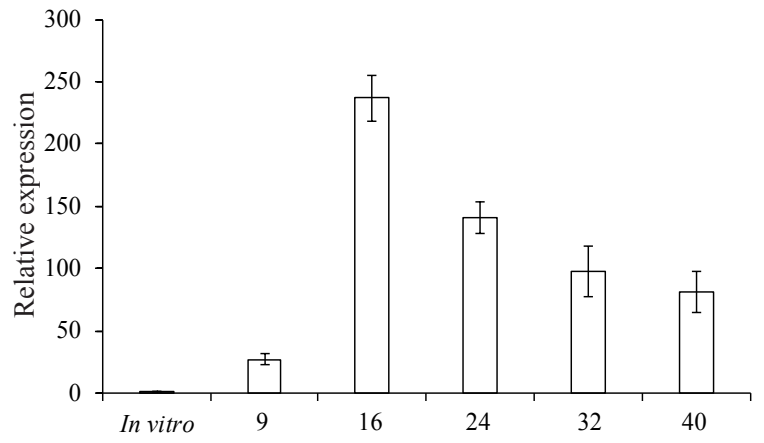

Figure 3. The SunI is highly induced during infection of Verticillium dahliae on sunflower. Twelve day-old sunflower (cv. Tutti) seedlings were root-inoculated with $V$. dahliae strain $85 \mathrm{~S}$ and stems were harvested at 9, $16,24,32$ and 40 days post inoculation (dpi). Real-time PCR was performed to determine the relative expression level of Sun using the V. dahliae GAPDH gene as a reference. Expression of Sun in vitro (potato dextrose agar) was set to 1 . 


\section{The Sun1 effector quantitatively contributes to virulence on sunflower}

To further assess the contribution of the Suni effector to virulence of $V$. dahliae strain $85 \mathrm{~S}$ on sunflower, we generated deletion mutants for both effector gene copies through homologous recombination (Figure S2A). To this end, we first generated single gene copy deletion mutants, followed by deletion of the second Sunı gene copy. Putative single and double gene deletion mutants were confirmed by PCR (Figure S2B). Thereby, we also confirmed that the predicted presence of the two gene copies is genuine and not the consequence of an assembly artefact

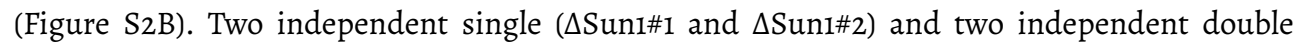
( $\Delta \Delta$ Suni\#1 and $\Delta \Delta$ Sun1\#2) gene deletion mutants were selected for subsequent inoculation assays.

Single deletion ( $\triangle$ Suni) mutants exhibited markedly reduced virulence on sunflower when compared with wild-type strain $85 \mathrm{~S}$ at 45 days post inoculation (dpi) (Figure $4 \mathrm{~A}$ ), demonstrated by significantly reduced stunting and compromised fungal colonization of the host plants (Figure $4 \mathrm{~B}-\mathrm{C}$ ). Interestingly, sunflower plants that were inoculated with double deletion ( $\Delta \Delta$ Suni) mutants showed a similar disease phenotype as plants upon inoculation with $\Delta$ Suni mutants during relatively early stages of infection up until $24 \mathrm{dpi}$, as no significant difference in disease symptoms and plant height reduction was observed. However, from 32 dpi onwards, sunflower plants that were inoculated with $\Delta \Delta$ Sun mutants showed significantly less wilting symptoms and stunting than plants inoculated with $\Delta$ Sun1 mutants (Figure $4 \mathrm{~B}$ ).

Moreover, real-time PCR quantification of fungal biomass demonstrated that $\Delta \Delta$ Suni mutants accumulated significantly less fungal biomass during infection than $\Delta S u n 1$ mutants and the wild type strain (Figure $4 \mathrm{C}$ ). Taken together, these data demonstrate that the Sun1 effector quantitatively contributes to virulence on sunflower plants. 
A

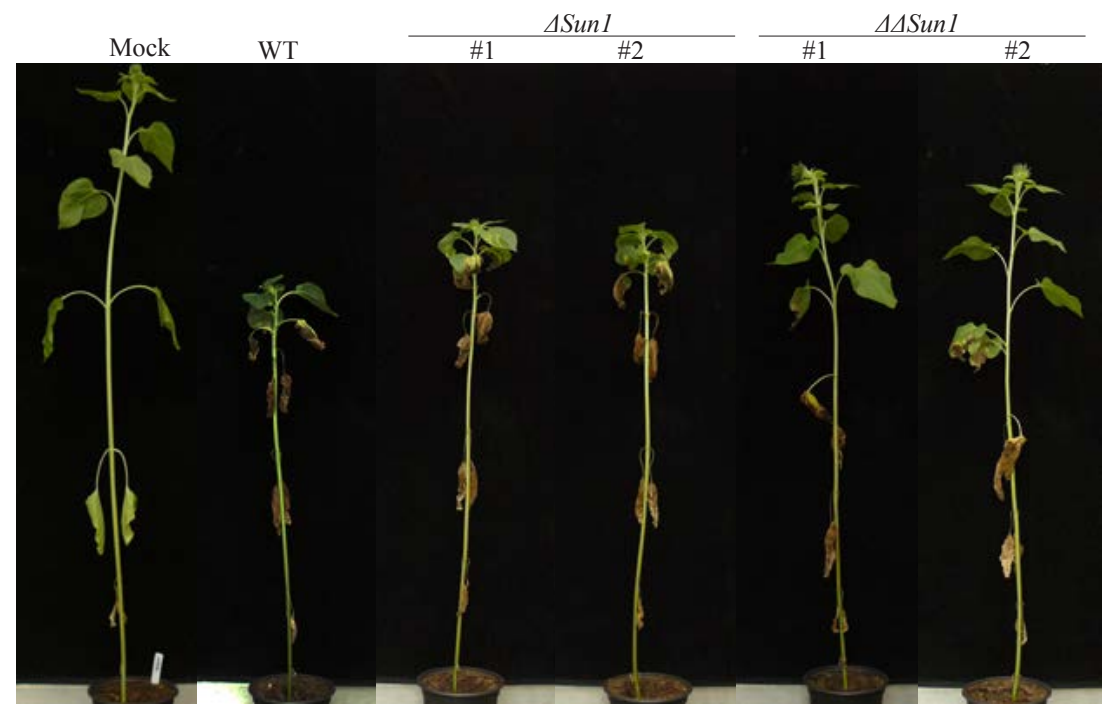

B

C
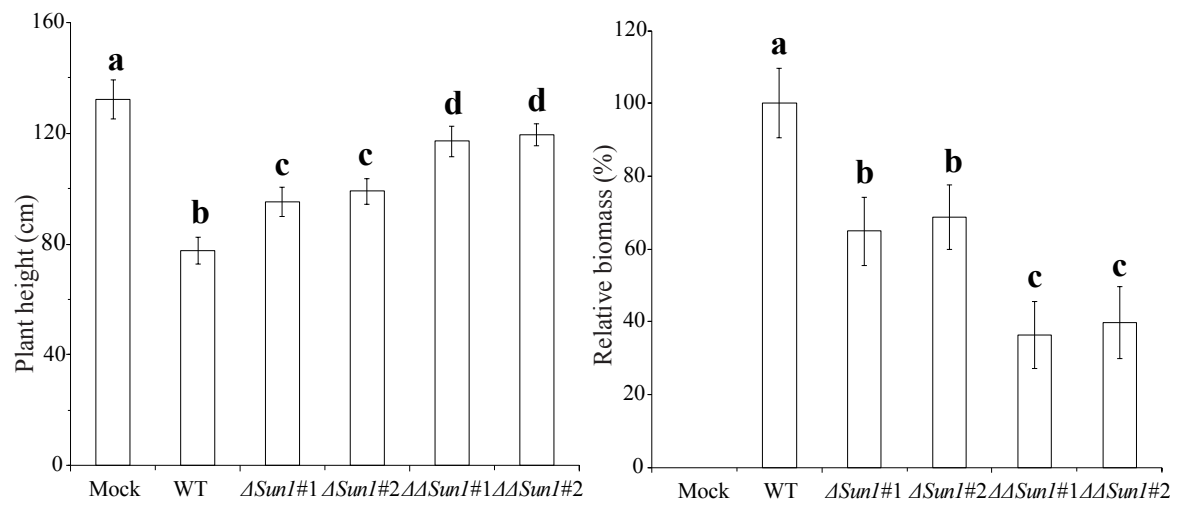

Figure 4. Sunt is required for full virulence on sunflower. (A) Typical phenotype of sunflower (cv. Tutti) upon mockinoculation or inoculation with wild-type strain $85 \mathrm{~S}$ (WT), two Sun1 single deletion strains ( $\triangle$ Suni\#1 and $\triangle$ Sun1\#2) and two Sun1 double deletion strains ( $\Delta \Delta \operatorname{Sun} 1 \# 1$ and $\Delta \Delta$ Sun1\#2). Photographs were taken at 45 days post inoculation (dpi). (B) Quantification of V. dahliae-induced plant stunting at 45 dpi. Bars represent the average height of five plants with standard deviation. (C) Fungal biomass as determined with real-time PCR at 45 dpi. Bars represent $V$. dahliae ITS levels relative to sunflower elongation factor $1-\alpha$ levels (for equilibration) with standard deviation in a sample of five pooled plants. The fungal biomass in sunflower plants upon inoculation with the wild-type strain $85 \mathrm{~S}$ is set to $100 \%$. Different letter labels indicate statistically significant differences (Student's $t$-test; $P<0.05$ ). Inoculation experiments were performed with five plants for each fungal strain and independently repeated twice with similar results. 
The Sun1 effector is dispensable for virulence on Nicotiana benthamiana and Arabidopsis thaliana

To investigate whether the observed role of Sunt in virulence is confined to sunflower only or also extends to other host species, we first tested the virulence of the V. dahliae strain $85 \mathrm{~S}$ on the Solanaceous crop tomato, the model plant $N$. benthamiana, the Malvaceae crop cotton and the Brassicaceous model plant $A$. thaliana. While $85 \mathrm{~S}$ failed to cause wilt disease on tomato (Figure S3) and caused only mild wilt disease symptom on cotton (Figure S4), clear symptoms of disease were observed on A. thaliana and $N$. benthamiana upon inoculation. Next, we examined the virulence of Suni deletion mutants ( $\Delta$ Sun1 and $\Delta \Delta$ Sun1) on A. thaliana and $N$. benthamiana to evaluate the contribution of this effector to virulence on these two hosts. However, unlike our observations on sunflower, deletion of Sunt did not result in significantly compromised virulence on $N$. benthamiana, as similar Verticillium wilt symptoms, including wilting and stunting, were observed for $\Delta$ Sun1 and $\Delta \Delta$ Sun1 mutants as for the wild-type strain $85 S$ at 3 weeks post inoculation (Figure 5A, C). Real time PCR quantification of fungal biomass confirmed that all strains colonized N. benthamiana plants to a similar extent (Figure 5D). Similarly, Sun1 effector was also not found to contribute to virulence on A. thaliana (Figure 5B, E-F). Therefore, we conclude that the Sunt effector does not play a general role in virulence, but its contribution appears to be confined to virulence on sunflower. 

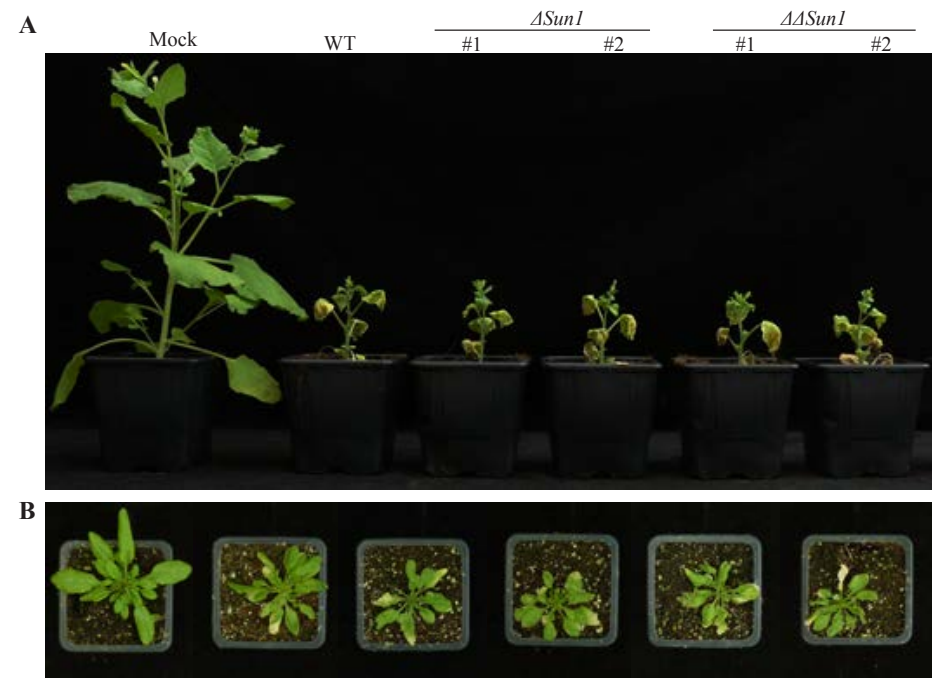

C

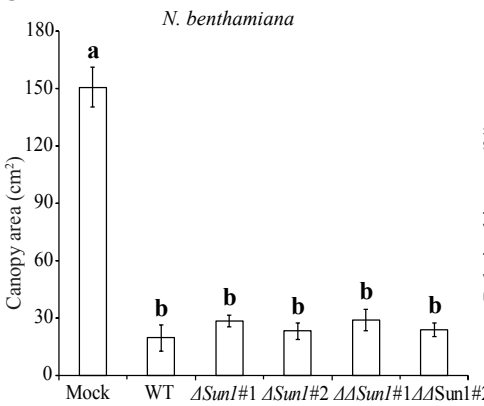

D

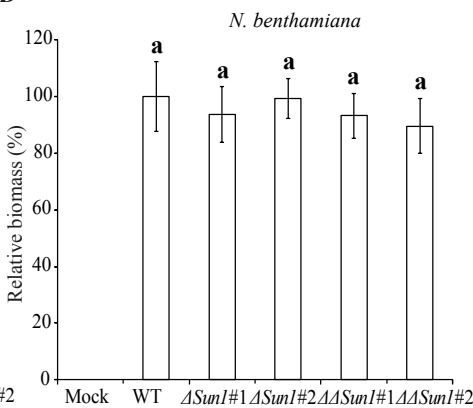

$\mathbf{E}$

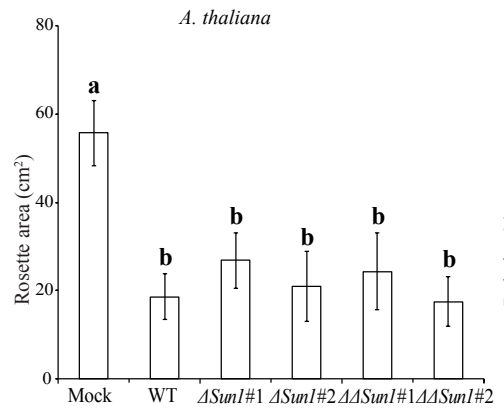

F

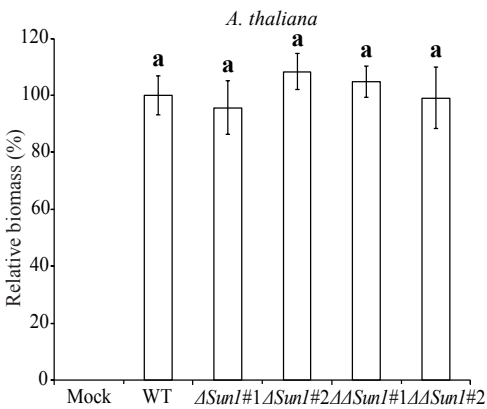

Figure 5. Sun1 is dispensable for virulence on Nicotiana benthamiana and Arabidopsis thaliana. (A) Typical phenotype of $N$. benthamiana plants that were mock-inoculated or inoculated with wild type strain 85S (WT), two Sun1 single deletion strains ( $\triangle \operatorname{Sun} \#_{1}$ and $\left.\Delta \operatorname{Sun} 1 \# 2\right)$ and two $\operatorname{Sun1}$ double deletion strains $\left(\Delta \Delta \operatorname{Sun} \#_{1}\right.$ and $\left.\Delta \Delta \operatorname{Sun} 1 \# 2\right)$. (B) Typical phenotype of $A$. thaliana (Col-o) plants that were mock-inoculated or inoculated with indicated fungal strains in panel $\mathbf{A}$ at 21 days post inoculation (dpi). (C) Quantification of the canopy area of N. benthamiana at 21 dpi. Bars represent the average canopy area of five plants with standard deviation. Different letter labels indicate statistically significant differences (Student's $t$-test; $P<0.05$ ). (D) Fungal biomass as determined with real-time PCR at 21 dpi. Bars represent $V$. dahliae ITS levels relative to $N$. benthamiana RuBisCo levels (for equilibration) with standard deviation in a sample of five pooled plants. The fungal biomass in N. benthamiana plants upon 
inoculation with the wild-type strain $85 \mathrm{~S}$ is set to $100 \%$. The same letter labels indicate no statistically significant differences (Student's $t$-test; $P<0.05$ ). (E) Quantification of the rosette area of five A. thaliana plants at 21 dpi. Bars represent the average rosette area of five plants with standard deviation. Different letter labels indicate statistically significant differences (Student's $t$-test; $P<0.05$ ). (F) Fungal biomass as determined with real-time PCR at 21 dpi. Bars represent $V$. dahliae ITS levels relative to A. thaliana RuBisCo levels (for equilibration) with standard deviation in a sample of five pooled plants. The fungal biomass in A. thaliana plants upon inoculation with the wild-type strain $85 \mathrm{~S}$ is set to $100 \%$. The same letter labels indicate no statistically significant differences (Student's $t$-test; $P<0.05$ ). Photographs were taken at 21 days post inoculation (dpi). Inoculation experiments were performed with five plants for each fungal strain and independently repeated twice with similar results.

\section{Discussion}

While $V$. dahliae strains are typically characterized by their broad host range, pathogenic isolates still display differential host specificity as individual isolates only infect a limited number of plant species (Bhat and Subbarao, 1999). Like many filamentous pathogens, V. dahliae also employs effector molecules as virulence factors to establish disease (Klimes et al., 2015). To date, a number of $V$. dahliae effectors have been reported to contribute to disease establishment on various hosts. For example, the effector proteins Ave1 and NLP1 (necrosis-and ethylene-inducing-like protein 1) have been shown to function as virulence factors on multiple host plants, such as tomato, $N$. benthamiana, as well as A. thaliana (de Jonge et al., 2012; Song et al., 2018; Santhanam et al., 2013). The recently identified $D$ effector was shown to act as a pathogenicity factor of $V$. dahliae defoliating (D) pathotype strains on cotton, olive, N. benthamiana and A. thaliana (Chapter 2). In contrast, other $V$. dahliae effectors may promote fungal virulence only on particular host species or genotypes. For instance, the chitin-binding effector $\mathrm{Vd} 2 \mathrm{LyM}$ was reported to contribute to fungal virulence on tomato, but not on $N$. benthamiana or A. thaliana (Kombrink et al., 2017). Similarly, the effector NLP-2 is required for full virulence of $V$. dahliae strain JR2 on tomato and A. thaliana, but not on $N$. benthamiana (Santhanam et al., 2013). In addition, the Tomr effector was found to function as a pathogenicity effector that determines host specificity of $V$. dahliae on tomato only (Chapter 3). In this study we observed that the Sun1 effector quantitatively contributes to fungal aggressiveness on sunflower (Figure 4), but not on N. benthamiana or A. thaliana (Figure 5). Thus, we anticipate that the Sun1 effector may specifically facilitate fungal virulence on sunflower, but future experiments on other hosts are needed to confirm this hypothesis.

Various mechanisms have been described that can facilitate the development of effector gene repertoires in pathogenic microbes, such as genome hybridization (Stukenbrock et al., 2012), gene duplication (Dutheil et al., 2016), and horizontal gene transfer (HGT) (Friesen et al., 2006; de Jonge et al., 2012). It has been suggested that the well-characterized V. dahliae race-specific effector Ave1 has been acquired from plants via HGT (de Jonge et al., 2012). Genomic comparisons of multiple $V$. dahliae strains revealed that all $V$. dahliae strains carry highly variable LS genomic regions, accounting for $1-5 \mathrm{Mb}$ of their $\sim 35-\mathrm{Mb}$ genome, that are unique or shared by only a subset of V. dahliae isolates (de Jonge et al., 2013; Faino et al., 2015, 2016). Interestingly, numerous in planta-induced effector genes reside in LS genomic regions that largely consist of segmental genomic duplications, suggesting that gene duplications may play an important role in the emergence of effector genes in V. dahliae (Jonge et al., 2013; Faino et al., 2016). In the present 
study, we show that two identical Sunı effector genes arose by a segmental genomic duplication event and the high level of similarity between flanking sequences of the Sun1 effector gene suggests that this duplication occurred rather recently (Figure 2). In line with this finding, two exact copies of the $D$ effector gene in $V$. dahliae defoliating pathotype strains have emerged by a recent segmental duplication as well (Chapter 2). The relevance of the occurrence of two identical effector gene copies and their impact on fungal adaption remains unknown at this point. Possibly, the emergence of two copies of the effector gene is relevant to maintain fungal aggressiveness on host plants. In this light it is interesting to note that the functionality of the two copies is not redundant, as they both quantitatively contribute to virulence and, consequently, deletion of a single copy markedly affects fungal virulence.

Recent duplications of effector genes can be subjected to subsequent evolutionary diversification, leading to novel or altered functionality of one of the two gene copies (Plissonneau et al., 2017; Sanchez-Vallet et al., 2018). Thus, effector genes of filamentous pathogens that arise from gene duplication events typically evolve in a so called "duplication-divergence" pattern: following a gene duplication event, one gene copy diverges to some extent due to functional redundancy and evolves a distinct function (Plissonneau et al., 2017). For example, gene duplications followed by sequence divergence were proposed to be responsible for the generation of novel effector genes in the smut fungus Ustilago maydis (Dutheil et al., 2016). Similarly, a large number of effector genes of the oomycete pathogen Phytophthora sojae underwent sequence diversification after gene duplication (Shen et al., 2013). In addition to experiencing functional diversification, the recent duplications of effector genes may also be subject to differential loss of the duplicated gene copies (Dong et al., 2015; Pedersen et al., 2012). Frequent effector gene losses after segmental duplications have been proposed to occur in the powdery mildew fungus Blumeria graminis, which contribute to the diversity of the effector repertoires of the pathogen (Wicker et al., 2013; Menardo et al., 2017). Possibly, selective forces from host immune systems contribute to this process. However, it is unclear whether either of the two copies of the Sun1 effector gene will experience sequence divergence or gene loss over time.

\section{Acknowledgements}

J.L. acknowledges receipt of a PhD fellowship from the China Scholarship Council (CSC). B.P.H.J.T. is supported by the Research Council for Earth and Life sciences (ALW) of the Netherlands Organization for Scientific Research (NWO). 


\section{References}

Badouin H, Gouzy J, Grassa CJ, Murat F, Staton SE, Cottret L, Lelandais-Brière C, Owens GL, Carrère S, Mayjonade B, et al. (2017) The sunflower genome provides insights into oil metabolism, flowering and Asterid evolution. Nature 546: 148-152.

Bhat RG, Subbarao KV (1999) Host range specificity in Verticillium dahliae. Phytopathology 89: 1218-1225.

Chen JY, Xiao HL, Gui YJ, Zhang DD, Li L, Bao YM, Dai XF (2016) Characterization of the Verticillium dahliae exoproteome involves in pathogenicity from cotton-containing medium. Front Microbiol 7: 1709.

Cook DE, Mesarich CH, Thomma BPHJ (2015) Understanding plant immunity as a surveillance system todetect invasion. Annu Rev Phytopathol 53: 541-563.

de Jonge R, Bolton MD, Thomma BPHJ (2011) How filamentous pathogens co-opt plants: the ins and outs of fungal effectors. Curr Opin Plant Biol 14: 400-406.

de Jonge R, Bolton MD, Kombrink A, van den Berg GC, Yadeta KA, Thomma BPHJ (2013) Extensivechromosomal reshuffling drives evolution of virulence in an asexual pathogen. Genome Res 23: 1271-1282.

de Jonge R, van Esse HP, Maruthachalam K, Bolton MD, Santhanam P, Saber MK, Zhang Z, Usami T, Lievens B, Subbarao KV, et al. (2012) Tomato immune receptor Ve1 recognizes effector of multiple fungal pathogens uncovered by genome and RNA sequencing. Proc Natl Acad Sci USA 109: 5110-5115.

Depotter JR, Deketelaere S, Inderbitzin P, Tiedemann AV, Höfte M, Subbarao KV, Wood TA and Thomma BPHJ (2016) Verticillium longisporum, the invisible threat to oilseed rape and other brassicaceous plant hosts. Mol Plant Patho 17: 1004-1016.

Depotter JRL, Shi-Kunne X, Missonnier H, Liu T, Faino L, van den Berg GCM, Wood TA, Zhang B, Jacques A, Seidl MF, Thomma BPHJ (2018) Dynamic virulence-related regions of the fungal plant pathogen Verticillium dahliae display remarkably enhanced sequence conservation. bioRxiv doi: https://doi.org/10.1101/277558.

Dong S, Raffaele S, Kamoun S (2015) The two-speed genomes of filamentous pathogens: waltz with plants. Curr Opin Genet Dev 35: 57-65.

Dutheil JY, Mannhaupt G, Schweizer G, MK Sieber C, Münsterkötter M, Güldener U, Schirawski J, Kahmann RA (2016) A tale of genome compartmentalization: the evolution of virulence clusters in smut fungi. Genome Biol Evol 8: 681-704.

Ellendorff U, Fradin EF, De Jonge R, Thomma BPHJ (2009) RNA silencing is required for Arabidopsis defence against Verticillium wilt disease. J Exp Bot 60: 591-602.

El-Bebany AF, Rampitsch C, Daayf F (2010) Proteomic analysis of the phytopathogenic soilborne fungus Verticillium dahliae reveals differential protein expression in isolates that differ in aggressiveness. Proteomics 10: 289303.

Faino L, Seidl MF, Datema E, van den Berg GC, Janssen A, Wittenberg AH, Thomma BPHJ (2015) Single-molecule real-time sequencing combined with optical mapping yields completely finished fungal genome. mBio 6: e00936-00915.

Faino L, Seidl MF, Shi-Kunne X, Pauper M, van den Berg GC, Wittenberg AH, Thomma BPHJ (2016) Transposons passively and actively contribute to evolution of the two-speed genome of a fungal pathogen. Genome Res 26: $1091-1100$.

Faino L, Thomma BP (2014) Get your high-quality low-cost genome sequence. Trends Plant Sci 19: 288-291.

Fradin EF, Thomma BPHJ (2006) Physiology and molecular aspects of Verticillium wilt diseases caused by V. dahliae and V. albo-atrum. Mol Plant Pathol 7: 71-86.

Fradin EF, Zhang Z, Ayala JCJ, Castroverde CD, Nazar RN, Robb J, Liu C-M, Thomma BPHJ (2009) Genetic dissection of Verticillium wilt resistance mediated by tomato Ve1. Plant Physiol 150: 320-332.

Frandsen RJ, Andersson JA, Kristensen MB, Giese H (2008) Efficient four fragment cloning for the construction of vectors for targeted gene replacement in filamentous fungi. BMC Mol Biol 9: 70 .

Friesen TL, Stukenbrock EH, Liu Z, Meinhardt S, Ling H, Faris JD, Rasmussen JB, Solomon PS, McDonald BA, Oliver RP (2006) Emergence of a new disease as a result of interspecific virulence gene transfer. Nat Genet 38: 953-956. 
Guo S, Zuo Y, Zhang Y, Wu C, Su W, Jin W, Yu H, An Y, Li Q (2017) Large-scale transcriptome comparison of sunflower genes responsive to Verticillium dahliae. BMC Genomics 18: 42.

Guy L, Kultima JR, Andersson SG (2010) genoPlotR: comparative gene and genome visualization in R. Bioinformatics 26: 2334-2335.

Holt C, Yandell M (2011) MAKER2: an annotation pipeline and genome-database management tool for secondgeneration genome projects. BMC Bioinformatics 12: 491 .

Inderbitzin P, Subbarao KV (2014) Verticillium systematics and evolution: how confusion impedes Verticillium wilt management and how to resolve it. Phytopathology 104: 564-574.

Jones JD, Dangl JL (2006) The plant immune system. Nature 444: 323-329.

Kane NC, Rieseberg LH (2007) Selective sweeps reveal candidate genes for adaptation to drought and salt tolerance in common sunflower, Helianthus annuus. Genetics 175: 1823-1834.

Klimes A, Dobinson KF, Klosterman SJ, Thomma BPHJ (2015) Genomics spurs rapid advances in ourunderstanding of the basic biology of vascular wilt pathogens in the genus Verticillium. Annu Rev Phytopathol 53: 181-198.

Klosterman SJ, Atallah ZK, Vallad GE, Subbarao KV (2009) Diversity, pathogenicity, and management of Verticillium species. Annu Rev Phytopathol 47: 39-62.

Klosterman SJ, Subbarao KV, Kang S, Veronese P, Gold SE, Thomma BPHJ, Chen Z, Henrissat B, Lee YH, Park J (2011) Comparative genomics yields insights into niche adaptation of plant vascular wilt pathogens. PLOS Pathog 7: e1002137.

Kombrink A, Rovenich H, Shi-Kunne X, Rojas-Padilla E, van den Berg G, Domazakis E, De Jonge R, Valkenburg DJ, Sánchez-Vallet A, Seidl MF, et al. (2017) Verticillium dahliae LysM effectors differentially contribute to virulence on plant hosts. Mol Plant Pathol 18: 596-608.

Kurtz S, Phillippy A, Delcher AL, Smoot M, Shumway M, Antonescu C, Salzberg SL (2004) Versatile and open software for comparing large genomes. Genome Biol 5: R12.

Li H, Durbin R (2010) Fast and accurate long-read alignment with Burrows-Wheeler transform Bioinformatics 26: 589-595.

Menardo F, Praz CR, Wicker T, Keller B (2017) Rapid turnover of effectors in grass powdery mildew (Blumeria graminis). BMC Evol Biol 17: 223.

Pedersen C, Ver Loren van Themaat E, McGuffin LJ, Abbott JC, Burgis TA, Barton G, Bindschedler LV, Lu X, Maekawa T, et al. (2012) Structure and evolution of barley powdery mildew effector candidates. BMC Genomics 13: 694 .

Pegg GF, Brady BL (2002) Verticillium wilts. Wallingord, Oxfordhire: CABI Publishing.

Petersen TN, Brunak S, von Heijne G, Nielsen H (2011) SignalP 4.0: discriminating signal peptides from transmembrane regions. Nat Methods 8: 785-786.

Plett JM, Daguerre Y, Wittulsky S, Vayssières A, Deveau A, Melton SJ, Kohler A, Morrell-FalveyJL, Brun A, VeneaultFourrey C, et al. (2014) Effector MiSSP7 of the mutualistic fungus Laccaria bicolor stabilizes the Populus JAZ6 protein and represses jasmonic acid (JA) responsive genes. Proc Natl Acad Sci USA 111: 8299-8304.

Plissonneau C, Benevenuto J, Mohd-Assaad N, Fouché S, Hartmann FE, Croll D (2017) Using population and comparative genomics to understand the genetic basis of effector-driven fungal pathogen evolution. Front Plant Sci 8: 119.

Quinlan AR, Hall IM (2010) BEDTools: a flexible suite of utilities for comparing genomic features. Bioinformatics 26: 841-842.

Rodriguez-Moreno L, Ebert MK, Bolton MD, Thomma BPHJ (2018) Tools of the crook-infection strategies of fungal plant pathogens. Plant J 93: 664-674.

Rovenich H, Boshoven JC, Thomma BPHJ (2014) Filamentous pathogen effector functions: of pathogens, hosts and microbiomes. Curr Opin Plant Biol 20: 96-103.

Sánchez-Vallet A, Fouché S, Fudal I, Hartmann FE, Soyer JL, Tellier A, Croll D (2018) The genome biology of effector gene evolution in filamentous plant pathogens. Annu Rev Phytopathol 56: 1.

Santhanam P (2012) Random insertional mutagenesis in fungal genomes to identify virulence factors. Plant Fungal Pathogens Springer (Methods and Protocols) 835: 509-517. 
Santhanam P (2014) Insertional mutagenesis in the vascular wilt pathogen Verticillium dahliae. Wageningen University $\mathrm{PhD}$ thesis.

Santhanam P, van Esse HP, Albert I, Faino L, Nürnberger T, Thomma BPHJ (2013) Evidence forfunctional diversification within a fungal NEP1-like protein family. Mol Plant-Microbe Interact 26: 278-286.

Schaible L, Cannon OS, Waddoups V (1951) Inheritance of resistance to Verticillium wilt in a tomato cross. Phytopathology 41: 986-990.

Shen D, Liu T, Ye W, Liu L, Liu P, Wu Y, Wang Y, Dou D (2013) Gene duplication and fragment recombination drive functional diversification of a superfamily of cytoplasmic effectors in Phytophthora sojae. PLoS One 8: e70036.

Simko I, Costanzo S, Haynes K, Christ B, Jones R (2004) Linkage disequilibrium mapping of a Verticillium dahliae resistance quantitative trait locus in tetraploid potato (Solanum tuberosum) through a candidate gene approach. Theor Appl Genet 108: 217-224.

Snelders NC, Kettles GJ, Rudd JJ, Thomma BPHJ (2018) Plant pathogen effector proteins as manipulators of host microbiomes? Mol Plant Pathol 19: 257-259.

Song Y, Liu L, Wang Y, Valkenburg DJ, Zhang X, Zhu L, Thomma BPHJ (2018) Transfer of tomato immune receptor Ve1 confers Ave1-dependent Verticillium resistance in tobacco and cotton.Plant Biotechnol J 16: 638-648.

Song Y, Thomma BPHJ (2016) Host-induced gene silencing compromises Verticillium wilt in tomato and Arabidopsis. Mol Plant Pathol 19: 77-89.

Sperschneider J, Gardiner DM, Dodds PN, Tini F, Covarelli L, Singh KB, Manners JM, Taylor JM (2016) EffectorP: predicting fungal effector proteins from secretomes using machine learning. New Phytol 210: 743-761.

Stamatakis, A (2014) Raxml version 8: a tool for phylogenetic analysis and post-analysis of large phylogenies. Bioinformatics 30: 1312-1313.

Stergiopoulos I, de Wit PJ (2009) Fungal effector proteins. Annu Rev Phytopathol 47: 233-263.

Stukenbrock EH, Christiansen FB, Hansen TT, Dutheil JY, Schierup MH (2012) Fusion of two divergent fungal individuals led to the recent emergence of a unique widespread pathogen species. Proc Natl Acad Sci USA 109: 10954-10959.

Thomma BP, Nürnberger T, Joosten MH (2011) Of PAMPs and effectors: the blurred PTI-ETI dichotomy. Plant Cell 23: 4-15.

van der Does HC, Rep M (2007) Virulence genes and the evolution of host specificity in plant-pathogenic fungi. Mol Plant-Microbe Interact 20: 1175-1182.

Wang M, Weiberg A, Jin H (2015) Pathogen small RNAs: a new class of effectors for pathogen attacks. Mol Plant Pathol 16: 219-223.

Wicker T, Oberhaensli S, Parlange F, Buchmann JP, Shatalina M, Roffler S, Ben-David R, Doležel J, Šimková H, Schulze-Lefert P, et al. (2013) The wheat powdery mildew genome shows the unique evolution of an obligate biotroph. Nat Genet 45: 1092-1096.

Yao Z, Rashid KY, Adam LR, Daayf F (2011) Verticillium dahliae's VdNEP acts both as a plant defense elicitor and a pathogenicity factor in the interaction with Helianthus annuus. Can J Plant Pathol 33:375-388.

Zhang L, Ni H, Du X, Wang S, Ma XW, Nürnberger T, Guo HS, Hua C (2017) The Verticillium-specific protein VdSCP7 localizes to the plant nucleus and modulates immunity to fungal infections. New Phytol 215: 368-381.

Zhang T, Jin Y, Zhao JH, Gao F, Zhou BJ, Fang YY, Guo HS (2016) Host-induced gene silencing of the target gene in fungal cells confers effective resistance to the cotton wilt disease pathogen Verticillium dahliae. Mol Plant 9: 939-942. 


\section{Supplemental information}

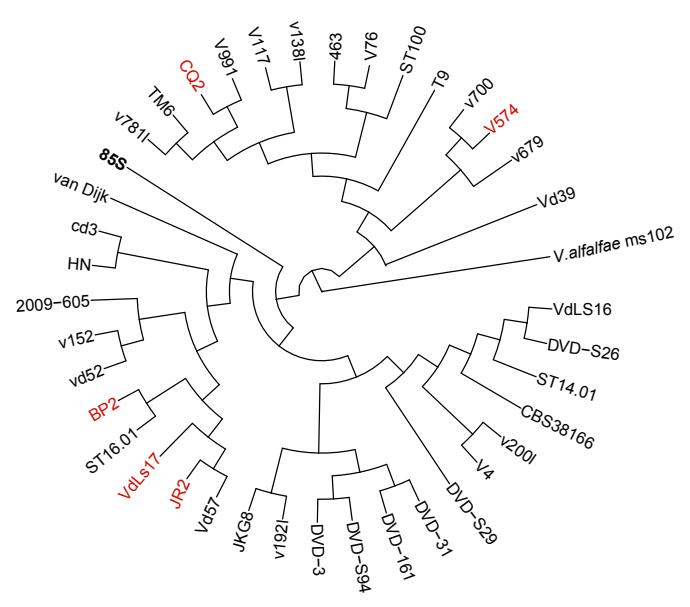

A

Single deletion

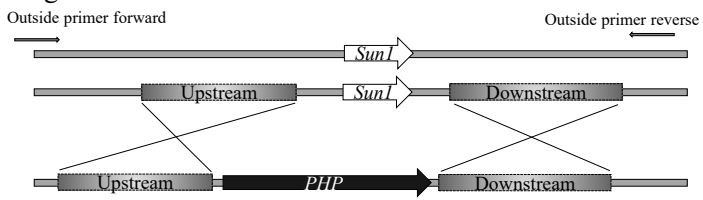

Double deletion Outside primer forward

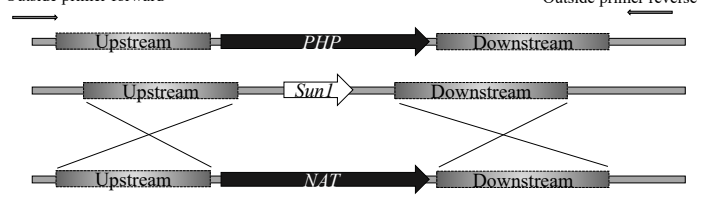

Figure S1. Phylogenetic tree of V. dahliae strains. Sunflower-pathogenic strain $85 \mathrm{~S}$ is shown in bold black. Strains that were selected for phenotypic characterization in this study are shown in red font. Phylogenetic relationships between sequenced $V$. dahliae strains are inferred using Realphy (Bertels et al., 2014). V. alfalfae strain ms102 was used to root the tree.

Figure S2. Construction and verification of Sun1 single deletion and double deletion mutants. (A) Schematic representation of the homologous recombination events to establish targeted replacement of Suni with phosphotransferase $(\mathrm{HPH})$ and the nourseothricin resistance gene cassette (NAT). (B) Verification of Sun single deletion and double deletion strains by PCR. Amplicons generated with outside primers indicated in panel A are shown for wild-type strain 85 S (WT), two Sun1 single deletion strains ( $\triangle$ Suni\#1 and $\Delta$ Suni\#2) and two Sun1 double deletion strains ( $\Delta \Delta$ Sun1\#1 and $\Delta \Delta$ Sun1\#2). Water was used as negative control (W). 


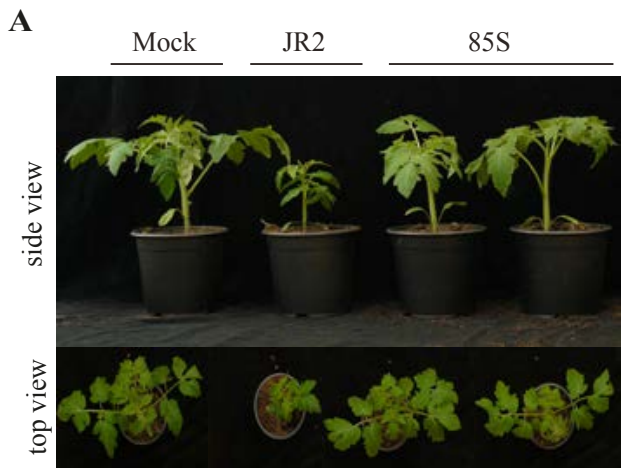

\section{B}

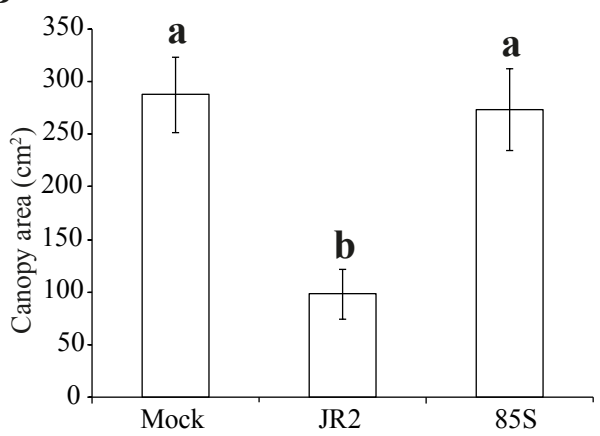

Figure S3. Phenotypes of tomato plants inoculated with V. dahliae strain $85 \mathrm{~S}$. (A) Typical phenotype of tomato (cv. Moneymaker) plants upon mock-inoculation or inoculation with $V$. dahliae strains $85 \mathrm{~S}$ and JR2 (as positive inoculation control) at 21 days post inoculation (dpi). (B) Quantification of the canopy area of tomato plants at 21 dpi. Bars represent average of canopy area of five plants with standard deviation. Different letters indicate statistically significant differences (Student's $t$-test; $P<0.05$ ). Inoculation experiments were performed with five plants for each fungal strain and independently repeated twice with similar results. 

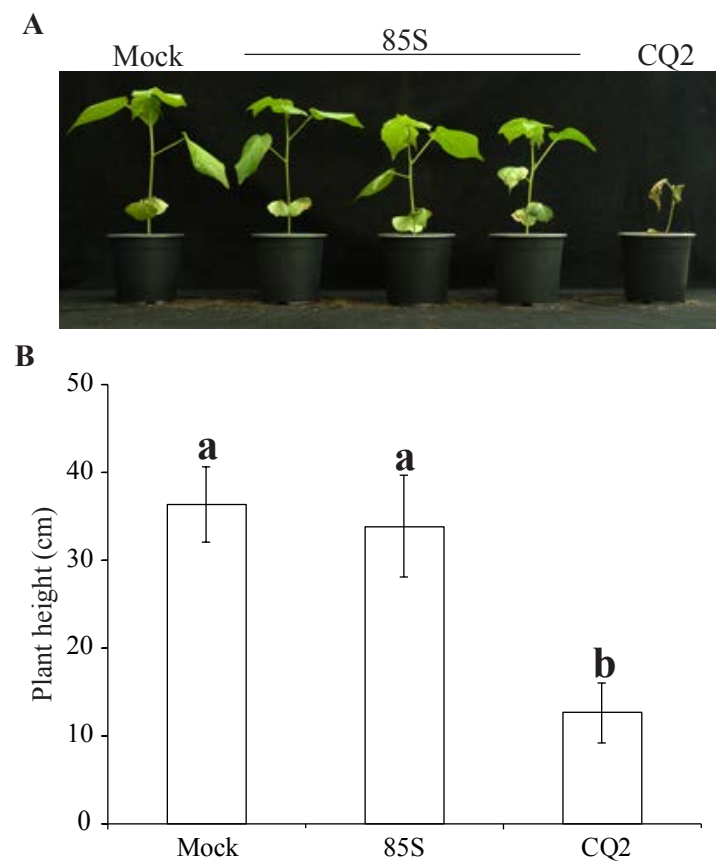

Figure S4. Phenotypes of cotton plants inoculated with V. dahliae strain 85S. (A) Typical phenotype of cotton (cv. Simian3) plants upon mock-inoculation or inoculation with $V$. dahliae strains $85 \mathrm{~S}$ and $\mathrm{CQ} 2$ (as positive inoculation control) at 28 days post inoculation (dpi). (B) Quantification of the plant height of cotton plants at 28 dpi. Bars represent average of height of five plants with standard deviation. Different letters indicate statistically significant differences (Student's $t$-test; $P<0.05$ ). Inoculation experiments were performed with five plants for each fungal strain and independently repeated twice with similar results. 
Table S1. V. dahliae strains used in this study.

\begin{tabular}{|c|c|c|c|c|}
\hline Strain & Sequencing platform & Reference & Origin & Geographical location \\
\hline $\mathrm{HN}$ & Illumina & $\mathrm{Xu}$ et al., 2012 & Cotton & China \\
\hline $\mathrm{cd} 3$ & Illumina & Xu et al., 2012 & Cotton & China \\
\hline VdLs17 & PacBio & Faino et al., 2015 & Lettuce & USA \\
\hline JR2 & PacBio & Faino et al., 2015 & Tomato & Canada \\
\hline $\mathrm{Vd}_{57}$ & Illumina & Chapter 2 of this thesis & Strawberry & Germany \\
\hline V152 & Illumina & Kombrink et al., 2017 & Oak & Hungary \\
\hline $\mathrm{Vd}_{52}$ & Illumina & Kombrink et al., 2017 & Pepper & Austria \\
\hline van Dijk & Illumina & Kombrink et al., 2017 & Chrysanthemum & The Netherlands \\
\hline $\mathrm{BP} 2$ & Illumina & Zhang et al., 2012 & Cotton & China \\
\hline ST16.01 & Illumina & Chapter 2 of this thesis & Cotton & Syria \\
\hline $2009-605$ & Illumina & Chapter 2 of this thesis & Bell pepper & Ukraine \\
\hline $\mathrm{V}_{4}$ & Illumina & Keykhasaber, 2017 & Olive & Spain \\
\hline V200I & Illumina & Chapter 2 of this thesis & Strawberry & Germany \\
\hline $\mathrm{CBS} 38166$ & Illumina & de Jonge et al., 2012 & Tomato & Canada \\
\hline DVD-S26 & Illumina & de Jonge et al., 2012 & Soil & Canada \\
\hline VdLS16 & Illumina & de Jonge et al., 2012 & Lettuce & USA \\
\hline ST14.01 & Illumina & de Jonge et al., 2012 & Pistachio & USA \\
\hline DVD-S29 & Illumina & de Jonge et al., 2012 & Soil & Canada \\
\hline DVD-31 & Illumina & de Jonge et al., 2012 & Tomato & Canada \\
\hline DVD-161 & Illumina & de Jonge et al., 2012 & Tomato & Canada \\
\hline DVD-S94 & Illumina & de Jonge et al., 2012 & Soil & Canada \\
\hline DVD-3 & Illumina & de Jonge et al., 2012 & Potato & Canada \\
\hline V192I & Illumina & Chapter 2 of this thesis & Cotton & Spain \\
\hline JKG8 & Illumina & Kombrink et al., 2017 & Potato & The Netherlands \\
\hline $85 S$ & PacBio & Chapter 2 of this thesis & Sunflower & France \\
\hline $\operatorname{Vd} 39$ & Illumina & Chapter 2 of this thesis & Sunflower & Germany \\
\hline V574 & Illumina & Milgroom et al., 2014 & Artichoke & Spain \\
\hline v700 & Illumina & Milgroom et al., 2014 & Artichoke & Spain \\
\hline v679 & Illumina & Milgroom et al., 2014 & Artichoke & Spain \\
\hline T9 & Illumina & Keykhasaber, 2017 & Cotton & USA \\
\hline V781I & Illumina & Chapter 2 of this thesis & Olive & Spain \\
\hline V138I & Illumina & Chapter 2 of this thesis & Cotton & Spain \\
\hline TM6 & Illumina & Keykhasaber, 2017 & Cotton & China \\
\hline V117 & Illumina & Keykhasaber, 2017 & Olive & Spain \\
\hline V991 & Illumina & Zhang et al., 2012 & Cotton & China \\
\hline $\mathrm{CQ}_{2}$ & PacBio & Chapter 2 of this thesis & Cotton & China \\
\hline ST100 & Illumina & de Jonge et al., 2012 & Soil & Belgium \\
\hline V76 & Illumina & Chapter 2 of this thesis & Cotton & Mexico \\
\hline 463 & Illumina & Chapter 2 of this thesis & Cotton & Mexico \\
\hline
\end{tabular}


Table S2. Primers used in this study.

\begin{tabular}{|c|c|c|}
\hline Primer name & Oligonucleotide sequence $\left(5^{\prime} \rightarrow 3^{\prime}\right)^{a}$ & Description \\
\hline SKO-Sun1-LF & GGTCTTAAUCAGATACCGATTATTGATCCTCGAC & For single Sunı deletion generation \\
\hline SKO-Sun1-LR & GGCATTAAUCGTTAAGAGTTCATAGGCGAAGTTA & For single Sunı deletion generation \\
\hline SKO-Sun1-RF & GGACTTAAUCTCGAAATTACAGAGCTTGCTATGA & For single Sunı deletion generation \\
\hline SKO-SunI-RB & GGGTTTAAUACTTGGCTATTTCTTCGTCTTTAGG & For single Sunı deletion generation \\
\hline DKO-SunI-LF & GGTCTTAAUTAGATTGTGTCCTGTGCAAGATATG & For double Sunı deletion generation \\
\hline DKO-Sun1-LR & GGCATTAAUAGGGTTAACGTACATTATCAGCATG & For double Sunı deletion generation \\
\hline DKO-Sun1-RF & GGACTTAAUGATCCCCTTGTCCATTATCTAGTGA & For double Sunı deletion generation \\
\hline DKO-Sun1-RB & GGGTTTAAUCCGGGACAAAGGAAGGTTAATATAC & For double Sunı deletion generation \\
\hline outside primer-F & GCCTCACAACCAATCCACAG & Verification of Sunı deletion mutants \\
\hline outside primer- $\mathrm{R}$ & ACATCGCCTCAGAGTCACAA & Verification of Sun1 deletion mutants \\
\hline Sun1-F (RT) & CTCATACTCTCCTCCGGTTCAT & Sun1, qRT-PCR \\
\hline Sun1-R (RT) & TTGTACCATCTCCACACGTTAAGTA & Sun1, qRT-PCR \\
\hline VdGAPDH-F & CGAGTCCACTGGTGTCTTCA & V. dahliae GAPDH, qRT-PCR \\
\hline VdGAPDH-F & CCCTCAACGATGGTGAACTT & V. dahliae GAPDH, qRT-PCR \\
\hline Ha-ELF-1 $\alpha-F$ & ACCAAATCAATGAGCCCAAG & Sunflower elongation Factor $1-\alpha$ gene \\
\hline Ha-ELF-1 $\alpha-R$ & GAGACTCGTGGTGCATCTCA & Sunflower elongation Factor 1- $\alpha$ gene \\
\hline AtRubisco-F & GCAAGTGTTGGGTTCAAAGCTGGTG & $\begin{array}{l}\text { Arabidopsis Rubisco gene, fungal } \\
\text { biomass quantification }\end{array}$ \\
\hline AtRubisco-R & CCAGGTTGAGGAGTTACTCGGAATGCTG & $\begin{array}{l}\text { Arabidopsis Rubisco gene, fungal } \\
\text { biomass quantification }\end{array}$ \\
\hline NbRubisco-F & TCCGGGTATTAGGAAAAGCGT & $\begin{array}{l}\text { N. benthamiana Rubisco gene, fungal } \\
\text { biomass quantification }\end{array}$ \\
\hline NbRubisco-R & CCCAAGATCTGGGTCAGAGC & $\begin{array}{l}\text { N. benthamiana Rubisco gene, fungal } \\
\text { biomass quantification }\end{array}$ \\
\hline ITS-F & AAAGTTTTAATGGTTCGCTAAGA & Fungal biomass quantification \\
\hline ITS-R & CTTGGTCATTTAGAGGAAGTAA & Fungal biomass quantification \\
\hline
\end{tabular}

${ }^{a}$ USER cloning sites present in primer sequence are underlined, RT-PCR, real-time PCR. 


\section{References}

de Jonge R, van Esse HP, Maruthachalam K, Bolton MD, Santhanam P, Saber MK, Zhang Z, Usami T,Lievens B, Subbarao KV, Thomma BPHJ (2012) Tomato immune receptor Ve1 recognizes effector of multiple fungal pathogens uncovered by genome and RNA sequencing. Proc Natl Acad Sci USA 109:5110-5115.

Faino L, Seidl MF, Datema E, van den Berg GC, Janssen A, Wittenberg AH, Thomma BPHJ (2015) Single-molecule real-time sequencing combined with optical mapping yields completely finished fungal genome. mBio 6: e00936-00915.

Keykhasaber M (2017) Unravelling aspects of spatial and temporal distribution of Verticillium dahliae in olive, maple and ash trees and improvement of detection methods Wageningen University \& Research PhD thesis.

Kombrink A, Rovenich H, Shi-Kunne X, Rojas-Padilla E, van den Berg G, Domazakis E, De Jonge R, Valkenburg DJ, Sanchez-Vallet A, Seidl MF, et al. (2017) Verticillium dahliae LysMeffectors differentially contribute to virulence on plant hosts. Mol Plant Pathol 18: 596-608.

Milgroom MG, Jiménez-Gasco MM, Olivares-García C, Jiménez-Díaz RM (2016) Clonal expansion and migration of a highly virulent, defoliating lineage of Verticillium dahliae. Phytopathology 106: 1036-1046.

Xu F, Yang L, Zhang J, Guo X, Zhang X, Li G (2012) Prevalence of the defoliating pathotype of Verticillium dahliae on cotton in central China and virulence on selected cotton cultivars. J Phytopathol 160: 369-376. 


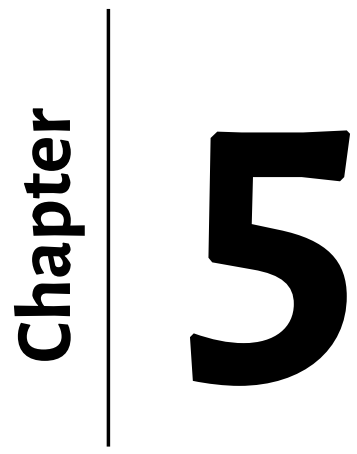

\section{Verticillium dahliae strains that infect the same host plants display highly divergent effector catalogs}

Hesham A.Y. Gibriel ${ }^{1,2, \$}$, Jinling Li ${ }^{1, \$}$, Longfu Zhu ${ }^{3}$,

Michael F. Seidl ${ }^{\# *}$, Bart P.H.J. Thomma ${ }^{1 *^{*}}$ 


\section{Abstract}

Effectors are proteins secreted by pathogens to support colonization of host plants, many of which are thought to deregulate host immunity. Effector genes are often localized within dynamic lineage-specific (LS) genomic regions of pathogen genomes, allowing rapid evolution of effector catalogues. It is thought that such localization permits pathogens to be competitive in the co-evolutionary arms races with their hosts. For a broad host-range pathogen such as Verticillium dahliae it is unclear to what extent single members from their total effector repertoires contribute to disease development on multiple hosts. Here, we determined the core and LS effector repertoires of a collection of $V$. dahliae strains, as well as the ability of these strains to infect a range of plant species comprising tomato, cotton, Nicotiana benthamiana, Arabidopsis, and sunflower to assess whether the presence of particular LS effectors correlates with the ability to infect particular plant species. Surprisingly, we found that $V$. dahliae strains that are able to infect the same host plant harbour highly divergent LS effector repertoires. Furthermore, we observed differential V. dahliae core effector gene expression between host plants. Our data suggest that different $V$. dahliae lineages utilise divergent effector catalogs to colonize the same host plant, suggesting considerable redundancy among the activities of effector catalogs between lineages. 


\section{Introduction}

Plant pathogens cause devastating diseases on crop plants, threatening food security worldwide (Fisher et al., 2012; Pennisi, 2010). In order to establish their infection, pathogens secrete effector molecules during attempted host ingress many of which modulate host physiology, often by deregulating host immune responses (Cook et al., 2015). However, in turn, effectors may become recognized by plant immune receptors, leading to the activation of immune responses and attempted arrest of pathogen invasion. Thus, pathogens need to continuously evolve their effector catalogues by modifying or purging existing effectors that became recognized, or by acquiring novel effectors to suppress effector-triggered immune responses (Cook et al., 2015).

Genomes of plant pathogens are often thought to have evolved roughly two distinct compartments; one comprising gene-rich, repeat-poor genomic regions that contain core genes that mediate general physiology, and one comprising gene-poor, plastic, repeat-rich genomic regions that contain effector genes and other pathogenicity-related genes (Dong et al., 2015; Raffaele and Kamoun, 2012). The plastic genomic regions are either embedded within core chromosomes, or reside on separate chromosomes that are often referred to as conditionally dispensable chromosomes (CDCs) (Dong et al., 2015; Raffaele and Kamoun, 2012). For instance, effector genes of the tomato-pathogen Fusarium oxysporum f.sp. lycopersici, known as secreted in xylem (SIX) genes, are located on dispensable chromosomes (Ma et al., 2010; Schmidt et al., 2013). In contrast, all effectors of the fungal wheat pathogen Zymoseptoria tritici are located on core chromosomes, while no recognizable effector genes reside on dispensable chromosomes (Kema et al., 2018; Marshall et al., 2011; Meile et al., 2018). Core chromosomes also carry effector genes in other fungal plant pathogens, such as the fungal smut pathogen Ustilago maydis and the fungal tomato pathogen Cladosporium fulvum (Hemetsberger et al., 2015; Stergiopoulos et al., 2010) A genome compartmentalisation with physically separated effector-containing regions is often referred to as a "two-speed" genome organisation since it is thought that gene-rich, repeatpoor genomic regions evolve slowly, while gene-poor, repeat-rich genomic regions evolve quicker (Croll and McDonald, 2012; Raffaele and Kamoun, 2012) Accordingly, the occurrence of effector genes within plastic genomic regions allows rapid evolution of effector catalogues and permits pathogens to be competitive in the co-evolution with hosts and evade their immune systems (Dong et al., 2015; Raffaele and Kamoun, 2012).

Verticillium dahliae is a soil-borne fungal plant pathogen that is able to infect a broad range of plant species, including crops such as tomato, potato, lettuce, and cotton (Fradin and Thomma, 2006; Inderbitzin et al., 2011). The fungus infects plants through their roots and subsequently colonizes the water-conducting xylem vessels, leading to vascular wilt disease (Fradin and Thomma, 2006). Comparative genomics study of $V$. dahliae strains revealed that they carry highly dynamic, repeat rich, lineage-specific (LS) regions that are only present in a subset of $V$. dahliae strains, and that account for up to $4 \mathrm{Mb}$ of the $\sim 35 \mathrm{Mb}$ genome size (de Jonge et al., 2013; Faino et al., 2016). These LS regions are enriched for in planta-induced effector genes that contribute to fungal virulence (de Jonge et al., 2013; Faino et al., 2016). However, effector genes are not only found in LS regions, as also the core genome harbours effector genes, such as those encoding 
a family of necrosis and ethylene-inducing-like proteins (NLPs) some of which were found to induce cell death in dicotyledonous plants (de Jonge et al., 2011; Santhanam et al., 2013). Similarly, also a family of lysin motif (LysM) effectors is encoded in the core genome, various homologs of which have been reported to enhance virulence by suppression of chitin-triggered immunity in other fungal pathogens (de Jonge et al., 2010; Kombrink et al., 2017; Marshall et al., 2011; Mentlak et al., 2012; Takahara et al., 2016). However, only a single LysM effector that is encoded in an LS region of V. dahliae strain VdLs17, and is not found in the genomes of other V. dahliae strains, was found to contribute to virulence by suppression of chitin-triggered immunity, whereas no role in virulence could be attributed to any of the core LysM effectors (Kombrink et al., 2017).

Whereas $V$. dahliae is characterized by its generally broad host range, and the observation that individual strains infect a diversity of hosts, differential pathogenicity among hosts occurs for individual strains (Bhat and Subbarao, 1999). In this study, we analysed the genomes of a collection of $V$. dahliae strains and assessed their core and LS effector catalogues in relation to their host ranges. To this end, we selected a set of strains that are well-adapted to cause disease on tomato (Solanum lycopersicum), cotton (Gossypium hirsutum), Australian tobacco (Nicotiana benthamiana), Arabidopsis (Arabidopsis thaliana), and sunflower (Helianthus annuus) and determined their core and LS effector catalogues as well as their in-planta expression profiles.

\section{Materials and methods}

\section{V. dahliae strains and plant inoculations}

In total, $21 \mathrm{~V}$. dahliae strains were used in this study (Table $\mathrm{S} 1$ ). All strains were grown on potato dextrose agar (PDA; Oxoid, Basingstoke, UK) at $22^{\circ} \mathrm{C}$, and conidiospores were collected from 10-day-old plates and washed with tap water. Disease assays were performed on sunflower (Helianthus annuus L. cv. Tutti), cotton (Gossypium hirsutum cv. Simian 3), tomato (Solanum lycopersicum cv. Moneymaker), Nicotiana benthamiana and Arabidopsis (Col-o) plants using the root-dipping inoculation method as previously described (Fradin et al., 2009; Song et al., 2017). Briefly, two-week-old (Arabidopsis, tomato, cotton, sunflower) or three-week-old ( $N$. benthamiana) seedlings were carefully uprooted and the roots were rinsed in water. Subsequently, the roots were dipped in a suspension of $10^{6}$ conidiospores $/ \mathrm{mL}$ for $8 \mathrm{~min}$. Control plants were treated similarly by root dipping in tap water without conidiospores. Disease symptoms were scored up to 21 (tomato, N. benthamiana, Arabidopsis), 28 (cotton) or 45 (sunflower) days post inoculation (dpi).

\section{Genome sequencing and assembly}

The genome sequences of $21 \mathrm{~V}$. dahliae strains were previously determined, 17 of which were previously sequenced using Illumina HiSeq 2000 (de Jonge et al., 2013; de Jonge et al., 2012; Kombrink et al., 2017) and four that were sequenced using long-read PacBio Single-Molecule Real-Time (SMRT) sequencing technology (Table S1) (Faino et al., 2015). V. dahliae strains that were sequenced with short-read sequencing technology (17 strains) were assembled with the A5 pipeline (default parameters) that automates data cleaning, error correction, assembly, 
and quality control (Tritt et al., 2012). Genome assembly statistics for $21 \mathrm{~V}$. dahliae strains were calculated using QUAST (Gurevich et al., 2013). Repeats were identified using RepeatModeler (version 1.0.8) (default parameters) (Smit and Hubley, 2010).

\section{Gene prediction and annotation}

Previously generated gene annotations of $V$. dahliae strains JR2 (Faino et al., 2015) and CQ2 (Unpublished data) were used in this study. For the remaining $19 \mathrm{~V}$. dahliae strains, gene annotation was performed using the Maker2 pipeline (Holt and Yandell, 2011) that combines $a b$ initio protein-coding gene evidence from SNAP (Korf, 2004), Augustus (Stanke and Waack, 2003), and GeneMark-HMM (Lukashin and Borodovsky, 1998). Additionally, Maker2 was provided with the previously generated reference gene annotation of $V$. dahliae strain JR2 (Faino et al., 2015), gene annotation of $V$. dahliae strain CQ2 (Unpublished data), and protein homologs of 260 predicted fungal proteomes obtained from the UniProt database (Apweiler et al., 2004).

\section{Effector profiling}

We determined core and LS regions of each V. dahliae strain. For LS regions, pairwise wholegenome alignments of the $21 \mathrm{~V}$. dahliae strains were performed using NUCmer (version 3.1) (-maxmatch), which is part of the MUMer package (Kurtz et al. 2004), and LS regions (here defined as genomic regions that are shared by $<19 \mathrm{~V}$. dahliae strains) were extracted. Subsequently, core regions (regions shared by $\geq 19 \mathrm{~V}$. dahliae strains) were determined. Genes localized within core and LS regions were extracted using BEDtools intersect (Quinlan and Hall 2010).

To identify candidate effectors, N-terminal signal peptides were first predicted with SignalP (version 4.1) (Petersen et al., 2011). Subsequently, the machine-learning approach applied in EffectorP (version 1.0) (default parameters) was used (Sperschneider et al., 2016). Effector genes localized within core and LS regions were extracted using BEDtools intersect (Quinlan and Hall, 2010). Sequence similarity between predicted LS effectors was established by an all-vs.-all analyses using BLASTp (E-value cutoff 1e-5) (Altschul et al., 1990). Clustering of LS effector sequences into different families was performed using MCL (default options) (Li et al., 2003) and visualized using the function heatmap.2, which is a part of the R package gplots (Warnes et al., 2015).

\section{Assessment of gene expression}

To assess gene expression levels, two RNA-seq datasets were used. The first RNA-seq dataset was previously generated from $V$. dahliae strain JR2-infected Nicotiana benthamiana plants at 4, 8, 12, and 16 day-post inoculation (dpi) (de Jonge et al., 2012; Faino et al., 2014). The second RNA-seq dataset was obtained from V. dahliae strain V991 infecting cotton plants at 6, 9, 12, and 15 dpi (L. Zhu, unpublished data). Mapping of RNA-seq datasets to the corresponding genomes was performed using STAR (version 2.5.3) (--runThreadN 16) (Dobin et al., 2013), and gene expression levels were determined using RSEM (version 1.2.3) (calculate-expression command) (default parameters) (Li and Dewey, 2011), by calculating transcripts per million (TPM) for each gene in each sample. 


\section{Results}

\section{Verticillium dahliae pathogenicity on a panel of potential host plants}

To evaluate the pathogenicity of a collection of $V$. dahliae strains on a panel of potential host plant species, we conducted inoculation experiments with 21 strains on the Solanaceae crop plant tomato and model plant $N$. benthamiana, the Malvaceae crop plant cotton, the Asteraceae crop plant sunflower, and the Brassicaceae model plant Arabidopsis. Despite the fact that V. dahliae is generally considered as a broad host range pathogen, there is no individual $V$. dahliae strain in this collection that has the capacity to cause disease on all five plant species (Table 1).

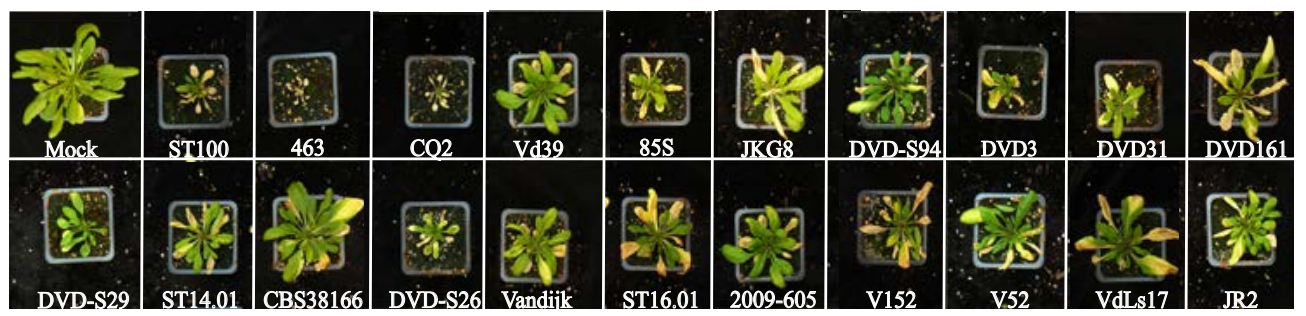

Figure 1. A collection of $V$. dahliae strains all are pathogenic on Arabidopsis thaliana. Typical appearance of A. thaliana (Col-o) plants upon mock-inoculation or inoculation with a collection of $V$. dahliae strains. Note that disease symptoms ranging from stunting, wilting to severe tissue necrosis. Pictures show representative plants at 21 days after inoculation taken from one of two independent inoculation experiments.

Table 1. Inoculation experiments with V. dahliae strains on a collection of potential host plants.

\begin{tabular}{cccccc}
\hline Strain & Arabidopsis & N. benthamiana & Cotton & Tomato & Sunflower \\
\hline ST100 & + & + & + & - & - \\
463 & + & + & + & - & - \\
CQ2 & + & + & + & - & - \\
Vd39 & + & + & + & - & + \\
$85 S$ & + & + & + & + & + \\
JKG8 & + & + & + & + & - \\
DVD-S94 & + & + & + & + & - \\
DVD3 & + & + & + & + \\
DVD31 & + & + & + & + & - \\
DVD161 & + & + & + & + & - \\
DVD-S29 & + & + & + & - \\
ST14.01 & + & + & + & - \\
CBS38166 & + & + & + & - \\
DVD-S26 & + & + & + & - \\
Vandijk & + & + & + & - \\
ST16.01 & + & + & + & - \\
2009-605 & + & + & + & + \\
V152 & + & + & + & + \\
V52 & + & + & + & -
\end{tabular}

"+"= pathogenic;"-"= non-pathogenic. Disease symptoms were scored up to 21 days post inoculation (dpi) (tomato, N. benthamiana, Arabidopsis), $28 \mathrm{dpi}$ (cotton) or $45 \mathrm{dpi}$ (sunflower). The inoculation experiments were executed twice with similar results. 
All isolates are pathogenic on Arabidopsis (Figure 1) and on N. benthamiana (Figure 2), albeit that the severity of disease symptoms that are induced by different strains vary considerably. Most strains were also found to cause disease on cotton, with the exception of strains 2009-605 and V152 that are non-pathogenic on this species. Interestingly, V. dahliae strains CQ2, 463 and ST100 cause severe defoliation, while the other pathogenic strains induce mild to moderate disease symptoms that includes wilting, stunting and chlorosis in the absence of defoliation (Figure 3 ).

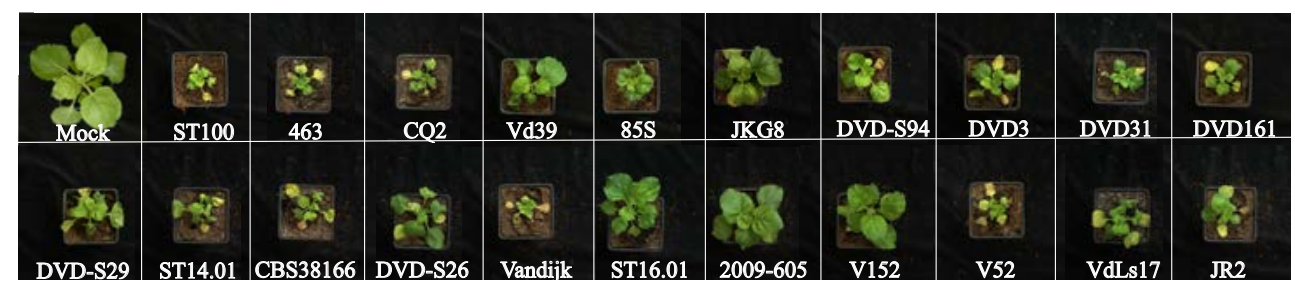

Figure 2. A collection of $V$. dahliae strains all are pathogenic on Nicotiana benthamiana. Typical appearance of $N$. benthamiana plants upon mock-inoculation or inoculation with a collection of V. dahliae strains. Note that disease symptoms including stunting, wilting and severe tissue necrosis. Pictures show representative plants at 21 days after inoculation taken from one of two independent inoculation experiments.

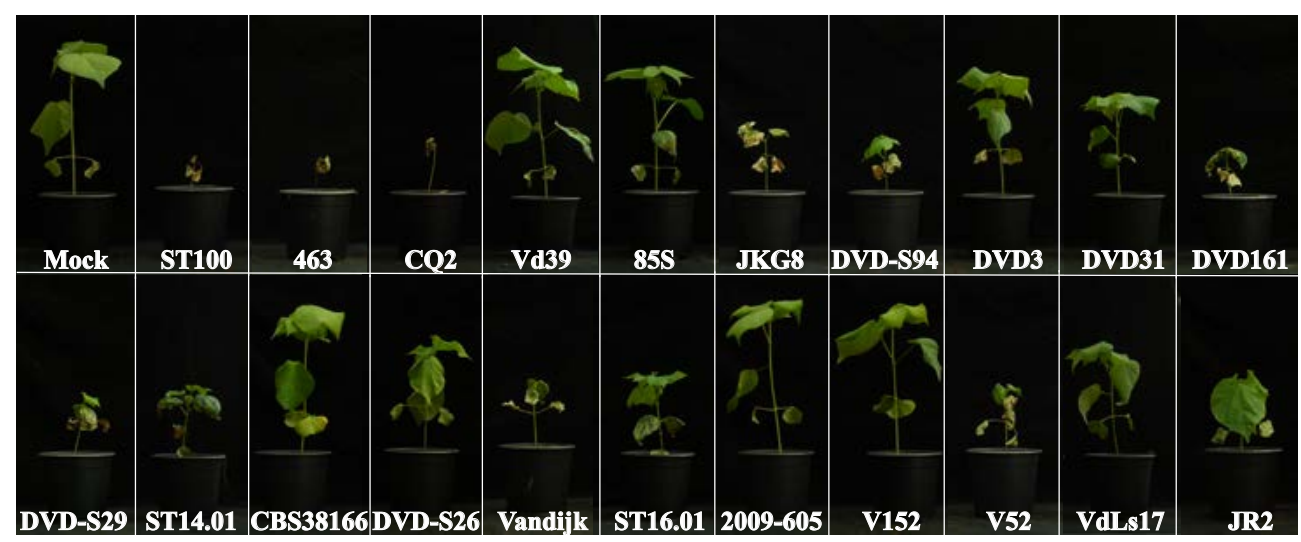

Figure 3. A collection of $V$. dahliae strains display differential pathogenicity on cotton plants. Typical appearance of cotton (cv. Simian 3) plants upon mock-inoculation or inoculation with a collection of V. dahliae strains. Note that several V. dahliae strains cause defoliation symptoms, while others induce wilting, stunting but not defoliation. Pictures show representative plants at 28 days after inoculation taken from one of two independent inoculation experiments.

Fewer V. dahliae strains are able to cause disease on tomato (Figure 4). Besides several strains that cause defoliation on cotton, the tomato non-pathogenic strains also include several nondefoliators on cotton like $\mathrm{Vd} 39$ and $85 \mathrm{~S}$. Interestingly, whereas strain V152 that is non-pathogenic on cotton also fails to cause disease on tomato, the cotton non-pathogenic strain 2009-605 is able to cause wilt disease on tomato (Figure 4). Strikingly, except for V. dahliae strain $85 \mathrm{~S}$ that induces clear wilt disease symptoms on sunflower plants such as stunting, including stunting, chlorosis and necrosis, all other strains fail to cause sunflower disease (Figure 5). Thus, differential pathogenicity occurs within the collection of $V$. dahliae strains tested here. 


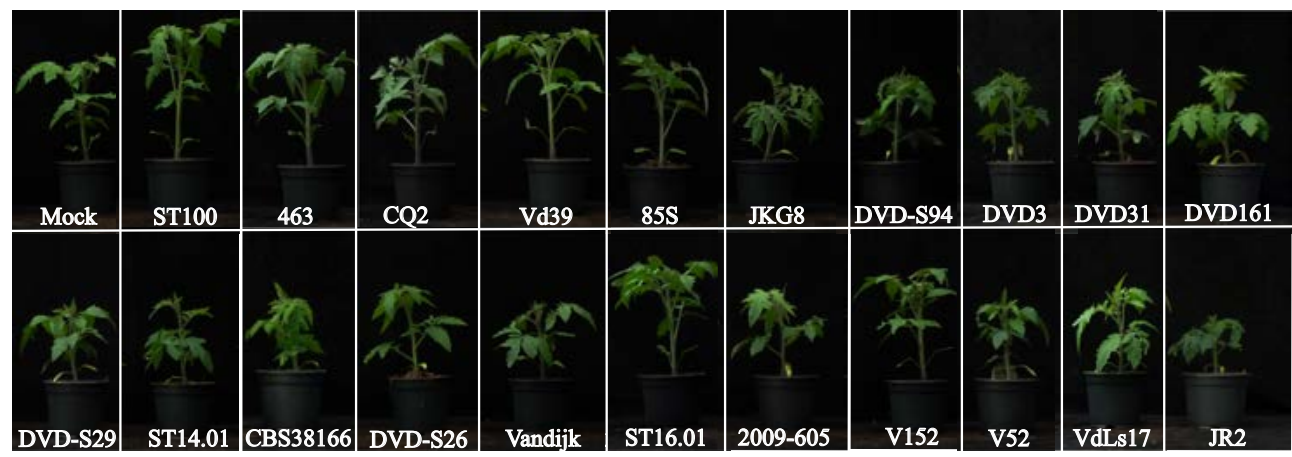

Figure 4. A collection of $V$. dahliae strains display differential pathogenicity on tomato plants. Typical appearance of tomato (cv. Moneymaker) plants upon mock-inoculation or inoculation with a collection of $V$. dahliae strains. Note that pathogenic strains induced clear stunting and significant reduction in canopy area development on inoculated plants. Pictures show representative plants at 21 days after inoculation taken from one of two independent inoculation experiments.

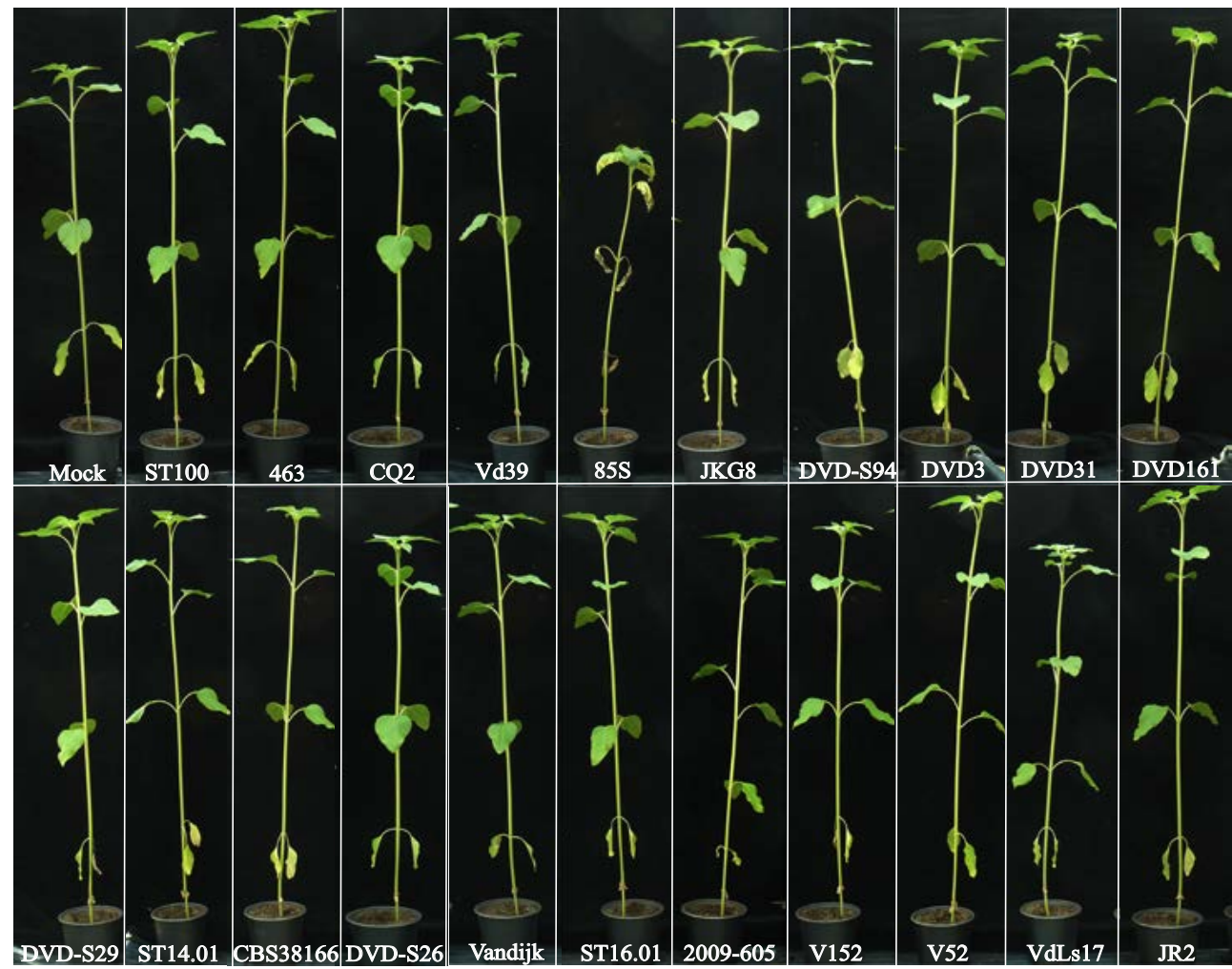

Figure 5. A collection of $\mathbf{V}$. dahliae strains display differential pathogenicity on sunflower plants. Typical appearance of sunflower (cv. Tutti) plants upon mock-inoculation or inoculation with a collection of V. dahliae strains. Note that besides the stunting, the plant inoculated with pathogenic strain $85 \mathrm{~S}$ also displays chlorosis and wilting symptoms. Pictures show representative plants at 45 days after inoculation taken from one of two independent inoculation experiments. 


\section{Genome assemblies and annotations of a collection of $V$. dahliae strains}

The genome sequences of $21 \mathrm{~V}$. dahliae strains (Table S1) were obtained from previous studies, 17 of which were determined using the Illumina HiSeq 2000 platform (de Jonge et al., 2013; de Jonge et al., 2012; Kombrink et al., 2017), and four were sequenced using long-read PacBio Single-Molecule Real-Time (SMRT) sequencing technology (Faino et al., 2015). As the genomes of $V$. dahliae strains that were previously sequenced with Illumina technology showed a reduced N50 size of about $35.55 \mathrm{~kb}$ (de Jonge et al., 2012), all the Illumina sequenced genomes were assembled in this study. The short reads of the $17 \mathrm{~V}$. dahliae strains that were sequenced with Illumina technology were assembled into $\sim 34 \mathrm{Mb}$, with the largest assembly of $35.90 \mathrm{Mb}$ for $\mathrm{V}$. dahliae strain Vd39, and the smallest assembly of $33.14 \mathrm{Mb}$ for V. dahliae strain DVD-S29 (Table S2). All assemblies comprised between 1,000 and 4,180 scaffolds with an N50 of approximately 50 $\mathrm{kb}$, except for $V$. dahliae strains 463 and v52 that were assembled in 4,188 and 3,419 scaffolds with an $\mathrm{N} 50$ of $17.74 \mathrm{~kb}$ and $21.80 \mathrm{~kb}$, respectively (Table S2).

To assess the completeness of the assemblies, the Benchmarking Universal Single-Copy Orthologs (BUSCO) software was used, which uses a set of 1,315 core Ascomycota genes as queries (Simão et al., 2015). The BUSCO scores amounted to $\sim 94 \%$ for all the assemblies, except for $V$. dahliae strains 463 and v52 that resulted in $75 \%$ and $78.6 \%$, respectively (Table S2). For the PacBio sequenced strains, BUSCO scored $99.30 \%$ for 85 S and $97.50 \%$ for CQ2, while the BUSCO scores for the gapless genome assemblies of JR2 and VdLs17 (Faino et al., 2015) amounted to $99.40 \%$ and 98.90\%, respectively (Table S2).

Repetitive elements are strong drivers of genome evolution in plant pathogens (Seidl and Thomma, 2017). Thus, the amounts and types of repetitive elements in the genomes of $V$. dahliae strains were predicted by combining de novo and known repetitive elements with RepeatMasker (Smit and Hubley, 2010). The repeat content within the V. dahliae genomes varied between $6.64 \%$ (2.26 Mb) for V. dahliae strain 2009-605 and 13.43\% (4.83 Mb) for V. dahliae strain $85 \mathrm{~S}$ (Table 2). Out of all the annotated repetitive elements, different repeat families were identified, which included long terminal repeats (LTRs) ( $2 \mathrm{Mb}, \sim 5.7 \%$ ), long interspersed nuclear elements (LINEs) (40 kb, $\sim 0.11 \%$ ), and short interspersed nuclear elements (SINEs) (2.9 kb, 0.01\%) (Table S3).

We subsequently inferred gene annotations for the various V. dahliae strains. For V. dahliae strains JR2 and CQ2 a previously determined gene annotation was used (Faino et al., 2015). The completeness of gene annotation for both strains was assessed using BUSCO that scored only a low score for CQ2 (72\%) compared to JR2 (90.80\%). Thus, gene annotations were inferred for all $20 \mathrm{~V}$. dahliae strains, except for V. dahliae strain JR2. The Maker2 pipeline (Holt and Yandell, 2011) was used that combines de novo, homology-based, and previous gene annotations for $V$. dahliae strains CQ2 (B. Thomma and J. Li, unpublished data) and JR (Faino et al., 2015) and protein homologs of 260 predicted fungal proteomes. The number of genes varied from 10,461 for $V$. dahliae strain VanDijk to 11,341 for V. dahliae v52 (Table 2). 


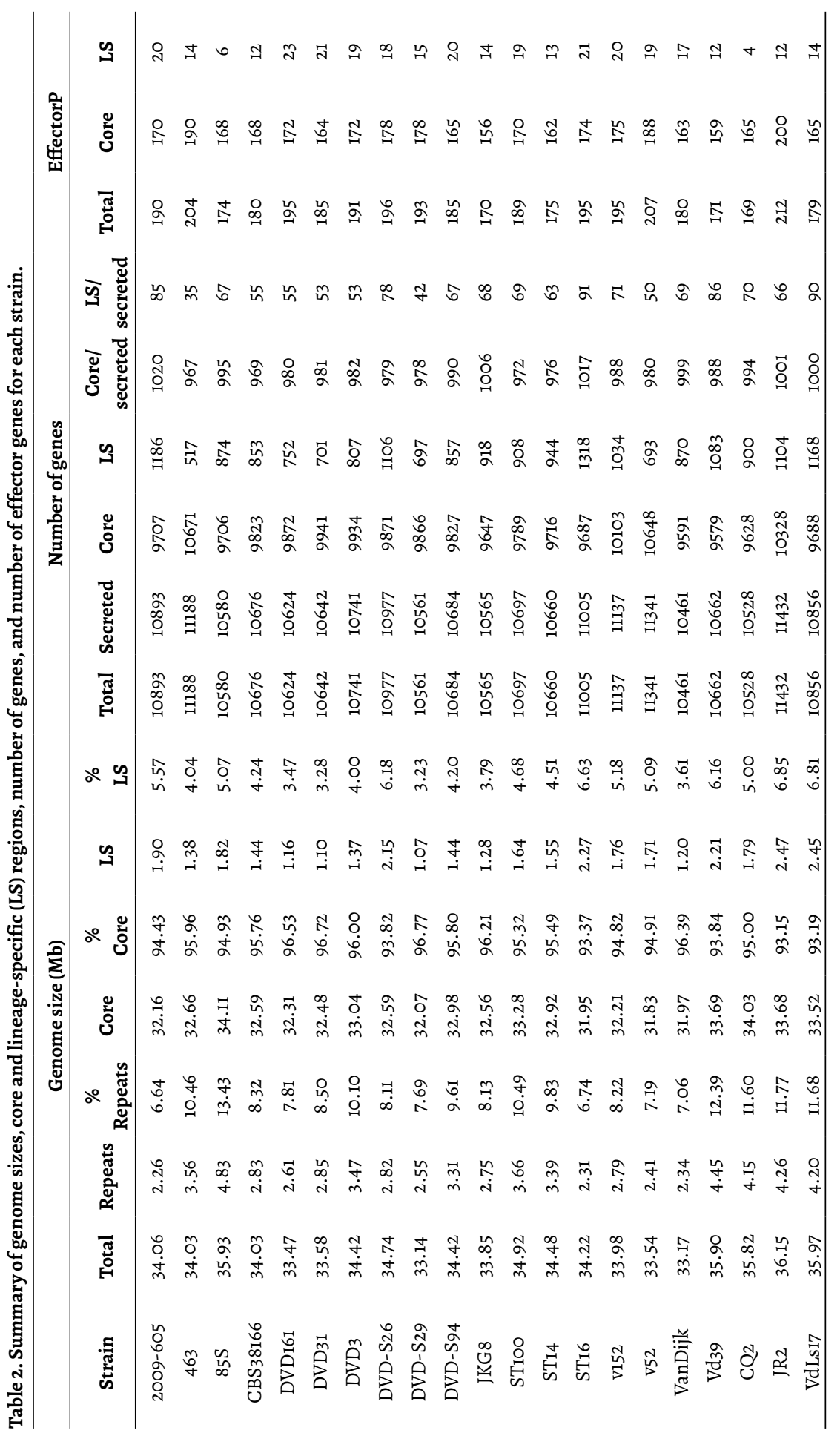




\section{Identification of core and lineage-specific (LS) effector catalogs}

Initially, the secretomes for each of the $V$. dahliae strains were predicted, identifying between 9,67 secreted proteins for $V$. dahliae strain 463 and 1,017 proteins for V. dahliae strain ST16 (Table 2). Subsequently, the machine-learning algorithm of EffectorP (Sperschneider et al., 2016) was used, which identified between 169 effectors for V. dahliae strain CQ2 and 212 effectors for $V$. dahliae strain JR2 (Table 2).

Subsequently, we determined the core genome, here defined as regions that are shared by $\geq 19 \mathrm{~V}$. dahliae strains, and LS regions, here defined as regions that are shared by $<19 \mathrm{~V}$. dahliae strains, for all $V$. dahliae strains. The core regions of all V. dahliae strains comprise $32.79 \mathrm{Mb}$ (93-97\%) of the genome, while LS regions comprise between 1.07 (strain DVDS-29) and 2.47 Mb (strain JR2) (3-7\%) (Table 2). The core regions of $V$. dahliae strains harbor 9,886 genes, comprising 988 genes that encode secreted proteins, of which 171 were classified as effectors based on EffectorP (Table 2). The LS regions of $V$. dahliae strains harbor between 517 genes for $V$. dahliae strain 463 and 1,318 genes for V. dahliae strain ST16 (Table 2). Of these LS genes, 35 genes encode secreted proteins for $V$. dahliae strain 463 and 91 for $V$. dahliae strain ST16, of which $\sim 15$ genes were classified as effectors for each $V$. dahliae strain (Table 2). We tested these predictions on the previously identified LS effector gene of $V$. dahliae strain JR2, namely Ave1, which was successfully identified as an LS effector gene (de Jonge et al., 2012) (Figure S1).

To assess general characteristics of core and LS effector genes, features such as their distance to transposable elements (TEs), gene length, inter-genic length, and expression were determined. For all strains, we observed that LS effector genes are shorter in length than core effector genes (Figure 6A, B; Figure S2). The average inter-genic length of LS effector genes is slightly longer (1476 bp) compared to the average inter-genic length of core effector genes (1232 bp) (Figure 6A, B; Figure S3). Moreover, LS effector genes localize closer to TEs than core effector genes, even though this trend is not significant for V. dahliae strain JR2 (Figure 6A, B; Figure S4). Finally, LS effector genes of $V$. dahliae strain JR2 were found to be significantly higher expressed in planta on $N$. benthamiana than core effector genes (Figure $7 \mathrm{~A}$ ), although no such difference was found between LS and core effectors of V. dahliae strain CQ2 in planta on cotton (Figure 7B). 


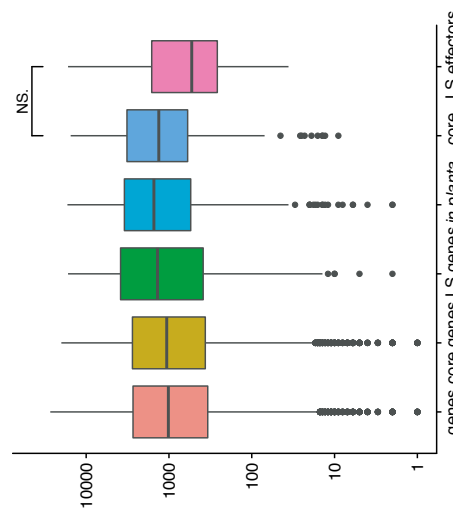

(0เ60|)S $\exists \perp$ 아 әJuets!a

앳유윤으요

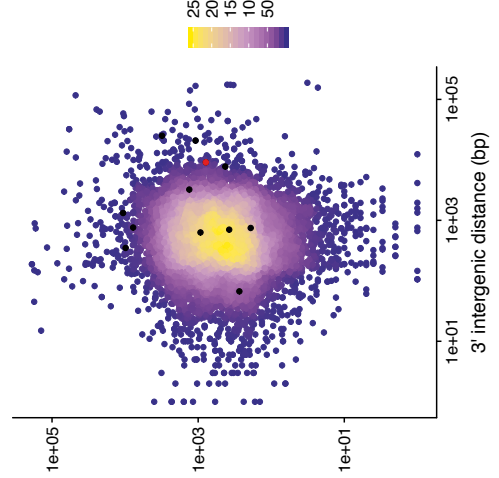

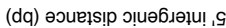

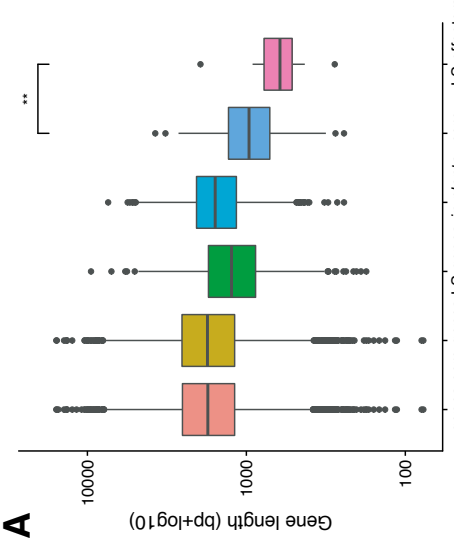

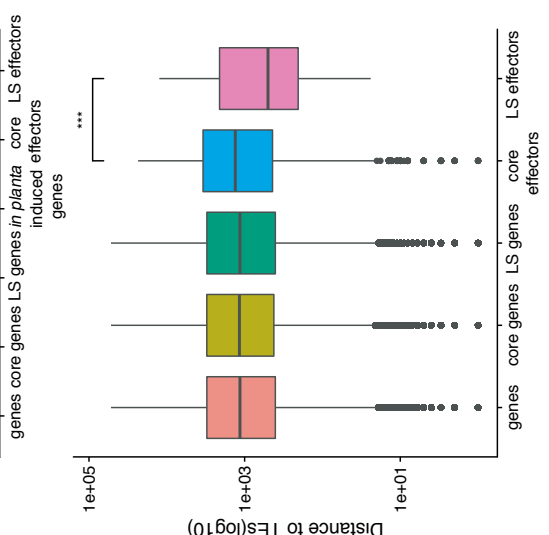

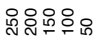

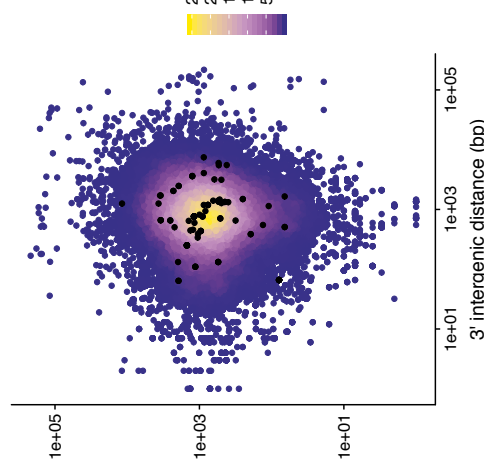

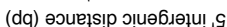

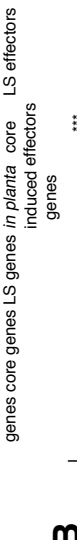

ต

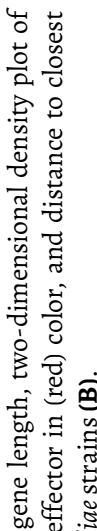

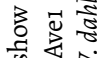

๑ี 坣

䒕苛客

¿ $\stackrel{\pi}{3}$

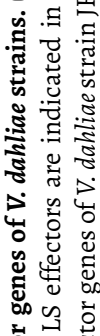

氙苋

艺求 क

भ ज्ञ

क :

ญ ญ

ชั

잉

氙站出

䓵苛

䒿芯芯

迅密

0 -

氮 


\section{V. dahliae strains that infect the same host plant harbor divergent effector repertoires}

It has previously been shown that $V$. dahliae strains display differential capacity to infect particular host plants (Bhat and Subbarao, 1999). We furthermore showed that especially the LS effectors contribute to $V$. dahliae pathogenicity on individual plant hosts (de Jonge et al., 2013; de Jonge et al., 2012; Kombrink et al., 2017). Collectively, this suggests that $V$. dahliae strains may harbour an array of specialized effectors that only function on particular host plants, and thus we assessed whether the presence of particular LS effectors in the various $V$. dahliae strains correlates with the ability to infect particular hosts. In total, we predicted $333 \mathrm{LS}$ effectors over the various strains (Table 2) that were clustered into 110 families that are either shared by sub-groups of $V$. dahliae strains, or are strain-specific (Figure 8). Furthermore, we searched the 333 LS effector genes against V. dahliae genomes using BLAST (tblastn) and identified XLOC_00170, XLOC_008951, and XLOC_009059 of V. dahliae strain JR2, which are shared by a subset of V. dahliae strains (Figure 8). Intriguingly, we observed highly dissimilar LS effector catalogs among V. dahliae strains that are able to infect the same host plant (Figure 8). Strikingly, V. dahliae strains that infect the same host plant do not cluster based on their LS effector repertoires (Figure 8). Thus, V. dahliae strains harbor highly divergent LS effector catalogs, the composition of which does not correlate with the host plant they are able to infect.
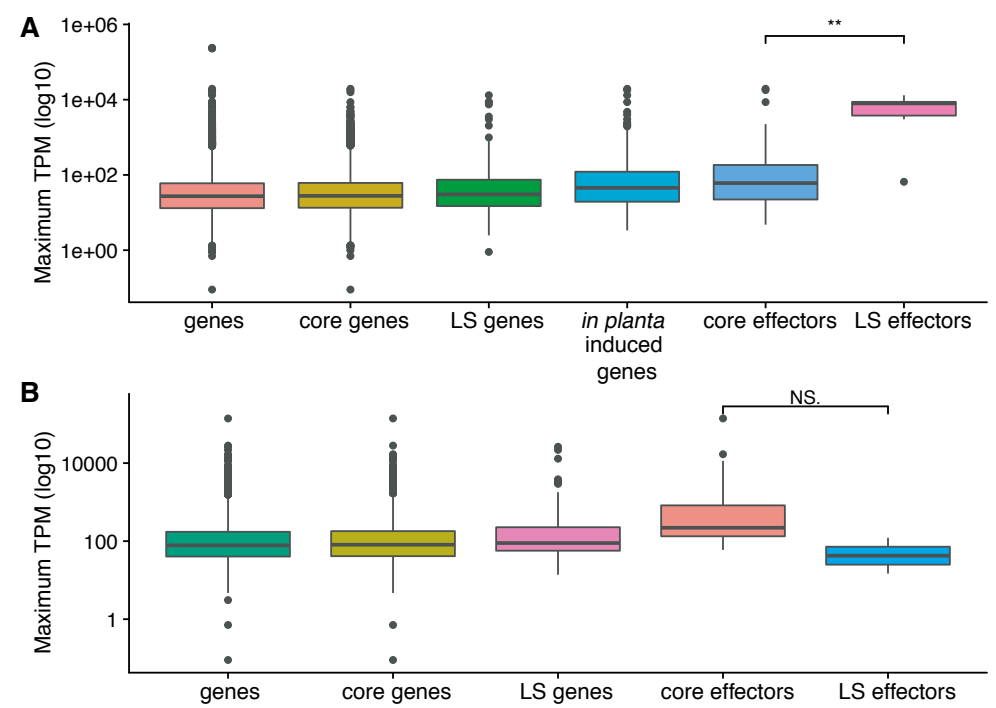

Figure 7. Maximum TPM values of core and LS effector genes over four time points during N. benthamiana and cotton infection by V. dahliae strains JR2 vs CQ2. (A) Maximum TPM values of core and LS effector genes over 4, 8, 12 , and 16 time points during N. benthamiana infection by V. dahliae strain JR2. (B) Maximum TPM values of core and LS effector genes over 6, 9, 12, and 15 time points during cotton infection by V. dahliae strain CQ2. 


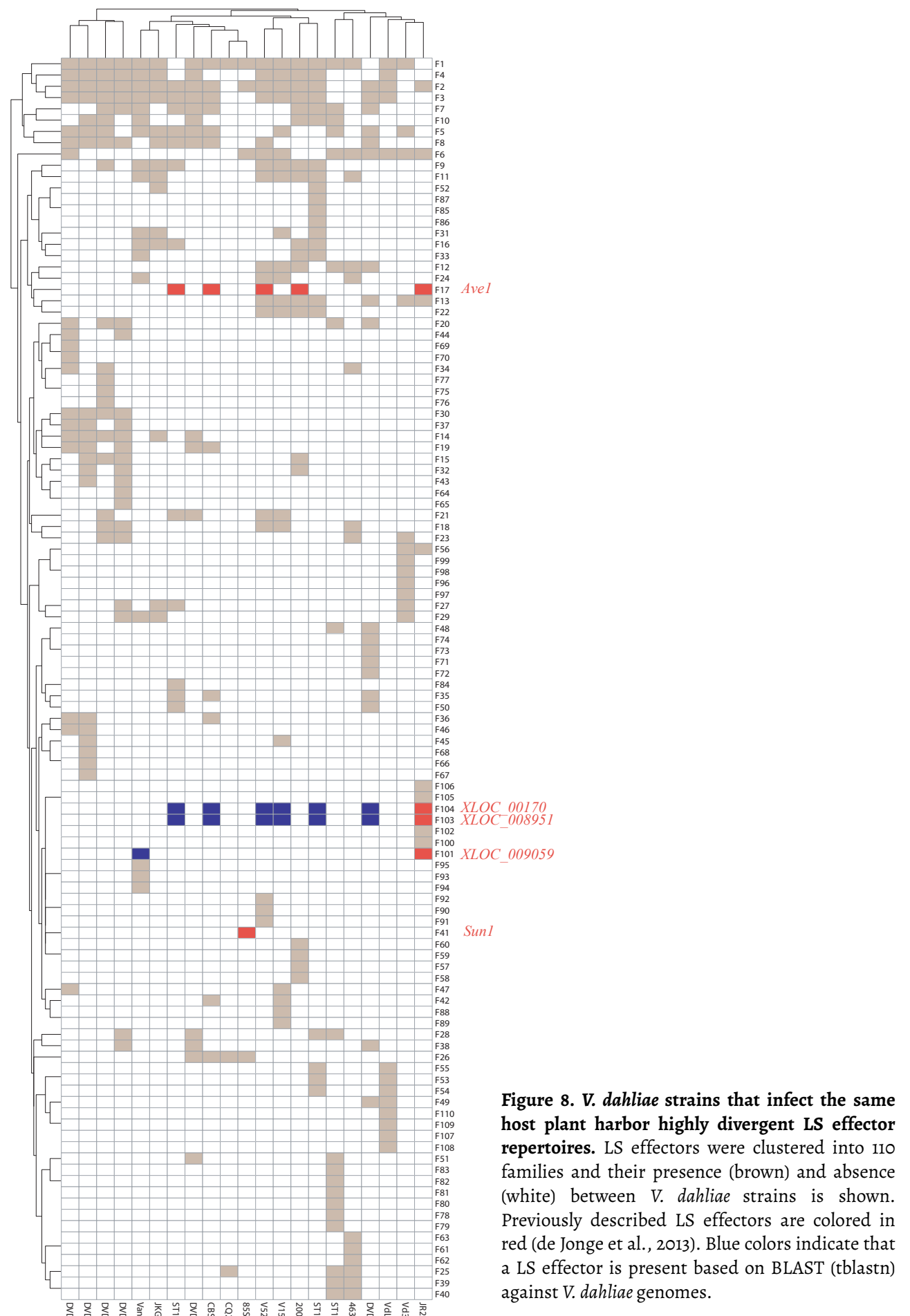




\section{Variability in core effector transcription profiles}

In many plant pathogens, core effector genes are highly induced in planta and play essential roles on a multitude of hosts (Guyon et al., 2014; Hemetsberger et al., 2015; Santhanam et al., 2013; Yin et al., 2017). Thus, we assessed the expression of $V$. dahliae core effector genes during invasion of different plant species. First, we mapped RNA-seq datasets from $N$. benthamiana plants colonized by $V$. dahliae strain JR2 (de Jonge et al., 2012) against the reference genome sequence of $V$. dahliae strain JR2 (Faino et al., 2015), and cotton plants colonized by V. dahliae strain V991 (LF Zhu, unpublished data) against its closely related $V$. dahliae strain CQ2. Subsequently, RNAseq reads overlapping core effector genes of V. dahliae JR2 and V. dahliae strain CQ2 were quantified and core effector genes that are shared between both strains were determined. We observed that the transcription profiles can be clustered into: 1) transcribed effector genes on both hosts, 2) differentially transcribed effector genes between the two hosts, and 3) non-transcribed effector genes on either hosts (Figure 9A). Of the 165 shared core effector genes between JR2 and CQ2, 61 effector genes were transcribed during cotton as well as $N$. benthamiana colonization, whereas 19 effector genes were only transcribed on cotton, and 41 effector genes were transcribed on $N$. benthamiana (Figure 9B). Additionally, we identified 44 effector genes that were non-transcribed in both strains (Figure 9A). Thus, differential $V$. dahliae core effector gene expression is observed on different host plants. Overall, we are not able to link the composition or the expression of effector gene catalogs to the ability to infect particular host plants. 
A

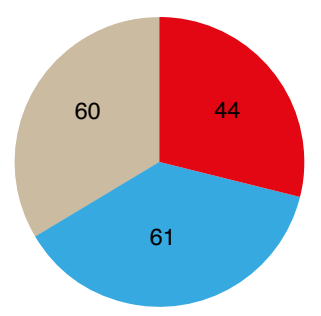

Non-transcribed on two hosts

Transcribed on two hosts

Differentially transcribed
Figure 9. Variability in transcription profiles of core effector genes of $\mathrm{V}$. dahliae strains JR2 and CQ2. (A) Pie chart showing the number of non-transcribed, transcribed, and differentially transcribed core effector genes of $V$. dahliae strain JR2 and $\mathrm{CQ}_{2}$ on N. benthamiana and cotton. (B) Transcription profile comparisons of core effector genes of JR2 (left) and CQ2 (right) over four time points during infection. The log-scaled color gradient shows TPM values for each core effector at different time points.

\section{B}

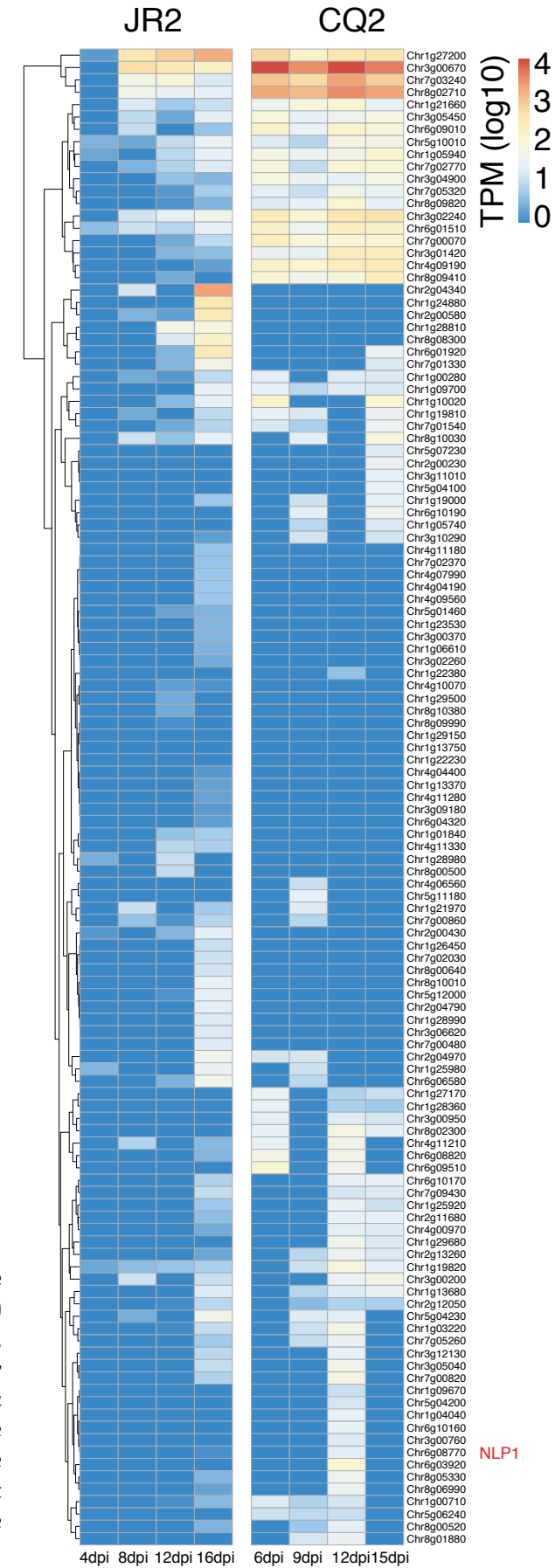




\section{Discussion}

For broad host-range pathogens such as $V$. dahliae it is unclear to what extent co-evolution of the pathogen with multiple hosts occurs simultaneously, and what implications this has for their effector repertoires. Whereas it is conceivable that broad host-range pathogens employ core effectors target broadly conserved general physiological processes in a multitude of hosts, they may also harbour an array of specialized effectors that only exert activity on particular host species. Presence of such specialized effectors is suggested by the observation that different $V$. dahliae strains, despite their general ability to infect a wide array of host plants, generally display differential capacity to infect particular hosts (Bhat and Subbarao, 1999). Therefore, in this study we investigated whether the absence or presence of particular effectors correlates with the ability to infect particular hosts. Intriguingly, we observed that $V$. dahliae strains that are able to infect the same host plant, in this case focussed on tomato, cotton, N. benthamiana, Arabidopsis, and sunflower, harbour highly divergent LS effector catalogs (Figure 8). This strongly suggests that different strains infect the same host plant by utilizing different effector compositions. If one assumes that different strains of $V$. dahliae must target the same host physiological processes in order to establish the infection, this implies that there must be a significant degree of redundancy among the various effectors that occur in the different strains. Interestingly, fungi of the ascomycete species Fusarium oxysporum display a similar infection biology as V. dahliae, being soil-borne pathogens that colonize the xylem tissues of their host plants to cause vascular wilt disease and with a largely overlapping host range. However, whereas individual strains of $V$. dahliae are characterized by their generally large host range, strains of $F$. oxysporum are generally host-specific and are therefore assigned to formae specialis. Comparative genomics revealed that Fusarium strains within a formae specialis carry highly overlapping LS effector repertoires (Coleman et al., 2009; Ma et al., 2010; van Dam et al., 2016). Moreover, strains within the same Fusarium formae specialis cluster based on their LS effector repertoires (van Dam et al., 2016). Thus, in contrast to F. oxysporum strains that harbour highly overlapping LS effectors based on their host range, $V$. dahliae strains evolved highly divergent LS effector catalogs, the composition of which does not correlate with the host plant they are able to infect.

Plant pathogens harbour an array of in planta highly-induced core effector genes that play essential roles on a multitude of hosts (Guyon et al., 2014; Hemetsberger et al., 2015; Santhanam et al., 2013; Yin et al., 2017). We quantified RNAseq reads (RNAseq reads of V. dahliae JR2-infecting $N$. benthamiana plants and RNAseq reads of V. dahliae strain V991-infecting cotton) overlapping core effector genes of JR2 and CQ2 (closely related to V991). Subsequently, we categorized the effectors in three groups based on their expression profiles. We identified a group of effector genes that are transcribed in both strains (Figure. 9B), suggesting that this group of effectors contributes to $V$. dahliae colonization of $N$. benthamiana and cotton. Additionally, we observed a group of effector genes that are highly transcribed in $V$. dahliae strain JR2 on N. benthamiana but only lowly transcribed in strain $\mathrm{CQ}_{2}$ on cotton, and vice versa (Figure 9B), suggesting that they differentially contribute to virulence on these two host plants. Furthermore, we identified a group of effector genes that are not transcribed in either strains (Figure 9A), suggesting that this group of core effectors do not play a role in virulence on $N$. benthamiana or on cotton. 
Nevertheless, it may well be that this group of effector genes is transcribed during $V$. dahliae colonization of other host plants. Surprisingly, we observed that a member of the family of necrosis- and ethylene-inducing-like proteins (NLPs), namely NLP-1, is found within the group of non-transcribed effector genes (Figure 9), whereas we previously found based on real-time PCR that this effector gene is transcribed in V. dahliae strain JR2 on N. benthamiana and on tomato, but also in V. dahliae strain V592 on cotton (Santhanam et al., 2013; Zhou et al., 2012). Likely, the lack of NLP-1 expression based on our RNAseq data may be due to the low amount of fungal RNAseq reads among plant-derived ones, as only $0.05 \%$ of the reads could be mapped to the V. dahliae genome (Faino et al., 2014). Thus, it needs to be taken into account that only highly expressed fungal genes are identified, and it might be worthwhile to confirm whether the group of non-transcribed effector genes still contains lowly or moderately expressed genes based on real-time PCR.

Localization of pathogen effector genes within dynamic genomic regions allows pathogens to rapidly evolve to evade plant immunity once an effector gets recognized by the host (Dong et al., 2015; Raffaele and Kamoun, 2012). When we assessed the core and LS effector repertoires among the analysed $V$. dahliae strains, we observed no remarkable differences in the number of core and LS effectors (Table 2). Nevertheless, by comparing features of core and LS effectors we observed that LS effectors are typically shorter in length, localize significantly closer to TEs, and have slightly longer inter-genic lengths when compared with core effectors (Figure 6). Consistent with this observation, a recent study that analysed the genomes of nine Verticillium spp. showed that species-specific genes displayed significantly shorter gene lengths and longer inter-genic lengths when compared with genes that are conserved across the various species within the genus (Shi-Kunne et al., 2017). Similarly, LS genes of the fungal wheat pathogen $Z$. tritici were frequently found to be shorter, closer to TEs, and have longer inter-genic lengths, when compared with core genes (Haueisen et al., 2017; Plissonneau et al., 2018; Plissonneau et al., 2016). It has been previously suggested that the localization of effector genes in close proximity to TEs and within gene-poor regions mediate rapid evolution of effector catalogs (Raffaele and Kamoun, 2012; Seidl and Thomma, 2017). Thus, the localization of LS effector genes of V. dahliae strains in close proximity to TEs may mediate accelerated evolution of effector catalogs.

In conclusion, our data demonstrate the extensive variability within the effector repertoires of the broad host range pathogen $V$. dahliae. We have demonstrated that LS effectors are highly divergent among $V$. dahliae strains that infect the same host plant, and core effector genes are differentially expressed between hosts. The variability within LS and core effector genes of $V$. dahliae strains may lead to rapid immunity evasion, which may allow pathogen strains to be competitive in the co-evolution with their multiple hosts. 


\section{Acknowledgements}

Work in the laboratories of M.F.S and B .P.H.J.T. is supported by the Research Council Earth and Life Sciences (ALW) of the Netherlands Organization of Scientific Research (NWO). J Li acknowledges a PhD fellowship from China Scholarship Council (CSC). 


\section{References}

Altschul SF, Gish W, Miller W, Myers EW, Lipman DJ (1990) J Mol Biol 215: 403-410.

Apweiler R, Bairoch A, Wu CH, Barker WC, Boeckmann B, Ferro S, Gasteiger E, Huang H, Lopez R, Magrane M, et al. (2004) UniProt: the universal protein knowledgebase. Nucleic Acids Res 32: D115-Di19.

Bhat RG, Subbarao KV (1999) Host range specificity in Verticillium dahliae. Phytopathology 89: 1218-1225.

Coleman JJ, Rounsley SD, Rodriguez-Carres M, Kuo A, Wasmann CC, Grimwood J, Schmutz J, Taga M, White GJ, Zhou S, et al. (2009) The genome of Nectria haematococca: contribution of supernumerary chromosomes to gene expansion. PLOS Genet 5: e1000618.

Cook DE, Mesarich CH, Thomma BPHJ (2015) Understanding plant immunity as a surveillance system todetect invasion. Annu Rev Phytopathol 53: 541-563.

Croll D, McDonald BA (2012) The accessory genome as a cradle for adaptive evolution in pathogens. PLoS Pathog 8: e1002608.

de Jonge R, Bolton MD, Kombrink A, van den Berg GC, Yadeta KA, Thomma BPHJ (2013) Extensivechromosomal reshuffling drives evolution of virulence in an asexual pathogen. Genome Res 23: 1271-1282.

de Jonge R, Bolton MD, Thomma BPHJ (2011) How filamentous pathogens co-opt plants: the ins and outs of fungal effectors. Curr Opin Plant Biol 14: 400-406.

de Jonge R, van Esse HP, Kombrink A, Shinya T, Desaki Y, Bours R, van der Krol S, Shibuya N, Joosten MH, Thomma BP (2010) Conserved fungal LysM effector Ecp6 prevents chitin-triggered immunity in plants. Science 329: 953-955.

de Jonge R, van Esse HP, Maruthachalam K, Bolton MD, Santhanam P, Saber MK, Zhang Z, Usami T, Lievens B, Subbarao KV, et al. (2012) Tomato immune receptor Ve1 recognizes effector of multiple fungal pathogens uncovered by genome and RNA sequencing. Proc Natl Acad Sci USA 109: 5110-5115.

Dobin A, Davis CA, Schlesinger F, Drenkow J, Zaleski C, Jha S, Batut P, Chaisson M, Gingeras TR (2013) STAR: ultrafast universal RNA-seq aligner. Bioinformatics 29: 15-21.

Dong S, Raffaele S, Kamoun S (2015) The two-speed genomes of filamentous pathogens: waltz with plants. Curr Opin Genet Dev 35: 57-65.

Faino L, de Jonge R, Thomma BPHJ (2014) The transcriptome of Verticillium dahliae-infected Nicotiana benthamiana determined by deep RNA sequencing. Plant Signal Behav 7: 1065-1069.

Faino L, Seidl MF, Datema E, van den Berg GC, Janssen A, Wittenberg AH, Thomma BPHJ (2015) Single-molecule real-time sequencing combined with optical mapping yields completely finished fungal genome. mBio 6: e00936-00915.

Faino L, Seidl MF, Shi-Kunne X, Pauper M, van den Berg GC, Wittenberg AH, Thomma BPHJ (2016) Transposons passively and actively contribute to evolution of the two-speed genome of a fungal pathogen. Genome Res 26: 1091-1100.

Fisher MC, Henk DA, Briggs CJ, Brownstein JS, Madoff LC, McCraw SL and Gurr SJ (2012) Emerging fungal threats to animal, plant and ecosystem health. Nature 484: 186-194.

Fradin EF, Thomma BPHJ (2006) Physiology and molecular aspects of Verticillium wilt diseases caused by V. dahliae and V. albo-atrum. Mol Plant Pathol 7: 71-86.

Fradin EF, Zhang Z, Ayala JCJ, Castroverde CD, Nazar RN, Robb J, Liu C-M, Thomma BPHJ (2009) Genetic dissection of Verticillium wilt resistance mediated by tomato Ve1. Plant Physiol 150: 320-332.

Gurevich A, Saveliev V, Vyahhi N, Tesler G (2013) QUAST: quality assessment tool for genome assemblies. Bioinformatics 29: 1072-1075.

Guyon, K, Balagué C, Roby D, Raffaele S (2014) Secretome analysis reveals effector candidates associated with broad host range necrotrophy in the fungal plant pathogen Sclerotinia sclerotiorum. BMC Genomics 15: 336.

Haueisen J, Moeller M, Eschenbrenner CJ, Grandaubert J, Seybold H, Adamiak H, Stukenbrock EH (2017) Extremely flexible infection programs in a fungal plant pathogen. bioRxiv. doi: https://doi.org/10.1101/229997.

Hemetsberger C, Mueller AN, Matei A, Herrberger C, Hensel G, Kumlehn J, Mishra B, Sharma R, Thines M, Hückelhoven R, Doehlemann G (2015) The fungal core effector Pepı is conserved across smuts of dicots and monocots. New Phytologist 206: 1116-1126. 
Holt C, Yandell M (2011) MAKER2: an annotation pipeline and genome-database management tool for secondgeneration genome projects. BMC Bioinformatics 12: 491.

Inderbitzin P, Bostock RM, Davis RM, Usami T, Platt HW, Subbarao KV (2011) Phylogenetics and taxonomy of the fungal vascular wilt pathogen Verticillium, with the Descriptions of Five New Species. PLOS ONE 6: e28341.

Kema GHJ, Mirzadi Gohari A, Aouini L, Gibriel H, Ware SB, van den Bosch F, Manning-Smith R, Alonso-Chavez V, Helps J, Ben M'Barek S, et al. (2018) Stress and sexual reproduction affect the dynamics of the wheat pathogen effector AvrStb6 and strobilurin resistance. Nat. Genet 23: 375-380.

Kombrink A, Rovenich H, Shi-Kunne X, Rojas-Padilla E, van den Berg GCM, Domazakis E, de Jonge R, Valkenburg DJ, Sánchez-Vallet A, Seidl, MF, et al. (2017) Verticillium dahliae LysM effectors differentially contribute to virulence on plant hosts. Mol Plant Pathol 18: 596-608.

Korf I (2004) Gene finding in novel genomes. BMC Bioinformatics 5: 59.

Kurtz S, Phillippy A, Delcher AL, Smoot M, Shumway M, Antonescu C, Salzberg SL (2004) Versatile and open software for comparing large genomes. Genome Biol 5: Ri2.

Li B, Dewey CN (2011) RSEM: accurate transcript quantification from RNA-Seq data with or without a reference genome. BMC Bioinformatics 12: 323 .

Li L, Stoeckert CJ, Roos DS (2003) OrthoMCL: identification of ortholog groups for eukaryotic genomes. Genome Res 13: 2178-2189.

Lukashin AV, Borodovsky M (1998) GeneMark.hmm: new solutions for gene finding. Nucleic Acids Res 26: 11071115 .

Ma LJ, van der Does HC, Borkovich KA, Coleman JJ, Daboussi MJ, Di Pietro A, Dufresne M, Freitag M, Grabherr M, Henrissat B, et al. (2010) Comparative genomics reveals mobile pathogenicity chromosomes in Fusarium. Nature 464: 367-373.

Marshall R, Kombrink A, Motteram J, Loza-Reyes E, Lucas J, Hammond-Kosack KE, Thomma BPHJ, Rudd JJ (2011) Analysis of two in planta expressed LysM effector homologs from the fungus Mycosphaerella graminicola reveals novel functional properties and varying contributions to virulence on wheat. Plant Physiol 156: 756-769.

Meile L, Croll D, Brunner PC, Plissonneau C, Hartmann FE, McDonald BA, Sánchez-Vallet A (2018) A fungal avirulence factor encoded in a highly plastic genomic region triggers partial resistance to septoria tritici blotch. New Phytol 219: 1048-1061.

Mentlak TA, Kombrink A, Shinya T, Ryder LS, Otomo I, Saitoh H, Terauchi R, Nishizawa Y, Shibuya N, Thomma BPHJ, et al. (2012) Effector-mediated suppression of chitin-triggered immunity by Magnaporthe oryzae is necessary for rice blast disease. Plant Cell 24: 322-335.

Pennisi E (2010) Armed and dangerous. Science 327: 804-805.

Petersen TN, Brunak S, von Heijne G, Nielsen H (2011) SignalP 4.0: discriminating signal peptides from transmembrane regions. Nat Methods 8: 785-786.

Plissonneau C, Hartmann FE, Croll D (2018) Pangenome analyses of the wheat pathogen Zymoseptoria tritici reveal the structural basis of a highly plastic eukaryotic genome. BMC Biol. 16: 673 .

Plissonneau C, Stürchler A, Croll, D (2016) The evolution of orphan regions in genomes of a fungal pathogen of wheat. mBio 7: e01231-16.

Quinlan AR, Hall IM (2010) BEDTools: a flexible suite of utilities for comparing genomic features. Bioinformatics 26: $841-842$.

Raffaele S, Kamoun S (2012) Genome evolution in filamentous plant pathogens: why bigger can be better. Nat Rev Microbiol 10: 417-430.

Santhanam P, van Esse HP, Albert I, Faino L, Nürnberger T, Thomma BPHJ (2013) Evidence for functional diversification within a fungal NEP1-like protein family. Mol Plant-Microbe Interact 26: 278-286.

Schmidt SM, Houterman PM, Schreiver I, Ma L, Amyotte S, Chellappan B, Boeren S, Takken FL W, Rep M (2013) MITEs in the promoters of effector genes allow prediction of novel virulence genes in Fusarium oxysporum. BMC Genomics 14: 1-21.

Seidl MF, Thomma BPHJ (2017) Transposable elements direct the coevolution between plants and microbes. Trends Genet 33: 842-851. 
Shi-Kunne X, Faino L, van den Berg GCM, Thomma BPHJ, Seidl MF (2017) Evolution within the fungal genus Verticillium is characterized by chromosomal rearrangement and gene loss. Environ Microbiol 20: 1362-1373.

Simão FA, Waterhouse RM, Ioannidis P, Kriventseva EV, Zdobnov EM (2015) BUSCO: assessing genome assembly and annotation completeness with single-copy orthologs. Bioinformatics 31: 3210-3212.

Smit AF, Hubley R (2010) RepeatModeler Open-1.0. 2008-2015. http://www.repeatmasker.org.

Sperschneider J, Gardiner DM, Dodds PN, Tini F, Covarelli L, Singh KB, Manners JM, Taylor JM (2016) EffectorP: predicting fungal effector proteins from secretomes using machine learning. New Phytol 210: 743-761.

Song Y, Zhang Z, Seidl MF, Majer A, Jakse J, Javornik B, Thomma BP (2017) Broad taxonomic characterization of Verticillium wilt resistance genes reveals an ancient origin of the tomato Ve1 immune receptor. Mol Plant Pathol 18: 195-209.

Stanke M, Waack S (2003) Gene prediction with a hidden Markov model and a new intron submodel. Bioinformatics 19.

Stergiopoulos I, van den Burg HA, Okmen B, Beenen HG, van Liere S, Kema GH, de Wit PJ (2010) Tomato Cf resistance proteins mediate recognition of cognate homologous effectors from fungi pathogenic on dicots and monocots. Proc Natl Acad Sci USA 107: 7610-7615.

Takahara H, Hacquard S, KombrinkA, Hughes HB, HalderV, Robin GP, Hiruma K, Neumann U, Shinya T, Kombrink A, et al. (2016) Colletotrichum higginsianum extracellular LysM proteins play dual roles in appressorial function and suppression of chitin-triggered plant immunity. New Phytol 211: 1323-1337.

Tritt A. Eisen JA, Facciotti MT, Darling AE (2012) An integrated pipeline for de novo assembly of microbial genomes. PLOS ONE 7: e42304.

van Dam P, Fokkens L, Schmidt SM, Linmans JHJ, Kistler HC, Ma LJ, Rep M (2016) Effector profiles distinguish formae speciales of Fusarium oxysporum. Environ Microbiol 18: 4087-4102.

Warnes GR, Bolker B, Bonebakker L, Gentleman R, Liaw WHA, Lumley T, Maechler M, Magnusson A, Moeller S, Schwartz M (2015) gplots: various R programming tools for plotting data. R package version 2.17. 0 . Computer software]. Available online at: http://cran/. R-project. org/package= gplots.

Yin J, Gu B, Huang G, Tian Y, Quan J, Lindqvist-Kreuze H, Shan W (2017) Conserved RxLR effector genes of Phytophthora infestans expressed at the early stage of potato infection are suppressive to host defense. Front Plant Sci 8: 215.

Zhou BJ, Jia PS, Gao F, Guo HS (2012) Molecular characterization and functional analysis of a necrosis- and ethyleneinducing, protein-encoding gene family from Verticillium dahliae. Mol Plant-Microbe Interact 25: 964-975. 


\section{Supplemental information}

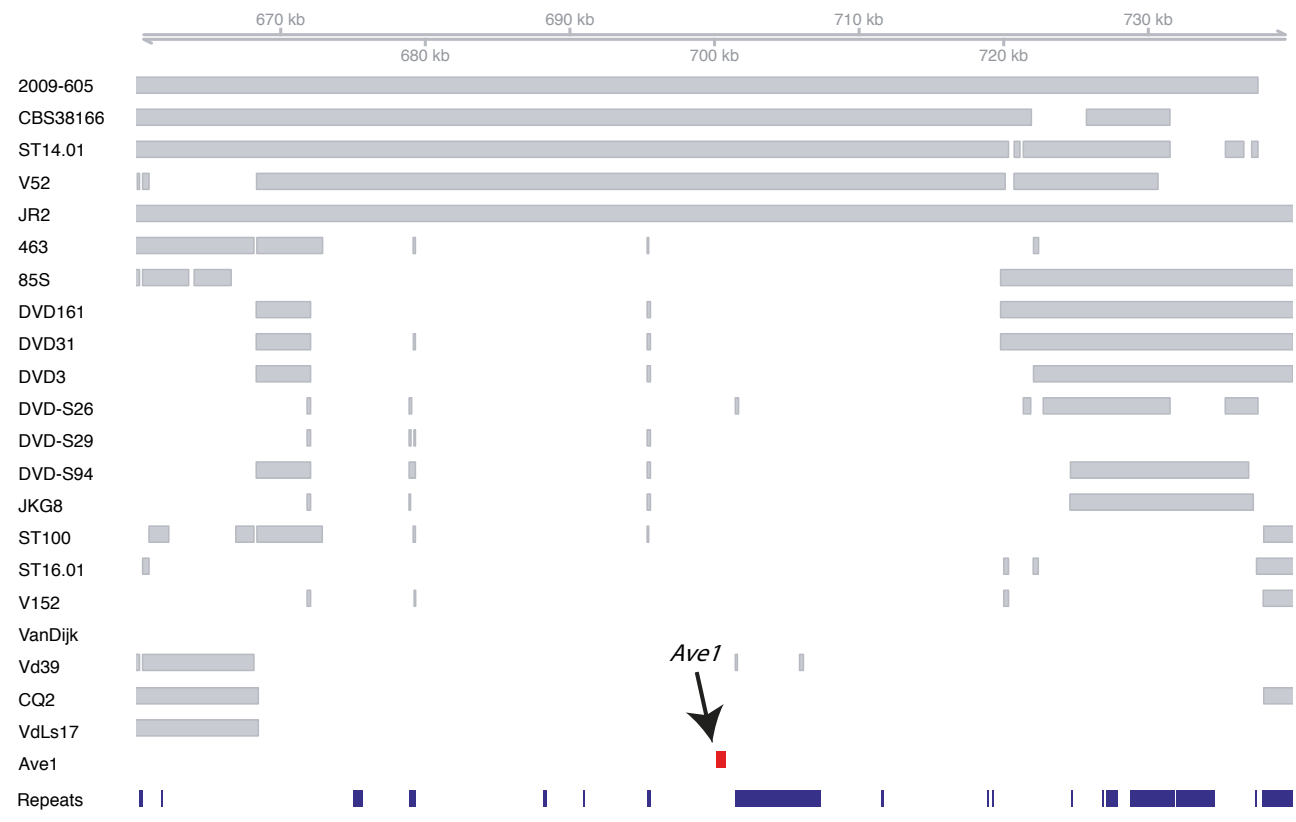

Figure S1. V. dahliae effector gene Ave1 is localized within an LS region. A highly variable, repeat-rich (blue), LS region, which harbors the Ave1 effector gene (red) of V. dahliae is shown. This LS effector gene is only present in a subset of $V$. dahliae strains. Grey bars indicate the genome alignments of $V$. dahliae strains to the reference strain JR2. This effector gene is only present in strains 2009-605, CBS38166, ST14.01, V52, JR2, and absent in the other strains. 

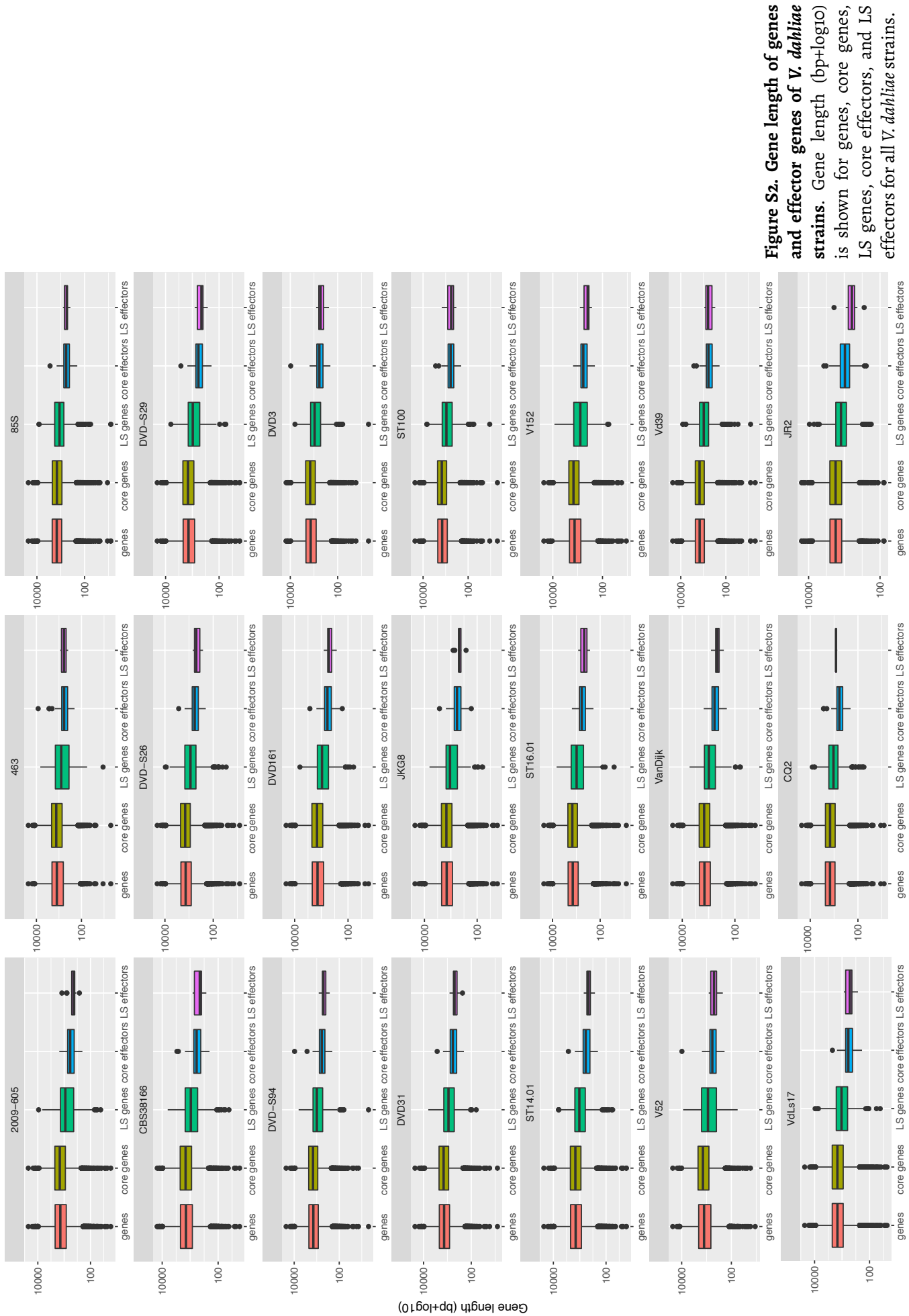


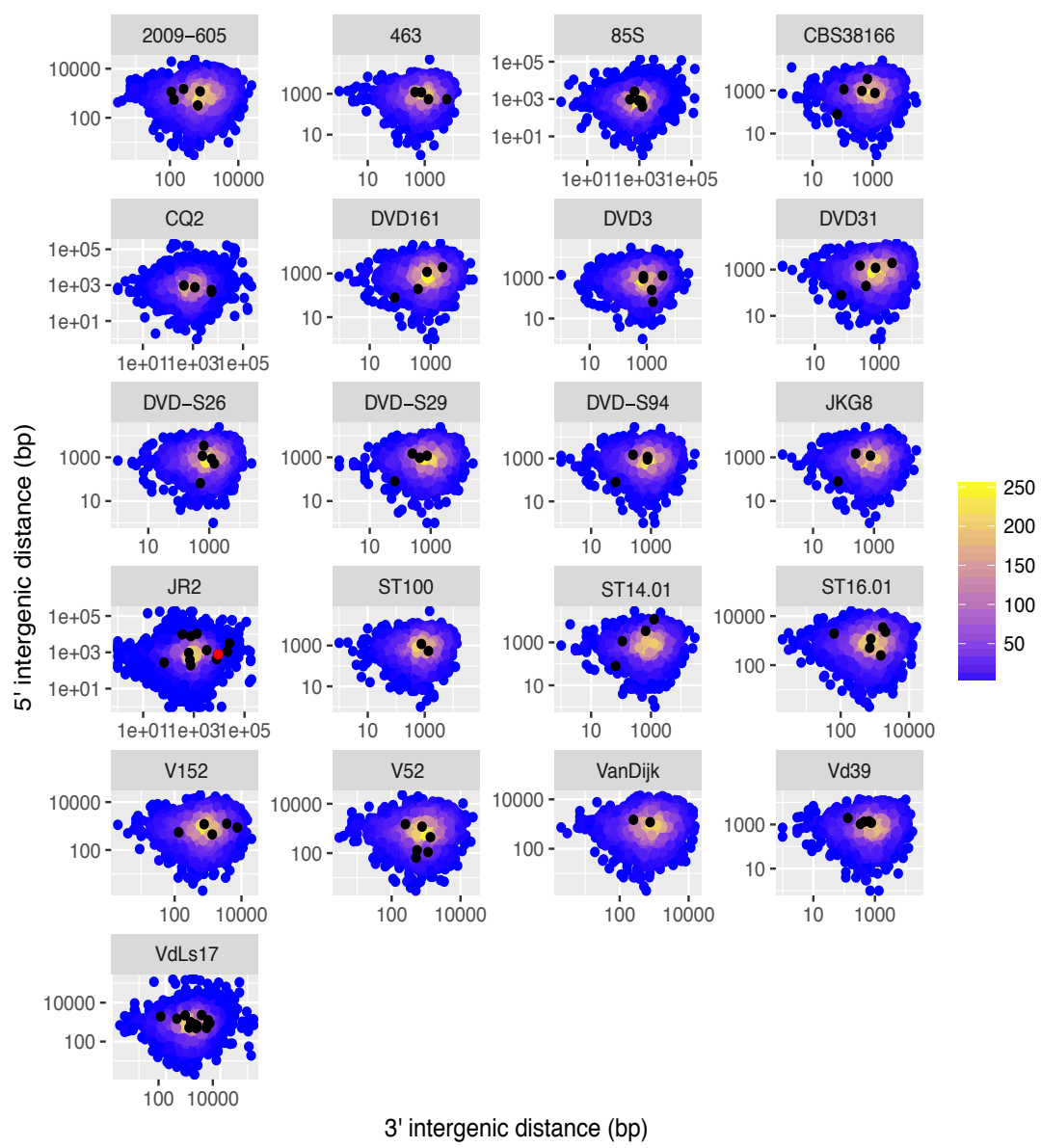

Figure $S_{3 .} 5^{\prime}$ and $3^{\prime}$ inter-genic length of genes and effector genes of $V$. dahliae strains. Inter-genic length (bp) is shown for genes (blue) and LS effector genes (black) for all V. dahliae strains. Aver effector gene of V. dahliae strain JR2 is highlighted in red. 


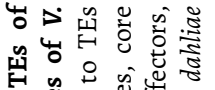

幽造离

$\circ$ 颉

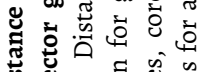

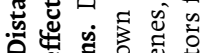

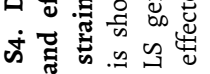

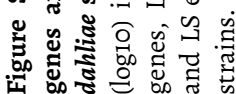
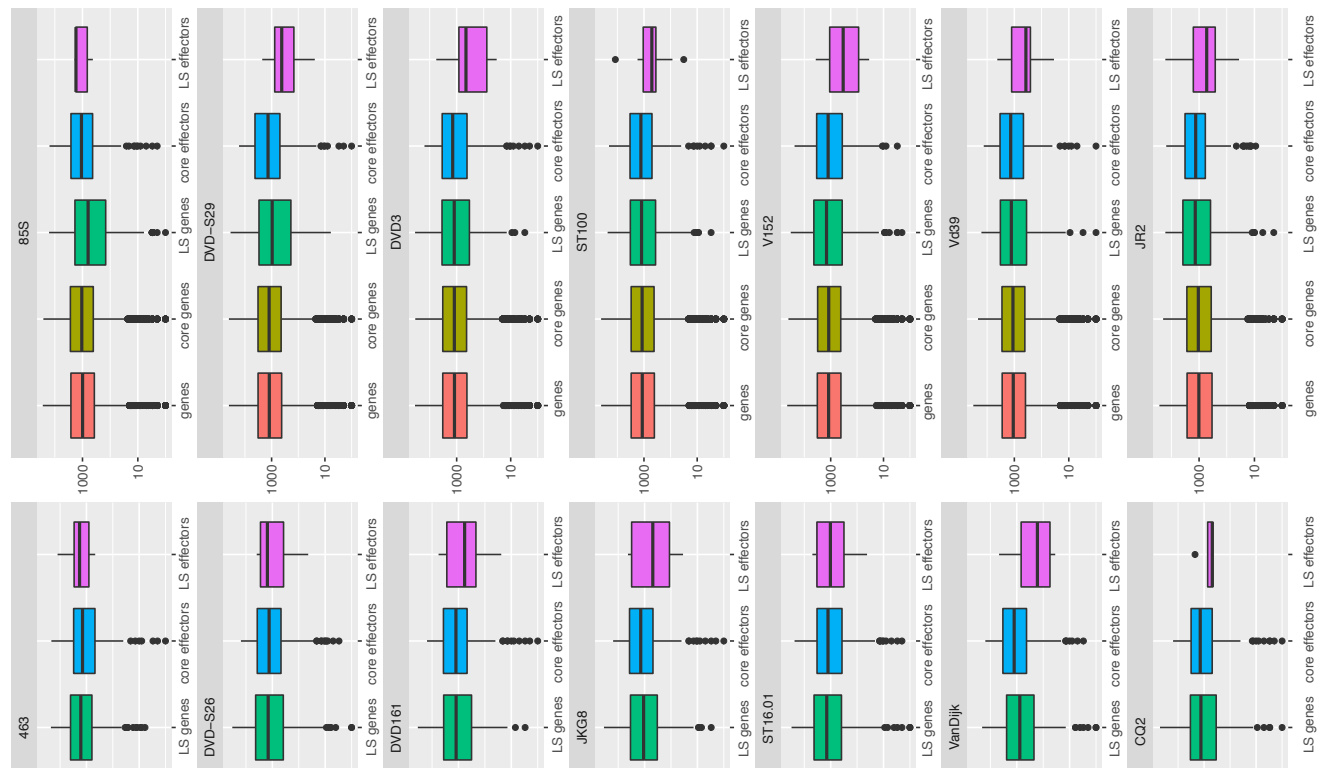

$-\mathbb{- 1}\|-\|-\|-\|-1-\mathbb{- 1}-\mathbb{- 1}-\mathbb{\|}-1$

$-\|-1-\|-1-\|-1-\|-1,\|-1-\|-1-\|-1$

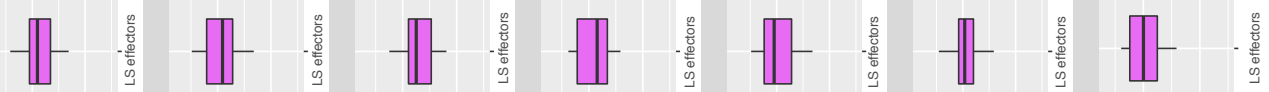

$\mathbb{\|}-\mathbb{\|}-\mathbb{\|}-\boldsymbol{\|}-\mathbb{\|}-\cdot \mathbb{\|} \cdot-\mathbb{\|}-$

|

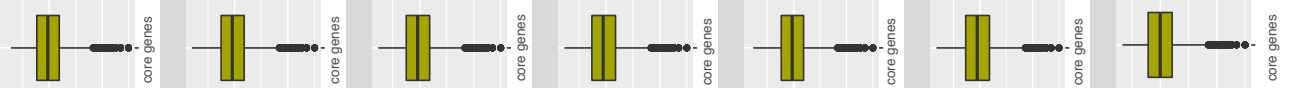

$\|-1-\|-1-\|-1-\|-1-\|-1-\|-1-\mathbb{- 1}$ 
Table S1. V. dahliae strains used in this study.

\begin{tabular}{ccccc}
\hline Strain & Sequencing platform & Reference & Isolated from & Country of isolation \\
\hline CQ2 & PacBio & Depotter et al., 2018 & Cotton & China \\
85S & PacBio & Depotter et al., 2018 & Sunflower & France \\
VdLs17 & PacBio & Faino et al., 2015 & Lettuce & USA \\
JR2 & PacBio & Faino et al., 2015 & Tomato & Canada \\
CBS381.66 & Illumina HiSeq 2000 & de Jonge et al., 2012 & Tomato & Canada \\
St14.01 & Illumina HiSeq 2000 & de Jonge et al., 2012 & Pistachio & USA \\
St100 & Illumina HiSeq 2000 & de Jonge et al., 2012 & Soil & Belgium \\
DVD-3 & Illumina HiSeq 2000 & de Jonge et al., 2012 & Potato & Canada \\
DVD-31 & Illumina HiSeq 2000 & de Jonge et al., 2012 & Tomato & Canada \\
DVD161 & Illumina HiSeq 2000 & de Jonge et al., 2012 & Potato & Canada \\
DVD-S26 & Illumina HiSeq 2000 & de Jonge et al., 2012 & Soil & Canada \\
DVD-S29 & Illumina HiSeq 2000 & de Jonge et al., 2012 & Soil & Canada \\
DVD-S94 & Illumina HiSeq 2000 & de Jonge et al., 2012 & Soil & Canada \\
JKG8 & Illumina HiSeq 2000 & Thomma et al. unpublished & Potato & The Netherlands \\
2009-605 & Illumina HiSeq 2000 & Thomma et al. unpublished & Bell pepper & Ukraine \\
463 & Illumina HiSeq 2000 & Thomma et al. unpublished & Cotton & Mexico \\
St16.01 & Illumina HiSeq 2000 & Thomma et al. unpublished & Cotton & Syria \\
V152 & Illumina HiSeq 2000 & Thomma et al. unpublished & Oak & Hungry \\
Vd52 & Illumina HiSeq 2000 & Thomma et al. unpublished & Pepper & Austria \\
Vd39 & Illumina HiSeq 2000 & Thomma et al. unpublished & Sunflower & Germany \\
van Dijk & Illumina HiSeq 2000 & Thomma et al. unpublished & Chrysanthemum & The Netherlands \\
\hline
\end{tabular}


Table S2. Assembly statistics for the various Verticillium dahliae genomes.

\begin{tabular}{|c|c|c|c|c|c|c|c|}
\hline Strain & $\begin{array}{c}\text { Genome size } \\
(\mathrm{Mb})\end{array}$ & $\begin{array}{c}\text { \# scaffolds } \\
\text { (>= obp) }\end{array}$ & $\begin{array}{l}\text { \# scaffolds } \\
\text { (>=1000 bp) }\end{array}$ & GC (\%) & N50 (Kb) & \# N's per $100 \mathrm{kbp}$ & BUSCO (\%) \\
\hline $2009-605$ & 34.06 & 1931 & 1521 & 54.76 & 55.11 & 123.45 & 95.4 \\
\hline 463 & 34.03 & 4188 & 3562 & 53.47 & 17.74 & 244.06 & 75 \\
\hline $85 \mathrm{~S}$ & 35.93 & 40 & 40 & 53.55 & 3176.09 & ० & 99.3 \\
\hline $\mathrm{CBS} 38166$ & 34.03 & 2092 & 1727 & 54.24 & 45.08 & 316.06 & 91.6 \\
\hline DVD161 & 33.47 & 2155 & 1819 & 54.4 & 41.42 & 330.79 & 90.8 \\
\hline DVD31 & 33.58 & 2429 & 2064 & 54.14 & 35.75 & 336.71 & 89.2 \\
\hline DVD3 & 34.42 & 1921 & 1693 & 53.62 & 42.77 & 378.65 & 88.9 \\
\hline DVD-S26 & 34.74 & 2275 & 1894 & 54.2 & 43.54 & 367.67 & 92.2 \\
\hline DVD-S29 & 33.14 & 2226 & 1811 & 54.56 & 42.73 & 306.89 & 91.6 \\
\hline DVD-S94 & 34.42 & 1730 & 1494 & 53.92 & 53.17 & 287 & 91.9 \\
\hline JKG8 & 33.85 & 1840 & 1458 & 54.5 & 56.35 & 172.12 & 95.6 \\
\hline ST100 & 34.92 & 2137 & 1756 & 53.63 & 49.89 & 315.39 & 93 \\
\hline ST14 & 34.48 & 1571 & 1336 & 54.03 & 61.81 & 221.84 & 95 \\
\hline ST16 & 34.22 & 1821 & 1454 & 54.9 & 57.46 & 121.71 & 95.6 \\
\hline v152 & 33.98 & 2539 & 2174 & 54.28 & 32.47 & 146.98 & 87.6 \\
\hline v52 & 33.54 & 3419 & 2920 & 54.39 & 21.80 & 162.37 & 78.6 \\
\hline VanDijk & 33.17 & 1769 & 1389 & 54.71 & 61.05 & 109.26 & 95.7 \\
\hline Vd39 & 35.90 & 1579 & 1222 & 53.55 & 94.44 & 222.52 & 98.7 \\
\hline $\mathrm{CQ}_{2}$ & 35.82 & 17 & 17 & 53.26 & 3754.19 & ० & 97.5 \\
\hline $\mathrm{JR} 2$ & 36.15 & 8 & 8 & 53.89 & 4168.63 & 0 & 99.4 \\
\hline VdLs17 & 35.97 & 8 & 8 & 54 & 5894.01 & 0 & 98.9 \\
\hline
\end{tabular}


Table S3. Summary of transposable elements of the various Verticillium dahliae strains.

\begin{tabular}{|c|c|c|c|c|c|c|}
\hline \multirow[b]{2}{*}{ Strain } & \multicolumn{2}{|c|}{ SINES } & \multicolumn{2}{|c|}{ LINEs } & \multicolumn{2}{|c|}{ LTRs } \\
\hline & $\begin{array}{c}\text { Length } \\
\text { occupied (bb) }\end{array}$ & $\begin{array}{l}\text { Percentage of } \\
\text { sequence (\%) }\end{array}$ & $\begin{array}{c}\text { Length } \\
\text { occupied (bb) }\end{array}$ & $\begin{array}{c}\text { Percentage of } \\
\text { sequence (\%) }\end{array}$ & $\begin{array}{c}\text { Length } \\
\text { occupied (bb) }\end{array}$ & $\begin{array}{c}\text { Percentage of } \\
\text { sequence (\%) }\end{array}$ \\
\hline $2009-605$ & 0 & 0 & 0 & 0 & 1403090 & 4.12 \\
\hline 463 & 0 & 0 & 43660 & 0.13 & 1601065 & 4.7 \\
\hline $85 S$ & 2289.00 & 0.01 & 57668.00 & 0.16 & 3082210.00 & 8.58 \\
\hline CBS38166 & 0.00 & 0.00 & 29731.00 & 0.09 & 1625629.00 & 4.78 \\
\hline DVD161 & 1994.00 & 0.01 & 0.00 & 0.00 & 1871766.00 & 5.59 \\
\hline DVD31 & 15326.00 & 0.05 & 14424.00 & 0.04 & 1718276.00 & 5.12 \\
\hline DVD3 & 1923.00 & 0.01 & 17323.00 & 0.05 & 2262138.00 & 6.57 \\
\hline DVD-S26 & 0.00 & 0.00 & 34185.00 & 0.10 & 1847224.00 & 5.32 \\
\hline DVD-S29 & 22393.00 & 0.01 & 7832.00 & 0.02 & 1297199.00 & 3.91 \\
\hline DVD-S94 & 0.00 & 0.00 & 23539.00 & 0.07 & 2082451.00 & 6.05 \\
\hline JKG8 & 2294.00 & 0.01 & 0.00 & 0.00 & 1344573.00 & 3.97 \\
\hline ST100 & 1720.00 & 0.01 & 50597.00 & 0.14 & 2693973.00 & 7.71 \\
\hline ST14 & 0.00 & 0.00 & 30264.00 & 0.09 & 1610719.00 & 4.67 \\
\hline ST16 & 1582.00 & 0.00 & 50167.00 & 0.15 & 1009974.00 & 2.95 \\
\hline v152 & 0.00 & 0.00 & 40614.00 & 0.12 & 1660694.00 & 4.89 \\
\hline v52 & 3965.00 & 0.01 & 28553.00 & 0.09 & 1442720.00 & 4.30 \\
\hline VanDijk & 1954.00 & 0.01 & ० & 0 & 1337583.00 & 4.03 \\
\hline $\mathrm{Vd} 39$ & 1582.00 & 0.00 & 71392.00 & 0.20 & 3201873.00 & 8.92 \\
\hline $\mathrm{CQ}_{2}$ & 3965.00 & 0.01 & 54386.00 & 0.15 & 3156817.00 & 8.81 \\
\hline $\mathrm{JR} 2$ & 1954.00 & 0.01 & 98739.00 & 0.27 & 2841008.00 & 7.86 \\
\hline VdLs17 & 0.00 & 0.00 & 235025.00 & 0.65 & 2875975.00 & 7.99 \\
\hline
\end{tabular}




\section{References}

de Jonge R, van Esse HP, Maruthachalam K, Bolton MD, Santhanam P, Saber MK, Zhang Z, Usami T,Lievens B, Subbarao KV, Thomma BPHJ (2012) Tomato immune receptor Ve1 recognizes effector of multiple fungal pathogens uncovered by genome and RNA sequencing. Proc Natl Acad Sci USA 109:5110-5115.

Depotter J, Shi-Kunne X, Missionnier H, Liu T, Faino L, van den Berg G, Wood T, Zhang B, Jacques A, Seidl M, Thomma B (2018) Dynamic virulence-related regions of the fungal plant pathogen Verticillium dahliae display remarkably enhanced sequence conservation. bioRxiv doi: https://doi.org/10.1101/277558.

Faino L, Seidl MF, Datema E, van den Berg GC, Janssen A, Wittenberg AH, Thomma BPHJ (2015) Single-molecule real-time sequencing combined with optical mapping yields completely finished fungal genome. mBio 6: e00936-00915. 


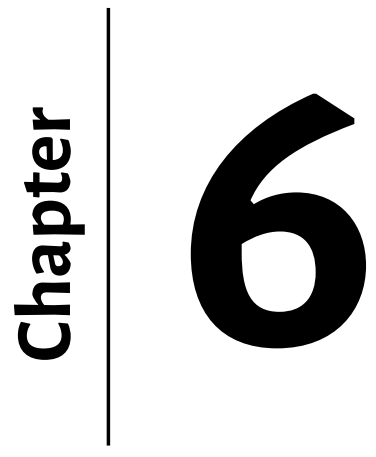

Engineering of a chimeric receptor to mediate improved chitin-triggered immunity in Arabidopsis

Jinling Li', Dongli Yu', Luigi Faino', and Bart P.H.J. Thomma' 


\section{Abstract}

Plants employ cell surface-localized immune receptors to detect the presence of potential fungal pathogens and activate appropriate immune responses, for instance by recognizing the conserved fungal cell wall molecule chitin. In Arabidopsis, two lysin motif (LysM) containing receptors, AtCERK1 and AtLYK5, have been implicated in chitin perception. Various fungal pathogens have been shown to secrete LysM effectors to suppress the activation of chitintriggered host immune responses. For instance, the tomato leaf mould fungus Cladosporium fulvum secretes the LysM effector Ecp6 to supress chitin-induced immune responses through direct competition with plant receptors for chitin binding. Chitin binding by Ecp6 is based on intramolecular LysM dimerization that results in increased substrate binding affinity when compared with immune receptors whose LysM domains cannot undergo such intramolecular dimerization. In this study, we attempted to generate chimeric chitin receptors with increased chitin binding affinity by replacing the LysM domains of AtCERK1 and AtLYK5 with the LysM domains of Ecp6. Next, we tested whether the chimeric Ecp6::CERK1 and Ecp6::LYK5 receptors display increased responsiveness to chitin, trigger more robust immune responses, and confer enhanced resistance to fungal infection. Our data suggest that expression of the chimeric receptor Ecp6::LYK5, but not of Ecp6::CERK1, confers responsiveness to fungal chitin. Moreover, we show that Ecp6 treatment fails to suppress chitin-triggered immunity in plants that express the chimeric Ecp6::LYK5 receptor whereas this immune response is suppressed in wild-type plants. This finding suggests that the chimeric Ecp6::LYK5 receptor possesses enhanced chitinbinding characteristics when compared with the native LYK5 receptor. Although the chimeric Ecp6::LYK5 receptor is able to complement enhanced susceptibility of lyk4/lyk5-2 mutant plants towards the necrotrophic fungal pathogen Alternaria brassicicola, no enhanced resistance when compared with wild-type plants was observed. 


\section{Introduction}

In order to prevent colonization by potentially harmful microbes, plants employ various types of immune receptors to detect pathogen invasion through sensing pathogen-derived or pathogen-induced molecular patterns of various nature, collectively termed invasion patterns (IPs), that betray microbial invasion to activate appropriate immune responses (Cook et al., 2015; Rodriguez-Moreno et al., 2017). A well described IP is chitin, an important structural component of fungal cell walls, which is recognized by cell surface immune receptors (Felix et al., 1993; Sanchez-Vallet et al., 2015; Rovenich et al., 2016). The recognition of chitin fragments by host receptors subsequently prompts the activation of immune responses aimed at halting pathogen invasion (Boller and Felix, 2009; Rovenich et al., 2014).

To date, a number of plant immune receptors for chitin recognition have been characterized from Arabidopsis thaliana and from rice (Oryza sativa) (Sánchez-Vallet et al., 2015; Shinya et al., 2015). These receptors all contain a varying number of extracellular lysin motifs (LysMs) that are required for chitin-binding (Kombrink et al., 2011; Tanaka et al., 2013). The first chitin receptor that was characterized as chitin elicitor-binding protein (OsCEBiP) was isolated from the plasma membranes of rice cells and is a typical receptor-like protein that contains extracellular LysM domains but lacks an obvious intracellular kinase domain (Kaku et al., 2006). OsCEBiP directly binds chitin and forms a receptor complex with chitin elicitor receptor kinase-1 (OsCERK1) to initiate downstream signalling (Kaku et al., 2006; Hayafune et al., 2014). In contrast to OsCERK1, the A. thaliana LysM-containing receptor AtCERK1 has been proposed to directly bind long-chain chitin oligomers through one of the LysM domains, albeit with relatively low binding affinity (Liu et al., 2012). Additionally, the LysM receptor-like kinases AtLYK4 and AtLYK5, both of which carry an inactive kinase domain, were identified as chitin-binding proteins in chitin pull-down assays (Petutschnig et al., 2010). Recently, Cao et al. (2014) proposed that AtLYK5 acts as the major chitin receptor in A. thaliana due to its higher affinity for chitin binding. AtLYK5 functions in chitin recognition partly overlaps with its paralogue AtLYK4, and Atlyk4/Atlyk5-2 double mutants showed a loss of chitin responsiveness (Cao et al., 2014).

To overcome chitin-triggered immune responses, fungal plant pathogens employ several strategies, including the secretion of LysM-containing effector proteins (Sánchez-Vallet et al., 2015). For instance, the tomato leaf mould fungus Cladosporium fulvum abundantly secretes the LysM effector Ecp6 (extracellular protein 6) during host colonization to compete with plant receptors for chitin binding, and thus prevents the activation of chitin-triggered immune responses (Bolton et al., 2008; de Jonge et al., 2010). Structural analysis of Ecp6 revealed that the concerted action of two of the three LysM domains of Ecp6 results in the formation of a groove with ultra-high chitin-binding affinity that permits to outcompete host immune receptors (Sánchez-Vallet et al., 2013). Interestingly, conserved Ecp6 orthologues widely occur in the fungal kingdom (Bolton et al., 2008; de Jonge and Thomma, 2009), which suggests that the suppression of chitin-triggered immunity is a common strategy used by fungal pathogens (de Jonge et al., 2011). Indeed, various fungal plant pathogens, such as the Septoria tritici blotch fungus Zymoseptoria tritici, the Brassicaceae anthracnose fungus Colletotrichum higginsianum, the rice 
blast fungus Magnaporthe oryzae and the vascular wilt fungus Verticillium dahliae, have been shown to secrete LysM effectors to perturb the activation of chitin-triggered immunity to promote host colonization (Marshall et al., 2011; Mentlak et al., 2012; Takahara et al., 2016; Kombrink et al., 2017).

Since Ecp6 was shown to outcompete host immune receptors for chitin binding due to increased substrate binding affinity (Sánchez-Vallet et al., 2013), we attempted to generate chimeric chitin receptors with increased affinity for chitin binding by replacing the LysM domains of AtCERK1 and AtLYK5 with the LysM domains of Ecp6. We hypothesized that chimeric receptors with increased affinity for chitin would result in increased responsiveness to fungal chitin, more robust immune responses, and increased resistance to fungal infection.

\section{Materials and methods}

\section{Plant materials and chitin treatment}

The A. thaliana mutant lines used in this study were cerk1-2 (Miya et al., 2007), pad-3 (Glazebrook and Ausubel, 1994) and lyk4/lyk5-2 mutant kindly provided by Prof. Dr. Volker Lipka (GeorgAugust-University, Göttingen, Germany). A. thaliana plants were grown in soil in a growth chamber at $21^{\circ} \mathrm{C}, 65 \%$ humidity and a photoperiod of 12 hours. Four-week-old plants were used for all experiments, in which plants were treated by either spraying with water or with $100 \mu \mathrm{g} / \mathrm{ml}$ polymeric chitin (Sigma-Aldrich Chemie BV, Zwijndrecht, the Netherlands).

\section{Construction of chimeric receptors and plant transformation}

The primers that were used for the generation of chimeric receptors are listed in Supplemental Table 1. A pGEM-T vector containing the coding sequence of Ecp6 (Sánchez-Vallet et al., 2013) was used as template to amplify the region containing the three LysM domains of Ecp6 (28-220 aa). For construction of the chimeric receptor Ecp6::CERK1, a DNA fragment comprising the CERK1 promoter sequence and the coding region of CERKI was amplified from the proCERK1:CERK1GFP plasmid (Petutschnig et al., 2014). The three LysM domains (35-232 aa) of CERK1 were then replaced by the LysM domains of Ecp6 via overlap-extension PCR. Similarly, a DNA segment comprising the LYK5 promoter sequence and the LYK5 coding sequence was amplified from the proLYK5:LYK5 mCitrine plasmid (Erwig et al., 2017). The LysM domains of LYK5 (27-278 aa) were replaced by the LysM domains of Ecp6 (28-220 aa) via overlap-extension PCR as well. All resulting PCR amplicons were cloned into the pDONR207 entry vector using the Gateway ${ }^{\circ} \mathrm{BP}$ Clonase ${ }^{\circ} \mathrm{II}$ Enzyme Mix (Invitrogen, Carlsbad, USA). The resulting vectors subsequently recombined into the Gateway-compatible vector pFAST RoI (Shimada et al., 2010) using Gateway ${ }^{\circ}$ LR Clonase ${ }^{\bullet}$ II Enzyme Mix (Invitrogen, Carlsbad, USA). The constructs were transformed into Agrobacterium tumefaciens strain GV3101 (pMP90) via electroporation and used for Arabidopsis transformation via the floral-dip transformation method (Clough and Bent, 1998). Arabidopsis transformation was confirmed by reverse transcription-PCR (RT-PCR). After two generations of selfing, T2 seeds were used for further experiments. 


\section{Oxidative burst assays}

Oxidative burst assays were performed as previously described (Rovenich, 2017). Briefly, fourweek-old Arabidopsis leaf discs ( $5 \mathrm{~mm}$ diameter) were incubated in $200 \mu \mathrm{l} \mathrm{sterile} \mathrm{water} \mathrm{overnight}$ in a 96-well plate (one leaf disc per well). The following day, the water was replaced with 100 $\mu \mathrm{l}$ reaction solution containing $100 \mu \mathrm{M} \mathrm{L}-012$ substrate and $20 \mu \mathrm{g} / \mathrm{ml}$ horseradish peroxidase (HRP). ROS generation was elicited with $100 \mu \mathrm{g} / \mathrm{ml}$ polymeric chitin or $100 \mathrm{nM}$ flg22 peptide (AnaSpec, Fremont, CA, USA), in the presence or absence of $10 \mu \mathrm{M}$ of the recombinant effector protein Ecp6 that produced in Pichia pastoris (de Jonge et al., 2010; Sánchez-Vallet et al., 2013). Luminescence was measured over a 70 min period using an Infinite M200 multimode plate reader (TECAN, Männedorf, Switzerland). Eight leaf discs from three different plants were used for each treatment.

\section{Fungal pathogen inoculation}

Inoculation of Arabidopsis plants with the fungus Alternaria brassicicola (strain MUCL20297) was performed as previously described (Thomma et al., 1999). Four-week-old Arabidopsis rosette leaves were inoculated with $5 \mu$ ldroplets of spore suspension $\left(10^{6} \mathrm{spores} / \mathrm{ml}\right)$ or mock-inoculated with $5 \mu \mathrm{l}$ droplets of water. Disease symptoms were examined at 7 days post inoculation and lesion sizes were determined as previously described (Thomma et al., 1999).

\section{Quantitative reverse transcript PCR}

To examine the expression of Ecp6::CERK1, Ecp6::LYK5 and the chitin responsive genes AtWRYK22 and AtWRKY75 (Egusa et al., 2015; Shinya et al., 2014) in the transgenic plants, leaves of four-weekold Arabidopsis were collected $20 \mathrm{~min}$ after plants were treated by spraying $100 \mu \mathrm{g} / \mathrm{ml}$ polymeric chitin or water. Total RNA isolation, CDNA synthesis and quantitative reverse transcript PCR (qRT-PCR) were performed as described earlier (Petutschnig et al., 2014), and the AtRubisco gene was used as a reference control (Supplemental Table 1).

\section{Results and discussion}

\section{Generation of Ecp6::CERK1 and Ecp6::LYK5-expressing plants}

In order to design a host chitin receptor with enhanced chitin-binding affinity, we generated two chimeric receptor constructs, named Ecp6::CERK1 and Ecp6::LYK5, by replacing the LysM domain-containing region of AtCERKI and AtLYK5 with the LysM domain-containing region of Ecp6, respectively (Figure 1). The resulting Ecp6::CERK1 construct was expressed under the control of the AtCERK1 promoter in the cerk1-2 knock-out mutant that completely lost the ability to respond to the chitin (Miya et al., 2007). The Ecp6::LYK5 construct was expressed under control of AtLYK5 promoter in the lyk4/lyk5-2 mutant (Figure S1). Reverse transcription polymerase chain reaction (RT-PCR) confirmed that both the Ecp6::CERK1 and Ecp6::LYK5 chimeras are expressed in T2 lines in response to chitin treatment (Figure 2) that were used for further assays to assess the functionality of these chimeric receptors. 


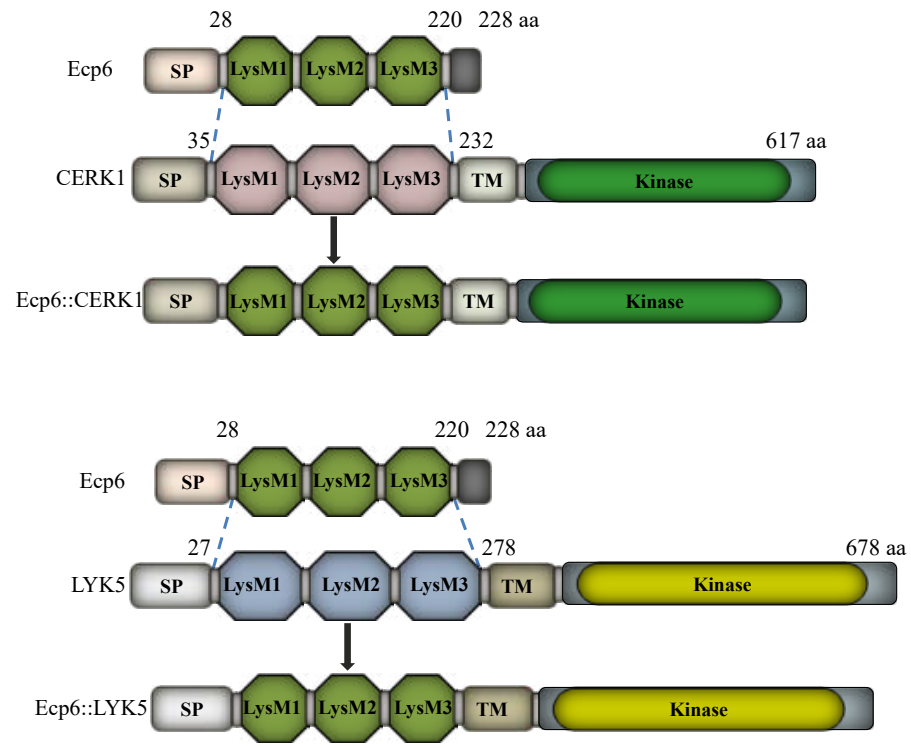

Figure 1. Schematic representation of the chimeric chitin Ecp6::CERK1 and Ecp6::LYK5 receptors. SP: signal peptide, TM: transmembrane region. Amino acids at the fusion points of the protein are indicated.

A

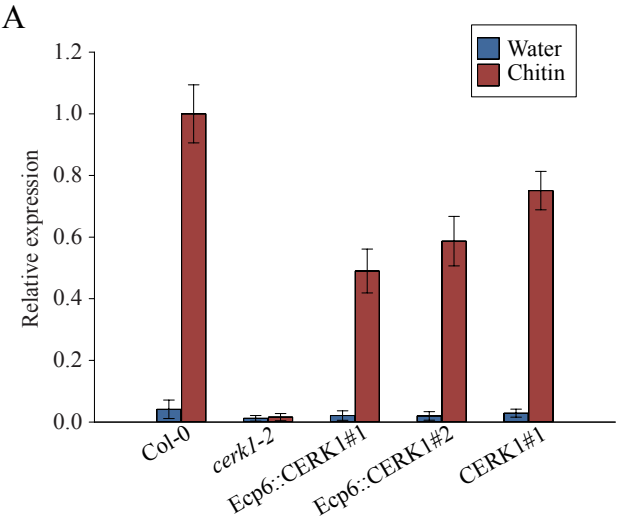

B

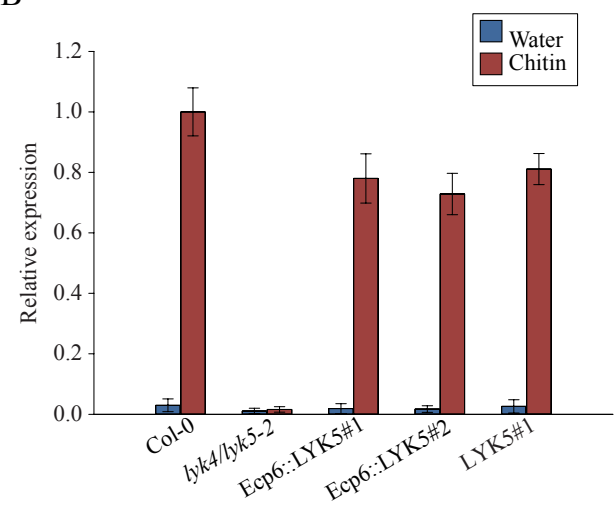

Figure 2. Relative quantification of transgene expression in T2 Arabidopsis lines. Expression of Ecp6::CERK1 relative to AtCERKI (A) and expression of Ecp6::LYK5 relative to AtLYK5 (B). Transcript levels were normalized to the AtRubisco gene and values are expressed as fold changes ( \pm SD) relative to the transcript level of AtCERK1 or AtLYK5 in wild type Col-o, which was set at 1 . The experiment was performed twice with similar results. 


\section{Transgenic expression of Ecp6::LYK5, but not of Ecp6::CERK1, confers chitin responsiveness}

Plant chitin receptors can swiftly prompt the activation of multiple downstream responses upon chitin perception, including the generation of reactive oxygen species (ROS) and the expression of defence-related genes (Shibuya and Minami, 2001). We first examined the functionality of the chimeric receptors by testing their ability to confer chitin-induced ROS production.

A

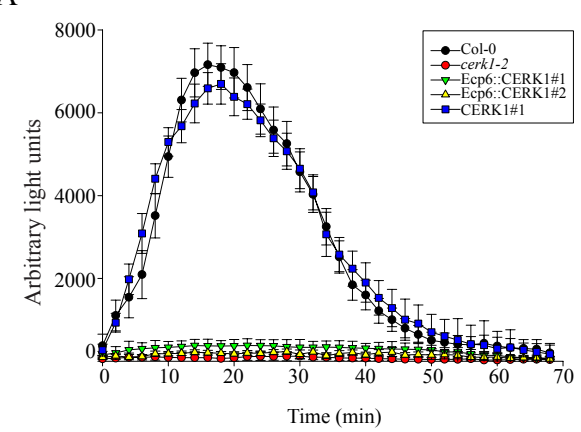

B

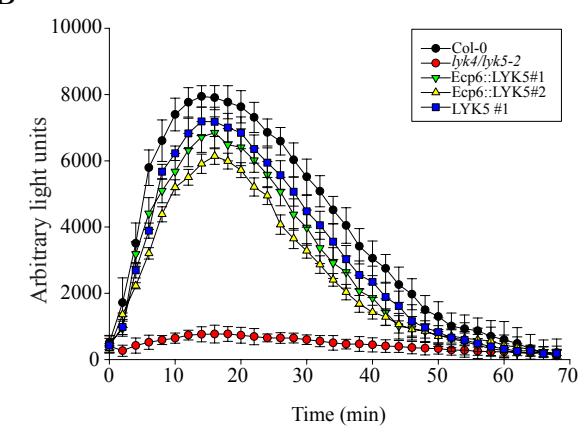

Figure 3. Chitin-induced ROS production in Ecp6:CERKI (A) or Ecp6::LYK5 (B) transgenic plants. Production of ROS was measured by using luminol-dependent chemiluminescence over a period of $70 \mathrm{~min}$ following treatment of Arabidopsis leaf discs with $100 \mu \mathrm{g} / \mathrm{ml}$ of polymeric chitin. The relative luminescence was calculated by normalization to water-treated leaf discs. Plotted are means \pm SD of 8 leaf discs. The experiment was performed twice with similar results.

To this end, the accumulations of ROS in transgenic lines that express the chimeric receptors were measured upon chitin treatment using a luminol-based chemiluminescence detection assay (de Jonge et al., 2010). Whereas clear a ROS burst occurred with a peak at $15 \mathrm{~min}$ following chitin treatment of a wild type Col-o line and a AtCERKI complementation line (CERK1\#1), no ROS burst was monitored in two independent Ecp6::CERK1 transgenic lines or in cerk1 mutant plants (Figure 3A). Interestingly, whereas chitin-induced ROS production was significantly lower in the lyk4/lyk5-2 mutant plants when compared with wild-type plants, treatment of Ecp6::LYK5expression plants with polymeric chitin resulted in high levels of ROS accumulation as similarly observed in wild type plants and a LYK5 complementation line (LYK5 \#1)(Figure 3B). As a control, we monitored ROS production triggered by the well-characterized bacterial elicitor flg22 (Zipfel et al., 2004) in these lines, showing that all genotypes accumulated similar levels of ROS production (Figure $\mathrm{S} 2$ ).

In addition to ROS production, we examined the expression of two well-established chitinresponsive genes, AtWRKY22 and AtWRKY75, in response to chitin treatment (Egusa et al., 2015; Shinya et al., 2014). Similar to the oxidative burst, no clear expression of AtWRKY22 and AtWRKY75 was observed in Ecp6::CERK1 expression lines upon chitin treatment (Figure 4). In contrast, clear expression of AtWRKY22 and AtWRKY75 was monitored after chitin treatment of Ecp6::LYK5 expression lines (Figure 4). 
Collectively, our data show that expression of the Ecp6::LYK5 chimera, but not of the Ecp6::CERK1 chimera, confers responsiveness to chitin and activates chitin-dependent immune responses. Hence, we focused on further characterization of chimeric Ecp6::LYK5 receptor.
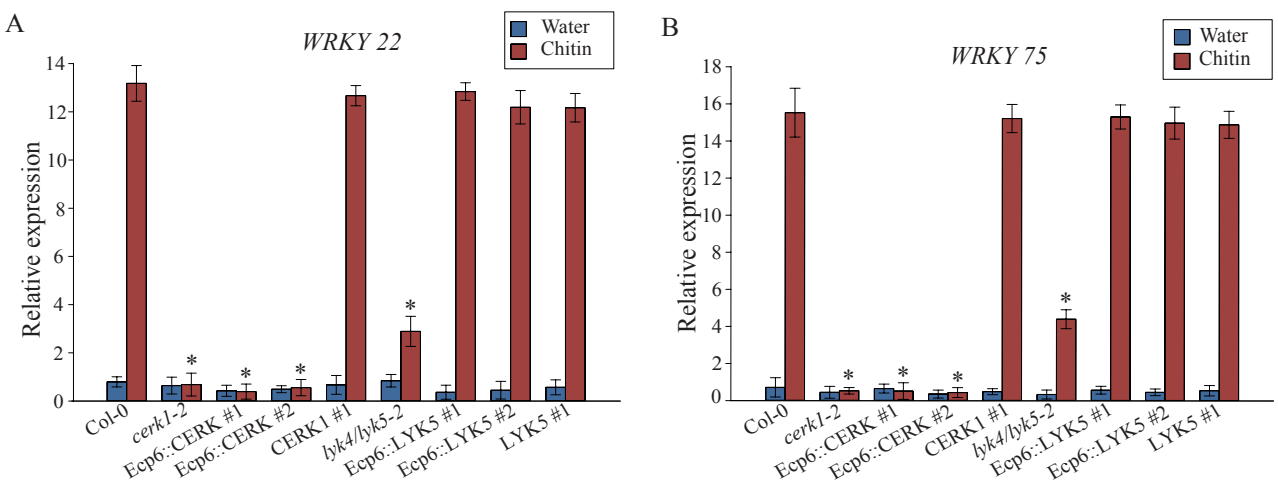

Figure 4. Expression of the chitin-responsive genes AtWRKY22 and AtWRKY75 in Ecp6::CERK1 or Ecp6:LYK5 transgenic plants upon chitin treatment. The bars represent the transcript levels of AtWRKY22 (A) and AtWRKY75 (B) relative to the constitutively expressed Arabidopsis Rubisco gene in various Arabidopsis genotypes. Data represent means \pm SD of three biological replicates consisting of pools of three plants from one of a single experiment. The asterisk indicates statistically significant differences from the wild type upon chitin treatment as determined with the Student's $t$-test $(P<0.05)$. The experiment was performed twice with similar results.

\section{Ecp6::LYK5 prompts chitin-induced ROS production in the presence of Ecp6}

It has previously been shown that Ecp6 can sequester chitin fragments with ultra-high chitinbinding affinity to effectively prevent the activation of chitin induced immunity, not only in tomato and rice, but also in Arabidopsis plants (de Jonge et al., 2010; Rovenich, 2017). As we have shown that the chimeric receptor Ecp6::LYK5 is able to mediate a chitin response, we further tested if this receptor can compete for chitin binding with Ecp6 to mediate chitin-induced ROS production. Intriguingly, Ecp6 treatment did not compromise ROS production in Ecp6::LYK5 plants, resulting in the accumulation of similar levels as upon chitin treatment in the absence of Ecp6 (Figure 5). This finding suggests that the Ecp6::LYK5 chimera has gained a significantly higher chitin-binding affinity when compared with the native AtLYK5 receptor, and can no longer be outcompeted by the Ecp6 effector for chitin binding. In contrast, bacterial flg22-induced ROS productions in these plants were not affected in the presence of Ecp6 (Figure S3). 


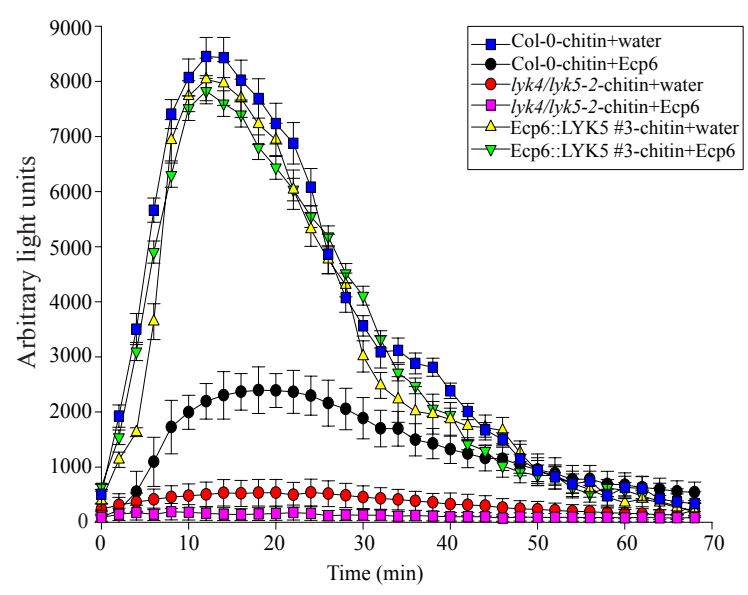

Figure 5. The chimeric receptor Ecp6::LYK5 prompts chitin-induced ROS production in the presence of Ecp6. Production of ROS was measured by using luminol-dependent chemiluminescence over a period of $69 \mathrm{~min}$ following treatment of Arabidopsis leaf discs with $100 \mu \mathrm{g} / \mathrm{ml}$ of polymeric chitin, or a mixture of $100 \mu \mathrm{g} / \mathrm{ml}$ of polymeric chitin and $10 \mu \mathrm{M}$ Ecp6 protein. The relative luminescence was calculated by normalization to watertreated leaf discs. Plotted are means \pm SD of 8 leaf discs. The experiment was performed twice with similar results.

\section{Expression of Ecp6::LYK5 does not confer enhanced resistance to the fungal pathogen Alternaria brassicicola}

As the expression of Ecp6::LYK5 enables transgenic Arabidopsis plants to sense and respond to chitin in such manner that it can no longer be abolished by Ecp6 treatment, we further tested whether the enhanced chitin responsiveness results in enhanced disease resistance. To this end, we challenged these transgenic plants with necrotrophic fungal pathogen A. brassicicola. The Arabidopsis mutant pad3-1 that has previously been shown to display enhanced susceptibility towards A. brassicicola was used as positive control for successful inoculation (Thomma et al., 1999). As expected, lyk4/lyk5-2 mutant plants showed increased susceptibility to A. brassicicola when compared with Col-o plants, as inoculated plants showed significantly lager lesions when compared with Col-o plants at 7 days post inoculation (dpi) (Figure 6). However, lesion sizes on Ecp6::LYK5 expression plants were similar to those on Col-o plants or on a LYK5 complementation line (LYK5\#1) (Figure 6). Although these data confirm that the chimeric Ecp6::LYK5 receptor is a functional immune receptor, no enhanced pathogen immunity properties when compared with the native receptor were revealed. However, it needs to be noted that it is not clear to what extent A. brassicicola depends on LysM effector activity to subvert chitin-triggered immunity during host invasion. Therefore, more pathogens, preferably alongside with LysM effector gene deletion strains, need to be tested in order to determine to what extent the chimeric Ecp6::LYK5 receptor can counteract the activity of fungal LysM effectors during pathogen invasion. 
A

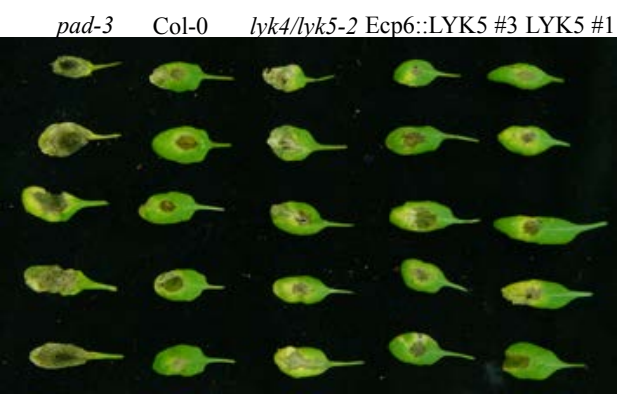

B

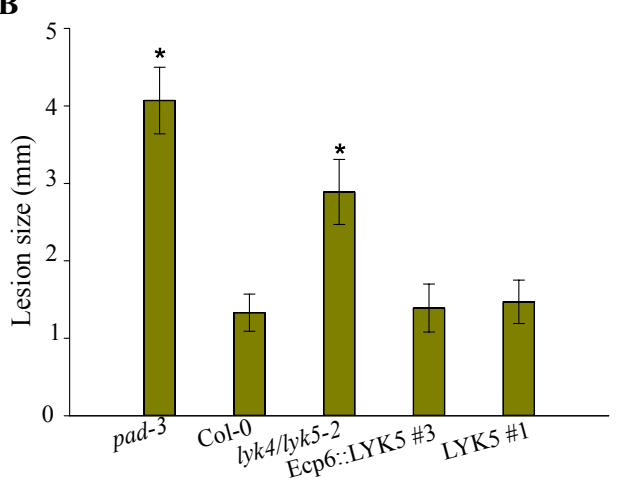

Figure 6. Inoculation assays on Ecp6::LYK5 transgenic plants with the fungal pathogen Alternaria brassicicola. (A) Representative picture showing disease symptoms upon inoculation with A. brassicicola at 7 days post inoculation (dpi). The padz-1mutant that displays enhanced susceptibility to A. brassicicola was used as positive inoculation control. (B) Quantification of the average lesion size at $7 \mathrm{dpi}$ with standard deviations ( $\mathrm{n} \geq 20$ independent lesions). Asterisks indicate statistically significant differences when compared with Col-o plants (Student's $t$-test; $P<0.05$ ). This experiment was performed two times with similar results.

\section{Conlusion}

Our data suggest that the chimeric Ecp6::LYK5 receptor displays enhanced chitin-binding ability, as its chitin-binding activity can no longer be suppressed by treatment with the LysM effector Ecp6. This indicates that the receptor has the potential to mediate enhanced resistance to fungal pathogen infection. Although an initial attempt to demonstrate with the fungal pathogen $A$. brassicicola was unsuccessful, further attempts that included more fungal plant pathogens should be made to verify this hypothesis. 


\section{Acknowledgements}

J.L.L acknowledges a PhD fellowship from the China Scholarship Council (CSC). B.P.H.J.T. is supported by a Vici grant of the Research Council for Earth and Life sciences (ALW) of the Netherlands Organization for Scientific Research (NWO). We thank Prof. Dr. Volker Lipka (Georg-August-University, Göttingen, Germany) for kindly providing proCERK1:CERK1-GFP plasmid and proLYK5:LYK5 mCitrine plasmid. Bert Essenstam is acknowledged for excellent plant care at Unifarm. 


\section{References}

Boller T, Felix G (2009) A renaissance of elicitors: perception of microbe-associated molecular patterns and danger signals by pattern-recognition receptors. Annu Rev Plant Biol 60: 379-406.

Bolton MD, van Esse HP, Vossen JH, de Jonge R, Stergiopoulos I, Stulemeijer IJ, van den Berg GC, Borrás-Hidalgo O, Dekker HL, de Koster CG, et al. (2008) The novel Cladosporium fulvum lysin motif effector Ecp6 is a virulence factor with orthologues in other fungal species. Mol Microbiol 69: 119-136.

Cao Y, Liang Y, Tanaka K, Nguyen CT, Jedrzejczak RP, Joachimiak A, Stacey G (2014) The kinase LYK5 is a major chitin receptor in Arabidopsis and forms a chitin-induced complex with related kinase CERK1. eLife 3: e03766.

Clough SJ, Bent AF (1998) Floral dip: a simplified method for Agrobacterium-mediated transformation of Arabidopsis thaliana. Plant J 16: 735-743.

Cook DE, Mesarich CH, Thomma BPHJ (2015) Understanding plant immunity as a surveillance system todetect invasion. Annu Rev Phytopathol 53: 541-563.

de Jonge R, Bolton MD, Thomma BP (2011) How filamentous pathogens co-opt plants: the ins and outs of fungal effectors. Curr Opin Plant Biol 14: 400-406.

de Jonge R, Thomma BP (2009) Fungal LysM effectors: extinguishers of host immunity? Trends Microbiol 17: 151157.

de Jonge R, van Esse HP, Kombrink A, Shinya T, Desaki Y, Bours R, van der Krol S, Shibuya N, Joosten MH, Thomma BP (2010) Conserved fungal LysM effector Ecp6 prevents chitin-triggered immunity in plants. Science 329: 953-955.

Egusa M, Matsui H, Urakami T, Okuda S, Ifuku S, Nakagami H, Kaminaka H (2015) Chitin nanofiber elucidates the elicitor activity of polymeric chitin in plants. Front Plant Sci 6: 1098.

Erwig J, Ghareeb H, Kopischke M, Hacke R, Matei A, Petutschnig E, Lipka V (2017) Chitin-induced and CHITIN ELICITOR RECEPTOR KINASEI (CERKI) phosphorylation-dependent endocytosis of Arabidopsis thaliana LYSIN MOTIF-CONTAINING RECEPTOR-LIKE KINASE5 (LYK5). New Phytol 215: 382-396.

Felix G, Regenass M, Boller T (1993) Specific perception of subnanomolar concentrations of chitin fragments by tomato cells: induction of extracellular alkalinization, changes in protein phosphorylation, and establishment of a refractory state. Plant J 4:307-316.

Hayafune M, Berisio R, Marchetti R, Silipo A, Kayama M, Desaki Y, Arima S, Squeglia F, Ruggiero A, Tokuyasu K, Molinaro A, Kaku H, et al. (2014) Chitin-induced activation of immune signaling by the rice receptor CEBiP relies on a unique sandwich-type dimerization. Proc Natl Acad Sci USA 111: E404-E413.

Glazebrook J, Ausubel FM (1994) Isolation of phytoalexin-deficient mutants of Arabidopsis thaliana and characterization of their interactions with bacterial pathogens. Proc Natl Acad Sci USA 91: 8955-8859.

Kaku H, Nishizawa Y, Ishii-Minami N, Akimoto-Tomiyama C, Dohmae N, Takio K, Minami E, Shibuya N (2006) Plant cells recognize chitin fragments for defense signaling through a plasma membrane receptor. Proc Natl Acad Sci USA 103: 11086-11091.

Kombrink A, Rovenich H, Shi-Kunne X, Rojas-Padilla E, van den Berg GC, Domazakis E, de Jonge R, Valkenburg DJ, Sánchez-Vallet A, Seidl MF, et al. (2017) Verticillium dahliae LysM effectors differentially contribute to virulence on plant hosts. Mol Plant Pathol 18: 596-608.

Kombrink A, Sánchez-Vallet A, Thomma BPHJ (2011) The role of chitin detection in plant-pathogen interactions. Microbes Infect 13: 1168-1176.

Liu T, Liu Z, Song C, Hu Y, Han Z, She J, Fan F, Wang J, Jin C, Chang J, et al. (2012) Chitin-induced dimerization activates a plant immune receptor. Science 336: 1160-1164.

Marshall R, Kombrink A, Motteram J, Loza-Reyes E, Lucas J, Hammond-Kosack KE, Thomma BP, Rudd JJ (2011) Analysis of two in planta expressed LysM effector homologs from the fungus Mycosphaerella graminicola reveals novel functional properties and varying contributions to virulence on wheat. Plant Physiol 156: 756569. 
Mentlak TA, Kombrink A, Shinya T, Ryder LS, Otomo I, Saitoh H, Terauchi R, Nishizawa Y, Shibuya N, Thomma BP, Talbot NJ (2012) Effector-mediated suppression of chitin-triggered immunity by magnaporthe oryzae is necessary for rice blast disease. Plant Cell 24: 322-335.

Miya A, Albert P, Shinya T, Desaki Y, Ichimura K, Shirasu K, Narusaka Y, Kawakami N, Kaku H, Shibuya N (2007) CERK1, a LysM receptor kinase, is essential for chitin elicitor signaling in Arabidopsis. Proc Natl Acad Sci USA 104: 19613-19618.

Petutschnig EK, Jones AM, Serazetdinova L, Lipka U, Lipka V (2010) The lysin motif receptor-like kinase (LysM-RLK) CERK1 is a major chitin-binding protein in Arabidopsis thaliana and subject to chitin-induced phosphorylation. J Biol Chem 285: 28902-28911.

Petutschnig EK, Stolze M, Lipka U, Kopischke M, Horlacher J, Valerius O, Rozhon W, Gust AA, Kemmerling B, Poppenberger B, et al. (2014) A novel Arabidopsis CHITIN ELICITOR RECEPTOR KINASE 1 (CERK1) mutant with enhanced pathogen-induced cell death and altered receptor processing. New Phytol 204: 955-967.

Sánchez-Vallet A, Mesters JR, Thomma BP (2015) The battle for chitin recognition in plant-microbe interactions. FEMS Microbiol Rev 39: 171-183.

Sánchez-Vallet A, Saleem-Batcha R, Kombrink A, Hansen G, Valkenburg DJ, Thomma BP, Mesters JR (2013) Fungal effector Ecp6 outcompetes host immune receptor for chitin binding through intrachain LysM dimerization. eLife 2: e00790.

Rodriguez-Moreno L, Ebert MK, Bolton MD, Thomma BPHJ (2018) Tools of the crook-infection strategies of fungal plant pathogens. Plant J 93: 664-674.

Rovenich H (2017) Evasion of chitin-triggered immunity by fungal plant pathogens. Wageningen University PhD thesis.

Rovenich H, Zuccaro A, Thomma BP (2016) Convergent evolution of filamentous microbes towards evasion of glycan-triggered immunity. New Phytol 212: 896-901.

Shibuya N, Minami E (2001) Oligosaccharide signalling for defence responses in plant. Physiol. Mol Plant Pathol 59: $223-233$.

Shimada TL, Shimada T, Hara-Nishimura I (2010) A rapid and non-destructive screenable marker, FAST, for identifying transformed seeds of Arabidopsis thaliana. Plant J 61: 519-528.

Shinya T, Nakagawa T, Kaku H, Shibuya N (2015) Chitin-mediated plant-fungal interactions: catching, hiding and handshaking. Curr Opin Plant Biol 26: 64-71.

Shinya T, Yamaguchi K, Desaki Y, Yamada K, Narisawa T, Kobayashi Y, Maeda K, Suzuki M, Tanimoto T, Takeda J, et al. (2014) Selective regulation of the chitin-induced defense response by the Arabidopsis receptor-like cytoplasmic kinase PBL27. Plant J 79: 56-66.

Takahara H, Hacquard S, KombrinkA, Hughes HB, HalderV, Robin GP, Hiruma K, Neumann U, Shinya T, Kombrink A, et al. (2016) Colletotrichum higginsianum extracellular LysM proteins play dual roles in appressorial function and suppression of chitin-triggered plant immunity. New Phytol 211: 1323-1337.

Tanaka K, Nguyen CT, Liang Y, Cao Y, Stacey G (2013) Role of LysM receptors in chitin-triggered plant innate immunity. Plant Signal Behav 8: e22598.

Thomma BP, Nelissen I, Eggermont K, Broekaert WF (1999) Deficiency in phytoalexin production causes enhanced susceptibility of Arabidopsis thaliana to the fungus Alternaria brassicicola. Plant J 19: 163-171.

Zipfel C, Robatzek S, Navarro L, Oakeley EJ, Jones JD, Felix G, Boller T (2004) Bacterial disease resistance in Arabidopsis through flagellin perception. Nature 428: 764-767. 


\section{Supplemental information}

$\mathbf{A}$

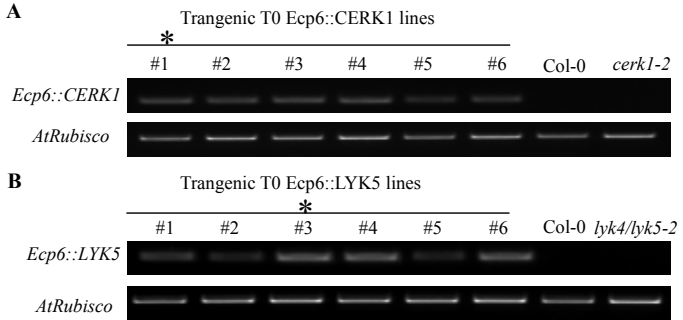

Figure S1. Expression of Ecp6::CERK1, Ecp6::LYK5, AtCERK1, and AtLYK5 in To transgenic Arabidopsis plants. Detection of Ecp6::CERKI (A) or Ecp6::LYK5 (B) transcripts in independent To transformation events measured by RT-PCR with primers specific for the LysM domain of Ecp6. The A. thaliana Rubisco gene was used as an endogenous control. The transgenic line that was used for selfing is indicated with an asterisk. Detection of AtCERKI (C) or AtLYK5 (D) transcripts in independent To transformation events measured by RT-PCR with primers specific for the kinase domain of AtCERK1 or AtLYK5. The A. thaliana Rubisco gene was used as an endogenous control. The transgenic line that used for selfing is indicated with an asterisk.
C AtCERK1

D
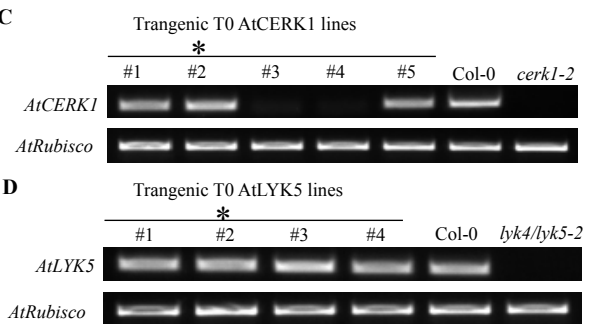

AtLYKS

AtRubisco 


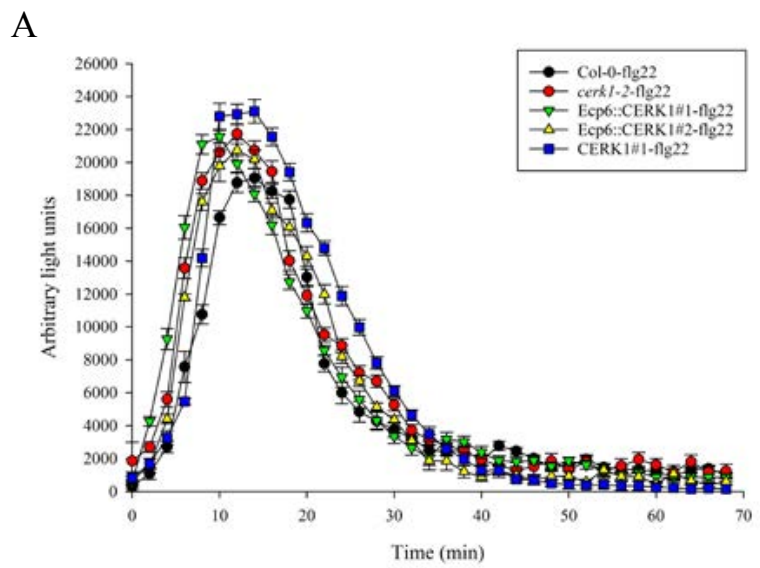

B

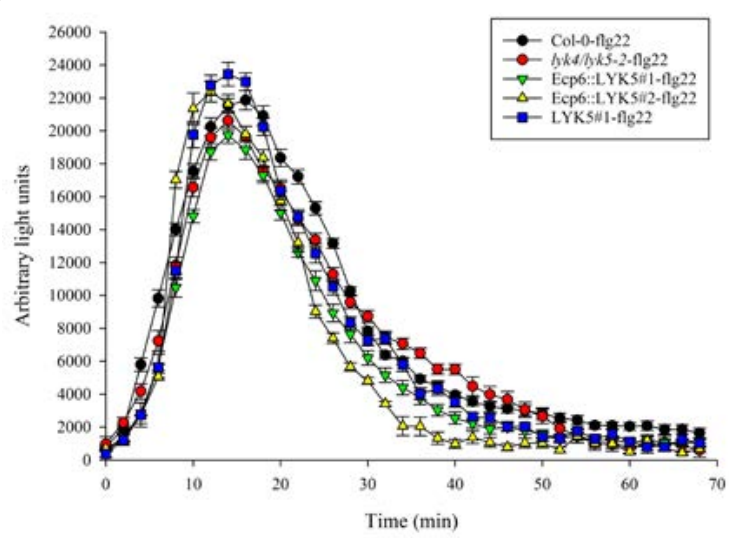

Figure S2. ROS production in Ecp6::CERK1 (A) or Ecp6::LYK5 (B) transgenic plants upon bacterial elicitor flg22 treatment. Production of ROS was measured by using luminol-dependent chemiluminescence over a period of 70 min following treatment of Arabidopsis leaf discs with $100 \mathrm{nM}$ of flg22 or water. The relative luminescence was calculated by normalization to water-treated leaf discs. Plotted are means \pm SD of 8 leaf discs. The experiment was performed twice with similar results. 


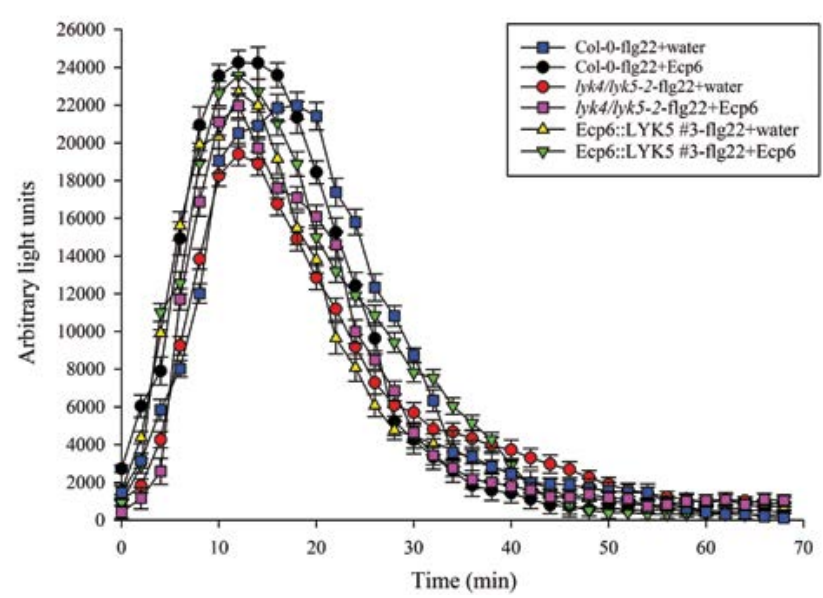

Figure S3. Bacterial flg22-induced ROS production in the presence of Ecp6. Production of ROS was measured by using luminol-dependent chemiluminescence over a period of $70 \mathrm{~min}$ following treatment of Arabidopsis leaf discs with $100 \mathrm{nM}$ flg22 in the presence or absence of $10 \mu \mathrm{M}$ Ecp 6 protein. The relative luminescence was calculated by normalization to water-treated leaf discs. Plotted are means \pm SD of 8 leaf discs. The experiment was performed twice with similar results. 
Table S1. Primers used in this study.

\begin{tabular}{|c|c|c|}
\hline Primer name & Oligonucleotide sequence $\left(5^{\prime} \rightarrow 3^{\prime}\right)$ & Description $^{a}$ \\
\hline Ecp6::CERK1_LysM-F & $\begin{array}{l}\text { CTCATTCTTCTTCGCCGTGGAATCTAGCAA- } \\
\text { CATCAAATACACTGTC }\end{array}$ & $\begin{array}{l}\text { Amplification of Ecp } 6 \text { LysM domains; } \\
\text { overhang present in primer for } \\
\text { overlap with region of CERK1 is } \\
\text { underlined }\end{array}$ \\
\hline Ecp6::CERK1_LysM-R & $\frac{\text { CTATACCAGCAATAACTCCAGCTG- }}{\text { GCAGAATGATCTGCTG }}$ & $\begin{array}{l}\text { Amplification of Ecp } 6 \text { LysM domains; } \\
\text { overhang present in primer for } \\
\text { overlap with region of CERKI is } \\
\text { underlined }\end{array}$ \\
\hline CERK1_pro-F & GGCGCGCCTATATGAAGAAGG & $\begin{array}{l}\text { Amplification of CERK1 promotor } \\
\text { region }\end{array}$ \\
\hline CERKI_pro-R & $\begin{array}{l}\text { GACAGTGTATTTGATGTTGCTAGATTCCAC- } \\
\text { GGCGAAGAAG }\end{array}$ & $\begin{array}{l}\text { Amplification of CERK1 region; } \\
\text { overhang present in primer for } \\
\text { overlap with region of Ecp6 is } \\
\text { underlined }\end{array}$ \\
\hline CERK1_ID-F & $\frac{\text { TTGGTCAGCAGATCATTCTGCCAGCTG- }}{\text { GAGTTATTGCTGGT }}$ & $\begin{array}{l}\text { Amplification of CERKI intracellular } \\
\text { domains; overhang present in primer } \\
\text { for overlap with region of Ecp } 6 \text { is } \\
\text { underlined }\end{array}$ \\
\hline CERK1_ID-R & CTACCGGCCGGACATAAGACTGAC & $\begin{array}{l}\text { Amplification of CERKI intracellular } \\
\text { domains }\end{array}$ \\
\hline Ecp6::LYK5_LysM-F & $\begin{array}{l}\text { CTTTGCCGTGTCACCGGCGAAAGCTAG- } \\
\text { CAACATCAAATACACTGT }\end{array}$ & $\begin{array}{l}\text { Amplification of Ecp } 6 \text { LysM domains; } \\
\text { overhang present in primer for } \\
\text { overlap with region of LYK5 is } \\
\text { underlined }\end{array}$ \\
\hline Ecp6::LYK5_LysM-R & $\begin{array}{l}\text { AGAGAAGCAAACCAGCTCCGGCTTAG- } \\
\text { ATGGGTTAACGTTGTTGTT }\end{array}$ & $\begin{array}{l}\text { Amplification of Ecp } 6 \text { LysM domains; } \\
\text { overhang present in primer for } \\
\text { overlap with region of LYK5is } \\
\text { underlined }\end{array}$ \\
\hline LYK5_pro_F & CCTCTGTTTTTGTTGTGGATTATTATAG & $\begin{array}{l}\text { Amplification of } L Y K 5 \text { promotor } \\
\text { region }\end{array}$ \\
\hline LYK5_pro_R & $\begin{array}{l}\text { ACAGTGTATTTGATGTTGCTAGCTTTCGC- } \\
\text { CGGTGACACGGCAAAG }\end{array}$ & $\begin{array}{l}\text { Amplification of } L Y K 5 \text {, overhang } \\
\text { present in primer for overlap with } \\
\text { region of Ecp6 is underlined }\end{array}$ \\
\hline LYK5_ID-F & $\begin{array}{l}\text { AACAACAACGTTAACCCATCTAAGCCG- } \\
\text { GAGCTGGTTTGCTTCTCT }\end{array}$ & $\begin{array}{l}\text { Amplification of LYK5 intracellular } \\
\text { domains; overhang present in primer } \\
\text { for overlap with region of Ecp } 6 \text { is } \\
\text { underlined }\end{array}$ \\
\hline LYK5_ID-R & CTAGTTGCCAAGAGAGCCGGA & $\begin{array}{l}\text { Amplification of LYK5 intracellular } \\
\text { domains }\end{array}$ \\
\hline CERK1-qPCR-F & AGTGTCTGCAAAAGTAGATG & Reverse Transcription-PCR \\
\hline CERK1-qPCR-R & CTACCGGCCGGACATAAGACTG & Reverse Transcription-PCR \\
\hline LYK5-qPCR-F & TCTTTCGGGGAGAGAAGCAG & Reverse Transcription-PCR \\
\hline LYK5-qPCR-R & AAGGTCATCAGAAGGCTCCC & Reverse Transcription-PCR \\
\hline WRKY22-qPCR-F & TCCTTCGGAGAGATTCGAGA & Reverse Transcription-PCR \\
\hline WRKY22-qPCR-R & CTGCTGCTACATGGCACACT & Reverse Transcription-PCR \\
\hline
\end{tabular}




\begin{tabular}{lll}
\hline Primer name & Oligonucleotide sequence (5' $\left.^{\prime} \rightarrow \mathbf{3}^{\prime}\right)$ & Description $^{\mathbf{a}}$ \\
\hline WRKY75-qPCR -F & CCAAAAGGCCGTCAAGAACAACAA & Reverse Transcription-PCR \\
\hline WRKY75-qPCR-R & TGCTTCTTCACATTGCATCCTCCA & Reverse Transcription-PCR \\
\hline AtRubisco-F & GCAAGTGTTGGGTTCAAAGCTGGTG & Reverse Transcription-PCR \\
\hline AtRubisco-R & CCAGGTTGAGGAGTTACTCGGAATGCTG & Reverse Transcription-PCR \\
\hline
\end{tabular}




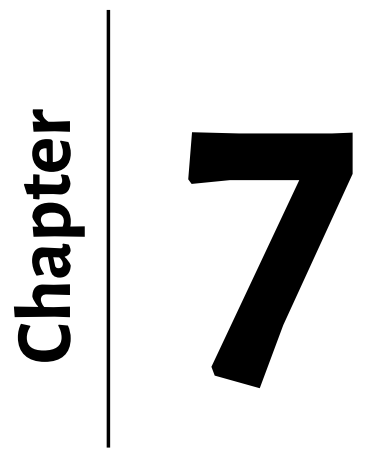

General discussion:

How do microbes evolve to become plant pathogens? 


\begin{abstract}
Microbial plant pathogens cause considerable crop yield losses in agricultural production systems worldwide. In order to establish their parasitic relationships with host plants, microbial pathogens rely on the secretion of effector molecules to support host colonization. To this end, pathogens carry genes to secrete dozens (for bacteria) to hundreds (for fungi and oomycetes) effectors. It is generally demonstrated that significant redundancy occurs among effectors that are present in effector catalogs of a single pathogen. Consequently, deletions of single effector genes most frequently result in modestly attenuated virulence phenotypes. However, in some cases, single effector genes seem to make a major contribution to pathogenicity, even to an extent where pathogenicity relies on a single effector only. Depending on the pathogen, its lifestyle and its host range, the utilization of a single effector that act as a pathogenicity factor on a particular host plant may offer an evolutionary advantage to the microbial pathogen.
\end{abstract}




\section{Introduction}

In nature, plants are teeming with a diverse range of microorganisms, including commensal, symbiotic, and pathogenic ones. Among these, pathogenic microorganisms colonize their plant hosts while adversely affecting them, which typically leads to the expression of disease symptoms (Aung et al., 2018). Commonly referred to as pathogenicity, the ability to cause disease is a widely shared trait among diverse plant-associated microorganisms, including bacteria, fungi, and oomycetes (Plissonneau et al., 2017). Interestingly, phylogenetic studies have shown that pathogenic microbial species do not occur in closely related monophyletic clusters, but are spread as discrete subdivisions within larger phylogenetic groups that also comprise non-pathogenic species (Fitzpatrick et al., 2006). Consequently, pathogens are found in all taxonomic divisions of microorganisms, and it is generally accepted that microbial pathogenicity arose multiple times during evolution (James et al., 2006; Soanes et al., 2007; van der Does and Rep, 2007).

Since plant pathogenic microorganisms cause substantial crop yield losses, they have long been known as major biotic constraints to crop production worldwide. Deciphering mechanisms of microbial pathogenicity is therefore a long-standing objective of plant pathology research (Strange and Scott, 2005; Fisher et al., 2012). Over the years, accumulating evidence has shown that the pathogenicity of a plant pathogen is largely mediated by so-called effector molecules that are secreted during host infection (Jones and Dangl, 2006; de Jonge et al., 2011; Rovenich et al., 2014; Rodriguez-Moreno et al., 2018). These effectors are typically considered to be small cysteine-rich proteins, but may also comprise other types of molecules such as secondary metabolites and small RNAs (Rodriguez-Moreno et al., 2018). Most of the secreted effector molecules are involved in suppression of plant immune responses or in manipulation of other elements of plant physiology to support host colonization (Rovenich et al., 2014; RodriguezMoreno et al., 2018).

Because plant pathogens secrete a battery of effector molecules to facilitate host colonization (Büttner et al., 2016; Rovenich et al., 2014), it is not surprising that many effectors appear to be functionally redundant (Win et al., 2012). For instance, the genome of the oomycete pathogen Phytophthora infestans encodes over 500 RxLR-motif containing effectors besides other types of effectors (Haas et al., 2009), which are unlikely to all have unique targets (Birch et al., 2008; Stassen and Van den Ackerveken, 2011). Similarly, the maize head smut fungus Sporisorium reilianum possesses a pool of functionally redundant effectors to modulate virulence on maize, as individual effector gene deletions only showed a modest impact on virulence (Ghareeb et al., 2018). In the same fashion, the bacterial pathogen Pseudomonas syringae pv. tomato (Pst) carries approximately 30 genes that encode type III secreted effectors (Xin and He, 2013), of which multiple members can be deleted simultaneously without a noticeable effect on virulence (Kvitko et al., 2009). Thus, for various types of pathogens it is generally considered that effector catalogues carry redundant activities and the effectors collectively mediate microbial pathogenicity through the simultaneous manipulation of diverse host processes (de Jonge et al., 2011; Tan et al., 2015; Win et al., 2012). 


\section{Pathogen lifestyles are associated with genomic adaption}

Plant pathogens have evolved different strategies to interact with their host plants and acquire nutrients. Generally, their pathogenic lifestyles can be assigned to two extremes: biotrophy and necrotrophy (Glazebrook, 2005; Spanu, 2012). While biotrophic pathogens comprise species that can only obtain nutrients from living plant tissue, necrotrophic pathogens kill host cells to secure their nutrient supply (Mengiste, 2012). However, many pathogens reside in the continuum between these two extreme lifestyles and are labelled as hemibiotrophs that start with a biotrophic phase followed, sooner or later, by a transition to a necrotrophic stage (Spanu, 2012).

To date, thousands of genomes of pathogenic microbes have been sequenced and are publically available (Thomma et al., 2016), and so-called pathogenomics has revealed genomic adaptations that are associated with lifestyles (Schmidt et al., 2010; Guttman et al., 2014). For instance, the genomic analysis of several obligate biotrophic pathogens has provided a plausible molecular explanation for their obligate parasitism (Baxter et al., 2010; Spanu et al., 2010; Duplessis et al., 2011; Guttman et al., 2014). A characteristic feature of these genomes is the considerable loss of genes that are involved in primary metabolic pathways (Baxter et al., 2010; Spanu et al., 2010; Guttman et al., 2014). For instance, genes for nitrate and nitrite reductases, as well as for sulfite reductases, are largely missing from the genome of the oomycete pathogen Hyaloperonospora arabidopsidis (Baxter et al., 2010). Similar observations were made for powdery mildew fungi (Spanu et al., 2010). Thus, gene losses in primary metabolism may explain why $H$. arabidopsidis, powdery mildew fungi and likely also other biotrophic pathogens became obligate parasites (Spanu et al., 2010, 2012; Guttman et al., 2014). Furthermore, for obligate biotrophs, it is imperative to maintain host cell viability and avoid the activation of host immune responses, especially if these involve apoptosis or other types of host cell death. Thus, another characteristic feature of obligate biotrophic pathogen genomes is that many gene families encoding plant cell wall hydrolases and secondary metabolites are significantly reduced (Spanu et al., 2010; Duplessis et al., 2011; Baxter et al., 2010).

The genome sequences of necrotrophic fungal pathogens, such as the fungal cereal pathogens Pyrenophora teres f. teres and Parastagonospora nodorum (formerly Stagonospora nodorum), typically reveal an abundance of genes encoding carbohydrate hydrolases, cytochrome $\mathrm{P} 450$ monooxygenases, non-ribosomal peptide synthetases (NRPSs), and polyketide synthases (PKSs) that can be attributed to their necrotrophic lifestyle (Hane et at., 2007; Ellwood et al., 2010; Schmidt et al., 2011). For instance, carbohydrate hydrolases are involved in degradation of plant cell walls (Lombard et al., 2014), while cytochrome P450 monooxygenases, NRPSs and PKSs are typically associated with the biosynthesis of secondary metabolites, some of which are toxic to plant cells (Möbius and Hertweck, 2009; Stergiopoulos et al., 2013). Genomic analysis of the necrotrophic pathogens Sclerotinia sclerotiorum and Botrytis cinerea has shown similar arsenals of genes that can be implicated in necrotrophic processes, such as genes involved in plant cell wall degradation and oxalic acid production that have been involved in tissue maceration (Amselem et al., 2011). 
Genome sequencing combined with stage-specific transcriptomic analysis of the hemibiotrophic Arabidopsis pathogen Colletotrichum higginsianum and the maize pathogen Colletotrichum graminicola revealed a number of pathogenicity-related genes that are transcribed in successive waves and can be linked to the lifestyle transition (O'Connell et al., 2012). Here, the majority of genes encoding effectors and secondary metabolite biosynthesis components are strongly induced during the initial biotrophic phase, whereas lytic enzymes and transporter genes are upregulated in the subsequent necrotrophic phase (O'Connell et al., 2012). It is likely that these fungi need effectors or even particular secondary metabolites for the manipulation of host defence responses during early biotrophic stages, while the pathogen later uses lytic enzymes for destruction of host cells during necrotrophic growth (O'Connell et al., 2012).

\section{The effector arsenal of biotrophic pathogens}

As indicated above, for biotrophic pathogens it is vitally important to supress host defences without perturbing host cellular homeostasis (Doehlemann et al, 2014). Cladosporium fulvum is a biotrophic fungal pathogen that causes tomato leaf mould disease (Joosten and Wit, 1999). To establish biotrophy and promote colonization of the apoplast, a hostile environment that contains various plant-secreted hydrolytic enzymes including chitinases and glucanases, $C$. fulvum secretes a plethora of effector proteins (de Wit et, 2016; Rovenich et al., 2016). Hostsecreted chitinases target fungal cell walls not only to release chitin fragments that activate host immune receptors but also to induce cellular collapse, and thus inhibition of fungal proliferation (Sánchez-Vallet et al., 2015; Rovenich et al., 2016). To prevent this, C. fulvum secretes the apoplastic effector Avr4 that binds fungal cell walls through an invertebrate chitin-binding domain to render the cell wall chitin inaccessible to chitinases and consequently protects it against hydrolysis (van den Burg et al., 2006; van Esse et al., 2007). Besides Avr4, C. fulvum also secretes the LysM domain-containing effector protein Ecp6 to sequester chitin fragments and prevent the activation of chitin-induced plant immunity during host colonization (Bolton et al., 2008; de Jonge et al., 2010). Besides various types of hydrolytic enzymes, the host apoplast also contains diverse proteases and other types of antifungal compounds that adversely affect fungal invasion (van Esse et al., 2008; Jashni et al, 2015). The C. fulvum effector Avr2 was shown to inhibit a set of tomato defense-related proteases to support fungal growth in the apoplast (van Esse et al., 2008). In addition, C. fulvum secretes the glycosyl hydrolase CfTomi to detoxify $\alpha$-tomatine, an antifungal glycoalkaloid (Ökmen et al., 2013).

Several effectors of the maize smut fungus Ustilago maydis have been characterized and implicated in its biotrophic life style (Lanver et al., 2017). For example, Pep1 inhibits the maize peroxidase POX12 to block the peroxidase driven oxidative burst (Doehlemann et al., 2009; Hemetsberger et al., 2012). Like the C. fulvum effector Avr2, the apoplastic U. maydis effector Pit2 functions as an inhibitor of maize cysteine proteases (Doehlemann et al., 2011, Mueller et al., 2013). In addition, $U$. maydis secretes the chorismate mutase Cmul into the host cytoplasm to suppress the synthesis of salicylic acid (SA), a canonical defense hormone that plays a crucial role in the activation of defense responses that are directed against biotrophic pathogens (Thomma et al., 1998; Glazebrook, 2005), by reducing the pool of the salicylic acid precursor chorismate (Djamei et al., 2011). 


\section{The effector arsenal of necrotrophic pathogens}

Host selective toxins (HSTs) are known to induce necrotic reactions and promote susceptibility on plants that harbour the corresponding toxin target (Wolpert et al., 2002). Therefore, these toxins are frequently called necrotrophic effectors as well (Friesen et al., 2008). For example, victorin is a HST produced by the necrotrophic fungus Cochliobolus victoriae, the causal agent of the Victoria blight on oat plants (Meehan and Murphy, 1947; Scheffer et al., 1967; Wolpert et al., 1985, 1986). It has been shown that victorin targets the defense-associated thioredoxin TRX-h5, which is guarded by Arabidopsis resistance protein LOV1, and thus activates a LOV1-mediated cell death response (Lorang et al., 2012). In this manner, C. victoriae exploits plant immunity to trigger host cell death and mediate disease establishment (Lorang et al., 2012).

The necrotrophic plant pathogens P. nodorum and Pyrenophora tritici-repentis produce several necrotrophic effectors that induce disease in wheat cultivars that carry corresponding susceptibility genes (Friesen et al, 2008; McDonald and Solomon, 2018). P. tritici-repentis effector PrToxA interacts with the wheat Tsn 1 in a gene-for-gene manner to induce necrosis (Ciuffetti et al., 2010; Shi et al., 2016). It was reported that PrToxA was horizontally acquired by $P$. tritici-repentis from P. nodorum (Friesen et al., 2006; Stukenbrock and McDonald, 2007), and more recently ToxA has been discovered in the wheat pathogen Bipolaris sorokiniana as well (McDonald et al., 2018). The P. nodorum effector SnToxi was shown to interact with wheat Snn1 to induce hallmarks of apoptosis including an oxidative burst and DNA laddering (Liu et al., 2012). Interestingly, the wheat susceptibility gene Tsn 1 displays disease resistance protein-like features, including S/TPK and NBS-LRR domains (Faris et al., 2010), while Snn1 is a wall-associated kinase receptor (Shi et al., 2016). Collectively, these studies show that, like biotrophic pathogens, also necrotrophic fungal pathogens utilize effectors to modulate host immunity to mediate host interactions (Wolpert et al., 2002; Faris et al., 2010; Liu et al., 2012, 2016; Shi et al., 2016).

\section{The effector arsenal of hemibiotrophic pathogens}

Magnaporthe oryzae is a hemibiotrophic fungal pathogen that causes rice blast, which is one of the most devastating diseases of cultivated rice (Wilson and Talbot, 2009). The M. oryzae apoplastic effector Slp1, which is a homolog of C. fulvum Ecp6, specifically accumulates at the plant-fungus interface during the early stages of rice blast infections (Mentlak et al., 2012). Slp1 competes with the rice chitin receptor CEBiP for binding of chitin oligosaccharides, and thus sequesters chitin oligosaccharides to prevent the activation of chitin-triggered immunity in rice (Mentlak et al., 2012). It was reported that the M. oryzae cytoplasmic effector AvrPiz-t suppresses the transcriptional activity of the bZIP-type transcription factor APIP5, which leads to rapid cell necrosis and lesion formation at the necrotrophic stage (Wang et al., 2016). Thus, it is likely that effector AvrPiz-t plays a role in the transition from the biotrophic to the necrotrophic stage of $M$. oryzae (Wang et al., 2016).

The hemibiotrophic oomycete pathogen P. infestans is the causal agent of the devastating late blight disease of potato and tomato (Du et al., 2015). During its early biotrophic infection stage, the cytoplasmic effector AVR3a is secreted from haustoria into host cells to stabilize the host E3 
ligase CMPG1 to mediate suppression of cell death induced by P. infestans elicitor INF1 (Armstrong et al., 2005; Bos et al., 2010). Another P. infestans effector protein, SNE1 (suppressor of necrosis 1), is highly expressed during biotrophy to suppress host cell death induced by the P. infestans NLP effector PiNPP1.1 (Kelley et al., 2010). Interestingly, at the necrotrophic phase, expression levels of SNE1 decline, while PiNPP1 expression increases (Kelley et al., 2010). Thus, SNE1 and PiNPP1.1 are coordinately expressed during biotrophy and necrotrophy, respectively, to orchestrate the transition from biotrophy to necrotrophy (Kelley et al., 2010).

These examples suggest that hemibiotrophs carry two types of effectors, namely the ones that are typically produced by biotrophic pathogens to subvert immunity in the early stages of infections when typically no disease symptoms are expressed, and the ones that are typically produced by necrotrophic pathogens for later stages of infection when tissue maceration is induced.

\section{Comparative genomic analyses fail to unravel the molecular basis of pathogenicity in the Verticillium genus}

Although effectors are typically considered as molecules that are produced by microbial pathogens to support host colonization, it has become evident that also non-pathogenic microbes encode abundant effector catalogs (de Jonge and Thomma 2009; Seidl et al., 2015; Oome and Van den Ackerveken, 2014; Martin et al., 2008; 2010). The accessibility and relatively low cost of modernday sequencing technologies make that genome sequencing has become accessible to many research laboratories, including those studying non-model organisms (Faino and Thomma, 2014; Thomma et al., 2016). This has also spurred comparative genomic analyses that are aimed at unravelling the molecular basis of microbial pathogenicity.

The Verticillium genus comprises soil-borne asexual species that differ significantly in their lifestyles that range from saprophytic to pathogenic (Fradin and Thomma, 2006; Klosterman et al., 2011; Inderbitzin et al., 2011; Inderbitzin and Subbarao, 2014). Among them, Verticillium dahliae, V. albo-atrum, V. alfalfae, V. nonalfalfae and V. longisporum are plant pathogens that causes vascular wilt disease (Fradin and Thomma, 2006; Inderbitzin et al., 2011; Inderbitzin and Subbarao, 2014). The remaining Verticillium spp., namely V. isaacii, V. klebahnii, V.nubilum, V. tricorpus and V. zaregamsianum are mostly considered saprophytes that thrive on dead organic material and are only occasionally reported as opportunistic pathogens (Inderbitzin et al., 2011; Inderbitzin and Subbarao, 2014). Genome analysis of V. dahliae and V. tricorpus revealed that the $V$. tricorpus effector repertoire largely resembles that of $V$. dahliae (Seidl et al., 2015). Wellcharacterized effector families that have been implicated in fungal pathogenicity, such as LysM effectors (de Jonge et al., 2010; Marshall et al., 2011; Mentlak et al., 2012; Kombrink et al., 2017) and NLP effectors (Santhanam et al., 2013), are found in V. tricorpus as well (Seidl et al., 2015). Genuswide genome analyses furthermore showed all Verticillium spp. display similar genomic features, including the occurrence of extensive genomic rearrangements and the presence of similarly sized effector catalogs (Shi-Kunne et al., 2018; Shi-Kunne unpublished data). Consequently, no obvious genomic differences can be linked to pathogenicity in the Verticillium genus (Seidl et al., 2015; Shi-Kunne et al., 2018; Shi-Kunne unpublished data). This has fuelled the hypothesis that 
the ability to cause disease within the Verticillium genus is caused by subtle genomic traits that do not easily become apparent from whole-genome comparisons (Seidl et al., 2015; Shi-Kunne unpublished data).

\section{A single to few $V$. dahliae effectors determine pathogenicity on a particular host plant}

In this thesis I have shown that two effectors of $V$. dahliae individually are responsible for pathogenicity on different plant hosts. The $\mathrm{D}$ effector was shown to act as a pathogenicity determinant of $V$. dahliae strains that belong to the defoliating pathotype to cause disease on cotton and olive, but also for infections on Nicotiana benthamiana and Arabidopsis thaliana that do not respond to infection with defoliation (Chapter 2). Besides, the Tom1 effector was found to mediate V. dahliae pathogenicity on tomato (Chapter 3). Our attempt to identify a single such pathogenicity factor for Verticillium wilt disease on sunflower failed, perhaps also because the analysis was performed on relatively few strains only. Nevertheless, also this analysis revealed an effector (named as Sun1) with a large impact on disease development (Chapter 4). This finding suggests that pathogenicity of $V$. dahliae on sunflower depends on relatively few effectors, such that the deletion of a single one has a marked impact on virulence. Collectively, these findings suggest that pathogenicity of $V$. dahliae on various plant hosts depends on relatively few effectors, and for some host species even on a single one, which challenges the common assumption that effector activities are redundant and that contributions of individual effectors to microbial pathogenicity are dispensable.

Perhaps it is not so surprising that $V$. dahliae as a broad host pathogen utilizes relatively few effectors to cause disease on a single host. On the one hand, it can be hypothesized that broad host-range pathogens possess a collection of "one-fits-all" effectors that interact with targets that are conserved in a wide range of plant species to mediate compatibility on many hosts. On the other hand, broad host-range pathogens may possess multiple sets of more specific effectors that operate on single to few hosts only. This latter option requires that relatively few effectors are required to cause disease on a single host as it is unlikely that a single pathogen would possess extensive effector catalogs for a wide range of host species. In this respect our finding that different strains that are able to infect the same host carry divergent effector catalogs (Chapter 5) is interesting, as it suggests that effector catalogs are subject to considerable diversification with a continuous evolution of novel effectors, which argues against the general occurrence of "onefits-all" effectors that interact with targets that are conserved in a wide range of plant species, as these would be evolutionary more ancient and conserved.

Considering its wide host range, it is conceivable that $V$. dahliae strains display a relatively low degree of co-evolution with individual host species. This is also reflected by its colonization biology, as the fungus thrives in xylem vessels that consists of lignified tracheary elements that have lost their protoplasts, and hence relatively little interaction with the host occurs (Yadeta and Thomma, 2013). Furthermore, the fungus does not develop highly evolved appressoria for penetration, or haustoria for feeding and effector deposition. Finally, little convincing evidence exists that a suite of effector proteins is directed towards the cytoplasm of host cells. Considering 
the relatively low degree of co-evolution, it is unlikely that the fungus evolved large numbers of effectors that meticulously manipulate a wide array of host targets of the immune system or other components that mediate the physiology of the different host plants, like for instance powdery mildews and rust fungi do (Spanu et al., 2010; Pliego et al., 2013; Petre et al., 2014; Ramachandran et al., 2017). Therefore it is perhaps not surprising that we found that $V$. dahliae strains only need a single to a few effectors to be able to cause disease on particular host plant species. However, given that strains that are compatible on a particular host show marked differences in their aggressiveness (Chapters 2-5), it is evident that other effectors that are likely not crucial for pathogenicity contribute to optimal aggressiveness. The catalog of such effectors differs per strain, as illustrated in Chapter 5. For example, whereas the expression of Tom1 is imperative for the ability to cause tomato disease (Chapter 2), the additional expression of Ave1 in race 1 strains significantly contributes to aggressiveness on this host plant (de Jonge et al., 2012).

Plant hosts try to intercept pathogen invasion through the evolution of diverse kinds of receptors for invasion patterns (Cook et al., 2015). In this manner, also effectors can become invasion patterns once they become recognized by host immune receptors (Cook et al., 2015). Consequently, the more effectors are secreted during host colonization, the higher the chance that one of the effectors gets recognized by a host immune receptor. Thus, an added advantage for $V$. dahliae of utilizing only few effectors for colonization of a single plant host is that the chance of being recognized by a host immune receptor through effector recognition significantly decreases. Obviously, the flip side of the same coin is that dependency on few effectors makes that recognition of such an effector immediately has large consequences. Once effector recognition occurs, it is important for pathogens to employ strategies to overcome this recognition, often through mutation or loss of the recognized effector (Rovenich et al., 2014). However, loss of an effector that is crucial for pathogenicity, or plays a major role in virulence, has the implication that the pathogen is no longer able to infect the host, or is considerably less aggressive, respectively. Indeed, V. dahliae strains that have overcome recognition by the Ver immune receptor of tomato have lost the major virulence factor Ave1 and are significantly compromised in their aggressiveness (de Jonge et al., 2012). However, given the fact that V. dahliae strains generally possess the ability to infect a wide array of host plants, loss of a crucial pathogenicity factor may impact the ability to cause disease on particular hosts, but the ability to colonize other host plants remains. After all, it is unlikely that multiple host plants simultaneously evolve immune receptors to recognize the same effector. Thus, considering the nature of $V$. dahliae as a rather unsophisticated pathogen that has a low degree of adaptation towards individual plant hosts, the utilization of relatively few effectors for host colonization may have considerable evolutionary advantages, as it perhaps facilitates host jumps and the addition of novel hosts to its host range. In this respect it is interesting to remember that $V$. dahliae is a soil-borne pathogen that does not have the capacity to move over large distances, which foliar pathogens can spread spores over large distances to establish new infections on their host plants. Consequently, V. dahliae will have to remain quiescent, in its resting stage, until a root from a new host plant is in the vicinity, or establish compatibility on the hosts that happen to be around. 


\section{Concluding remarks}

Plant pathogens pose great threats to global food security, and understanding the molecular basis of microbial pathogenesis is crucial for developing effective control strategies. It is generally considered that effector catalogues collectively mediate microbial pathogenicity and that disease establishment requires the concerted action of multiple effectors simultaneously. Pathogens that display a high degree of host specialization, which is typically the consequence of a relatively high degree of co-evolution with their host species, typically evolved large numbers of effectors to meticulously manipulate a wide array of host targets of the immune system. This makes sense considering that such pathogens need to guarantee a successful infection once they come in contact with their host, as the failure to infect may usher an evolutionary dead end. However, V. dahliae, which has the ability to infect a wide range of hosts and, consequently, shows a low level of adaptation towards these hosts, seems to rely only on a single to few effectors for host colonization. Perhaps this can be explained when considering that the pathogen is an immobile soil-resident that will have to establish compatibility with plant hosts in its immediate micro-environment, and thus flexibility to interact with a multitude of hosts is of benefit. Given this life style, utilization of a single to a few effectors to mediate compatibility on a single host may confer a considerable evolutionary advantage. In this thesis, the $\mathrm{D}$, Tom1, but also Sun1 effectors were identified as important effectors to cause disease on particular host plants. It can be anticipated that these effectors target essential components of the host immune system or other biological processes that enable host infection. Future research focusing on elucidating the mode of action of these effectors and identification of their targets will not only advance our understanding of microbial pathogenesis and of host immunity, but perhaps also identify novel molecular components that can be targeted for improved disease control. 


\section{References}

Amselem J, Cuomo CA, van Kan JA, Viaud M, Benito EP, Couloux A, Coutinho PM, de Vries RP, Dyer PS, Fillinger S, et al. (2011) Genomic analysis of the necrotrophic fungal pathogens Sclerotinia sclerotiorum and Botrytis cinerea. PLoS Genet 7: e1002230.

Armstrong MR, Whisson SC, Pritchard L, Bos JI, Venter E, Avrova AO, Rehmany AP, Böhme U, Brooks K, Cherevach I, et al. (2005) An ancestral oomycete locus contains late blight avirulence gene Avr3a, encoding a protein that is recognized in the host cytoplasm. Proc Natl Acad Sci U S A 102: 7766-7771.

Aung K, Jiang Y, He SY (2018) The role of water in plant-microbe interactions. Plant J 93: 771-780.

Baxter L, Tripathy S, Ishaque N, Boot N, Cabral A, Kemen E, Thines M, Ah-Fong A, Anderson R, Badejoko W, et al. (2010) Signatures of adaptation to obligate biotrophy in the Hyaloperonospora arabidopsidis genome. Science 330: 1549-1551.

Birch PR, Boevink PC, Gilroy EM, Hein I, Pritchard L, Whisson SC (2008) Oomycete RXLR effectors: delivery, functional redundancy and durable disease resistance. Curr Opin Plant Biol 11: 373-379.

Bos JI, Armstrong MR, Gilroy EM, Boevink PC, Hein I, Taylor RM, Zhendong T, Engelhardt S, Vetukuri RR, Harrower B, et al. (2010) Phytophthora infestans effector AVR3a is essential for virulence and manipulates plant immunity by stabilizing host E3 ligase CMPG1. Proc Natl Acad Sci USA 107: 9909-9914.

Bolton MD, Thomma BP, Nelson BD (2006) Sclerotinia sclerotiorum (Lib.) de Bary: biology and molecular traits of a cosmopolitan pathogen. Mol Plant Pathol 7: 1-16.

Bolton MD, van Esse HP, Vossen JH, de Jonge R, Stergiopoulos I, Stulemeijer IJ, van den Berg GC, Borrás-Hidalgo O, Dekker HL, de Koster CG, et al. (2008) The novel Cladosporium fulvum lysin motif effector Ecp6 is a virulence factor with orthologues in other fungal species. Mol Microbiol 69: 119-136.

Büttner (2016) Behind the lines-actions of bacterial type III effector proteins in plant cells. FEMS Microbiol Rev 40: 894-937.

Ciuffetti LM, Manning VA, Pandelova I, Betts MF, Martinez JP (2010) Host-selective toxins, Ptr ToxA and Ptr ToxB, as necrotrophic effectors in the Pyrenophora tritici-repentis-wheat interaction. New Phytol 187: 911-919.

Cook DE, Mesarich CH, Thomma BPHJ (2015) Understanding plant immunity as a surveillance system todetect invasion. Annu Rev Phytopathol 53: 541-563.

de Jonge R, Bolton MD, Thomma BPHJ (2011) How filamentous pathogens co-opt plants: the ins and outs of fungal effectors. Curr Opin Plant Biol 14: 400-406.

de Jonge R, van Esse HP, Kombrink A, Shinya T, Desaki Y, Bours R, van der Krol S, Shibuya N, Joosten MH, Thomma BPHJ (2010) Conserved fungal LysM effector Ecp6 prevents chitin-triggered immunity in plants. Science 329: 953-955.

de Jonge R, van Esse HP, Maruthachalam K, Bolton MD, Santhanam P, Saber MK, Zhang Z, Usami T, Lievens B, Subbarao KV, et al. (2012) Tomato immune receptor Ve1 recognizes effector of multiple fungal pathogens uncovered by genome and RNA sequencing. Proc Natl Acad Sci USA 109: 5110-5115.

de Jonge R, Thomma BP (2009) Fungal LysM effectors: extinguishers of host immunity? Trends Microbiol 17: 151157.

de Wit PJ (2016) Cladosporium fulvum Effectors: Weapons in the Arms Race with Tomato. Annu Rev Phytopathol 54: $1-23$.

Djamei A, Schipper K, Rabe F, Ghosh A, Vincon V, Kahnt J, Osorio S, Tohge T, Fernie AR, Feussner I, et al. (2011) Metabolic priming by a secreted fungal effector. Nature 478: 395-398.

Doehlemann G, Reissmann S, Assmann D, Fleckenstein M, Kahmann R (2011) Two linked genes encoding a secreted effector and a membrane protein are essential for Ustilago maydis-induced tumour formation. Mol Microbiol 81: 751-766.

Doehlemann G, Requena N, Schaefer P, Brunner F, O'Connell R, Parker JE (2014) Reprogramming of plant cells by filamentous plant-colonizing microbes. New Phytol 204: 803-814.

Doehlemann G, van der Linde K, Assmann D, Schwammbach D, Hof A, Mohanty A, Jackson D, Kahmann R (2009) Pepi, a secreted effector protein of Ustilago maydis, is required for successful invasion of plant cells. PLoS Pathog 5: e1000290. 
Du Y, Mpina MH, Birch PR, Bouwmeester K, Govers F (2015) Phytophthora infestans RXLR Effector AVR1 Interacts with Exocyst Component Sec5 to Manipulate Plant Immunity. Plant Physiol 169: 1975-1990.

Duplessis S, Cuomo CA, Lin YC, Aerts A, Tisserant E, Veneault-Fourrey C, Joly DL, Hacquard S, Amselem J, Cantarel BL, et al. (2011) Obligate biotrophy features unraveled by the genomic analysis of rust fungi. Proc Natl Acad Sci U S A 108: 9166-9171.

Ellwood SR, Liu Z, Syme RA, Lai Z, Hane JK, Keiper F, Moffat CS, Oliver RP, Friesen TL (2010) A first genome assembly of the barley fungal pathogen Pyrenophora teres f. teres. Genome Biol. 11: Rio9.

Faino L, Thomma BP (2014) Get your high-quality low-cost genome sequence.Trends Plant Sci 19: 288-291.

Faris JD, Zhang Z, Lu H, Lu S, Reddy L, Cloutier S, Fellers JP, Meinhardt SW, Rasmussen JB, Xu SS, et al. (2010) A unique wheat disease resistance-like gene governs effector-triggered susceptibility to necrotrophic pathogens. Proc Natl Acad Sci USA 107: 13544-13549.

Fisher MC, Henk DA, Briggs CJ, Brownstein JS, Madoff LC, McCraw SL, Gurr SJ (2012) Emerging fungal threats to animal, plant and ecosystem health. Nature 484: 186-194.

Fitzpatrick DA, Logue ME, Stajich JE, Butler G (2006) A fungal phylogeny based on 42 complete genomes derived from supertree and combined gene analysis. BMC Evol Biol 6: 99.

Fradin EF, Thomma BPHJ (2006) Physiology and molecular aspects of Verticillium wilt diseases caused by V. dahliae and V. albo-atrum. Mol Plant Pathol 7: 71-86.

Friesen TL, Faris JD, Solomon PS, Oliver RP (2008) Host-specific toxins: effectors of necrotrophic pathogenicity. Cell Microbiol 10: 1421-1428.

Friesen TL, Stukenbrock EH, Liu Z, Meinhardt S, Ling H, Faris JD, Rasmussen JB, Solomon PS, McDonald BA, Oliver RP (2006) Emergence of a new disease as a result of interspecific virulence gene transfer. Nat Genet 38: $953-956$.

Ghareeb H, Zhao Y, Schirawski J (2018) Sporisorium reilianum possesses a pool of effector proteins that modulate virulence on maize. Mol Plant Pathol doi: 10.1111/mpp.12744.

Glazebrook J (2005) Contrasting mechanisms of defense against biotrophic and necrotrophic pathogens. Annu Rev Phytopatho 43: 205-227.

Guttman DS, McHardy AC, Schulze-Lefert P (2014) Microbial genome-enabled insights into plant-microorganism interactions. Nat Rev Genet 15: 797-813.

Haas BJ, Kamoun S, Zody MC, Jiang RH, Handsaker RE, Cano LM, Grabherr M, Kodira CD, Raffaele S, TortoAlalibo T, et al. (2009) Genome sequence and analysis of the Irish potato famine pathogen Phytophthora infestans. Nature 461: 393-398.

Hane JK, Lowe RG, Solomon PS, Tan KC, Schoch CL, Spatafora JW, Crous PW, Kodira C, Birren BW, Galagan JE, et al. (2007) Dothideomycete plant interactions illuminated by genome sequencing and EST analysis of the wheat pathogen Stagonospora nodorum. Plant Cell 19: 3347-3368.

Hemetsberger C, Herrberger C, Zechmann B, Hillmer M, Doehlemann G (2012) The Ustilago maydis effector Pep1 suppresses plant immunity by inhibition of host peroxidase activity. PLoS Pathog 8: e1002684.

Inderbitzin P, Bostock RM, Davis RM, Usami T, Platt HW, Subbarao KV (2011) Phylogenetics and taxonomy of the fungal vascular wilt pathogen Verticillium, with the descriptions of five new species. PLOS ONE 6: e28341.

Inderbitzin P, Subbarao KV (2014) Verticillium systematics and evolution: how confusion impedes Verticillium wilt management and how to resolve it. Phytopathology 104: 564-574.

James TY, Kauff F, Schoch CL, Matheny PB, Hofstetter V, Cox CJ, Celio G, Gueidan C, Fraker E, Miadlikowska J, et al. (2006) Reconstructing the early evolution of Fungi using a six-gene phylogeny. Nature 443: 818-822.

Jashni MK, Mehrabi R, Collemare J, Mesarich CH, de Wit PJ (2015) The battle in the apoplast: further insights into the roles of proteases and their inhibitors in plant-pathogen interactions. Front Plant Sci 6: 584.

Jones JD, Dangl JL (2006) The plant immune system. Nature 444: 323-329.

Joosten M, de Wit P (1999) THE TOMATO-CLADOSPORIUM FULVUM INTERACTION: A versatile experimental system to study plant-pathogen interactions. Annu Rev Phytopathol 37: 335-367.

Kelley BS, Lee SJ, Damasceno CM, Chakravarthy S, Kim BD, Martin GB, Rose JK (2010) A secreted effector protein (SNE1) from Phytophthora infestans is a broadly acting suppressor of programmed cell death. Plant J 62: 357366. 
Klosterman SJ, Subbarao KV, Kang S, Veronese P, Gold SE, Thomma BPHJ, Chen Z, Henrissat B, Lee YH, Park J (2011) Comparative genomics yields insights into niche adaptation of plant vascular wilt pathogens. PLOS Pathog 7: e1002137.

Kvitko BH, Park DH, Velásquez AC, Wei CF, Russell AB, Martin GB, Schneider DJ, Collmer A (2009) Deletions in the repertoire of Pseudomonas syringae pv. tomato DC3000 type III secretion effector genes reveal functional overlap among effectors. PLoS Pathog 5: e1000388.

Lanver D, Tollot M, Schweizer G, Lo Presti L, Reissmann S, Ma LS, Schuster M, Tanaka S, Liang L, Ludwig N, et al. (2017) Ustilago maydis effectors and their impact on virulence. Nat Rev Microbiol 15: 409-421.

Liu Z, Gao Y, Kim YM, Faris JD, Shelver WL, de Wit PJ, Xu SS, Friesen TL (2016) SnTox1, a Parastagonospora nodorum necrotrophic effector, is a dual-function protein that facilitates infection while protecting from wheatproduced chitinases. New Phytol 211: 1052-1064.

Liu Z, Zhang Z, Faris JD, Oliver RP, Syme R, McDonald MC, McDonald BA, Solomon PS, Lu S, Shelver WL, et al. (2012) The cysteine rich necrotrophic effector SnTox1 produced by Stagonospora nodorum triggers susceptibility of wheat lines harboring Snni. PLoS Pathog 8: e1002467.

Lombard V, Golaconda Ramulu H, Drula E, Coutinho PM, Henrissat B (2014) The carbohydrate-active enzymes database (CAZy) in 2013. Nucleic Acids Res 42: D490-495.

Lorang J, Kidarsa T, Bradford CS, Gilbert B, Curtis M, Tzeng SC, Maier CS, Wolpert TJ (2012) Tricking the guard: exploiting plant defense for disease susceptibility. Science 338: 659-662.

Martin F, Aerts A, Ahrén D, Brun A, Danchin EG, Duchaussoy F, Gibon J, Kohler A, Lindquist E, Pereda V, et al. (2008) The genome of Laccaria bicolor provides insights into mycorrhizal symbiosis. Nature 452: 88-92.

Martin F, Kohler A, Murat C, Balestrini R, Coutinho PM, Jaillon O, Montanini B, Morin E, Noel B, Percudani R, et al. (2010) Périgord black truffle genome uncovers evolutionary origins and mechanisms of symbiosis. Nature 464: 1033-1038.

Matei A, Doehlemann G (2016) Cell biology of corn smut disease-Ustilago maydis as a model for biotrophic interactions. Curr Opin Microbiol 34: 60-66.

McDonald MC, Ahren D, Simpfendorfer S, Milgate A, Solomon PS (2018) The discovery of the virulence gene ToxA in the wheat and barley pathogen Bipolaris sorokiniana. Mol Plant Pathol 19: 432-439.

McDonald MC, Solomon PS (2018) Just the surface: advances in the discovery and characterization of necrotrophic wheat effectors. Curr Opin Microbiol 46: 14-18.

Meehan F, Murphy HC (1947) Differential phytotoxicity of metabolic by-products of Helminthosporium victoriae. Science 106: 270-271.

Mengiste T (2012) Plant immunity to necrotrophs. Annu Rev Phytopathol 50: 267-294.

Mentlak TA, Kombrink A, Shinya T, Ryder LS, Otomo I, Saitoh H, Terauchi R, Nishizawa Y, Shibuya N, Thomma BP, et al. (2012) Effector-mediated suppression of chitin-triggered immunity by Magnaporthe oryzae is necessary for rice blast disease. Plant Cell 24: 322-335.

Möbius N, Hertweck C (2009) Fungal phytotoxins as mediators of virulence. Curr Opin Plant Biol 12: 390-398.

Mueller AN, Ziemann S, Treitschke S, Aßmann D, Doehlemann G (2013) Compatibility in the Ustilago maydis-maize interaction requires inhibition of host cysteine proteases by the fungal effector Pit2. PLoS Pathog 9: e1003177.

O'Connell RJ, Thon MR, Hacquard S, Amyotte SG, Kleemann J, Torres MF, Damm U, Buiate EA, Epstein L, Alkan $\mathbf{N}$, et al. (2012) Lifestyle transitions in plant pathogenic Colletotrichum fungi deciphered by genome and transcriptome analyses. Nat Genet 44: 1060-1065.

Ökmen B, Etalo DW, Joosten MH, Bouwmeester HJ, de Vos RC, Collemare J, de Wit PJ (2013) Detoxification of $\alpha$-tomatine by Cladosporium fulvum is required for full virulence on tomato. New Phytol 198: 1203-1214.

Oome S, Van den Ackerveken G (2014) Comparative and functional analysis of the widely occurring family of Nep1like proteins. Mol Plant-Microbe Interact 27: 1081-1094.

Petre B, Joly DL, Duplessis S (2014) Effector proteins of rust fungi. Front Plant Sci 5: 416.

Pliego C, Nowara D, Bonciani G, Gheorghe DM, Xu R, Surana P, Whigham E, Nettleton D, Bogdanove AJ, Wise RP, et al. (2013) Host-induced gene silencing in barley powdery mildew reveals a class of ribonuclease-like effectors. Mol Plant-Microbe Interact 26: 633-642. 
Plissonneau C, Benevenuto J, Mohd-Assaad N, Fouché S, Hartmann FE, Croll D (2017) Using population and comparative genomics to understand the genetic basis of effector-driven fungal pathogen evolution. Front Plant Sci 8: 119.

Ramachandran SR, Yin C, Kud J, Tanaka K, Mahoney AK, Xiao F, Hulbert SH (2017) Effectors from wheat rust fungi suppress multiple plant defense responses. Phytopathology 107: 75-83.

Rodriguez-Moreno L, Ebert MK, Bolton MD, Thomma BPHJ (2018) Tools of the crook-infection strategies of fungal plant pathogens. Plant J 93: 664-674.

Rovenich H, Boshoven JC, Thomma BPHJ (2014) Filamentous pathogen effector functions: of pathogens, hosts and microbiomes. Curr Opin Plant Biol 20: 96-103.

Rovenich H, Zuccaro A, Thomma BP (2016) Convergent evolution of filamentous microbes towards evasion of glycan-triggered immunity. New Phytol 212: 896-901.

Sánchez-Vallet A, Mesters JR, Thomma BPHJ (2015) The battle for chitin recognition in plant-microbe interactions. FEMS Microbiol Rev 39: 171-183.

Scheffer RP, Nelson RR, Ullstrup AJ (1967) Inheritance of toxin production and pathogenicity in Cochliobolus carbonum and Cochliobolus victoriae. Phytopathology 57: 1288.

Schmidt SM, Panstruga R (2011) Pathogenomics of fungal plant parasites: what have we learnt about pathogenesis? Curr Opin Plant Biol 14: 392-399.

Seidl MF, Faino L, Shi-kunne X, van den Berg GCM, Bolton MD, Thomma BPHJ (2015) The genome of the saprophytic fungus Verticillium tricorpus reveals a complex effector repertoire resembling that of its pathogenic relatives. Mol Plant-Microbe Interact 28: 362-373.

Shi G, Zhang Z, Friesen TL, Raats D, Fahima T, Brueggeman RS, Lu S, Trick HN, Liu Z, Chao W, et al. (2016) The hijacking of a receptor kinase-driven pathway by a wheat fungal pathogen leads to disease. Sci Adv 2: e1600822.

Shi-Kunne X, Faino L, van den Berg GCM, Thomma BPHJ, Seidl MF (2018) Evolution within the fungal genus Verticillium is characterized by chromosomal rearrangement and gene loss. Environ Microbiol. 220: 13621373.

Soanes DM, Richards TA, Talbot NJ (2007) Insights from sequencing fungal and oomycete genomes: what can we learn about plant disease and the evolution of pathogenicity? Plant Cell 19: 3318-3326.

Spanu PD (2012) The genomics of obligate (and nonobligate) biotrophs. Annu Rev Phytopathol 50: 91-109.

Spanu PD, Abbott JC, Amselem J, Burgis TA, Soanes DM, Stüber K, Ver Loren van Themaat E, Brown JK, Butcher SA, Gurr SJ, et al. (2010) Genome expansion and gene loss in powdery mildew fungi reveal tradeoffs in extreme parasitism. Science 330: 1543-1546.

Stassen JH, Van den Ackerveken G (2011) How do oomycete effectors interfere with plant life? Curr Opin Plant Biol 2011 14: 407-414.

Stergiopoulos I, Collemare J, Mehrabi R, De Wit PJ (2013) Phytotoxic secondary metabolites and peptides produced by plant pathogenic Dothideomycete fungi. FEMS Microbiol Rev 37: 67-93.

Strange RN, Scott PR (2005) Plant disease: A threat to global food security. Annu Rev Phytopathol 43: 83-116.

Stukenbrock EH, McDonald BA (2007) Geographical variation and positive diversifying selection in the hostspecific toxin SnToxA. Mol Plant Pathol 8: 321-332.

Tan KC, Phan HT, Rybak K, John E, Chooi YH, Solomon PS, Oliver RP (2015) Functional redundancy of necrotrophic effectors - consequences for exploitation for breeding. Front Plant Sci 6: 501.

Thomma BP, Eggermont K, Penninckx IA, Mauch-Mani B, Vogelsang R, Cammue BP, Broekaert WF (1998) Separate jasmonate-dependent and salicylate-dependent defense-response pathways in Arabidopsis are essential for resistance to distinct microbial pathogens. Proc Natl Acad Sci USA 95: 15107-15111.

Thomma BPHJ, Seidl MF, Shi-Kunne X, Cook DE, Bolton MD, van Kan JAL, Faino L (2016) Mind the gap; seven reasons to close fragmented genome assemblies. Fungal Genet Biol 90: 24-30.

van den Burg HA, Harrison SJ, Joosten MH, Vervoort J, de Wit PJ (2006) Cladosporium fulvum Avr4 protects fungal cell walls against hydrolysis by plant chitinases accumulating during infection. Mol Plant-Microbe Interact 19: $1420-1430$. 
van der Does HC, Rep M (2007) Virulence genes and the evolution of host specificity in plant-pathogenic fungi. Mol Plant-Microbe Interact 20: 1175-1182.

van Esse HP, Bolton MD, Stergiopoulos I, de Wit PJ, Thomma BPHJ (2007) The chitin-binding Cladosporium fulvum effector protein Avr4 is a virulence factor. Mol Plant-Microbe Interact 20: 1092-1101.

van Esse HP, Van't Klooster JW, Bolton MD, Yadeta KA, van Baarlen P, Boeren S, Vervoort J, de Wit PJ, Thomma BPHJ (2008) The Cladosporium fulvum virulence protein Avr2 inhibits host proteases required for basal defense. Plant Cell 20: 1948-1963.

Wang R, Ning Y, Shi X, He F, Zhang C, Fan J, Jiang N, Zhang Y, Zhang T, Hu Y, et al. (2016) Immunity to rice blast disease by suppression of effector-triggered necrosis. Curr Biol 26: 2399-2411.

Wilson RA, Talbot NJ (2009) Under pressure: investigating the biology of plant infection by Magnaporthe oryzae. Nat Rev Microbiol 7: 185-195.

Win J, Chaparro-Garcia A, Belhaj K, Saunders DG, Yoshida K, Dong S, Schornack S, Zipfel C, Robatzek S, et al. (2012) Effector biology of plant-associated organisms: concepts and perspectives. Cold Spring Harb Symp Quant Biol 77: 235-247.

Wolpert TJ, Dunkle LD, Ciuffetti LM (2002) Host-selective toxins and avirulence determinants: what's in a name? Annu Rev Phytopathol 40: 251-285.

Wolpert TJ, Macko V, Acklin W, Jaun B, Arigoni D (1986) Structure of minor host-selective toxins from Cochliobolus victoriae. Experientia 42: 1296-1299.

Wolpert TJ, Macko V, Acklin W, Jaun B, Seibl J, Meili J, Arigoni D (1985) Structure of Victorin-C, the major hostselective toxin from Cochliobolus victoriae. Experientia 41: 1524-1529.

Xin XF, He SY (2013) Pseudomonas syringae pv. tomato DC3000: a model pathogen for probing disease susceptibility and hormone signaling in plants. Annu Rev Phytopathol 251: 473-498.

Yadeta KA, Thomma BP (2013) The xylem as battleground for plant hosts and vascular wilt pathogens. Front Plant Sci 4: 97. 



\section{Summary}

Plants have evolved various types of immune receptors to protect themselves against deleterious microbial invasions. In order to establish symbiotic relationships with host plants, microbes secrete effector molecules to suppress host immune responses and facilitate host colonization. Besides pathogenic microbes, endophytes and mutualists are thought to similarly employ effectors to establish their associations with host plants. The research described in this thesis is focussed on the pathogenic broad host range vascular wilt fungus Verticillium dahliae and aims to identify critical effectors that contribute to the establishment of infections on host plants. Such knowledge is essential for designing and developing novel and effective Verticillium wilt disease management strategies. As highly versatile molecules, the role of effectors in niche establishment of symbionts with diverse lifestyles is discussed in Chapter 1.

On particular host plants, $V$. dahliae strains are assigned to so-called pathotypes. For example, $V$. dahliae strains that are highly aggressive and cause severe defoliation on cotton, olive, okra and pistachio are referred to as strains of the defoliating (D) pathotype, whereas strains that are moderately virulent and only induce wilting symptoms without defoliation on these hosts are assigned to the non-defoliating (ND) pathotype. In Chapter 2, comparative genomics of a collection of D and ND pathotype strains revealed two D pathotype-specific effector genes that are highly expressed during host colonization. Intriguingly, these two effector genes appeared to be identical copies that arose by a segmental duplication. We show that the effector (named D) that is encoded by the duplicated effector gene is a pathogenicity factor on cotton and olive, as targeted deletion of the two gene copies resulted in loss of the ability to cause disease symptoms on these plants. Moreover, application of heterologously produced effector protein to cotton seedling induces defoliation, suggesting that the effector protein itself, rather than extensive fungal proliferation in the xylem vessels, is responsible for the defoliation symptoms. Interestingly, besides on cotton and olive, the $\mathrm{D}$ effector is required for pathogenicity of $\mathrm{D}$ pathotype strains on Nicotiana benthamiana and Arabidopsis thaliana as well.

$V$. dahliae is generally characterized as a broad host range pathogen, although differential pathogenicity between individual strains occurs on nearly all hosts. Currently, the molecular basis underlying differences in pathogenicity between $V$. dahliae strains remains largely unknown. Chapter 3 focuses on elucidating the molecular basis of $V$. dahliae pathogenicity on tomato. While genome analysis of tomato-pathogenic and non-pathogenic $V$. dahliae strains revealed five effector candidate genes that specifically occur in pathogenic strains, only one of them was expressed during host colonization. Functional analyses showed that this in plantainduced effector (named TomI) gene governs pathogenicity of $V$. dahliae on tomato, as deletion of the effector gene resulted in loss of the ability to colonize tomato plants. Furthermore, transfer of this effector gene into a non-pathogenic $V$. dahliae isolate or into non-pathogenic, saprophytic, sister species V. tricorpus and V. nubilum resulted in tomato disease. Overall, our findings show that a single effector is required and sufficient to mediate pathogenicity of $V$. dahliae on tomato. 
Sunflower cultivation regularly suffers from Verticillium wilt. Intriguingly, most V. dahliae isolates that we tested fail to cause sunflower disease. In Chapter 4, genome comparisons of a single sunflower-pathogenic strain with several non-pathogenic strains revealed that two candidate effector genes that solely occur in the pathogenic strain and are highly expressed during host colonization. Intriguingly, these two candidate effector genes appeared to be identical copies that arose by a segmental duplication. We further show that this duplicated effector (named Sun1) quantitatively contributes to $V$. dahliae virulence on sunflower. While single deletion mutants exhibited markedly reduced virulence on sunflower when compared with wild-type strain $85 \mathrm{~S}$, double deletion mutants showed more significantly compromised virulence than single deletion mutants. Interestingly, the Sunı effector gene is dispensable for virulence on the model plants $N$. benthamiana or A. thaliana. Thus, we anticipate that the Sun1 effector may specifically mediate fungal virulence on sunflower.

Despite the notion that most $V$. dahliae strains have a broad host range, the pathogenic potential and the severity of symptoms that are induced on a particular host plant may vary considerably between $V$. dahliae strains. In Chapter 5, we determined the core and lineage-specific (LS) effector repertoires of a collection of $V$. dahliae strains, as well as the ability of these strains to infect a panel of potential host plants comprising tomato, cotton, $N$. benthamiana, Arabidopsis, and sunflower to assess whether the presence of particular LS effectors correlates with the ability to infect particular plant species. Despite the fact that $V$. dahliae is generally considered as a broad host range pathogen, differential pathogenicity occurs among the collection of $21 \mathrm{~V}$. dahliae strains on these five plant species. Surprisingly, we found that $V$. dahliae strains that are able to infect the same host plant harbour highly divergent LS effector repertoires and differential $V$. dahliae core effector gene expression between host plants. This variability may reflect immunity evasion in the co-evolution of individual V. dahliae strains with multiple hosts.

Plants employ cell surface-localized immune receptors to detect invasions of fungal pathogens, for instance by recognizing the conserved fungal cell wall molecule chitin. In Arabidopsis, two lysin motif (LysM) containing receptors, AtCERK1 and AtLYK5, have been implicated in chitin perception. The LysM effector protein Ecp6 from tomato leaf mould fungus Cladosporium fulvum has been shown to supress chitin-induced immune responses through direct competition with plant receptors for chitin binding. In Chapter 6, we aimed to generate chimeric chitin receptors with increased chitin binding affinity by replacing the LysM domains of AtCERK1 and AtLYK5 with those of Ecp6. We show that expression of the chimeric receptor Ecp6::LYK5, but not of Ecp6::CERK1, confers responsiveness to fungal chitin. Moreover, the chimeric Ecp6::LYK5 receptor displays enhanced chitin-binding ability when compared with the native AtLYK5 receptor, and can compete with the Ecp6 effector protein for chitin binding. This indicates that the Ecp6::LYK5 chimeric receptor has the potential to mediate enhanced resistance to fungal pathogen infection.

Finally, in Chapter 7, the results described in this thesis are summarized and a perspective on how microbes evolve to become plant pathogens is presented. 


\section{Acknowledgements}

The time has finally come that my PhD thesis is finished. Looking back, I can wholeheartedly say that it was a remarkable experience, among which I had the opportunity to explore the Verticillium world and work together with helpful and friendly colleagues. I would like to express my sincerest appreciation to the people who helped me during this amazing journey.

First of all, I would like to convey my sincere gratitude to my supervisor. Bart, your knowledge and enthusiasm for science inspired me all the time. I still remembered we discussed PCR gel pictures until twelve o'clock at night via e-mails when I obtained $\mathrm{D}$ effector double deletion strains. It was an amazing feeling that I could share the excitement about my new results with you. Also thank you for your tremendous efforts in helping me to improve my writing, this experience was invaluable for me. Your high expectations motivated me to become not only a good researcher and a good "story-teller", I also felt valued and nurtured under your guidance and supervision. I am sure you will land in "a new, stimulating, vibrant, welcoming \& collegial career setting" in future.

My thanks also go to my co-promotor. Luigi, I am happy to be your first PhD student. Thank you for being patient with me, especially during my first days in the lab. Despite our different working strategies, we have managed to work out several chapters of this $\mathrm{PhD}$ thesis. Aside from science, I have learned that you are also a good food-hunter who knows where to find the best food. I really enjoyed superb nights and impressive food in Rome with you, Bart and Hui. I wish you great success in your new career and your life in Rome.

During my years in the Verticillium group I was lucky to work in the lab with many open-minded and helpful colleagues. Grardy, Mireille, Dirk-Jan, Andrea, David, Eduardo, Hanna, Jordi, Michael, Hesham, Martin and Nick, thanks for your advice and opportunities for invaluable discussions over the years. Xiaoqian, thanks for your help with some bioinformatics-related questions. I sometimes found it easier to understand when you explained in English. Hui, thanks for being my paranymph and thank you for sharing your expertise on Verticillium transformation. Your positive attitude always brings energy to people around you. Malaika, my other paranymph, you were actually the first one to read my chapters. Thank you so much for your encouragement and help with my writing. Jasper (Jappie) D., I always like to discuss some "raw" ideas and thoughts with you, and your quick mind impresses me a lot since you can easily get the point I try to make and give me your feedback. My MSc students, Jordan and Dongli, thanks for your help and contributions to this thesis.

Special thanks go to Zhao Zhang, Yu Du, Yan Wang, Yin Song, Guozhi Bi, Xu Cheng, Chunxu Song and Wei Qin, who have already graduated or left Wageningen. Your advice and insight have been valuable to my research and life in the Netherlands, especially at the beginning of my $\mathrm{PhD}$. I wish you all great success in your new careers.

And of course, thanks to my Chinese friends in the Netherlands (few of you are still there): Tao Zhao, Wenbiao, Fubiao, Bao Man, Huicui Lu, Ying Zheng, Defeng, Tian Zeng, Fengjiao, Hucheng, Xiao Lin, Kaile, Xiaoxue Sun, Mengjing Sun, Yiqian Fu, Xuexue Shen, Huayi, Xiao Ning Zhang, 
Feng Zhu. Without you my five-year stay would not have been so much fun. I really appreciate the great time we had together.

Many thanks also to all fellow Phyto PhDs. Thanks for all the interesting discussions at the coffee table or in the lab. Jinbin, Shuqing, Kiki, Sander, thank you for the many chats and your help with troubleshooting. It was great fun to work with you and I wish you all lots of success in your PhD research.

Thanks to my mates from the "escape room": Malaika, Aranka, Chara, Fernando and Nani. The last stage of our PhDs is certainly quite tough but I was very glad that we could share our happiness and frustrations. It is a happy ending now that we all finally "escape" from that (writing) room and move forward.

Finally, I would like to express great gratitude to my parents. Thank you for your endless love and unconditional support. I will always be very grateful for the encouragement you gave to find and develop myself.

\section{金岭}

$6^{\text {th }}$ January 2019

Wageningen 


\section{About the author}

Jinling Li (李金岭) was born on March $16^{\text {th }} 1987$ in Xinjiang, China. In 2006, he started his Bachelor study in Plant Protection at Northwest A\&F University in Yangling, Shaanxi Province, China. After graduation in June 2010, he continued his MSc study on biological control of the pathogenic fungus Alternaria alternata on tobacco under the supervision Prof. Derong An. In 2013, he obtained a PhD fellowship from the China Scholarship Council (CSC) to join the laboratory of Phytopathology at Wageningen University, the

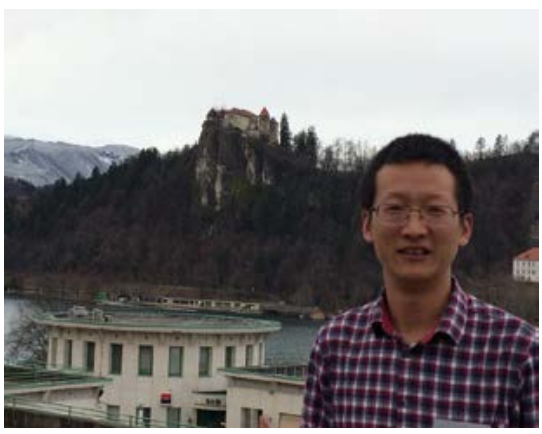
Netherlands. During his PhD studies he focused on the identification of virulence effectors of the vascular wilt pathogen Verticillium dahliae under the supervision of Prof. dr. Bart Thomma and Dr. Luigi Faino. After his PhD, he will work as post-doctoral researcher in the group of Dr. Timothy Friesen at the USDA in Fargo, USA, where he will investigate effector biology of the fungal barley pathogen Pyrenophora teres f. teres. 


\section{Education Statement of the Graduate School Experimental Plant Sciences}

Issued to: Jinling $\mathrm{Li}$

Date: 13 February 2019

Group: Laboratory of Phytopathology

University: Wageningen University \& Research

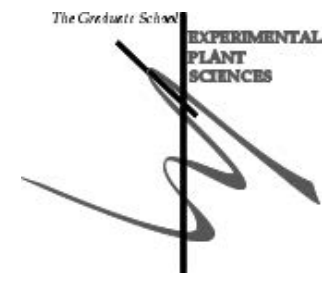

\section{1) Start-Up Phase}

date

- First presentation of your project

Identification and characterization of an ECP6 receptor from tomato

26 Sep 2014

- Writing or rewriting a project proposal

Functional analysis of virulence effectors from the vascular wilt fungus Verticillium

Oct 2013

dahliae identified through comparative population genomics comparative population

genomics

Writing a review or book chapter

- MSc courses

Plant-Microbe Interaction (PHP-30306)

\section{2) Scientific Exposure}

date

\section{- EPS PhD student days}

EPS PhD day 2013, Leiden University

29 Nov 2013

EPS PhD student Day, Get2Together 2015, Soest (NL)

29-30 Jan 2015

EPS PhD student Day, Get2Together 2017, Soest (NL)

09-10 Feb 2017

- EPS theme symposia

EPS theme 2 symposium \& Willie Commelin Scholten day, University of Amsterdam (NL)

$25 \operatorname{Jan} 2014$

EPS theme 2 symposium \& Willie Commelin Scholten day, University of Utrecht (NL)

20 Feb 2015

EPS theme 2 symposium \& Willie Commelin Scholten day, Leiden University (NL)

22 Jan 2016

EPS theme 2 symposium \& Willie Commelin Scholten day, Wageningen University (NL)

$23 \operatorname{Jan} 2017$

- National meetings (e.g. Lunteren days) and other National Platforms

Annual meeting 'Experimental Plant Sciences', Lunteren (NL)

14-15 Apr 2014

Annual meeting 'Experimental Plant Sciences', Lunteren (NL)

13-14 Apr 2015

Annual meeting 'Experimental Plant Sciences', Lunteren (NL)

11-12 Apr 2016

Annual meeting 'Experimental Plant Sciences', Lunteren (NL)

10-11 Apr 2017

Host-Microbe Genetics meeting, Wageningen (NL)

27 Oct 2017

- Seminars (series), workshops and symposia

Seminar: Prof. Jiayang Li, Understanding the molecular mechanisms underlying rice

15 Nov 2013

tillering

Seminar: Prof. Eric Schranz, Whole genome duplications as drivers of evolutions and

21 Nov 2013 relations?

Seminar: Prof. Jos Raaijmakers, Back to the Roots: exploring and exploiting the plant

07 Jan 2014 microbiome

Seminar: Dr. Jeroen Mesters, From protein solution to single crystal X-ray diffraction:

31 Mar 2014

Chitin binding by LysM domains at atomic resolution

Seminar: Prof. Jane Parker, Reprogramming cells for defence in plant innate immunity

09 Apr 2014 
Seminar: Dr. Frank van Breusegem, Plant metacaspases

O9 Apr 2014

Seminar: Prof. Sophien Kamoun, Genome and effector evolution in the Irish potato

28 May 2014

famine pathogen lineage

Farewell symposium: Prof. dr. Pierre de Wit: Fungal plant pathogens and the plant

O5 Jun 2014

immune system, Wageningen (NL)

Seminar: Prof. Yuanchao Wang, Dissecting the interaction between Phytophthora sojae

and soybean: making sense out of signalling and effectors

Seminar: Prof. Hanhui Kuang, Using the Nicotiana-TMV system to study resistance

gene evolution and plant genome stability

Seminar: Dr. Michael Freitag, Chromatin structure controls centromeres and secondary metabolism in filamentous fungi

Seminar: Dr. Ortrun Mittelsten Scheid, Genetics and epigenetics: a complex relationship Phytopathology Lab. mini-symposium (Erik Limpens, Tijs Ketelaar, Eric Schranz, Frank

Takken \& Weixing Shan), Wageningen (NL)

EPS symposium: Omics Advances for Academia and Industry - Towards True Molecular Plant Breeding, Wageningen (NL)

WEES seminar: Prof. Kevin Foster, The evolution of cooperation and competition in microbes

EPS flying seminar: Prof.dr. Yves van de Peer, "The evolutionary significance of gene and genome duplications

Seminar: Prof. Monica Hofte, Towards understanding rice brown spot, a disease induced by physiological stress

Seminar: Prof. Jiming Jiang, Structure and evolution of centromeres: lessions learned from plants

Phytopathology Lab. symposium: Crop Pathology and Plant-Microbe Interactions, Wageningen (NL)

Seminar: Joel Salatin, It's the food, my friend!

Plant sciences seminar: Into the Battle between Plants and Viruses, but what about

EVEs?

EPS flying seminar: Prof. Gero Steinberg, Long-distance endosome trafficking drives fungal effector production during plant infection

EPS flying seminar: Prof. Jane Parker, Plant intracellular immunity: evolutionary and molecular underpinnings

Seminar: Dr. Laura Grennvile Briggs, Molecular Oomycete-Host Interaction: The Good, the Bad and the Ugly

Seminar: Dr. Olivier Hamant, How do plants read their own shape?

Seminar, Prof. Alain Tissier, Insights into the inner working of a metabolic cell factory: the tomato glandular trichome

Seminar: Prof. Douglas Mitchell, Genomics-enabled natural products discovery

Seminar: Dr. Pierre-Marc Delaux, Evolution of symbiotic gene networks in land plants

Seminar: Prof. Caitilyn Allen, How Ralstonia solanacearum succeeds in plant xylem

vessels

Seminar: Dr. Katherine Goodrich, The volatile "language" of plants: from attraction to deterrence and back again

Seminar: Prof. Wenbo Ma, Effectors as molecular probes to understand pathogenesis

Mini-symposium: Dr. Edze Westra and Prof. Jennifer Doudna, Rewriting our genes?

CRISPR-CAS systems as tools for genome editing

1st WURomics symposium: Technology-Driven Innovation for Plant Breeding,

$16 \mathrm{Jul} 2014$

11 Sep 2014

11 Oct 2014

11 Nov 2014

24 Nov 2014

11 Dec 2014

$22 \operatorname{Jan} 2015$

O3 Feb 2015

o6 Feb 2015

O1 Apr 2015

O8 May 2015

09 May 2015

12 May 2015

O5 Jun 2015

21 Jan 2016

19 Feb 2016

16 Mar 2016

18 Mar 2016

31 Mar 2016

O8 Apr 2016

29 Apr 2016

23 May 2016

20 Jun 2016

30 Sep 2016

15 Dec 2016 Wageningen (NL) 
Seminar: Dr. Jan Lochman, Elicitins- What we know and do not know

24 Jan 2017

Farwell symposium: Prof. Ton Bisseling: The Undergrond Labyrinth: Roots, Friends and

Foes, Wageningen (NL)

EPS flying seminar: Dr. Gerben van Ooijen, Clocks across taxa: Conserved cellular

O8 Feb 2017

timekeeping mechanisms in plants, algae and other eukaryotes

29 May 2017

EPS flying seminar: Dr. Martin Cann,The immune receptor Rxi remodels chromatin and

$11 \mathrm{Jul} 2017$

chromatin interactors in immunity

Seminar: Dr. Sanjay Kapoor, Regulators of reproductive development in rice

29 Aug 2017

Inauguration Lecture: Prof. Gert Kema, Banana has a future after all

21 Sep 2017

Seminar: Prof. John Werren, Evolution of new gene functions: lateral gene transfers and

expression evolution

Seminar: Dr. Timothy Friesen, Genome wide association as a tool for identifying fungal

effectors important in virulence

Seminar: Dr. Ronald Snijder, Modern domestication of pelargonium in a commercial

environment

Seminar: Dr. Bob Schmitz, Epigenomic studies of nature and induced Epialleles in

plants

Seminar: Dr. Mary Wildermuth, Salicylic acid and cell cycle control of plant-microbe interactions

Seminar: Dr. Yan Wang, A leucine-rich repeat receptor-like protein as PAMP receptor recognising XEG1, a Phytophthora glycoside hydrolase 12

Seminar: Prof. Antonio Di Pietro, Host adaptation in the fungal cross-kingdom

06 Oct 2017

10 Apr 2018

O9 May 2018

06 Jun 2018

25 Jun 2018

10 Sep 2018

17 Oct 2018

pathogen Fusarium oxysporum

- Seminar plus

- International symposia and congresses

The 6th European Plant Science Retreat, University of Amsterdam, the Netherlands COST SUSTAIN workshop:pathogen-informed strategies for sustainable broadspectrum crop resistance, Bled, Slovenia

The 5th International Conference on Biotic Plant Interactions, Xiamen, China SIPIS meeting, Rome, Italy

\section{- Presentations}

Poster: Identification and characterization of an Ecp6 receptor from tomato, 6th

European Plant Science Retreat

Poster: Identification and functional analysis of the Verticillium dahliae "defoliation" effector, COST SUSTAIN workshop

Poster: A single Verticillium dahliae effector is responsible for cotton infection of the highly aggressive defoliating pathotype, 5th ICBPI

Talk: Identification and characterization of the Verticillium dahliae effector that is

OI-04 Jul 2014

01-03 Mar 2017

17-21 Aug 2017

27 Sep 2018

01-04 Jul 2014

01-03 Mar 2017

17-21 Aug 2017

23 Jan 2017

responsible for cotton defoliation, EPS Theme 2

Talk: Engineering of a chimeric receptor to mediate improved chitin-triggered

27 Sep 2018 immunity in Arabidopsis, SIPIS meeting

- IAB interview

- Excursions

Excursion to Enza Zaden, Enkhuizen

12 Jun 2015

Excursion to Keygene, Wageningen

12 Sep 2017

Subtotal Scientific Exposure 20.6 credits 


\section{3) In-Depth Studies}

date

- EPS courses or other PhD courses

EPS Spring School "Host-Microbe Interactomics", Wageningen (NL)

02-04 Jun 2014

Data analyses and visualizations in $\mathrm{R}$ (for biologist)

12-13 Dec 2016

- Journal club

Member of literature discussion at Verticillium group in Phytopathology Lab

2012-2016

- Individual research training

\section{4) Personal Development}

date

\section{- Skill training courses}

Scientific Writing

04 Sep -30 Oct 2017

Scientific Integrity

27 Aug 2018

Scientific Artwork - Vector graphics \& images

02-03 Oct 2018

- Organisation of PhD students day, course or conference

Participated in organizing "the Neighbours Week" Phytopathology Lab

20-21 Apr 2015

- Membership of Board, Committee or PhD council

Subtotal Personal Development

3.6 credits*

Herewith the Graduate School declares that the $\mathrm{PhD}$ candidate has complied with the educational requirements set by the Educational Committee of EPS which comprises of a minimum total of 30 ECTS credits.

* A credit represents a normative study load of 28 hours of study. 
This work was carried out in the Laboratory of Phytopathology, Wageningen University \& Research, the Netherlands. Jinling Li was financially sponsored by a $\mathrm{PhD}$ fellowship from the China Scholarship Council (CSC). Financial support from Wageningen University for printing this thesis is gratefully acknowledge.

Cover \& layout design: Iliana Boshoven-Gkini | AgileColor.com

Printed by GVO drukkers \& vormgevers B.V. | gvo.nl 


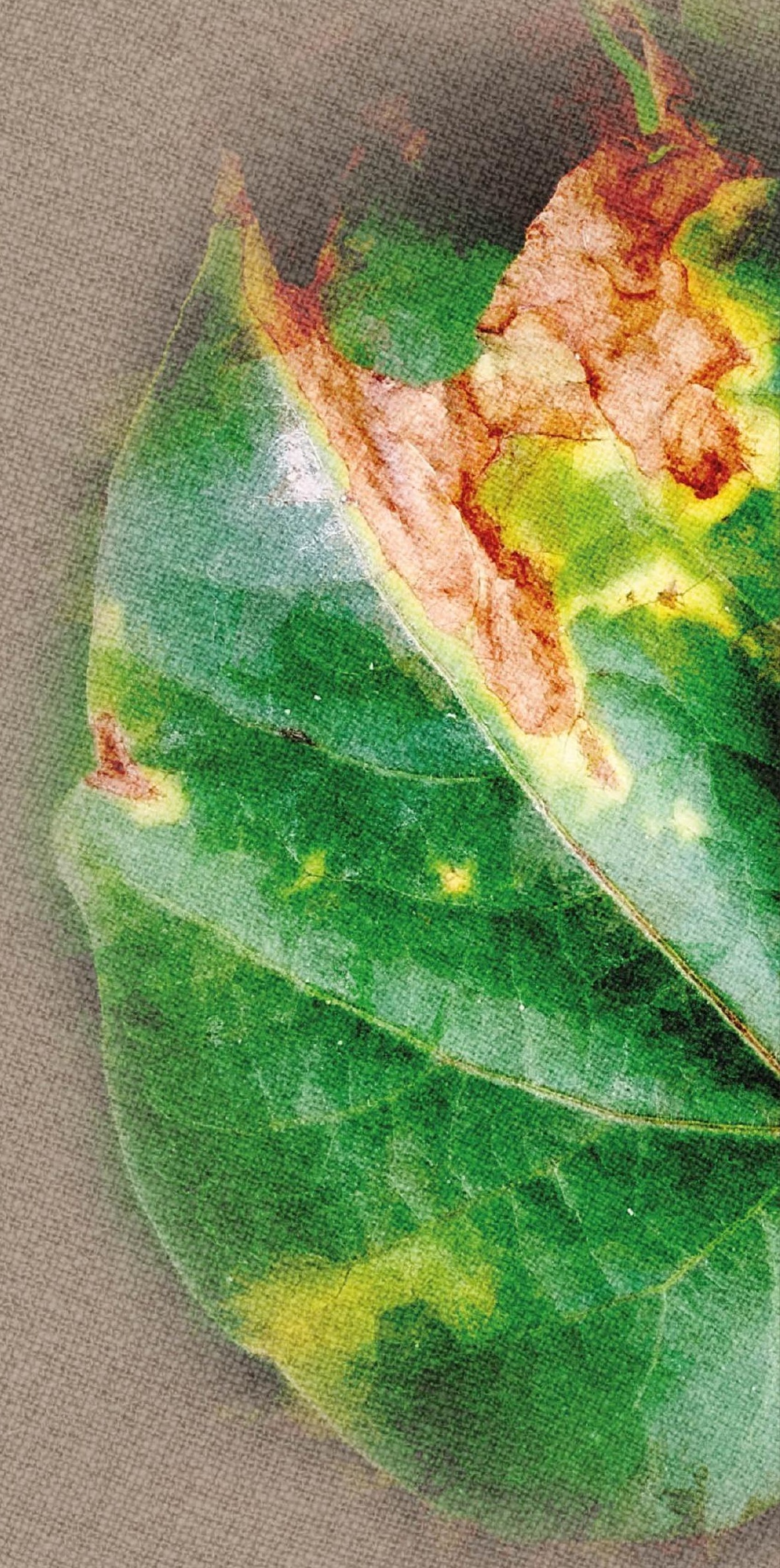

